\title{
Modeling and Control of Post-Combustion C02 Capture Process Integrated with a 550MWe Supercritical Coal-fired Power Plant
}

\author{
Qiang Zhang
}

Follow this and additional works at: https://researchrepository.wvu.edu/etd

\section{Recommended Citation}

Zhang, Qiang, "Modeling and Control of Post-Combustion CO2 Capture Process Integrated with a 550MWe Supercritical Coal-fired Power Plant" (2016). Graduate Theses, Dissertations, and Problem Reports. 7038.

https://researchrepository.wvu.edu/etd/7038

This Dissertation is protected by copyright and/or related rights. It has been brought to you by the The Research Repository @ WVU with permission from the rights-holder(s). You are free to use this Dissertation in any way that is permitted by the copyright and related rights legislation that applies to your use. For other uses you must obtain permission from the rights-holder(s) directly, unless additional rights are indicated by a Creative Commons license in the record and/ or on the work itself. This Dissertation has been accepted for inclusion in WVU Graduate Theses, Dissertations, and Problem Reports collection by an authorized administrator of The Research Repository @ WVU.

For more information, please contact researchrepository@mail.wvu.edu. 


\title{
Modeling and Control of Post-Combustion $\mathrm{CO}_{2}$ Capture Process Integrated with a 550MWe Supercritical Coal-fired Power Plant
}

\author{
Qiang Zhang
}

\author{
Dissertation submitted to the \\ Benjamin M. Statler College of Engineering and Mineral Resources \\ at West Virginia University \\ in partial fulfillment of the requirements for the degree of \\ Doctor of Philosophy in \\ Chemical Engineering
}

Richard Turton, $\mathrm{PhD}$, Chair

Debangsu Bhattacharyya, PhD

Fernando V. Lima, PhD

Jingxin Wang, $\mathrm{PhD}$

Stephen E. Zitney, PhD

Department of Chemical and Biomedical Engineering

Morgantown, West Virginia

2016

Keywords: Post-combustion $\mathrm{CO}_{2}$ Capture, Steady-state Modeling, Dynamic Modeling, Model Predictive Control, Robust Control

Copyrights 2016 Qiang Zhang 


\section{ABSTRACT \\ Modeling and Control of Post-Combustion $\mathrm{CO}_{2}$ Capture Process Integrated with a 550MWe Supercritical Coal-fired Power Plant}

Qiang Zhang

This work focuses on the development of both steady-state and dynamic models for an monoethanolamine (MEA)-based $\mathrm{CO}_{2}$ capture process for a commercial-scale supercritical pulverized coal (PC) power plant, using Aspen Plus ${ }^{\circledR}$ and Aspen Plus Dynamics ${ }^{\circledR}$. The dynamic model also facilitates the design of controllers for both traditional proportional-integralderivative (PID) and advanced controllers, such as linear model predictive control (LMPC), nonlinear model predictive control (NMPC) and $H_{\infty}$ robust control.

A steady-state MEA-based $\mathrm{CO}_{2}$ capture process is developed in Aspen Plus ${ }^{\circledR}$. The key process units, $\mathrm{CO}_{2}$ absorber and stripper columns, are simulated using the rate-based method. The steady-state simulation results are validated using experimental data from a $\mathrm{CO}_{2}$ capture pilot plant. The process parameters are optimized with the goal of minimizing the energy penalty. Subsequently, the optimized rate-based, steady-state model with appropriate modifications, such as the inclusion of the size and metal mass of the equipment, is exported into Aspen Plus Dynamics ${ }^{\circledR}$ to study transient characteristics and to design the control system. Since Aspen Plus Dynamics $^{\circledR}$ does not support the rate-based model, modifications to the Murphree efficiencies in the columns and a rigorous pressure drop calculation method are implemented in the dynamic model to ensure consistency between the design and off-design results from the steady-state and dynamic models. The results from the steady-state model indicate that between three and six parallel trains of $\mathrm{CO}_{2}$ capture processes are required to capture $90 \% \mathrm{CO}_{2}$ from a $550 \mathrm{MWe}$ supercritical PC plant depending on the maximum column diameter used and the approach to flooding at the design condition. However, in this work, only two parallel trains of $\mathrm{CO}_{2}$ capture process are modeled and integrated with a 550MWe post-combustion, supercritical PC plant in the dynamic simulation due to the high calculation expense of simulating more than two trains. 
In the control studies, the performance of PID-based, LMPC-based, and NMPC-based approaches are evaluated for maintaining the overall $\mathrm{CO}_{2}$ capture rate and the $\mathrm{CO}_{2}$ stripper reboiler temperature at the desired level in the face of typical input and output disturbances in flue gas flow rate and composition as well as change in the power plant load and variable $\mathrm{CO}_{2}$ capture rate. Scenarios considered include cases using different efficiencies to mimic different conditions between parallel trains in real industrial processes. MPC-based approaches are found to provide superior performance compared to a PID-based one. Especially for parallel trains of $\mathrm{CO}_{2}$ capture processes, the advantage of MPC is observed as the overall extent of $\mathrm{CO}_{2}$ capture for the process is maintained by adjusting the extent of capture for each train based on the absorber efficiencies. The NMPC-based approach is preferred since the optimization problem that must be solved for model predictive control of $\mathrm{CO}_{2}$ capture process is highly nonlinear due to tight performance specifications, environmental and safety constraints, and inherent nonlinearity in the chemical process. In addition, model uncertainties are unavoidable in real industrial processes and can affect the plant performance. Therefore, a robust controller is designed for the $\mathrm{CO}_{2}$ capture process based on $\mu$-synthesis with a DK-iteration algorithm. Effects of uncertainties due to measurement noise and model mismatches are evaluated for both the NMPC and robust controller. The simulation results show that the tradeoff between the fast tracking performance of the NMPC and the superior robust performance of the robust controller must be considered while designing the control system for the $\mathrm{CO}_{2}$ capture units. Different flooding control strategies for the situation when the flue gas flow rate increases are also covered in this work. 


\section{$\underline{\text { Dedication }}$}

I would like to dedicate this work to my parents, Fuxing Zhang and Liping Gao for their love and nursing me with affections, to my wife, Xue Yang, for her love, dedication and endless encouragement, and to Xue's parents, Huaishun Yang and Huimin Zhou for their support. 


\section{$\underline{\text { Acknowledgement }}$}

I would like to express my deepest gratitude to Dr. Richard Turton, who served as my graduate advisor and a great mentor during my stay in Morgantown, West Virginia. His guidance, patience and support helped immensely in completing my research. I would also like to thank my advisor Dr. Debangsu Bhattacharyya for his keen insight and guidance. His knowledge and expertise helped significantly with understanding the Aspen simulation packages and process control. There were many times when I was stuck with lack of progress and was able to find new directions after discussions with them. I also want to thank my committee members, Dr. Fernando Lima, Dr. Jingxin Wang and Dr. Stephen Zitney for their support, advice and direction in this research work.

I'd like to thank all my fellow lab members, Dustin, Job, Kiran, Prokash, Pratik, Srinivas, Yuan, Qiao, Anderson, Josh and Yifan for their company and help in research and coursework. Thanks also to my friends Xuan, Xiaoqian, Chenbo, Xiaoyan, Xin and others for making the life at Morgantown fun and memorable.

I would like to thank US-China Clean Energy Research Center (CERC) and U.S. Department of Energy (DOE) for providing the funding to this project. 


\section{TABLE OF CONTENTS}

1. INTRODUCTION............................................................

1.1 Fossil-fuel Pwer Plants...............................................................

1.2 Carbon Capture Processes and Technologies....................................2

1.3 Control of Carbon Capture Processes............................................... 5

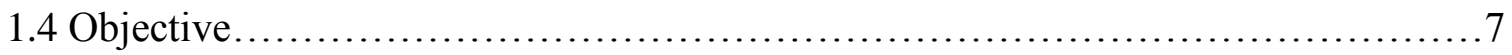

2. LITERRATURE REVIEW .......................................10

2.1 Steady-state Modeling and Simulations............................................10

2.2 Dynamic Modeling and Control System Design................................. 12

3. STEADY-STATE MODEL DEVELOPMENT .......................16

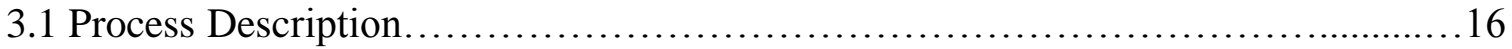

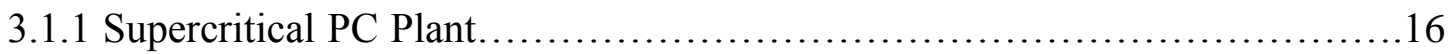

3.1.2 Post-Combustion $\mathrm{CO}_{2}$ Capture Plant....................................19

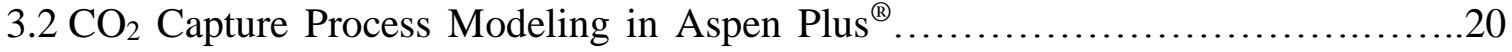

3.2.1 Thermodynamic and Kinetic Models........................................21

3.2.2 Transport Property Models.............................................22

3.3 Sensitivity Analysis and Optimization of the $\mathrm{CO}_{2}$ Capture Process...................23

4. DYNAMIC MODEL DEVELOPMENT ............................29

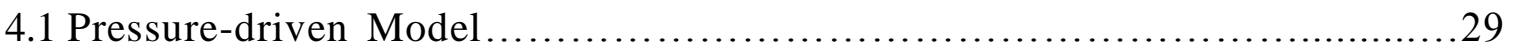

4.2 Equipment Size and Mass......................................................... 30

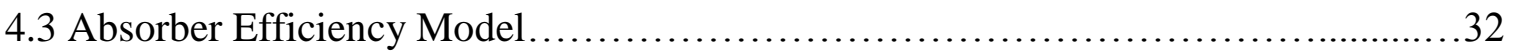

4.4 Absorber Pressure Drop Model.................................................... 36

5. LINEAR MODEL PREDICTIVE CONTROL.......................42

5.1 Plant-Wide Control Structure...............................................42

5.1.1 Flooding Control Strategy................................................ 44

5.1.1.1 Correlation of $\mathrm{CO}_{2}$ Absorber Flooding Approach...................45

5.1.1.2 $\mathrm{CO}_{2}$ Absorber Flooding Control Design...................................46

5.2 Open-Loop System..................................................... 48

5.3 Proportional-Integral-Derivative (PID) Control and Linear Model Predictive Control

(LMPC) for $\mathrm{CO}_{2}$ Capture Processes........................................51

5.3.1 Proportional-Integral-Derivative Control...............................51

5.3.2 Linear Model Predictive Control..........................................52

5.3.2.1 System Identification for LMPC ................................54

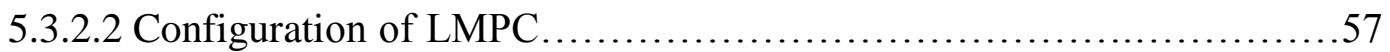

5.4 LMPC Transients Studies for Other Cases.....................................62

5.4.1 Transients Responses to Ramp Changes in the Flue Gas Flow Rate.........62

5.4.2 Transients Studies for Low $\mathrm{CO}_{2}$ Absorber Efficiency.......................64

5.4.3 Transients Studies for Parallel Trains of $\mathrm{CO}_{2}$ Capture Processes.............65

5.5 LMPC Transients Studies for Integrated System..................................67

5.5.1 Transients Studies in Response to Ramp Change in Power Loadings.........67

5.5.2 Transients Studies in Response to Random Changes in Power Loadings....72 
6. NONLINEAR MODEL PREDICTIVE CONTROL...................74

6.1 System Identification for NMPC .............................................. 74

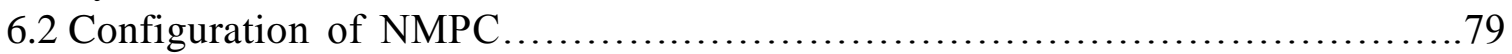

6.3 NMPC Transient Studies....................................................79

6.3.1 Transients Studies in Response to Ramp Changes in Power Plant Load......79

6.3.2 Transients Studies in Response to Simultaneous Ramp Changes in the Power Plant Load and $\mathrm{CO}_{2}$ Capture Target....................................81

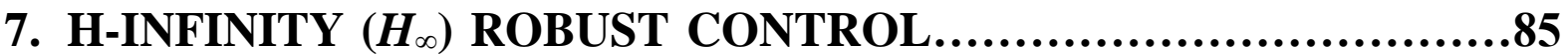

7.1 Robust Control of the Post-Combustion $\mathrm{CO}_{2}$ Capture Process......................85

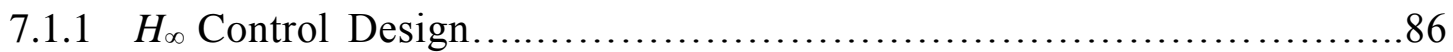

7.1.2 Plant and Uncertainty Modeling for Robust Control Design................89

7.1.3 Robust Control Design and Performance Analysis..........................992

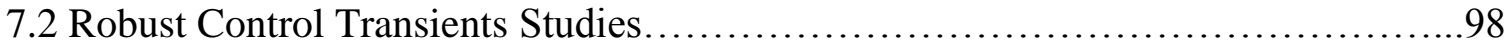

7.2.1 Transients in Response to Random $\mathrm{CO}_{2}$ Capture Targets under Design Power Plant Load.................................................................99

7.2.2 Transients in Response to Random $\mathrm{CO}_{2}$ Capture Targets under a Cyclic Power Plant Load.................................................103

7.2.3 Transients in Response to Random $\mathrm{CO}_{2}$ Capture Targets under a Cyclic Power Plant Load with Tight Constraints on the Rate of Change in Manipulated Variables for NMPC ...................................106

8. CONCLUSIONS................................................110

9. SUGGESTIONS FOR FUTURE WORK...........................113

9.1 Supercritical PC Plant Model.................................................113

9.2 MEA-Based Post-Combustion $\mathrm{CO}_{2}$ Capture Process Model........................113

9.3 Advanced Control of $\mathrm{CO}_{2}$ Capture Processes..................................114

REFERENCES........................................................115

Appendix A: Relative Gain Array (RGA)..............................124

Appendix B: D-K Iteration Algorithm..............................125

Appendix C: Structured Singular Value..................................126 


\section{LIST OF FIGURES}

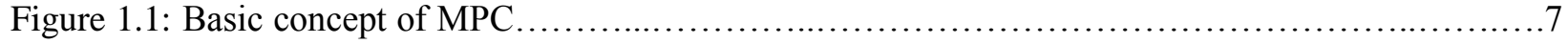

Figure 1.2: Flowsheet of the working approach.............................................................................

Figure 3.1: Simplified flowsheet of the supercritical coal-fired power plant with $\mathrm{CO} 2$ capture..........17

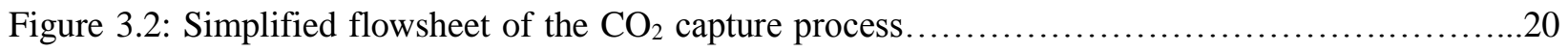

Figure 3.3: Reboiler and cooling duties under various flue gas temperature..........................23

Figure 3.4: Reboiler and cooling duties under various lean solvent temperature....................24

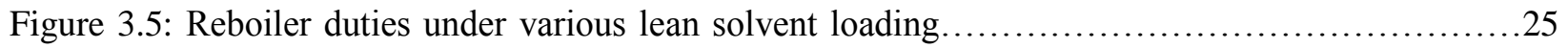

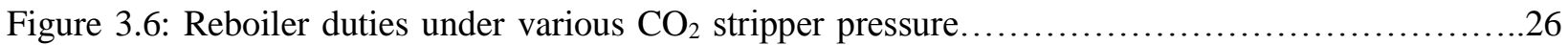

Figure 3.7: Reboiler duties and power plant efficiencies under various $\mathrm{CO}_{2}$ absorber pressure...............27

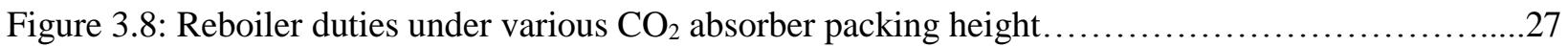

Figure 4.1: Schematics of a flash vessel in steady-state simulation (left) and pressure-driven dynamic

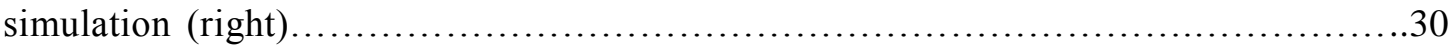

Figure 4.2: Comparisons of $\mathrm{CO}_{2}$ flow rate in scrubbed flue gas between correlated equilibrium and ratebased models under varying flue gas flow rates $(2.48-3.41 \mathrm{kmol} / \mathrm{s}) \ldots \ldots \ldots \ldots \ldots \ldots \ldots \ldots . \ldots . \ldots \ldots$

Figure 4.3: Comparisons of $\mathrm{CO}_{2}$ flow rate in scrubbed flue gas between correlated equilibrium and ratebased models under varying lean solvent flow rates $(7.44-11.70 \mathrm{kmol} / \mathrm{s}) \ldots \ldots \ldots \ldots \ldots \ldots . \ldots 34$

Figure 4.4: Comparisons of $\mathrm{CO}_{2}$ flow rate in scrubbed flue gas between correlated equilibrium and ratebased models under varying $\mathrm{CO}_{2}$ feed flow rates $(0.325-0.512 \mathrm{kmol} / \mathrm{s}) \ldots \ldots \ldots \ldots \ldots \ldots \ldots . . . \ldots 5$

Figure 4.5: Comparisons of $\mathrm{CO}_{2}$ flow rate in scrubbed flue gas between correlated equilibrium and ratebased models under varying lean solvent loadings $\left(0.116-0.276 \mathrm{kmol} \mathrm{CO}_{2} / \mathrm{kmol} \mathrm{MEA}\right) \ldots . .35$

Figure 4.6: Comparisons of $\mathrm{CO}_{2}$ flow rate in scrubbed flue gas between correlated equilibrium and ratebased models under varying MEA concentrations solvent (28-32 wt. \%) ................... 36

Figure 4.7: Packing pressure drop of Aspen Plus ${ }^{\circledR}$ and Aspen Plus Dynamics ${ }^{\circledR}$ default models when flue

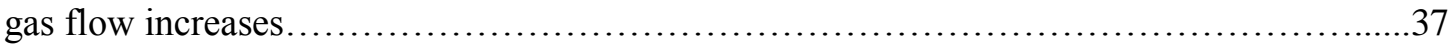

Figure 4.8: Pressure drop of Aspen Plus ${ }^{\circledR}$ and IMTP packing pressure drop models when absorber

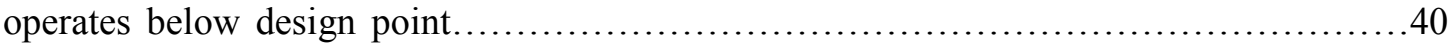

Figure 4.9: Pressure drop of Aspen Plus ${ }^{\circledR}$ and IMTP packing pressure drop models when absorber operates above design point.

Figure 4.10: Pressure drop of Aspen Plus ${ }^{\circledR}$ and IMTP models for direct contact cooler..................41

Figure 4.11: Pressure drop of Aspen Plus ${ }^{\circledR}$ and IMTP models for MEA washing section.................41

Figure 5.1: Proposed plant-wide control structure for MEA-based $\mathrm{CO}_{2}$ capture process................43

Figure 5.2: Proposed pressure control (left) and flooding approach control (right).....................44

Figure 5.3: Comparison of average flooding approach for top $7.8 \mathrm{~m}$ of packing bed in $\mathrm{CO}_{2}$ absorber between Equation (5.1) and Aspen Plus ${ }^{\circledR}$ in response to an increase in flue gas feed flow...45

Figure 5.4: Flooding approach at $1.8 \mathrm{~m}$ of absorber (from top) in response to $20 \%$ increase in flue gas feed

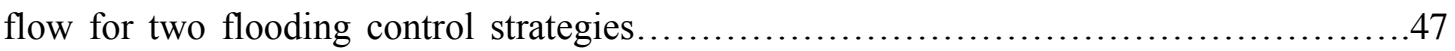

Figure 5.5: Overall $\mathrm{CO}_{2}$ capture efficiency in response to $20 \%$ increase in flue gas feed flow for two

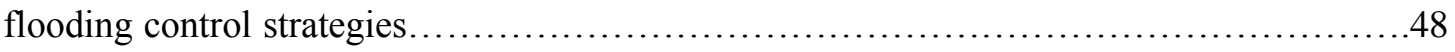


Figure 5.6: Open-loop transients of $\mathrm{CO}_{2}$ capture efficiency..................................49

Figure 5.7: Open-loop transients of $\mathrm{CO}_{2}$ stripper reboiler temperature.............................50

Figure 5.8: Transient of $\mathrm{CO}_{2}$ capture efficiency due to $5 \%$ ramp decrease in flue gas flow rate and $\mathrm{CO}_{2}$ composition of flue gas...................................................... 50

Figure 5.9: Transient of $\mathrm{CO}_{2}$ stripper reboiler temperature due to $5 \%$ ramp decrease in flue gas flow rate

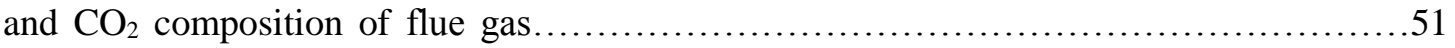

Figure 5.10: Implemented random signals of flue gas flow rate and steam flow rate for system

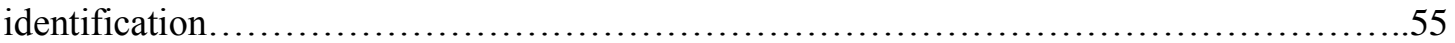

Figure 5.11: Implemented random signals of lean solvent flow rate and $\mathrm{CO}_{2}$ composition of flue gas for

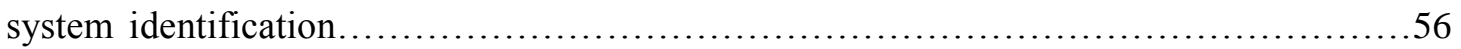

Figure 5.12: Comparison between Aspen Plus Dynamics ${ }^{\circledR}$ and identified process models.................57

Figure 5.13: Simulink schematic of the LMPC control strategy for $\mathrm{CO}_{2}$ capture process...............58

Figure 5.14: $\mathrm{CO}_{2}$ capture efficiency control performances of LMPCs and PID due to 5\% ramp decrease in flue gas flow rate and $\mathrm{CO}_{2}$ composition of flue gas.............................60

Figure 5.15: $\mathrm{CO}_{2}$ stripper reboiler temperature control performances of LMPCs and PID due to 5\% ramp decrease in flue gas flow rate and $\mathrm{CO}_{2}$ composition of flue gas......................60

Figure 5.16: Transients of lean solvent in response to $5 \%$ ramp decrease in flue gas flow rate and $\mathrm{CO}_{2}$ composition of flue gas....................................................61

Figure 5.17: Transients of low pressure steam in response to 5\% ramp decrease in flue gas flow rate and

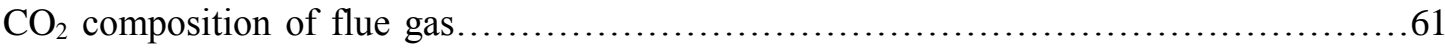

Figure 5.18: $\mathrm{CO}_{2}$ capture efficiency control performances of LMPC and PID due to $15 \%$ ramp decrease in flue gas flow rate and 5\% ramp decrease in $\mathrm{CO}_{2}$ composition of flue gas...............63

Figure 5.19: $\mathrm{CO}_{2}$ stripper reboiler temperature control performances of LMPC and PID due to $15 \%$ ramp decrease in flue gas flow rate and $5 \%$ ramp decrease in $\mathrm{CO}_{2}$ composition of flue gas........63

Figure 5.20: Performances of LMPC for $\mathrm{CO}_{2}$ capture control due to $5 \%$ ramp decrease in flue gas flow rate and $\mathrm{CO}_{2}$ composition of flue gas at different $\mathrm{CO}_{2}$ absorber efficiencies..............64

Figure 5.21: PID control performances for $\mathrm{CO}_{2}$ capture control when one absorber's efficiency deteriorates

Figure 5.22: LMPC control performances for $\mathrm{CO}_{2}$ capture control when one absorber's efficiency deteriorates

Figure 5.23: Performances of LMPC and PID for overall $\mathrm{CO}_{2}$ capture control due to $50 \%$ ramp decrease in power plant load for integrated system.

Figure 5.24: Performances of LMPC and PID for stripper reboiler temperature control due to 50\% ramp decrease in power plant load for integrated system.

Figure 5.25: Dynamic performances of LMPC and PID for overall $\mathrm{CO}_{2}$ capture control due to $50 \%$ ramp decrease in power plant load while ramping down $\mathrm{CO}_{2}$ capture target to $70 \%$ for integrated system.

Figure 5.26: Dynamic performances of LMPC and $\mathrm{PID}$ for $\mathrm{CO}_{2}$ stripper reboiler temperature control due to $50 \%$ ramp decrease in power plant load while ramping down $\mathrm{CO}_{2}$ capture target to $70 \%$ for integrated system. .71 
Figure 5.27: Implemented random input signal of power plant load for integrated system.....

Figure 5.28: $\mathrm{CO}_{2}$ capture control performances of LMPC and PID due to a random input signal of power plant load for integrated system.

Figure 5.29: $\mathrm{CO}_{2}$ stripper reboiler temperature control performances of LMPC and PID due to a random input signal of power plant load for integrated system.

Figure 6.1: Implemented variable MLS signals of lean solvent flow rate and $\mathrm{CO}_{2}$ composition of flue gas for system identification...................................................... 76

Figure 6.2: Implemented variable MLS signals of flue gas flow rate and steam flow rate for system

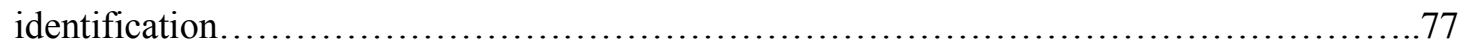

Figure 6.3: Comparisons between Aspen Plus Dynamics ${ }^{\circledR}$ and identified process models..............78

Figure 6.4: Dynamics of $\mathrm{CO}_{2}$ capture efficiency for MPCs and PID in response to $50 \%$ ramp decrease in power plant load........................................................... 80

Figure 6.5: Dynamics of $\mathrm{CO}_{2}$ stripper reboiler temperature for MPCs and PID in response to $50 \%$ ramp decrease in power plant load................................................. 81

Figure 6.6: Dynamics of $\mathrm{CO}_{2}$ capture efficiency for MPCs and PID in response to $50 \%$ ramp decrease in power plant load and reduction in $\mathrm{CO}_{2}$ capture target..............................82

Figure 6.7: Dynamics of $\mathrm{CO}_{2}$ stripper reboiler temperature for MPCs and PID in response to 50\% ramp decrease in power plant load and reduction in $\mathrm{CO}_{2}$ capture target.............................83

Figure 6.8: Transients of low pressure steam flow in response to 50\% ramp decrease in power plant load and reduction in $\mathrm{CO}_{2}$ capture target......................................... 83

Figure 7.1 : Standard control configuration................................................ 86

Figure 7.2: Closed-loop system configuration with weighted tracking error and manipulated input.....87

Figure 7.3: Closed-loop system configuration with 2DOF controller in the presence of model

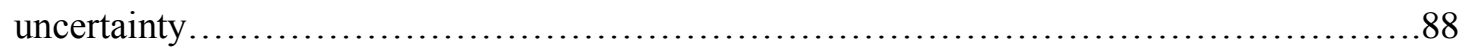

Figure 7.4: Relative errors for the perturbed plants...................................... 91

Figure 7.5: Desired model frequency response............................................... 94

Figure 7.6: Inverse of performance weight function....................................... 95

Figure 7.7: Control action weight function.................................................... 96

Figure 7.8: Robust performance of the designed 2DOF $H_{\infty}$ robust controller......................97

Figure 7.9: Frequency responses of the full-order controller and reduced-order controller, upper: $\mathrm{CO}_{2}$ capture controller; lower: reboiler temperature controller...........................97

Figure 7.10: Dynamics of $\mathrm{CO}_{2}$ capture efficiency for PID, NMPC and $H_{\infty}$ robust controller in response to random $\mathrm{CO}_{2}$ capture target under design power plant load in the face of uncertainty......100

Figure 7.11: Dynamics of stripper reboiler temperature for PID, NMPC and $H_{\infty}$ robust controller in response to random $\mathrm{CO}_{2}$ capture target under design power plant load in the face of uncertainty.... 101

Figure 7.12: Transients of rich solvent flow in response to random $\mathrm{CO}_{2}$ capture target under design power plant load in the face of uncertainty. 102

Figure 7.13: Transients of low pressure steam flow in response to random $\mathrm{CO}_{2}$ capture target under design power plant load in the face of uncertainty. 103 
Figure 7.14: Implemented power plant load profile for the integrated system based on International

Energy Agency's report...................................................... 104

Figure 7.15: Dynamics of $\mathrm{CO}_{2}$ capture efficiency for PID, NMPC and $H_{\infty}$ robust controller in response to random $\mathrm{CO}_{2}$ capture target under cyclic power plant load in the face of uncertainty........105

Figure 7.16: Dynamics of stripper reboiler temperature for PID, NMPC and $H_{\infty}$ robust controller in response to random $\mathrm{CO}_{2}$ capture target under cyclic power plant load in the face of

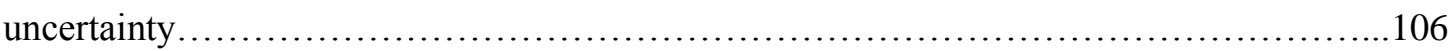

Figure 7.17: Dynamics of $\mathrm{CO}_{2}$ capture efficiency for constrained NMPC and $H_{\infty}$ robust controller in response to random $\mathrm{CO}_{2}$ capture target under cycled power plant load in the face of

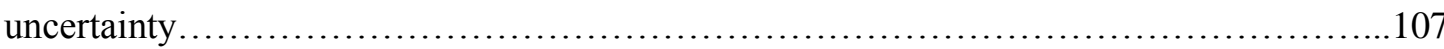

Figure 7.18: Dynamics of stripper reboiler temperature for constrained NMPC and $H_{\infty}$ robust controller in response to random $\mathrm{CO}_{2}$ capture target under cycled power plant load in the face of uncertainty.... 108 


\section{LIST OF TABLES}

Table 3.1: Coal Analysis of Illinois No. 6 Bituminous Coal................................... 18

Table 3.2: Composition of Combustion Air on Volume Basis $(\%$ Vol. $)$.................................18

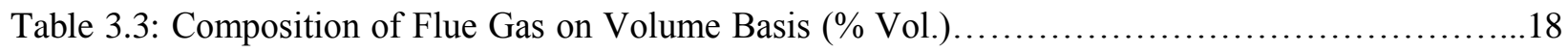

Table 3.4: Columns Sizing Results (for $94 \mathrm{~m}^{3} / \mathrm{s}$ capacity)....................................20

Table 3.5: Kinetic Parameters in the Reduced Power Law Expression (Equation 3.8)..................22

Table 3.6: Plant Energy Performances of Base Case and Optimized Case ...........................28

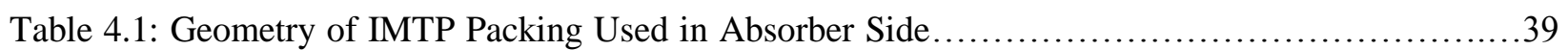

Table 4.2: Fitted Coefficients Value for IMTP Packing Pressure Drop Model.........................39

Table 5.1: Manipulated Input Constraints in the MPC Optimization Objective..........................58

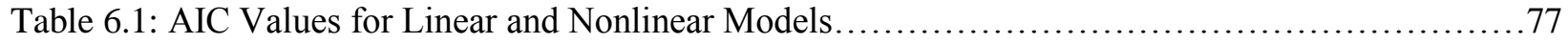

Table 6.2: Integral Square Error Analysis for PID, LMPC and NMPC .............................84

Table 7.1: Model Uncertainties in $\mathrm{CO}_{2}$ Capture Process......................................... 90

Table 7.2: Integral Square Error Analysis for Cases in Sections 7.2.1, 7.2.2, and 7.2.3..............109 


\section{NOMENCLATURE}

\section{Steady-state model development}

$a_{i}$

$C_{i}$

E

$k_{o}$

$N$

$n$

$R$

$r$

$T$ stoichiometric coefficient of component $i$ in the reaction equation

concentration of component $i\left(\mathrm{kmol} \cdot \mathrm{m}^{-3}\right)$

activation energy $\left(\mathrm{J} \cdot \mathrm{mol}^{-1}\right)$

pre-exponential factor

number of components in reaction

temperature exponent

universal gas constant, $8.314 \mathrm{~J} \cdot \mathrm{mol}^{-1} \cdot \mathrm{K}^{-1}$

rate of reaction

absolute temperature $(\mathrm{K})$

\section{Dynamic model development}

A

$A_{o}$

$C A$

D

$d_{h}$

$d_{n}$

E

Eo

$\varepsilon$

$\varepsilon_{C O 2, i}$

$\varepsilon_{C O 2, i}^{D}$

$F_{\mathrm{CO} 2}$

$F_{\mathrm{CO} 2}^{D}$

$F_{F G}$

$F_{F G}^{D}$

$F_{\text {Sol }}$

$F_{\text {Sol }}^{D}$ exchange area $\left(\mathrm{m}^{2}\right)$

dimensionless number that accounts for the effect of liquid holdup under the loading point

corrosion allowance $(\mathrm{m})$

diameter of the vessel (m)

packing hydraulic diameter $(\mathrm{m})$

packing nominal diameter $(\mathrm{m})$

weld efficiency

Eotvos number

packing void fraction

$\mathrm{CO}_{2}$ stage efficiency at $i^{\text {th }}$ stage

design point $\mathrm{CO}_{2}$ stage efficiency at $i^{\text {th }}$ stage

$\mathrm{CO}_{2}$ feed rate $\left(\mathrm{kmol} \cdot \mathrm{s}^{-1}\right)$

$\mathrm{CO}_{2}$ feed rate at design point $\left(\mathrm{kmol} \cdot \mathrm{s}^{-1}\right)$

flue gas flow rate $\left(\mathrm{kmol} \cdot \mathrm{s}^{-1}\right)$

flue gas flow rate at design point $\left(\mathrm{kmol} \cdot \mathrm{s}^{-1}\right)$

lean solvent flow rate $\left(\mathrm{kmol} \cdot \mathrm{s}^{-1}\right)$

lean solvent flow rate at design point $\left(\mathrm{kmol} \cdot \mathrm{s}^{-1}\right)$ 


\begin{tabular}{|c|c|}
\hline$F r_{L}$ & liquid Froude number \\
\hline$H_{\text {pack }}$ & packing height (m) \\
\hline$K_{o}$ & constant coefficient $\left(\mathrm{Pa} \cdot \mathrm{s}^{2} \cdot \mathrm{kg}^{-1} \cdot \mathrm{m}^{-3}\right)$ \\
\hline$L$ & liquid phase superficial velocity $\left(\mathrm{m} \cdot \mathrm{s}^{-1}\right)$ \\
\hline Lean $_{\text {loading }}$ & $\mathrm{CO}_{2}$ loading of the lean solvent $\left(\frac{\mathrm{kmol} \mathrm{CO}_{2}}{\mathrm{kmol} \mathrm{MEA}}\right)$ \\
\hline Lean loading & $\mathrm{CO}_{2}$ loading of the lean solvent at design point $\left(\frac{\mathrm{kmol} \mathrm{CO}_{2}}{\mathrm{kmol} \mathrm{MEA}}\right)$ \\
\hline$M E A_{w t}$ & weight percentage of MEA in the lean solvent (\%) \\
\hline$M E A_{w t}^{D}$ & weight percentage of MEA in the lean solvent at design point $(\%)$ \\
\hline$P$ & design pressure of the vessel (bar) \\
\hline$\rho_{G}$ & gas phase density $\left(\mathrm{kg} \cdot \mathrm{m}^{-3}\right)$ \\
\hline$\rho_{L}$ & liquid phase density $\left(\mathrm{kg} \cdot \mathrm{m}^{-3}\right)$ \\
\hline$Q$ & exchanger heat duty (watts) \\
\hline$R e_{L}$ & liquid Reynolds number \\
\hline$S$ & maximum allowable stress (bar) \\
\hline$s$ & minimum width of the packing at the edge where it is bent to $90^{\circ}(\mathrm{m})$ \\
\hline$t_{s}$ & thickness of the vessel wall (m) \\
\hline$U$ & heat transfer coefficient (watts $\cdot \mathrm{K}^{-1} \cdot \mathrm{m}^{-2}$ ) \\
\hline$V$ & gas phase superficial velocity $\left(\mathrm{m}^{3} \cdot \mathrm{s}^{-1}\right)$ \\
\hline$\Delta A$ & $\begin{array}{l}\text { dimensionless number that accounts for the effect of increasing liquid holdup over } \\
\text { the loading point }\end{array}$ \\
\hline$\Delta P$ & pressure drop across wet packing $(\mathrm{Pa})$ \\
\hline$\Delta P_{o}$ & pressure drop across dry packing $(\mathrm{Pa})$ \\
\hline
\end{tabular}

\section{Linear model predictive control}

$\begin{array}{ll}\alpha & \text { adaption speed } \\ C H & \text { control horizon } \\ e & \text { error value } \\ F A & \text { average flooding approach }(\%) \\ J & \text { optimization objective of model predictive control scheme } \\ K_{D} & \text { coefficient of the derivative term }\end{array}$




$\begin{array}{ll}K_{I} & \text { coefficient of the integral term } \\ K_{P} & \text { coefficient of the proportional term } \\ k & \text { time step } \\ P H & \text { prediction horizon } \\ \boldsymbol{r} & \text { desired set-point trajectory } \\ \boldsymbol{u} & \text { manipulated inputs } \\ u & \text { control variable } \\ \boldsymbol{w}_{u} & \text { weighting matrices for inputs } \\ \boldsymbol{w}_{y} & \text { weighting matrices for outputs } \\ \boldsymbol{y} & \text { model predictions } \\ \Delta P & \text { average pressure drop per } 0.6 \mathrm{~m} \text { of wet packing bed }(\mathrm{Pa})\end{array}$

\section{Nonlinear model predictive control}

$\begin{array}{ll}f & \text { input polynomials } \\ H & \text { parameter vector } \\ k & \text { time step } \\ m & \text { output memory } \\ n & \text { input memory } \\ s & \text { output polynomials } \\ u & \text { model inputs } \\ y & \text { model outputs }\end{array}$

\section{H-infinity robust control}

$\begin{array}{ll}e & \text { tracking error } \\ e_{u} & \text { weighted manipulated input } \\ e_{y} & \text { weighted tracking error } \\ G & \text { nominal plant } \\ G_{p} & \text { perturbed plant } \\ K & \text { controller } \\ K_{r} & \text { prefilter part of a } 2 \text { DOF } H_{\infty} \text { controller } \\ K_{y} & \text { feedback part of a } 2 \mathrm{DOF} H_{\infty} \text { controller }\end{array}$




$\begin{array}{ll}M & \text { model of the desired dynamic behavior } \\ P & \text { measurement noise } \\ r & \text { generalized plant } \\ S & \text { reference input } \\ T & \text { system sensitivity function } \\ u & \text { system complementary sensitivity function } \\ v & \text { manipulated input } \\ W_{n} & \text { measured output } \\ W_{p} & \text { noise shaping filter } \\ W_{u} & \text { performance weighting function } \\ W_{\Delta} & \text { control weighting function } \\ w & \text { uncertainty weighting function } \\ z & \text { external input } \\ \Delta & \text { error signal }\end{array}$




\section{INTRODUCTION}

As the concentrations of greenhouse gases, such as carbon dioxide $\left(\mathrm{CO}_{2}\right)$, nitrous oxide $\left(\mathrm{N}_{2} \mathrm{O}\right)$ and methane $\left(\mathrm{CH}_{4}\right)$ increase in the atmosphere, the Earth's surface temperature increases. The Intergovernmental Panel on Climate Change (IPCC) concluded that, among all the greenhouse gas, $\mathrm{CO}_{2}$ is responsible for about $50 \%$ of the increase in temperature based on the climate data since the Industrial Revolution (Metz et al., 2005). The main source of $\mathrm{CO}_{2}$ emissions is the combustion of fossil fuels, such as coal, petroleum, and natural gas, which are dominant in the current energy supply. In 2014, more than 2 billion tons of $\mathrm{CO}_{2}$ was released to the environment by the United States electricity sector, which accounts for $38 \%$ of the energy-related $\mathrm{CO}_{2}$ emissions (U.S. Energy Information Administration, 2016). In order to reduce the carbon pollution from power plants, the United States Environmental Protection Agency (EPA) finalized the Clean Power Plan (CPP) on August 3, 2015 (U.S. Environmental Protection Agency, 2015). The target of this new plan is to cut the carbon emissions from power plants by $32 \%$ of their 2005 levels within fifteen years. An effective way to reduce $\mathrm{CO}_{2}$ emissions without decreasing energy demand is the implementation of carbon capture technologies on existing and future fossil fuel power plants. This environment-friendly, electricity production process will consist of two sections; a fossil-fuel power plant and a $\mathrm{CO}_{2}$ capture plant.

\subsection{Fossil-fuel Power Plants}

In a fossil-fuel power plant, the chemical energy stored in fossil fuel such as coal, petroleum, or natural gas is converted into thermal energy, mechanical energy and finally electrical energy. Petroleum is mostly used for transportation while natural gas and coal are used mainly to produce electricity. Coal is the most abundant fossil fuel on the planet. Therefore, most existing fossil-fuel power plants are conventional pulverized coal (PC) power plants, in which the electricity is produced by burning coal to generate high-temperature, high-pressure steam, which then passes through multiple stages of steam turbines. Pulverized coal power plants can be classified into three categories: subcritical, supercritical, ultra-supercritical and advanced ultra- 
supercrtical. The primary difference between these three types of power plants is the operating temperature and pressure to which the steam is raised prior to entering the first turbine. Subcritical power plants typically generate high-pressure steam at around $540^{\circ} \mathrm{C}$ and 170 bar, which is below the critical pressure of water (221 bar), while supercritical plants generate steam at $600^{\circ} \mathrm{C}$ and 250 bar, ultra-supercritical plants generate steam at $615^{\circ} \mathrm{C}$ and 300 bar and advanced ultra-supercritical plants generate steam up to $760^{\circ} \mathrm{C}$ and 350 bar. As higher temperature enables higher thermal efficiency to be achieved, an advanced ultra-supercritical PC power plant has the highest efficiency at around $47 \%$, followed by an ultra-supercritical plant at $45 \%$ and a supercritical plant at around $40 \%$, and finally a subcritical plant has the lowest efficiency at around 37\%. The temperature and pressure used in the PC power plant is limited by the availability and reliability of materials to withstand such conditions. Based on the current status of metallurgy, a supercritical power plant is preferred for its efficiency and system reliability. Higher efficiency can be achieved by using other advanced technologies such as Integrated Gasification Combined Cycle (IGCC) and Natural Gas Combined Cycle (NGCC), in which steam turbine cycles and a gas combustion turbine cycles are used together. IGCC systems can make use of pre-combustion $\mathrm{CO}_{2}$ capture, while NGCC systems can be combined with postcombustion $\mathrm{CO}_{2}$ capture technologies. However, the designs and configurations of these two combined cycle technologies are more complicated than for conventional PC power plants that can make use of post-combustion $\mathrm{CO}_{2}$ capture. The loss in plant efficiency due to $\mathrm{CO}_{2}$ capture for supercritical PC, IGCC and NGCC usually are about 28\%, 26\% and 15\%, respectively (Black, 2010). For the two coal-based cases, the efficiency losses are about the same. IGCC with precombustion $\mathrm{CO}_{2}$ capture are reported to have the lowest cost per tonne of $\mathrm{CO}_{2}$ avoided at $23 \$$. For conventional PC plant with post-combustion $\mathrm{CO}_{2}$ capture and gas-fired plant with postcombustion $\mathrm{CO}_{2}$ capture, the cost are $34 \$$ and $58 \$$, respectively (Leung et al., 2014).

\subsection{Carbon Capture Processes and Technologies}

There are basically three different carbon capture processes: post-combustion, oxy-fuel combustion, and pre-combustion capture. Post-combustion capture removes $\mathrm{CO}_{2}$ from flue gas after the combustion of fuel. The oxidant used for combustion is usually air and $\mathrm{CO}_{2}$ concentration in the flue gas is low due to the significant dilution by nitrogen (approx. $13 \mathrm{~mol} \%$ $\mathrm{CO}_{2}$ ) and the low pressure of the gas stream $(1 \mathrm{~atm})$. To overcome the disadvantages of post- 
combustion capture, oxy-fuel combustion is carried out in the presence of high-purity oxygen instead of air. After condensation of water, the flue gas contains between $80 \sim 98 \% \mathrm{CO}_{2}$ depending on the type of fuel used (IPCC, 2005). Therefore, highly concentrated $\mathrm{CO}_{2}$ can be directly stored for sequestration. As nitrogen is removed before combustion, the mass and volume of the flue gas, as well as the size of capture equipment, are reduced by approximately $75 \%$. However, an air separation unit is required for oxy-fuel combustion capture, which may significantly increase the capital cost. Pre-combustion capture refers to the removal of $\mathrm{CO}_{2}$ before fossil fuel combustion. It is usually used in IGCC systems in which the feedstock is gasified in the presence of steam and oxygen/air under high temperature and pressure to produce synthesis gas or syngas. The major components of syngas are: $\mathrm{H}_{2}, \mathrm{CO}$ and $\mathrm{CO}_{2}$. The syngas goes through a water-gas shift reactor to convert $\mathrm{CO}$ and $\mathrm{H}_{2} \mathrm{O}$ to $\mathrm{CO}_{2}$ and $\mathrm{H}_{2}$, respectively. $\mathrm{CO}_{2}$ is then captured and the resulting $\mathrm{H}_{2}$-rich fuel is subsequently fed to a combustion turbine to produce power. Compared to post-combustion capture, the higher $\mathrm{CO}_{2}$ concentration in the shifted syngas and higher pressure enable the pre-combustion $\mathrm{CO}_{2}$ capture process to be more efficient and this is typically done using physical solvents such as Selexol ${ }^{\mathrm{TM}}$ and chilled methanol (RectisolTM). However, the gasification process has a significantly higher capital cost than conventional PC processes, which is the major disadvantage of power plants with precombustion capture.

Several capture technologies to separate $\mathrm{CO}_{2}$ from flue gas mixtures have been studied in the last several decades and are based on chemical absorption, physical absorption, membrane separation, and adsorption. In chemical absorption, $\mathrm{CO}_{2}$ in the gas stream reacts with a chemical solvent to form a set of intermediate compounds. Chemical absorption is preferred for a post-combustion $\mathrm{CO}_{2}$ capture process due to its good selectivity when the partial pressure of $\mathrm{CO}_{2}$ in flue gas is low. A number of chemical solvents can be used for $\mathrm{CO}_{2}$ absorption, such as amines, ammonia and potassium carbonate. Rao and Rubin (2002) indicated that amine-based post-combustion $\mathrm{CO}_{2}$ absorption technology is preferred for combustion-based PC power plants for many reasons. For example, it is applicable to the low $\mathrm{CO}_{2}$ concentration in the flue gas and can be easily retrofitted to existing PC power plants. In these processes, $\mathrm{CO}_{2}$ is absorbed by thermally regenerable chemical solvents and the $\mathrm{CO}_{2}$ is then recovered from the rich solvent at elevated temperature via a temperature-swing process. However, the thermal energy required for 
regeneration usually comes from extracted steam from the low-pressure steam turbines, which results in a significant decrease in the power plant efficiency. Aqueous monoethanolamine (MEA) is a common available chemical absorption solvent for post-combustion $\mathrm{CO}_{2}$ capture and has been used for commercial acid gas treating in Fluor Corporation's Econamine FG $^{\mathrm{TM}}$ and Econamine FG PLUS ${ }^{\mathrm{TM}}$ technologies (Mariz, 1998; Chapel et al., 1999). Many researchers have focused on developing novel solvents that are more energy efficient than MEA. However, Ma'mun et al. (2007) studied the performance of different $\mathrm{CO}_{2}$ absorbents and found that MEA is still superior compared with most other solvents. Compared with amines, ammonia has a higher absorption loading and less energy penalty (Pellegrini et al., 2010). However, because of its high vapor pressure it exhibits a significant loss of solvent that requires additional units and energy to minimize the loss, which increases capital and operating costs. Aqueous solutions of potassium carbonate are applicable to both pre- and post-combustion $\mathrm{CO}_{2}$ capture. But the reaction rate between $\mathrm{CO}_{2}$ and $\mathrm{KCO}_{3}$ is rather low compared with amines.

Physical absorption can only give good performance when acid gases such as $\mathrm{CO}_{2}$ have high partial pressure and low temperature. Therefore, they are preferred for pre-combustion $\mathrm{CO}_{2}$ capture in IGCC systems. One problem with the application of physical absorption in IGCC is that cooling is necessary before the syngas goes through the acid gas capture units. This cooling decreases the thermal efficiency of the power plant. Other capture technologies include adsorption and membrane separation. In adsorption processes, the gas stream is fed to a bed of solid adsorbent, which adsorbs $\mathrm{CO}_{2}$ selectively until equilibrium is reached. Compared with absorption technologies, adsorption processes can, in principle, be applied with less regeneration requirements and over a much wider range of operating conditions. However, the capacity, stability, and selectivity of solid sorbents limit their application in $\mathrm{CO}_{2}$ capture (Samanta et al., 2011). Membrane separation uses semi-permeable materials as filters to selectively remove $\mathrm{CO}_{2}$ by adsorption onto the surface of the membrane. The $\mathrm{CO}_{2}$ molecules then pass through the interior of the membrane to reach the low-pressure side. The limits of selectivity and permeability make it difficult to reach a high purity for a desired separation rate (Aaron and Tsouris, 2005). 


\subsection{Control of Carbon Capture Processes}

For a specific process, a control system is necessary to ensure the process variables meet the desired specification as well as guarantee stability of the system in the presence of disturbances and uncertainties without violating the constraints. The proportional-integral-derivative (PID) controller is widely used in industrial control systems. It uses a generic feedback control loop mechanism and, therefore, can provide satisfactory performance without the need for a process model. Inner and outer loop PID controllers can also be cascaded to provide better dynamic performance. However, the PID controllers do not guarantee optimal control of the system or even its stability due to the lack of knowledge of the dynamic system. $\mathrm{CO}_{2}$ capture processes are expected to be complicated because different units have different time constants and there are strong interactions between multiple process variables. Moreover, multiple parallel trains of $\mathrm{CO}_{2}$ capture processes might be required to capture the majority of $\mathrm{CO}_{2}$ (up to 90\%) from a commercial-scale fossil-fuel power plant. In order to provide optimal control for a system comprising multiple trains, as well as satisfying the design and operating constraints and the process stability under nominal and uncertain conditions, it is necessary to implement other advanced controller strategies.

Model Predictive Control (MPC) is by far the most commonly applied advanced control technique in the chemical process industry. The difference between MPC and other controllers is that MPC solves the optimal finite horizon control problem online and in real time for the current state of the plant. The basic idea of MPC is shown in Figure 1.1. At time step $k$, an optimization problem is solved. An objective function based on output predictions over a prediction horizon of $m$ time steps is minimized by the moves for the selected manipulated variable over a control horizon of $p$ control moves $(m>p)$. Although $p$ moves are optimized, only the first move is applied. After the controller move $u_{k}$ is applied, the measured closed-loop output at the next time step is obtained and is usually different from the model predicted value. Therefore, a new optimization problem is then solved and the former procedure is repeated. MPC is able to predict the future events and apply control actions accordingly. Depending on the usage of either a linear system model or a nonlinear system model in the prediction, MPC can be characterized either as Linear Model Predictive Control (LMPC) or Nonlinear Model Predictive Control (NMPC). The inherent nonlinearity of carbon capture processes and the complexity of the optimization 
problem make NMPC the preferred technique. But NMPC is more computationally expensive than LMPC.

In addition to the nonlinearities of the process, uncertainties are unavoidable for the carbon capture process. These uncertainties can be classified into two types: model uncertainty and parameter uncertainty. Model uncertainties in carbon capture processes may originate from different sources. For example, the flue gas $\mathrm{CO}_{2}$ composition may change and depend on the type of fuel burned and the different air-to-fuel ratios (AFR). Capture capacity can change if the solvent composition changes or if the sorbents get diluted, degraded, etc. Other possible sources of uncertainty such as gradual loss in $\mathrm{CO}_{2}$ absorber efficiency and input/output measurement noise may also affect the performance of carbon capture processes. Parametric uncertainties can originate due to model parameters that are used for mathematical modeling. For the modeling of $\mathrm{CO}_{2}$ capture process, parameters used in the density, viscosity, enthalpy, entropy, and other process sub-models can have high uncertainties. Discrepancies between an actual $\mathrm{CO}_{2}$ capture process and models used in a simulation environment also result in uncertainty. The closed-loop system should perform satisfactorily and remain stable in the face of these uncertainties. Motivated by the goal to achieve robustness in real engineering systems, the $H_{\infty}$ optimal control theory was introduced by Zames (1981) and Zames and Francis (1983). In this approach, the uncertainties are modeled and incorporated within the closed-loop system at the design stage for the optimal robust controller. It should be noted that the optimal robust controller is only optimal with respect to the robust performance and does not provide the optimal control performance in terms of normal criteria, such as settling time, energy expended, etc. 


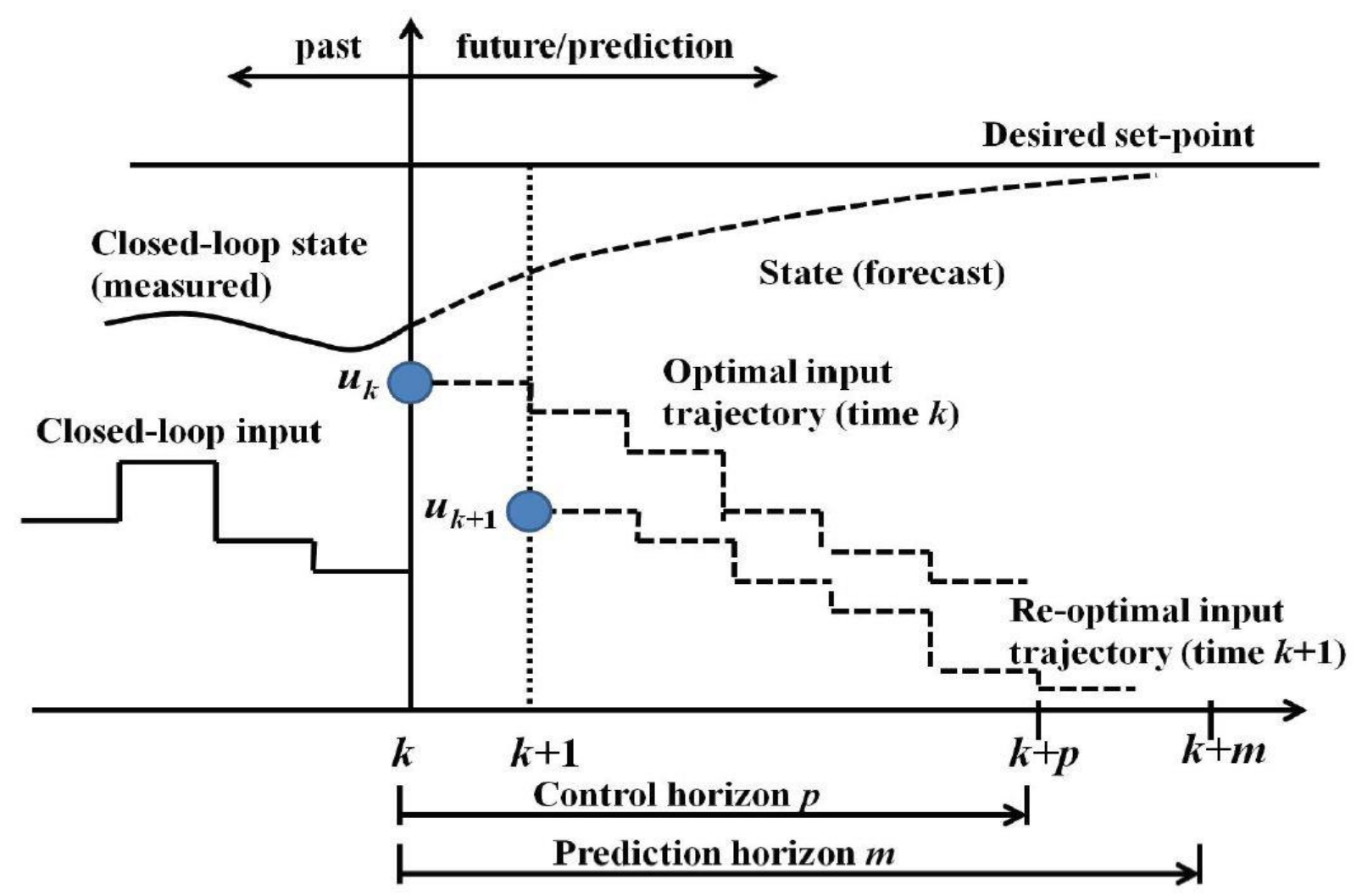

Figure 1.1 Basic concept of MPC (Dai et al., 2012)

\subsection{Objective}

In this work, a MEA-based post-combustion carbon capture process will be studied as most existing power plants are conventional PC power plants and their retrofit using carbon capture processes would have the most impact on climate change for coal-based power generation. The MEA-based post-combustion carbon capture process is chosen in the current work and is integrated with a 550MWe supercritical PC power plant. The objective of this work is to develop both high-fidelity steady-state and dynamic models, as well as design controllers for this MEAbased post-combustion carbon capture process. The steady-state and dynamic models are developed using Aspen Plus ${ }^{\circledR}$ and Aspen Plus Dynamics ${ }^{\circledR}$ software platforms, respectively. The Aspen software has user-friendly interfaces and comprehensive libraries of rigorous models for different process units. The extensive chemical and physical property databases make the simulation results reliable and accurate. Optimization of process variables is carried out based on 
the steady-state model with the goal to minimize the energy penalty of carbon capture process. The dynamic model is exported from the steady-state model and modifications and custom models are applied to ensure consistency between the two software platforms (rate-model developed in Aspen Plus ${ }^{\circledR}$ and equilibrium-based model in Aspen Plus Dynamics $\left.{ }^{\circledR}\right)$. The dynamic model provides the platform to design controllers for both traditional PID and advanced controllers, such as LMPC, NMPC, and $H_{\infty}$ robust control. System identification is required for the design of MPC. The outputs of the dynamic system are obtained by applying random signals to input variables. The identification process is accomplished using the System Identification Toolbox in Matlab. The dynamic model is identified as both a first-order linear process model and a nonlinear additive autoregressive model with exogenous variables (NAARX model). For the design of $H_{\infty}$ robust control, the model uncertainties within the MEA-based post-combustion carbon capture process are firstly quantified using appropriate assumptions, and modeled in the form of multiplicative input uncertainty. Design of the $H_{\infty}$ robust controller is accomplished using Matlab Robust Control Toolbox. LMPC, NMPC and $H_{\infty}$ robust controllers are implemented in Matlab Simulink. The Aspen Plus Dynamics ${ }^{\circledR}$ model is embedded in Simulink using an available custom block. The performance of these proposed advanced controllers are evaluated and compared with traditional PID controllers under different scenarios. The working approach is shown in Figure 1.2. 


\section{Aspen Plus $^{\circledR}$ :}

- Steady-state modeling and simulation

- Sensitivity analysis and optimization

- Model uncertainty quantification

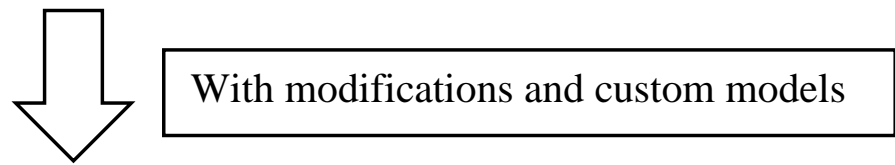

\section{Aspen Plus Dynamics ${ }^{\circledR}$ :}

- Dynamic modeling and simulation

- Generation of the outputs for system identification

- PID control system design

- Nonlinear plant in the configuration and evaluation of MPC and $H_{\infty}$ robust control

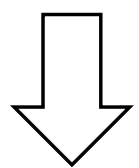

\section{Matlab and Matlab Simulink:}

- System identification

- Design of MPC and $H_{\infty}$ robust control

- Configuration and evaluation of MPC and $H_{\infty}$ robust control

Figure 1.2 Flowsheet of the working approach 


\section{LITERATURE REVIEW}

In recent decades, many researchers have focused on the development of steady-state and dynamic models as well as control system design for the MEA-based post-combustion carbon capture process. The accuracy of modeling and simulations of carbon capture process is important. For steady-state modeling, a high-fidelity model is necessary for design and optimization purposes. For dynamic modeling, the model should be able to reasonably predict the dynamic behavior of a carbon capture process so that the user can investigate the effect of various disturbances, and design and evaluate the control systems, especially the advanced model-based control system.

\subsection{Steady-state Modeling and Simulations}

Several steady-state models of MEA-based carbon capture processes have been developed in the literature from equilibrium-based to rate-based models. The rate-based model is rigorous and offers higher fidelity compared to the equilibrium-based model (Taylor et al., 2003). Kucka et al. (2003) developed a rigorous rate-based model for a MEA-based $\mathrm{CO}_{2}$ absorber using Aspen Custom Modeler ${ }^{\circledR}$ as the simulation platform. This model was validated with the published pilot plant data and the model was found to provide good predictions on the pilot plant scale and industrial scale processes. An equilibrium-based, deterministic mathematical model of a MEAbased $\mathrm{CO}_{2}$ capture process was proposed by Mores et al. (2011). This model was implemented in GAMS (General Algebraic Modeling System) and solved using the nonlinear programming solver, CONOPT. The result showed that this model could predict the experimental data well using the mass transfer correlation developed by Onda et al. (1968). An optimization and parametric study for a $\mathrm{CO}_{2}$ capture process from flue gas of a $600 \mathrm{MWe}$ coal fired power plant was presented by Abu-Zahra et al. (2007) using the Aspen Plus ${ }^{\circledR}$ simulation environment. Based on an equilibrium-based model, process variables, such as MEA concentration, lean solvent loading, stripper operating pressure, and lean solvent temperature were optimized to minimize the energy requirement for solvent regeneration. The carbon capture group at University of 
Texas at Austin reported a number of works on the rate-based modeling of $\mathrm{CO}_{2}$ capture process using MEA (Freguia and Rochelle, 2003; Dugas et al., 2009; Zhang et al., 2009; Plaza et al., 2010). All of their work used Aspen Plus ${ }^{\circledR}$ as the simulation platform. Freguia and Rochelle (2003) modeled the $\mathrm{CO}_{2}$ absorber with Aspen RateFrac ${ }^{\mathrm{TM}}$ and integrated the absorber with a FORTRAN user kinetic subroutine. Dugas et al. (2009), Zhang et al. (2009) and Plaza et al. (2010) modeled the $\mathrm{CO}_{2}$ capture pilot plant at University of Texas at Austin using Aspen RateSep $^{\mathrm{TM}}$, a second generation rate-based multistage separation unit operation model in Aspen Plus ${ }^{\circledR}$. Excellent matches were found between the predicted $\mathrm{CO}_{2}$ removal of the rate-based models and the comprehensive pilot plant data. On the basis of Freguia and Rochelle's Aspen RateFrac $^{\mathrm{TM}}$ model, Chang and Shih (2005) optimized the cost of MEA-based and DGA/MDEAbased $\mathrm{CO}_{2}$ capture process by applying an intercooler to the absorber and split-flow scheme. The benefits of applying split-flow scheme and absorber intercooler were also verified by simulating the MEA-based $\mathrm{CO}_{2}$ capture process on ProTreat ${ }^{\mathrm{TM}}$ plarform (Cousins et al., 2011). Tönnies et al. (2011) did a sensitivity analysis of the input parameters to the simulation results based on an MEA-based Aspen RateSep ${ }^{\mathrm{TM}}$ model. The results were helpful for deciding which parameters are important and should be measured, and which are less critical and could be estimated. Zhang et al. (2011) applied a scale-up protocol of packed tower to the $\mathrm{CO}_{2}$ capture process development and found that rate-based approach such as Aspen RateSep ${ }^{\mathrm{TM}}$ and ProTreat ${ }^{\mathrm{TM}}$ can help facilitating the scale-up design for the packed tower without using the empirical data. In the scale-up design for the absorber, correlations such as mass transfer and interfacial area should be carefully selected and validated against the pilot plant data. The simulation results using different correlations were found to differ widely (Razi et al., 2014). Since the $\mathrm{CO}_{2}$ stripper is operating at a high temperature, the predictions on $\mathrm{CO}_{2}$ recovery of rate-based and equilibrium-based models were found to be similar (Tobiesen et al., 2008; Plaza et al., 2010).

Based on these studies, a steady-state model of the MEA-based post-combustion $\mathrm{CO}_{2}$ capture process was developed using the RateSep ${ }^{\mathrm{TM}}$ operation in Aspen Plus ${ }^{\circledR}$ as a part of the current work. The steady-state model with appropriate modifications is subsequently exported to Aspen Plus Dynamics ${ }^{\circledR}$ for the dynamic modeling and control system design. 


\subsection{Dynamic Modeling and Control System Design}

In recent years, a number of researchers have focused on the dynamic model development and control system design for MEA-based $\mathrm{CO}_{2}$ capture process. Jayarathna et al. (2013) implemented a rate-based dynamic model representing all of the major equipment in a $\mathrm{CO}_{2}$ capture plant in Matlab. The dynamic behavior of the $\mathrm{CO}_{2}$ capture plant under varying operating conditions in the up-stream power plant and the capture plant itself was investigated. No control system was designed for this model as the goal of their work was to use this model in an on-line control system (e.g. MPC) for a $\mathrm{CO}_{2}$ capture plant. Gaspar et al. (2016) developed a mechanistic dynamic mathematical model for amine-based $\mathrm{CO}_{2}$ capture process and a good match between the model predictions and the pilot plant data were found under both transient and steady-state conditions. Rodriguez et al. (2014) developed a dynamic, solvent-based $\mathrm{CO}_{2}$ capture process using $\mathrm{gPROMS}^{\circledR}$ and applied the traditional PID controllers to the model to study the dynamic transients of the $\mathrm{CO}_{2}$ capture process in response to load change in power plant. Using the model developed in Aspen Custom Modeler ${ }^{\circledR}$, Ziaii et al. (2009) compared two control strategies, the reduction of steam rate with and without adjusting the rich-solvent rate, to avoid the high cost of energy during peaking hours. Their results showed that ratio control between rich solvent flow rate and heat rate can help reduce the response time significantly. Lin et al. $(2011 ; 2012)$ developed equilibrium-based, steady-state and dynamic models in Aspen Plus ${ }^{\circledR}$ and Aspen Plus Dynamics $^{\circledR}$, respectively. A control strategy where a portion of $\mathrm{CO}_{2}$ product was recycled back to the stripper, while keeping the lean solvent flow rate constant for stabilizing the absorber and stripper operations during peak and off-peak load hours, was then applied to the dynamic model. It was also found that the lean solvent flow, lean solvent loading, and water makeup are important variables for achieving desirable capture performance, energy efficiency, and process stability. On the basis of a comprehensive study of plant-wide control using a self-optimizing method, Panahi et al. $(2011 ; 2012)$ used UniSim $^{\circledR}$ as the dynamic simulator and compared the performance of MPC with other decentralized controllers, but the control performances were evaluated only by changing the flue gas flow rate. Lawal et al. $(2010 ; 2012)$ also pointed out the importance of the water balance in $\mathrm{CO}_{2}$ capture process stability based on a $\mathrm{gPROMS}^{\circledR}$ absorption plant model. Kvamsdal et al. (2010) and Leonard et al. (2013) indicated that water balance make-up can be significantly reduced by controlling the temperature of the cleaned flue 
gas. This strategy would thus ease the application of amine-based $\mathrm{CO}_{2}$ capture process when fresh water becomes the limiting factor. When the dynamic $\mathrm{CO}_{2}$ capture model was scaled up and integrated with a 500 MWe subcritical power plant, it was observed by the authors that the $\mathrm{CO}_{2}$ capture process was the limiting step since it had a slow response. Chalmers et al. (2009) stated that it is necessary for the post-combustion $\mathrm{CO}_{2}$ capture process to have a response time similar to that of the power plant in order to improve the flexibility of operation. Based on the mechanistic gPROMS ${ }^{\circledR}$ dynamic MEA-based $\mathrm{CO}_{2}$ absorption model developed by Harun et al. (2012), Nittaya et al. (2014) used the process response time to different disturbances and setpoint changes as the performance criteria to evaluate three different control structures. Their results showed that the control structure using Relative Gain Array (RGA) analysis was not optimal as it did not consider the process dynamics. The conventional control structure (pairing capture rate with lean solvent flow rate and reboiler temperature with reboiler duty) had the fastest response to reject disturbances and track the changes in set points, but may fail if the reboiler duty was limited. The gPROMS ${ }^{\circledR}$ model was then scaled-up for a $750 \mathrm{MWe}$ supercritical coal-fired power plant and resulted in a $\mathrm{CO}_{2}$ capture process consisting of three absorbers and two strippers (Nittaya et al., 2014). Flø et al. (2016) simulated a $\mathrm{CO}_{2}$ capture pilot plant using KSpice $^{\circledR}$ simulation tool and evaluated various operation modes for this pilot plant. Tait et al. (2016) did a flexibility study of the post-combustion $\mathrm{CO}_{2}$ capture process by using the pilot-scale facilities of Sulzer Chemtech in Winterthur, Switzerland. The pilot plant was tested under five different realistic scenarios and no significant barrier was found for the flexible operation of $\mathrm{CO}_{2}$ capture process. Arce et al. (2012) and Dowell et al. (2013) developed dynamic, nonequilibrium, gPROMS $^{\circledR}$ models of a $\mathrm{CO}_{2}$ stripper and absorber. The models were validated with pilot-plant data under steady-state. By using the SAFT-VR equation of state, the process models were significantly simplified. A multilevel MPC structure was also proposed and developed for the $\mathrm{CO}_{2}$ stripper to minimize solvent regeneration energy and ensure the safe operation of the system. Bedelbayev et al. (2008) applied MPC to their dynamic model for MEA-based $\mathrm{CO}_{2}$ capture. However, the controller was only implemented on the absorber, and again only one single scenario was studied. Considering both energy and environment constraints, Sahraei and Ricardez-Sandoval (2014) implemented a comprehensive MPC to a small-scale, post-combustion $\mathrm{CO}_{2}$ capture process model in the Aspen HYSYS ${ }^{\circledR}$ environment. With the same MPC scheme, an optimal scheduling of the $\mathrm{CO}_{2}$ capture process was further presented on the basis of a dynamic 
multi-objective optimization framework for the design of feasible and efficient operating policy of the $\mathrm{CO}_{2}$ capture plant. Modekurti et al. (2013) developed a two-stage bubbling fluidized bed absorber-reactor for solid-sorbent $\mathrm{CO}_{2}$ capture and evaluated the performance of different controllers for maintaining overall $\mathrm{CO}_{2}$ capture rate in the face of typical disturbances. The LMPC was found to provide the most satisfactory performance to reject all studied disturbances. Åkesson et al. (2012) developed a dynamic model of a MEA-based $\mathrm{CO}_{2}$ capture process using Dymola $^{\mathrm{TM}}$ as the simulation software and JModelica.org as the dynamic NMPC optimization solver platform. As the computation time was high and memory was limiting for the online optimization while using the original model in NMPC, the original model was reduced and validated using results from the original model.

It can be seen that most of the published models on the dynamics of $\mathrm{CO}_{2}$ capture systems are user-developed models in equation-based platforms such as gPROMS $^{\circledR}$ or Aspen Custom Modeler ${ }^{\circledR}$ and focus on the control structure and controller design for a single $\mathrm{CO}_{2}$ capture train. The Aspen Plus Dynamics ${ }^{\circledR}$ models developed by Lin et al. (2011; 2012) and Leonard et al. (2013) were exported from an equilibrium-based Aspen Plus ${ }^{\circledR}$ steady-state model. However, the Aspen Plus ${ }^{\circledR}$ rate-based models have been demonstrated to give improved accuracy over the equilibrium-based models in predicting the absorption of $\mathrm{CO}_{2}$ in $\mathrm{MEA}$ solution and validated with pilot plant data (Zhang et al., 2009). Moreover, for even modest sized power plants, the volume of flue gas generated requires multiple parallel trains of absorption and stripping columns for $90 \% \mathrm{CO}_{2}$ capture, as reported by Nittaya et al. (2014). Due to the pressure-flow dynamics and taking into account the unavoidable variations in the column and plant hardware during the course of operation, variability in performance between the columns is also expected.

As mentioned before, uncertainties are unavoidable for the $\mathrm{CO}_{2}$ capture process. Morgan et al. (2015) developed a systematic, generalized uncertainty quantification (UQ) methodology and applied it to the viscosity, density, and surface tension models of a MEA-CO $-\mathrm{H}_{2} \mathrm{O}$ system. The result of UQ analysis can be useful in investigating the effects of these parameter uncertainties on the key outputs of MEA-based $\mathrm{CO}_{2}$ capture process. Bahakim and Ricardez-Sandoval (2015) used a power series expansion (PSE) approximation of the $\mathrm{CO}_{2}$ capture process to obtain the output distribution of the process constraints due to model uncertainty. The authors considered 
uncertainties associated with the flue gas composition. This method was applied to the optimal design of the $\mathrm{CO}_{2}$ absorber and stripper to ensure that the environmental constraints were being met in the face of uncertainty. However, uncertainties in $\mathrm{CO}_{2}$ capture processes should not only be considered while designing the process, but while controlling the process at the face of uncertainties. To the best of my knowledge, there is no paper in the open literature that has designed the controllers for $\mathrm{CO}_{2}$ capture processes at the face of uncertainty.

In this work, an equilibrium-based dynamic post-combustion $\mathrm{CO}_{2}$ capture process model integrated with a commercial-sized power plant is developed using the results from a rate-based steady-state model. Then, advanced model-based controllers, such as MPC and $H_{\infty}$ robust controllers are implemented in the dynamic post-combustion $\mathrm{CO}_{2}$ capture process. Parallel trains of $\mathrm{CO}_{2}$ capture are considered and the effect of different column efficiencies are evaluated to simulate the expected variability in performance. The performance is compared with traditional PID controllers in the face of typical disturbances and model uncertainties. 


\section{STEADY-STATE MODEL DEVELOPMENT}

Steady-state simulation is used to design the base case process and to determine process variables under steady-state operating conditions. In this chapter, steady-state models of a MEAbased post-combustion $\mathrm{CO}_{2}$ capture plant and a supercritical PC power plant are developed in Aspen Plus ${ }^{\circledR}$ simulation environment. The design of the $\mathrm{CO}_{2}$ capture plant is for a $550 \mathrm{MWe}$ supercritical PC plant taken from Case 11 of the Cost and Performance Baseline for Fossil Energy Plants (Black, 2010). The $\mathrm{CO}_{2}$ absorption and stripping columns are simulated using Aspen Plus ${ }^{\circledR}$ RateSep ${ }^{\mathrm{TM}}$, a rigorous rate-based separation approach. The key process variables in the $\mathrm{CO}_{2}$ capture process are optimized to maximize the performance of the supercritical PC plant with carbon capture.

\subsection{Process Description}

\subsubsection{Supercritical PC Plant}

The simplified flowsheet of a supercritical PC plant using a single reheat $24.1 \mathrm{MPa} / 593^{\circ} \mathrm{C} / 593^{\circ} \mathrm{C}$ cycle is shown as Figure 3.1. The pulverized coal boiler consists of a coal burner, air preheater, superheater, reheater, and economizer. Coal and air are introduced into the boiler through the wall-fired burners. The boiler is operated at a sight negative pressure so that there are air leakages into the boiler. Flue gas exits the boiler at $169^{\circ} \mathrm{C}$ and passes through the fabric filter (baghouse) for ash removal. An induced draft fan (ID-fan) provides the motive force for the flue gas to pass through the flue gas desulfurization (FGD) unit and the flue gas temperature is increased to $181^{\circ} \mathrm{C}$ after the ID-fan. Because $\mathrm{SO}_{2}$ can react with MEA to form heat-stable salts that reduce the solvent absorption capacity (Rao and Rubin, 2002), a highly efficient FGD unit is used to remove virtually all the $\mathrm{SO}_{2}$ using wet limestone. The clean, saturated flue gas is separated from the gypsum and is subsequently sent to the $\mathrm{CO}_{2}$ capture plant. 
In the steam cycle, superheated steam $\left(24.1 \mathrm{MPa}\right.$ and $\left.593^{\circ} \mathrm{C}\right)$ passes through high-, intermediate-, and low-pressure steam turbines arranged sequentially to produce electricity. The steam from the outlet of the high-pressure turbines is reheated to $593^{\circ} \mathrm{C}$. The boiler feed water is heated by several heat exchangers in series by using steam of appropriate temperatures before returning to the boiler. A portion of steam $\left(0.51 \mathrm{MPa}\right.$ and $\left.290^{\circ} \mathrm{C}\right)$ is extracted before the inlet of the lowpressure steam turbines to supply the thermal energy for solvent regeneration in $\mathrm{CO}_{2}$ stripper.

Illinois No. 6 bituminous coal is used as the fuel feed to the supercritical PC plant and the coal analysis of Illinois No. 6 coal is presented in Table 3.1. The composition of combustion air is presented in Table 3.2. The temperature of incoming coal feed and combustion air is at $15^{\circ} \mathrm{C}$. The results for the main streams and units match with the reported data from the U.S. Department of Energy's National Energy Technology Laboratory (Black, 2010). The composition of flue gas after the FGD unit is presented in Table 3.3.

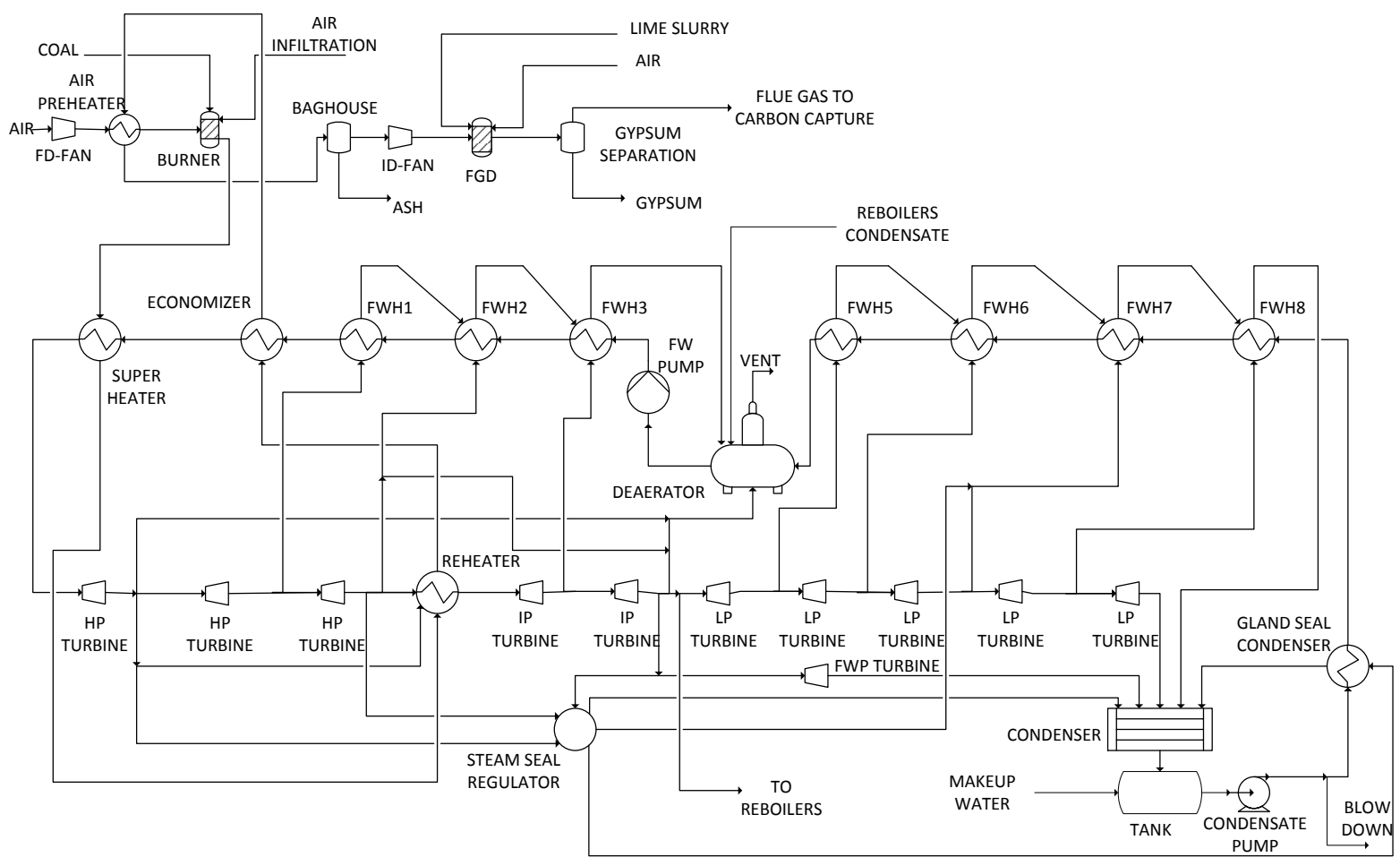

Figure 3.1 Simplified flowsheet of the supercritical coal-fired power plant with $\mathrm{CO}_{2}$ capture (Zhang et al., 2016) 
Table 3.1 Coal Analysis of Illinois No. 6 Bituminous Coal

\begin{tabular}{lrr}
\hline Proximate Analysis (weight \%) & as-received & dry \\
Moisture & $11.12 \%$ & $0.00 \%$ \\
Volatile matter & $34.99 \%$ & $39.37 \%$ \\
Ash & $9.70 \%$ & $10.91 \%$ \\
Fixed carbon & $44.19 \%$ & $49.72 \%$ \\
total & $100.00 \%$ & $100.00 \%$ \\
Ultimate Analysis (weight \%) & as-received & dry \\
Moisture & $11.12 \%$ & $0.00 \%$ \\
Carbon & $63.75 \%$ & $71.72 \%$ \\
Hydrogen & $4.50 \%$ & $5.06 \%$ \\
Nitrogen & $1.25 \%$ & $1.41 \%$ \\
Sulfur & $2.51 \%$ & $2.82 \%$ \\
Chlorine & $0.29 \%$ & $0.33 \%$ \\
Ash & $9.70 \%$ & $10.91 \%$ \\
Oxygen & $6.88 \%$ & $7.75 \%$ \\
total & $100.00 \%$ & $100.00 \%$ \\
Heating Value & as-received & dry \\
HHV (kJ/kg) & 27,113 & 30,506 \\
LHV (kJ/kg) & 26,151 & 29,444 \\
\hline & &
\end{tabular}

Table 3.2 Composition of Combustion Air on Volume Basis (\% Vol.)

\begin{tabular}{ccccc}
\hline $\mathrm{H}_{2} \mathrm{O}$ & $\mathrm{CO}_{2}$ & $\mathrm{~N}_{2}$ & $\mathrm{O}_{2}$ & $\mathrm{Ar}$ \\
$0.99 \%$ & $0.03 \%$ & $77.32 \%$ & $20.74 \%$ & $0.92 \%$ \\
\hline
\end{tabular}

Table 3.3 Composition of Flue Gas on Volume Basis (\% Vol.)

\begin{tabular}{ccccc}
\hline $\mathrm{H}_{2} \mathrm{O}$ & $\mathrm{CO}_{2}$ & $\mathrm{~N}_{2}$ & $\mathrm{O}_{2}$ & $\mathrm{Ar}$ \\
$15.17 \%$ & $13.53 \%$ & $68.08 \%$ & $2.40 \%$ & $0.82 \%$ \\
\hline
\end{tabular}




\subsubsection{Post-Combustion $\mathrm{CO}_{2}$ Capture Plant}

For the post-combustion $\mathrm{CO}_{2}$ capture process, the absorber and stripper column system uses a closed loop of circulating MEA shown in Figure 3.2. Flue gas blowers are used to provide the motive force to move the $\mathrm{CO}_{2}$ through absorption units. Flue gas first passes into a direct contact cooler (DCC) to lower the temperature of the gas feed using circulating water. Flue gas then passes counter-currently with the $30 \mathrm{wt} \%$ MEA solution in the absorber and the $\mathrm{CO}_{2}$ reacts with MEA. The cleaned flue gas then enters the MEA washing section to minimize solvent loss by recovering MEA, which is recycled back to the absorber and the MEA washing section. At the bottom of the absorber, rich solvent is pumped into the top of the stripper via a heat exchanger in which the rich solvent is preheated to a temperature close to the stripper operating temperature and the lean solvent is subsequently cooled. $\mathrm{CO}_{2}$ and MEA are recovered within the stripper at an elevated temperature and pressure. The energy penalty for $\mathrm{CO}_{2}$ removal is significant because thermal energy must be provided to regenerate the solvent in the stripper reboiler. This thermal energy is supplied by extracted, low-pressure steam. The overhead stream from the stripper contains mainly water and $\mathrm{CO}_{2}$. High purity $\mathrm{CO}_{2}$ may be stored or used for other purposes and may be pressurized (in 6 stages of intercooling and compression) to a suitable pressure for transportation in a pipeline and subsequent sequestration. Water is separated by a series of intermediate flash separators and a triethylene glycol (TEG) absorber as part of the $\mathrm{CO}_{2}$ compression unit, which is outside the scope of this work. Lean solvent from the bottom of the stripper is pumped back to the absorber via the rich/lean solvent heat exchanger and a cooler. Lean solvent finally enters the absorber at a temperature close to the absorber operating condition. Both the absorber and stripper are packed bed columns, which are used for their higher contact area and lower pressure drop compared with tray columns. Based on the pilot plant study from the University of Texas at Austin (Zhang et al., 2009), random packing and structured packing are used in the absorber and stripper, respectively, for this work. While it may be argued that the structured packing is desired for both the absorber and the stripper, especially for the absorber, this study is conducted with the random packing in the absorber and structured packing in the stripper as the model available in Aspen Plus ${ }^{\circledR}$ is validated for that configuration. 
From the simulation results for a $550 \mathrm{MWe}$ supercritical pulverized coal-fired power plant with $\mathrm{CO}_{2}$ capture, a total of $564 \mathrm{~m}^{3} / \mathrm{s}$ of flue gas at around 1 atm and $57^{\circ} \mathrm{C}$ needs to be treated. By equally splitting the overall flue gas into six streams, each train has a design capacity of $94 \mathrm{~m}^{3} / \mathrm{s}$ of flue gas. The column sizes indicated by Aspen Plus ${ }^{\circledR}$ RadFrac $^{\mathrm{TM}}$ column sizing calculation for each train of absorber and stripper can be seen in Table 3.4.

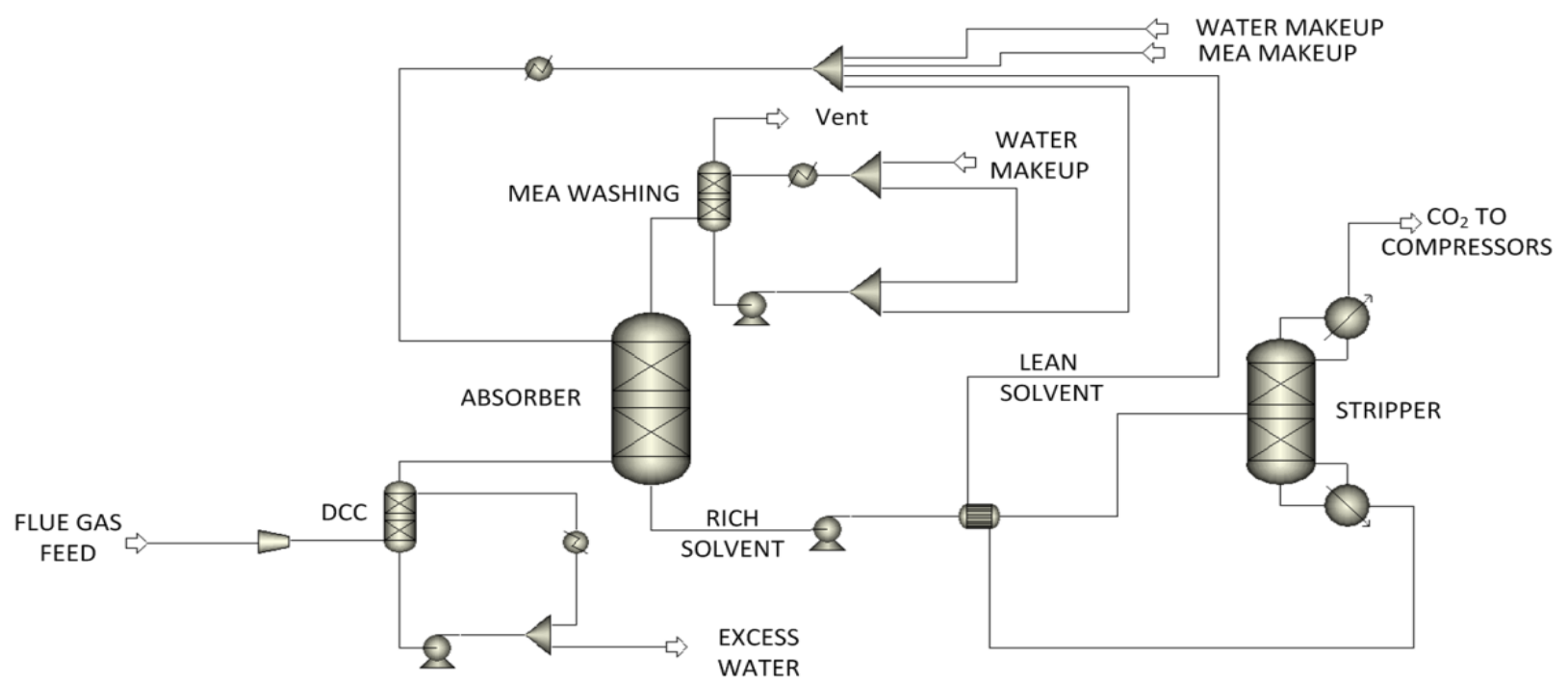

Figure 3.2 Simplified flowsheet of the $\mathrm{CO}_{2}$ capture process

Table 3.4 Columns Sizing Results (for $94 \mathrm{~m}^{3} / \mathrm{s}$ capacity)

\begin{tabular}{lcccc}
\hline & packing type & height, $\mathrm{m}$ & HETP, $\mathrm{m}$ & diameter, $\mathrm{m}$ \\
Direct contact cooler & IMTP & 6.4 & 0.6 & 7.15 \\
Absorber & IMTP & 24.0 & 0.6 & 5.8 \\
MEA washing & IMTP & 2.4 & 0.6 & 5.8 \\
Stripper & FLEXIPAC & 24.0 & 1.2 & 5.4 \\
\hline
\end{tabular}

\section{2 $\mathrm{CO}_{2}$ Capture Process Modeling in Aspen Plus ${ }^{\circledR}$}

The accurate modeling of the reactive absorption and regeneration processes are critical to the accurate simulation of the $\mathrm{CO}_{2}$ capture process. In Aspen Plus ${ }^{\circledR}$, there are two options for modeling absorption and stripping columns; namely, rate-based and equilibrium-based. The ratebased model is rigorous and offers higher fidelity compared to the conventional equilibrium 
model (Taylor et al., 2003). In the rate-based approach, mass transfer limitations at the interface between the vapor and liquid phases are considered. The equilibrium approach assumes that vapor and liquid phases are well mixed with each other on each theoretical stage and equilibrium has been reached between the bulk phases. The equilibrium assumption is always an approximation as contacting phases are rarely in equilibrium in real systems.

\subsubsection{Thermodynamic and Kinetic Models}

The electrolyte NRTL method and RK equation of state are used to compute liquid and vapor properties, respectively, in the rate-based $\mathrm{CO}_{2}$ capture process model. The thermophysical property model are based on the work of Austgen et al (1989). The set of reactions taking place in the $\mathrm{CO}_{2}-\mathrm{H}_{2} \mathrm{O}-\mathrm{MEA}$ system are given in Equations (3.1-3.7). The $\mathrm{CO}_{2}$ absorption and desorption reactions are given in Equations (3.4-3.7) and are assumed to be kinetically controlled while the others are at equilibrium.

$$
\begin{gathered}
2 \mathrm{H}_{2} \mathrm{O} \leftrightarrow \mathrm{H}_{3} \mathrm{O}^{+}+\mathrm{OH}^{-} \\
\mathrm{HCO}_{3}^{-}+\mathrm{H}_{2} \mathrm{O} \leftrightarrow \mathrm{CO}_{3}^{-2}+\mathrm{H}_{3} \mathrm{O}^{+} \\
\mathrm{RNH}_{3}^{+}+\mathrm{H}_{2} \mathrm{O} \leftrightarrow \mathrm{RNH}_{2}+\mathrm{H}_{3} \mathrm{O}^{+} \\
\mathrm{CO}_{2}+\mathrm{OH}^{-} \rightarrow \mathrm{HCO}_{3}^{-} \\
\mathrm{HCO}_{3}^{-} \rightarrow \mathrm{CO}_{2}+\mathrm{OH}^{-} \\
\mathrm{RNH}_{2}+\mathrm{H}_{2} \mathrm{O}+\mathrm{CO}_{2} \rightarrow \mathrm{RNHCOO}^{-}+\mathrm{H}_{3} \mathrm{O}^{+} \\
\mathrm{RNHCOO}^{-}+\mathrm{H}_{3} \mathrm{O}^{+} \rightarrow \mathrm{RNH}_{2}+\mathrm{H}_{2} \mathrm{O}+\mathrm{CO}_{2}
\end{gathered}
$$

where R- stands for the monoethanol group $\mathrm{CH}_{2}(\mathrm{OH}) \mathrm{CH}_{2}-$. The reduced power law expression (Equation 3.8) is used for the reaction rate calculation of the kinetically controlled reactions.

$$
r=k_{o} T^{n} \exp \left(-\frac{E}{R T}\right) \prod_{i=1}^{N} C_{i}^{a_{i}}
$$

Where:

$r=$ rate of reaction;

$k_{o}=$ pre-exponential factor; 
$T=$ absolute temperature;

$n=$ temperature exponent;

$E=$ activation energy, $\mathrm{J} \cdot \mathrm{mol}^{-1}$;

$R=$ universal gas constant, $8.314 \mathrm{~J} \cdot \mathrm{mol}^{-1} \cdot \mathrm{K}^{-1}$;

$N=$ number of components in reaction;

$C_{i}=$ concentration of component $i$ (molarity basis);

$a_{i}=$ the stoichiometric coefficient of component $i$ in the reaction equation.

The temperature exponent $n$ is zero. The kinetic parameters are taken from the work of Pinsent et al. (1956) and Hikita et al. (1977), and presented in the Table 3.5. The equilibrium constants for Reactions (3.1-3.3) are calculated from the standard Gibbs free energy change.

Table 3.5 Kinetic Parameters in the Reduced Power Law Expression (Equation 3.8)

\begin{tabular}{lcr}
\hline Reaction Equation No. & $k, \mathrm{kmol}^{1-\text { sum }} \cdot\left(\mathrm{m}^{3}\right)^{\mathrm{sum}-1} \cdot \mathrm{s}^{-1}$ a & $E, \mathrm{cal} / \mathrm{mol}$ \\
3.4 & $4.32 \mathrm{e}+13$ & $13,249.0$ \\
3.5 & $2.38 \mathrm{e}+17$ & $29,451.0$ \\
3.6 & $9.77 \mathrm{e}+10$ & $9,855.8$ \\
3.7 & $3.23 \mathrm{e}+19$ & $15,655.0$ \\
\hline
\end{tabular}

a sum depends on the summation of the stoichiometric coefficients of components in specified reactions

\subsubsection{Transport Property Models}

Various correlations of mass transfer, interfacial areas, holdup and heat transfer are required by the modeling of rate-based separation using Aspen Plus ${ }^{\circledR}$ RateSep ${ }^{\mathrm{TM}}$. In this work, mass transfer coefficients, interfacial areas, holdup correlations and heat transfer coefficients are taken from the work of Onda et al. (1968), Stichlmair et al. (1989), Bravo et al. (1985; 1992), and Chilton and Colburn (1934), respectively. Based on the results given in Rate Based model of the $\mathrm{CO}_{2}$ capture process by MEA using Aspen Plus (Aspen Technology, Inc., 2008), the density is calculated by the Clarke density model for electrolytes solutions with mixed solvents, viscosity is calculated using the Jones-Dole viscosity model (Jones and Dole, 1929) for liquid solutions with electrolytes, liquid mixture surface tension is calculated by the Onsager-Samaras surface tension 
model (Onsager and Samaras, 1934), liquid mixture thermal conductivity is calculated using the Riedel (1951) electrolyte correction model, and binary diffusivities are calculated by the NernstHartley model (Robinson and Stokes, 1959).

\subsection{Sensitivity Analysis and Optimization of the $\mathrm{CO}_{2}$ Capture Process}

The major disadvantage for the implementation of a MEA-based $\mathrm{CO}_{2}$ capture process to a supercritical PC plant is the significant energy penalty for $\mathrm{CO}_{2}$ removal, which leads to a decrease in the power plant efficiency. An intensive sensitivity analysis on different process variables is necessary to minimize the energy performance of the $\mathrm{CO}_{2}$ capture process.

Absorption of $\mathrm{CO}_{2}$ in MEA solution is exothermic. The extent of absorption (at equilibrium) increases with decreasing temperature. Therefore, the MEA flow rate can be decreased by lowering the flue gas and solvent temperatures. In the temperature range investigated in this work, lower temperatures result in a decrease in the absorbent flow rate as well as a decrease in the thermal energy requirement and these trends are observed in Figures 3.3 and 3.4. It should be noted that these results are generated under the constraint of $90 \% \mathrm{CO}_{2}$ capture from the flue gas leaving the power plant. The lowest temperature that can be achieved without refrigeration depends on the supply temperature of the cooling water. In this work, the cooling water supply temperature is assumed to be $25^{\circ} \mathrm{C}$. The overall cooling duty is given by the heat removed from the solvent, flue gas, and $\mathrm{CO}_{2}$ product. 


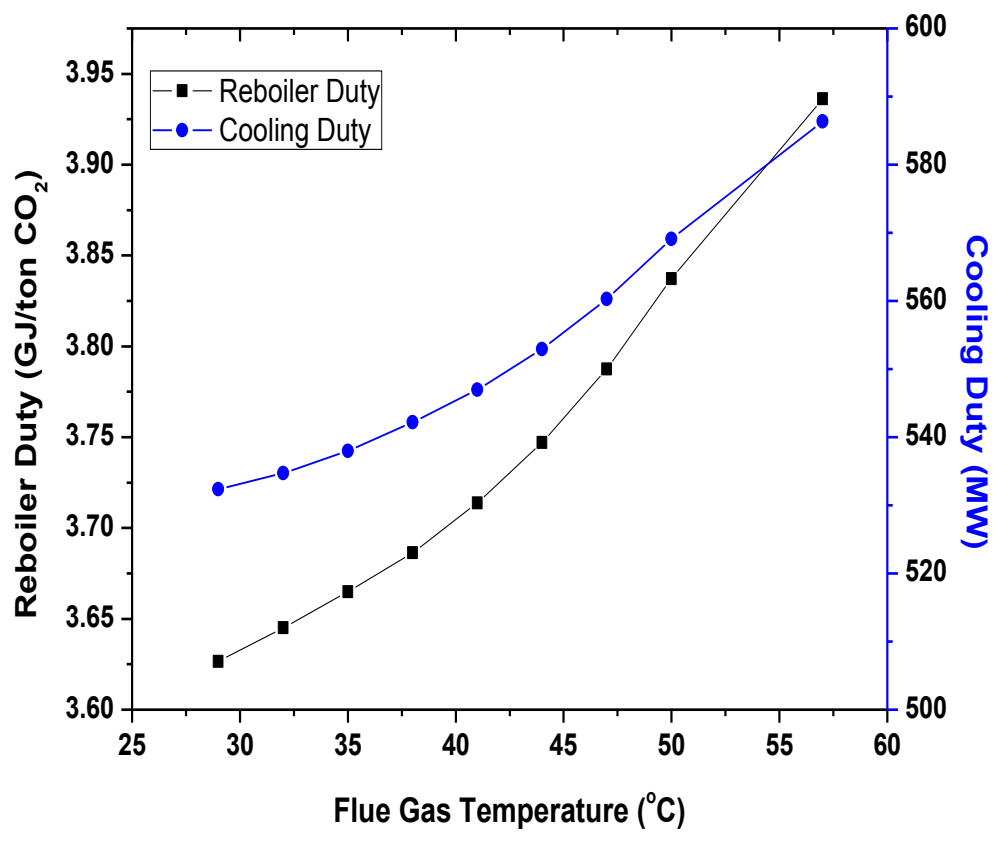

Figure 3.3 Reboiler and cooling duties under various flue gas temperature

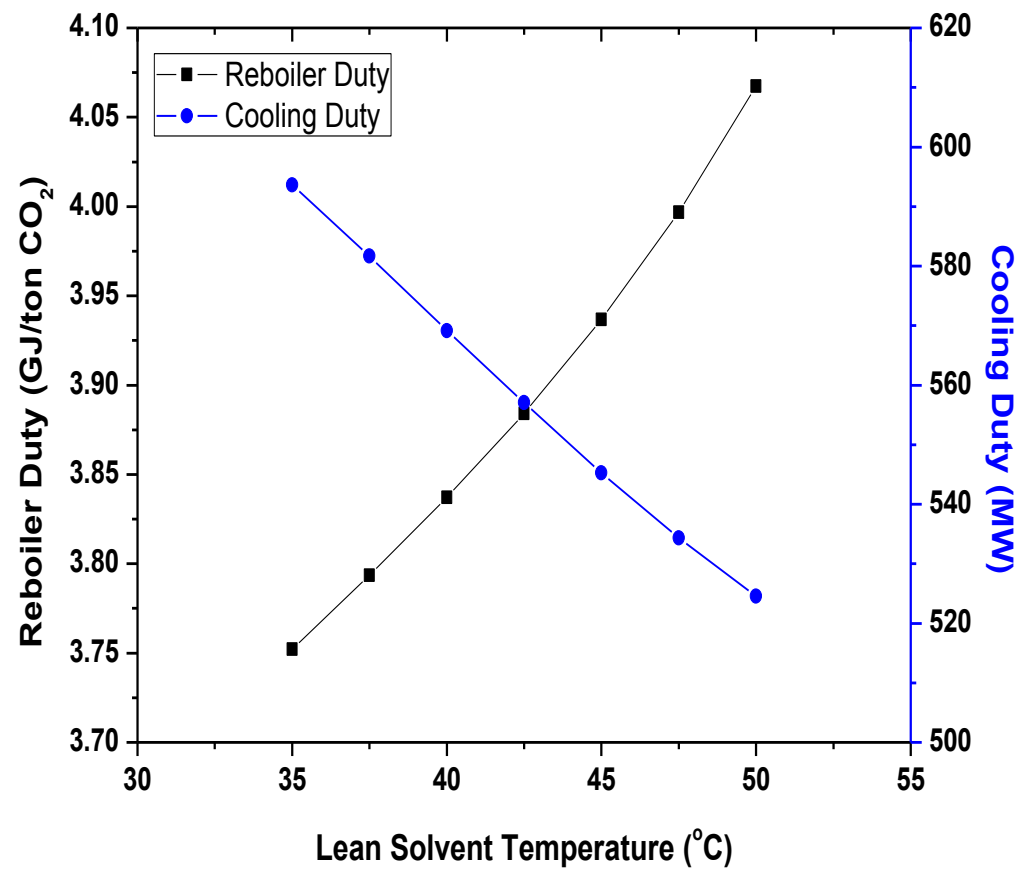

Figure 3.4 Reboiler and cooling duties under various lean solvent temperature 
The $\mathrm{CO}_{2}$ loading of the lean solvent reflects the extent of regeneration in the stripper. The solvent circulation rate varies depending on the $\mathrm{CO}_{2}$ loading of the lean solvent. At a high $\mathrm{CO}_{2}$ loading of the lean solvent, the energy to heat up the solvent for high circulation rates is the dominating factor in the thermal energy requirement. On the other hand, for low lean solvent loading of $\mathrm{CO}_{2}$, a large amount of steam will be required in order to reach the desired extent of regeneration. Therefore, there is an optimal loading of $\mathrm{CO}_{2}$ that minimizes the energy (cost) penalty. The result for this study is shown in Figure 3.5 that illustrates this tradeoff.

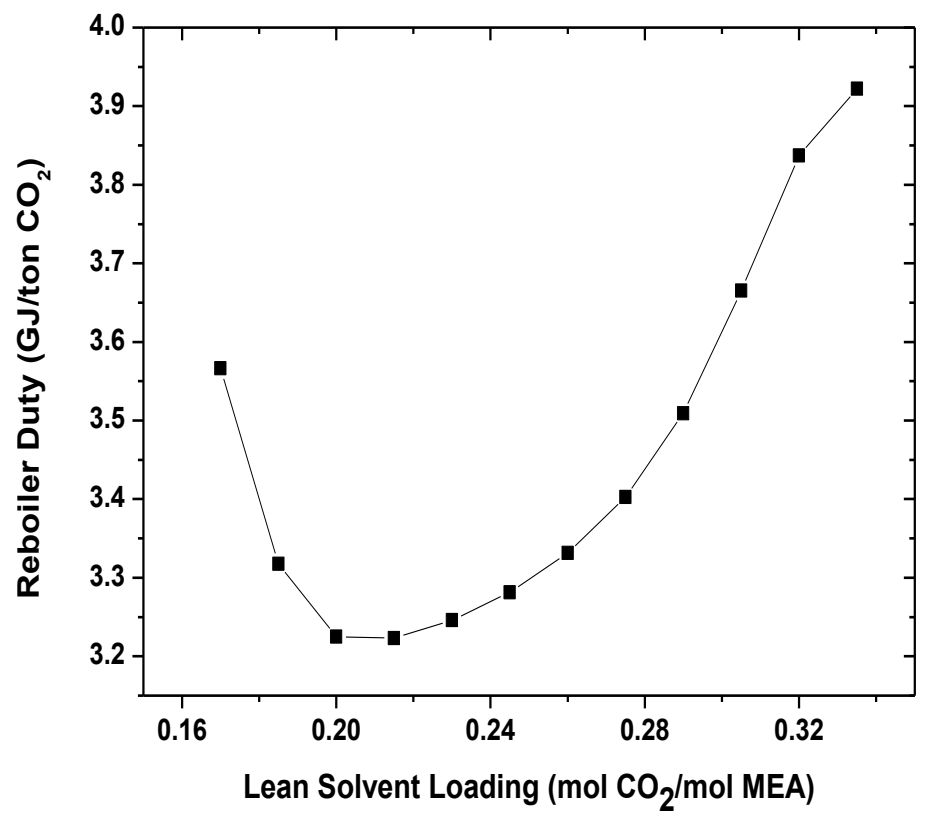

Figure 3.5 Reboiler duties under various lean solvent loading

The effect of the pressure at the top of the stripper is also investigated. For a specific lean solvent $\mathrm{CO}_{2}$ loading, high stripper pressures enable higher temperatures to be used within the stripper, which are preferred by the endothermic $\mathrm{CO}_{2}$ desorption reactions. However, at higher desorption temperatures, more steam must be sent to the stripper reboiler. Therefore, there will be an optimal stripper pressure. In this work, only the downward trend is investigated as the stripper pressure is not high enough to make the steam flow rate a dominant factor in the energy penalty. In addition, the degradation of MEA increases at higher stripper pressures. Davis and Rochelle (2009) studied the thermal degradation of MEA under different stripper conditions. It was found 
that temperatures exceeding $125^{\circ} \mathrm{C}$ increase the MEA degradation significantly. Therefore, $125^{\circ} \mathrm{C}$ is assumed to be the upper limit for the stripper temperature and this constrains the operating pressure of the stripper. This maximum pressure is shown by the dotted line in Figure 3.6.

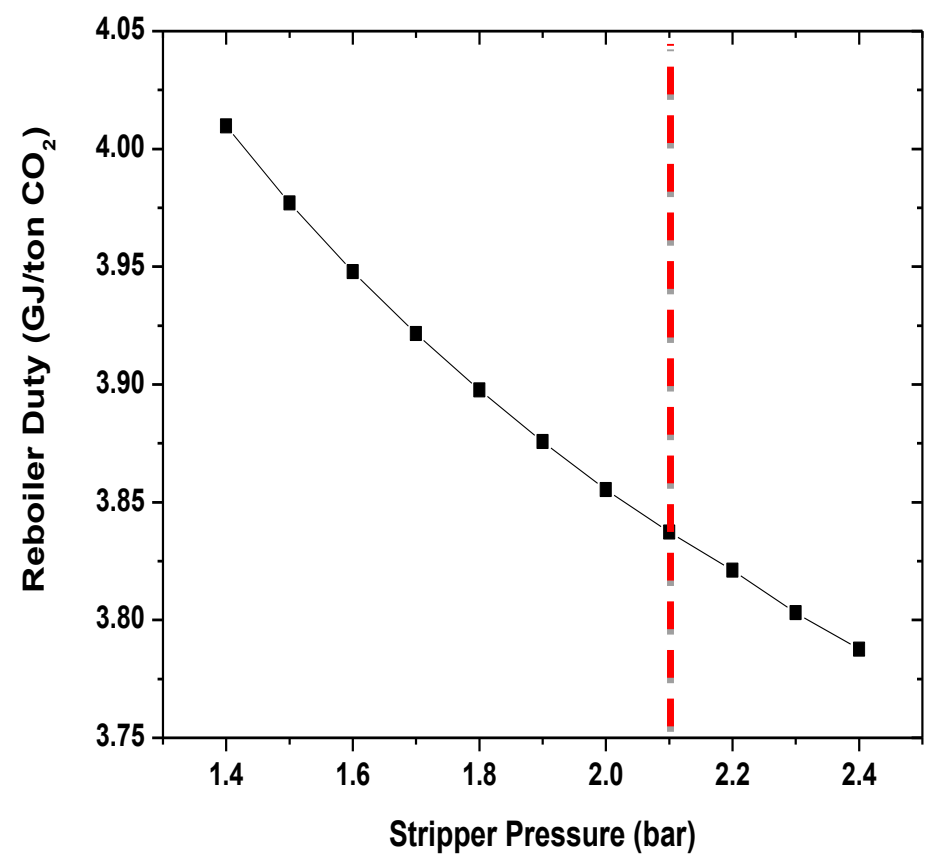

Figure 3.6 Reboiler duties under various $\mathrm{CO}_{2}$ stripper pressure (dotted line represents the maximum operating pressure)

Increasing absorber pressure also helps to reduce the thermal requirement for stripping as more $\mathrm{CO}_{2}$ per volume of solvent is removed. However, the overall power plant efficiency drops because more power is required for the flue gas blower as shown in Figure 3.7. For a specific HETP (height equivalent to theoretical plate), an increase in the height of the packing leads to a smaller solvent flow rate needed for $90 \% \mathrm{CO}_{2}$ capture. In addition, less thermal energy will be required for heating and vaporizing the solvent as shown in Figure 3.8. It is noted that an increase in the packing volume will result in an increase in the capital cost; however, the effect of capital costs were not considered in this study. 


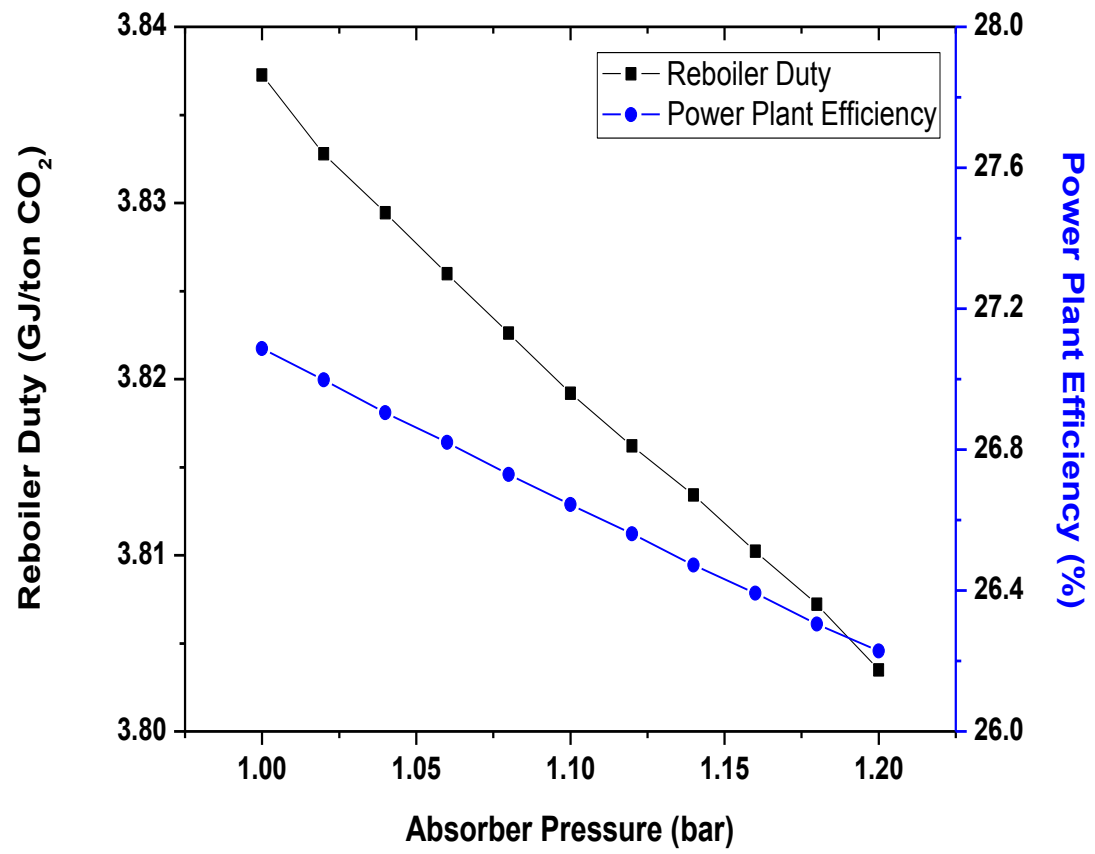

Figure 3.7 Reboiler duties and power plant efficiencies under various $\mathrm{CO}_{2}$ absorber pressure

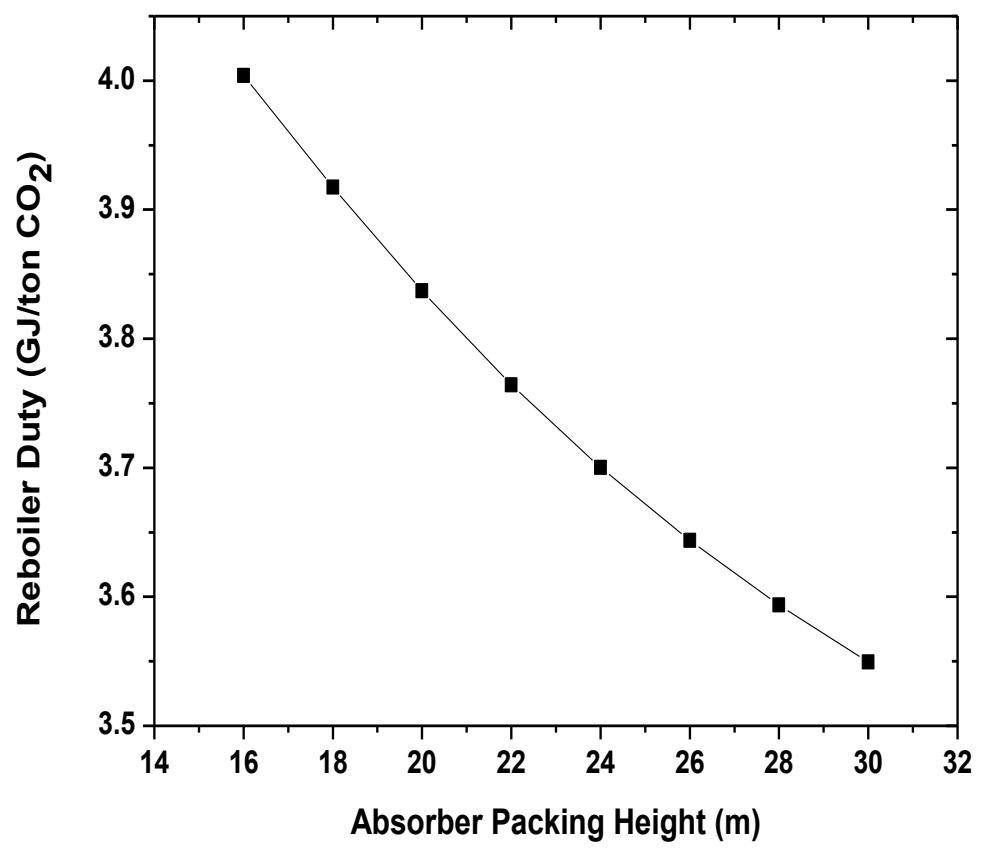

Figure 3.8 Reboiler duties under various $\mathrm{CO}_{2}$ absorber packing height 
As a starting point, the base case uses the optimal configurations of an equilibrium-based postcombustion $\mathrm{CO}_{2}$ capture process model developed by Abu-Zahra (2007). However, these configurations might not be optimal for a rate-based model due to the differences between equilibrium-based and rate-based Aspen Plus ${ }^{\circledR}$ separation models. Based on the sensitivity analysis results, the process variables are optimized to improve the energy performance of the base case. The energy performances of base and optimized cases are presented in Table 3.6. The heat duty due to $\mathrm{CO}_{2}$ recovery is reduced significantly from $4.05 \mathrm{GJ} /$ ton $\mathrm{CO}_{2}$ to $3.07 \mathrm{GJ} /$ ton $\mathrm{CO}_{2}$. The net plant efficiency with $\mathrm{CO}_{2}$ capture is increased by $3.48 \%$, which means that the optimized plant can provide about 49 MWe more net power (420 MWe for the optimized case vs. 371 MWe for the base case). For the optimized case, the power plant performance and the decreased efficiency in net plant efficiency due to $\mathrm{CO}_{2}$ capture process reported in Table 3.6 are similar to the DOE report (Black, 2010).

\section{Table 3.6 Plant Energy Performances of Base Case and Optimized Case}

\begin{tabular}{lll}
\hline & base case & optimized case \\
Net power without $\mathrm{CO}_{2}$ capture, kWe & 549,990 & 549,990 \\
Net plant efficiency without $\mathrm{CO}_{2}$ capture (HHV) & $39.30 \%$ & $39.30 \%$ \\
Power loss due to flue gas blower, kWe & 3,455 & 3,237 \\
Power loss due to $\mathrm{CO}_{2}$ compressor, kWe & 33,300 & 33,344 \\
Power loss due to rich solvent pump, kWe & 428 & 178 \\
Power loss due to steam to reboiler, kWe & 141,290 & 92,980 \\
Net power with $\mathrm{CO}_{2}$ capture, kWe & 371,517 & 420,251 \\
Net plant efficiency with $\mathrm{CO}_{2}$ capture $(\mathrm{HHV})$ & $26.55 \%$ & $30.03 \%$ \\
Efficiency penalty & $12.75 \%$ & $9.27 \%$ \\
$\mathrm{CO}_{2}$ capture & $90 \%$ & $90 \%$ \\
$\mathrm{Heat}^{2}$ duty per ton $\mathrm{CO}_{2}$ recovered, GJ/ton $\mathrm{CO}_{2}$ & 4.05 & 3.07 \\
\hline
\end{tabular}




\section{DYNAMIC MODEL DEVELOPMENT}

Dynamic simulations can provide information on the system characteristics, such as time delay, underdamped or overdamped responses, and inverse responses due to different inputs to the system. Moreover, dynamic simulations provide the platform for the control system design. In this chapter, dynamic models of a MEA-based post-combustion $\mathrm{CO}_{2}$ capture plant and a supercritical PC power plant are developed in Aspen Plus Dynamics ${ }^{\circledR}$ simulation environment. However, the rate-based separation approach is not supported in Aspen Plus Dynamics ${ }^{\circledR}$. In order to represent accurately the dynamics of the rigorous rate-based calculations provided in the steady-state simulator, the equilibrium dynamic model is exported from the rate-based, steadystate model developed in Chapter 3 with the inclusion of the size and metal mass of the equipment. Subsequently, modifications to the Murphree efficiencies in the columns and a rigorous pressure drop calculation method were implemented in the dynamic model to ensure consistency between the design and off-design results from the steady state and dynamic models.

\subsection{Pressure-driven model}

In a steady-state simulation, the flow into a unit operation model is determined by either the user input or the upstream unit. The flow out of a unit is based on the mass balance in the unit operation model. However, in real processes and dynamic simulations, the flow into and out of a unit operation (model) depends on the upstream and downstream pressures. The flow between units depends on the pressure differences between them. In order to solve the coupled, pressureflow equations, units must be connected via flow devices, such as valves. An example of a flash vessel (Figure 4.1) shows the difference in the unit operation model configurations between steady-state models (Aspen Plus ${ }^{\circledR}$ ) and dynamic models (Aspen Plus Dynamics ${ }^{\circledR}$ ). 

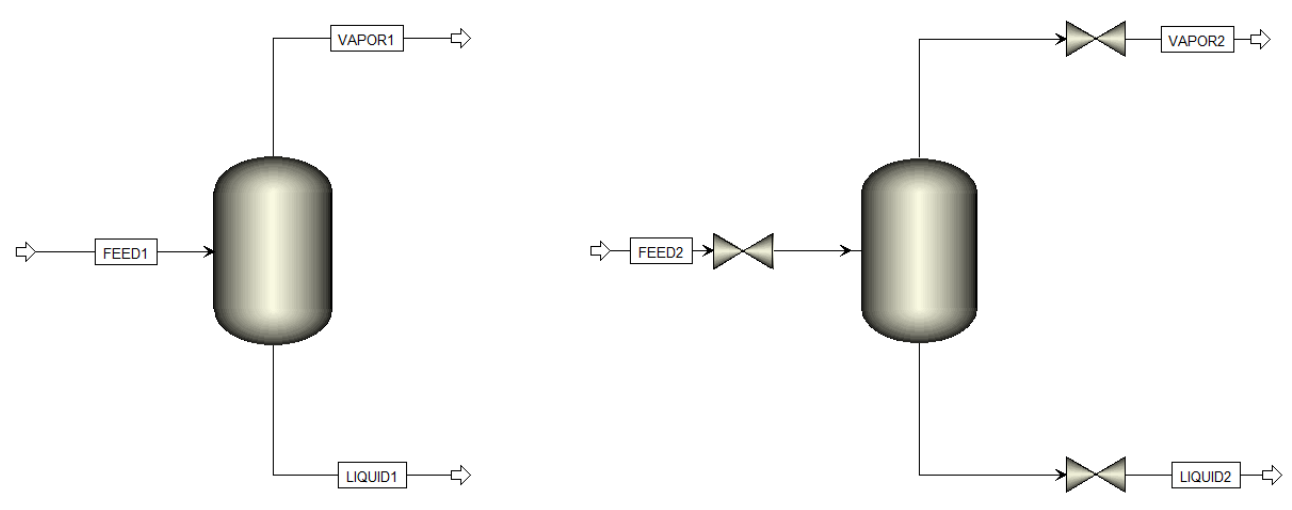

Figure 4.1 Schematics of a flash vessel in steady-state simulation (left) and pressure-driven dynamic simulation (right)

\subsection{Equipment Size and Mass}

In the dynamic simulation, volume information is important as it can affect the rate of accumulation in mass or energy. The equipment should be sized appropriately based on the steady-state results. In a post-combustion $\mathrm{CO}_{2}$ capture plant and a supercritical PC plant, the major equipment that need to be sized include the heat exchangers, flash or storage vessels and the $\mathrm{CO}_{2}$ absorber and stripper columns.

The sizing of $\mathrm{CO}_{2}$ absorber and stripper columns has been discussed in Chapter 3. The column sizes are provided by Aspen Plus ${ }^{\circledR}$ RadFrac ${ }^{\mathrm{TM}}$ column sizing calculations. Heat exchangers, such as the rich/lean solvent heat exchanger, coolers for the liquid feeds to the absorber, direct contact cooler and MEA washing section, coal boiler feed water heaters are sized using Aspen Exchanger Design \& Rating ${ }^{\circledR}$ (EDR). In Aspen EDR, the shell-side and tube-side volumes and the metal mass of the heat exchangers are calculated. Then, the shell-side and tube-side volumes are divided into two equal volumes as the inputs for the inlet and outlet volumes in Aspen Plus Dynamics $^{\circledR}$. A similar approach is taken for the metal mass. The heat transfer rate in a heat exchanger is determined as follows: 


$$
\begin{aligned}
Q & =U A \Delta T_{l m} \\
\Delta T_{l m} & =\frac{\Delta T_{A}-\Delta T_{B}}{\ln \left(\frac{\Delta T_{A}}{\Delta T_{B}}\right)}
\end{aligned}
$$

Where:

$Q=$ exchanger heat duty;

$U=$ heat transfer coefficient;

$A=$ exchange area;

$\Delta T_{l m}=$ logarithmic mean temperature difference (LMTD);

$\Delta T_{A}=$ temperature difference between hot stream and cold stream at end $\mathrm{A}$;

$\Delta T_{B}=$ temperature difference between hot stream and cold stream at end B.

Sizes of process vessels are determined by following a heuristic process from the book: Analysis, synthesis and design of chemical processes (Turton et al., 2012). The thickness of the walls are found by applying the following equation:

$$
t_{s}=\frac{P D}{2 S E-1.2 P}+C A
$$

Where:

$t_{s}=$ thickness of the vessel wall;

$P=$ design pressure of the vessel;

$D=$ diameter of the vessel;

$S=$ maximum allowable stress;

$E=$ weld efficiency;

$C A=$ corrosion allowance.

Carbon steel is used as the material of construction. Accordingly, the metal mass of the vessels are determined. 


\subsection{Absorber Efficiency Model}

As mentioned before, the dynamic model is exported from the steady-state Aspen Plus ${ }^{\circledR}$ model. A rigorous rate-based approach is used to simulate the $\mathrm{CO}_{2}$ absorber and stripper. However, the rate-based models for the absorber and stripper must be replaced by equilibrium-based models since the rate-based tower model is not supported in Aspen Plus Dynamics ${ }^{\circledR}$. Kinetic reactions (Equations 3.4-3.7) are replaced by equilibrium reactions (Equations 4.4-4.5). Since the use of Gibbs free energy change for calculating equilibrium constants is not supported in Aspen Plus Dynamics $^{\circledR}$, the equilibrium constants for Equations $(3.1-3.3 ; 4.4-4.5)$ are taken from the work of Edwards et al. (1978), Kent and Eisenberg (1976).

$$
\begin{gathered}
\mathrm{CO}_{2}+2 \mathrm{H}_{2} \mathrm{O} \leftrightarrow \mathrm{HCO}_{3}^{-}+\mathrm{H}_{3} \mathrm{O}^{+} \\
\mathrm{RNHCOO}^{-}+\mathrm{H}_{2} \mathrm{O} \leftrightarrow \mathrm{RNH}_{2}+\mathrm{HCO}_{3}^{-}
\end{gathered}
$$

where R- stands for the monoethanol group $\mathrm{CH}_{2}(\mathrm{OH}) \mathrm{CH}_{2}-$. A difference between the rate-based and equilibrium-based reactive $\mathrm{CO}_{2}$ absorber is expected. Since the $\mathrm{CO}_{2}$ stripper is operating at a high temperature, the difference between rate-based and equilibrium-based models is negligible (Tobiesen et al., 2008; Plaza et al., 2010). Since the $\mathrm{CO}_{2}$ capture rate is the primary controlled variable, it was decided to develop a semi-rigorous correlation for the $\mathrm{CO}_{2}$ absorber in Aspen Plus Dynamics ${ }^{\circledR}$ to predict flue gas separation. One approach to minimize the differences in scrubbed flue gas compositions predicted by the rate-based model and equilibrium-based models was to adjust the column Murphree efficiency for $\mathrm{CO}_{2}$. Since the separation on each stage is a result of both physical and chemical equilibrium, it is very difficult to develop a first-principles mathematical model to predict the component efficiencies for different operating conditions. However, $\mathrm{CO}_{2}$ efficiencies can be back-calculated using composition profiles for each stage at the design point for the rate-based model. This method resulted in a correlation for $\mathrm{CO}_{2}$ efficiency that is a function of key process variables and is given as Equation (4.6).

$$
\varepsilon_{C O 2, i}=0.7692 \varepsilon_{C O 2, i}^{D} \frac{F_{F G}^{D}}{F_{F G}} \frac{F_{C O 2}^{D}}{F_{C O 2}}\left(\frac{F_{S o l}}{F_{\text {Sol }}^{D}}\right)^{2}\left(\frac{\text { Lean }_{\text {loading }}^{D}}{\text { Lean }_{\text {loading }}}\right)^{0.5}\left(\frac{M E A_{w t}}{M E A_{w t}^{D}}\right)^{0.3}
$$

Where: 
$\varepsilon_{C O 2, i}=\mathrm{CO}_{2}$ stage efficiency at $i^{\text {th }}$ stage;

$\varepsilon_{C O 2, i}^{D}=$ design point $\mathrm{CO}_{2}$ stage efficiency at $i^{\text {th }}$ stage;

$F_{F G}=$ flue gas flow rate;

$F_{F G}^{D}=$ flue gas flow rate at design point, $3.11 \mathrm{kmol} / \mathrm{s}$ in this work;

$F_{\mathrm{CO} 2}=\mathrm{CO}_{2}$ feed rate;

$F_{C O 2}^{D}=\mathrm{CO}_{2}$ feed rate at design point, $0.465 \mathrm{kmol} / \mathrm{s}$ in this work;

$F_{S o l}=$ lean solvent flow rate;

$F_{S o l}^{D}=$ lean solvent flow rate at design point, $10.64 \mathrm{kmol} / \mathrm{s}$ in this work;

Lean $_{\text {loading }}=\mathrm{CO}_{2}$ loading of the lean solvent;

Lean $n_{\text {loading }}^{D}=\mathrm{CO}_{2}$ loading of the lean solvent at design point, $0.208 \frac{\mathrm{kmol} \mathrm{CO}_{2}}{\mathrm{kmol} \mathrm{MEA}}$ in this work;

$M E A_{w t}=$ weight percentage of MEA in the lean solvent;

$M E A_{w t}^{D}=$ weight percentage of MEA in the lean solvent at design point, $30 \mathrm{wt} \%$ in this work.

The correction factor of 0.7692 , calculated based on the steady-state results under design point, is necessary to take account of the effect of other non- $\mathrm{CO}_{2}$ components on $\mathrm{CO}_{2}$ separation. The Murphree efficiency for other components are found to be nearly invariant under different operating conditions and are set to 1 in this model. Comparisons of the predictions of Equation (4.6) and the full-rate based model at a variety of conditions are illustrated in Figures 4.2-4.6. A good match between the rate-based and equilibrium-based model using the correlated $\mathrm{CO}_{2}$ Murphree efficiency from Equation (4.6) can be seen. It is concluded that the $\mathrm{CO}_{2}$ Murphree efficiency model developed in this work is satisfactory and can be used to predict the $\mathrm{CO}_{2}$ capture rate for equilibrium models at both design and off-design conditions. 


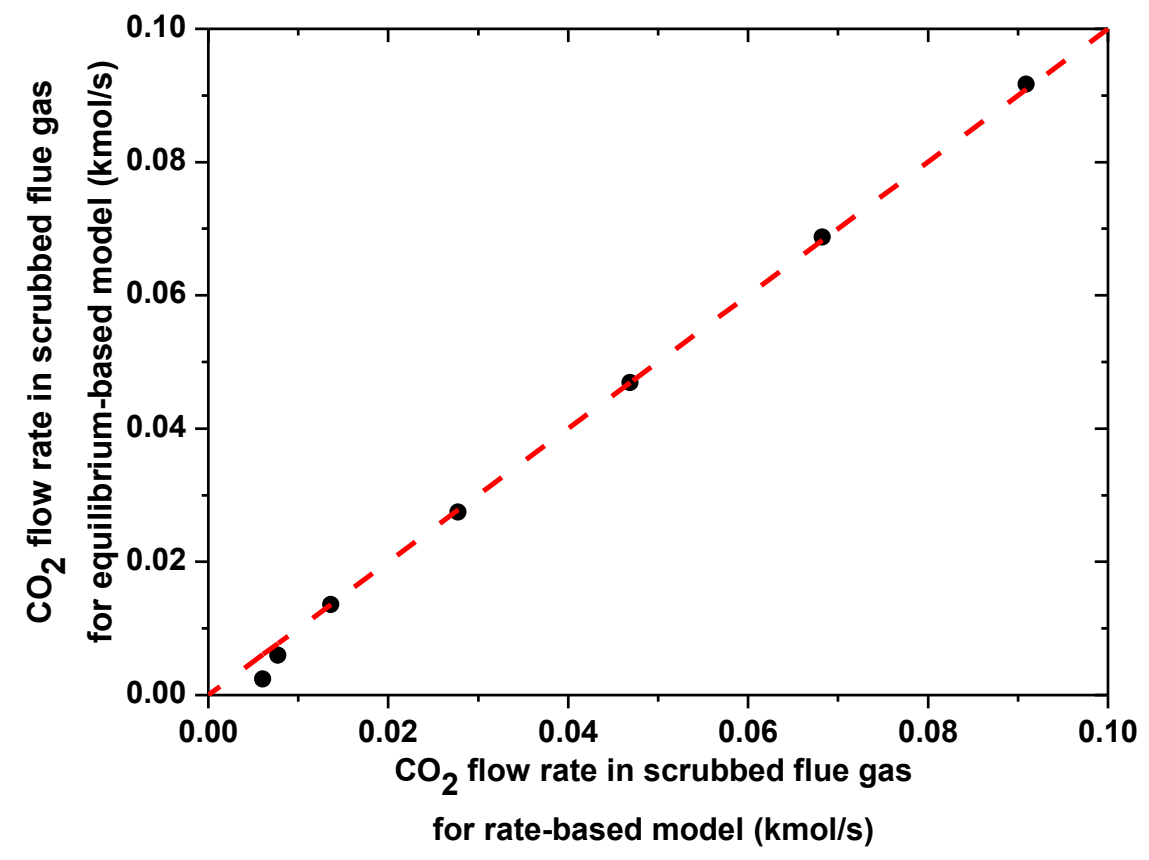

Figure 4.2 Comparisons of $\mathrm{CO}_{2}$ flow rate in scrubbed flue gas between correlated equilibrium and rate-based models under varying flue gas flow rates $(2.48-3.41 \mathrm{kmol} / \mathrm{s})$

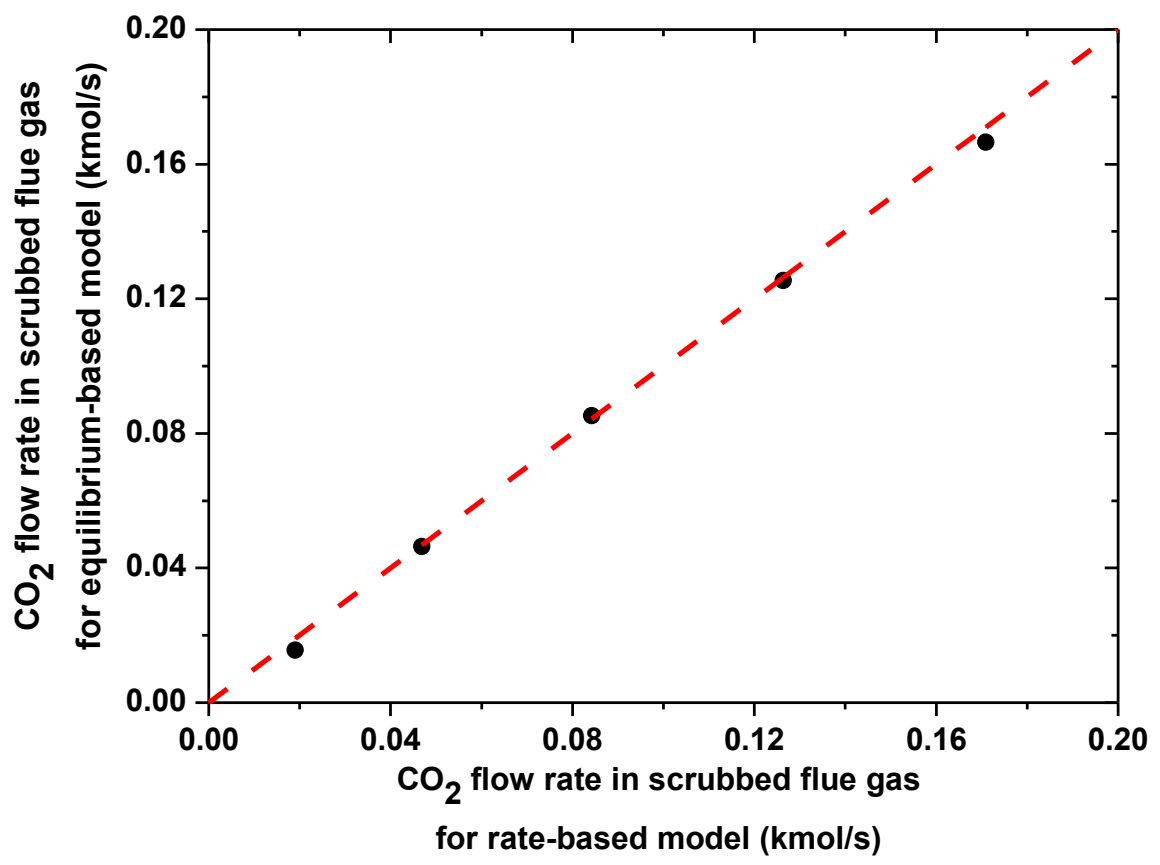

Figure 4.3 Comparisons of $\mathrm{CO}_{2}$ flow rate in scrubbed flue gas between correlated equilibrium and rate-based models under varying lean solvent flow rates $(7.44-11.70 \mathrm{kmol} / \mathrm{s})$ 


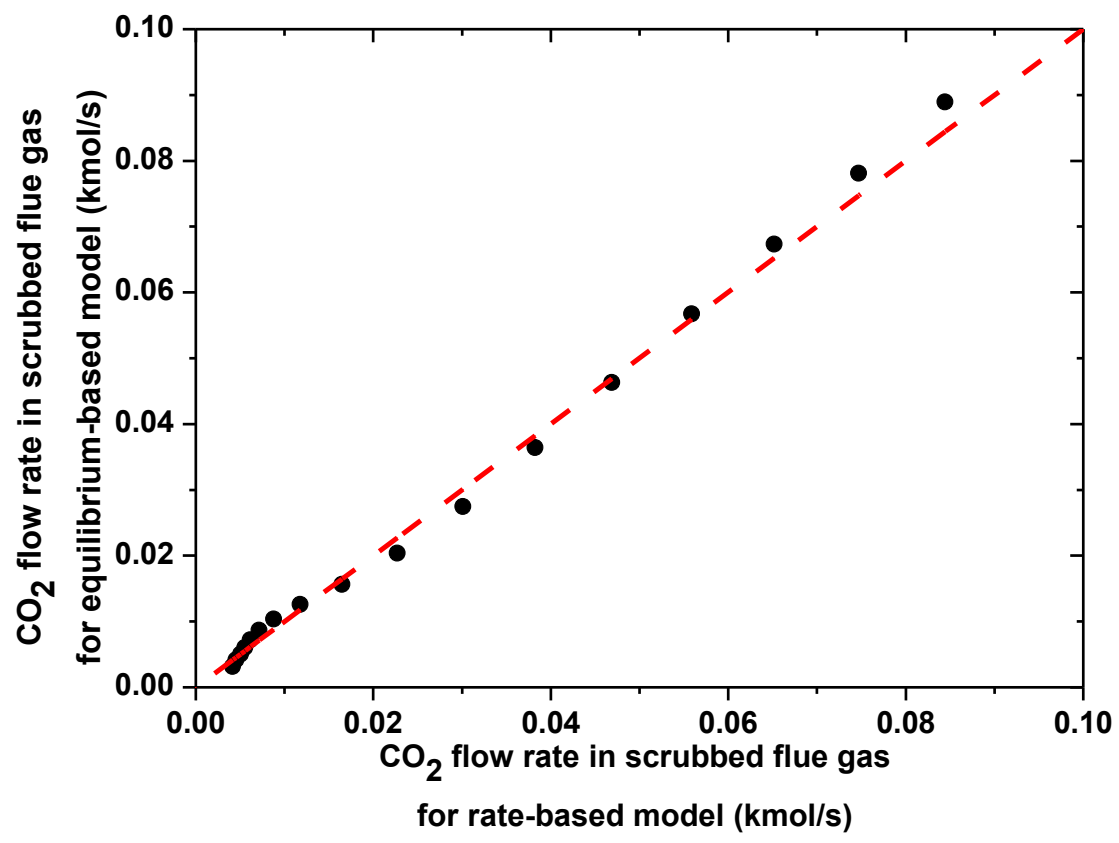

Figure 4.4 Comparisons of $\mathrm{CO}_{2}$ flow rate in scrubbed flue gas between correlated equilibrium and rate-based models under varying $\mathrm{CO}_{2}$ feed flow rates $(0.325-0.512 \mathrm{kmol} / \mathrm{s})$

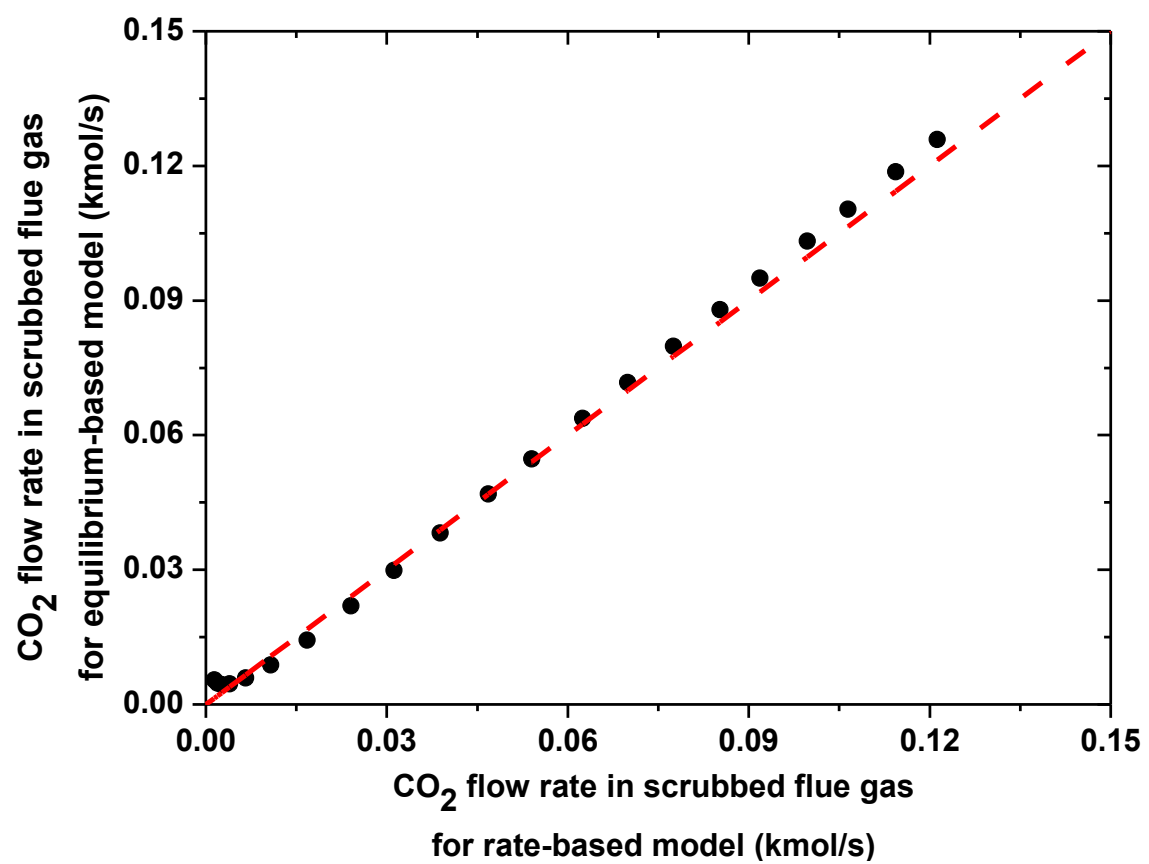

Figure 4.5 Comparisons of $\mathrm{CO}_{2}$ flow rate in scrubbed flue gas between correlated equilibrium and rate-based models under varying lean solvent loadings $\left(0.116-0.276 \frac{\mathrm{kmol} \mathrm{CO}_{2}}{\mathrm{kmol} \mathrm{MEA}}\right)$ 


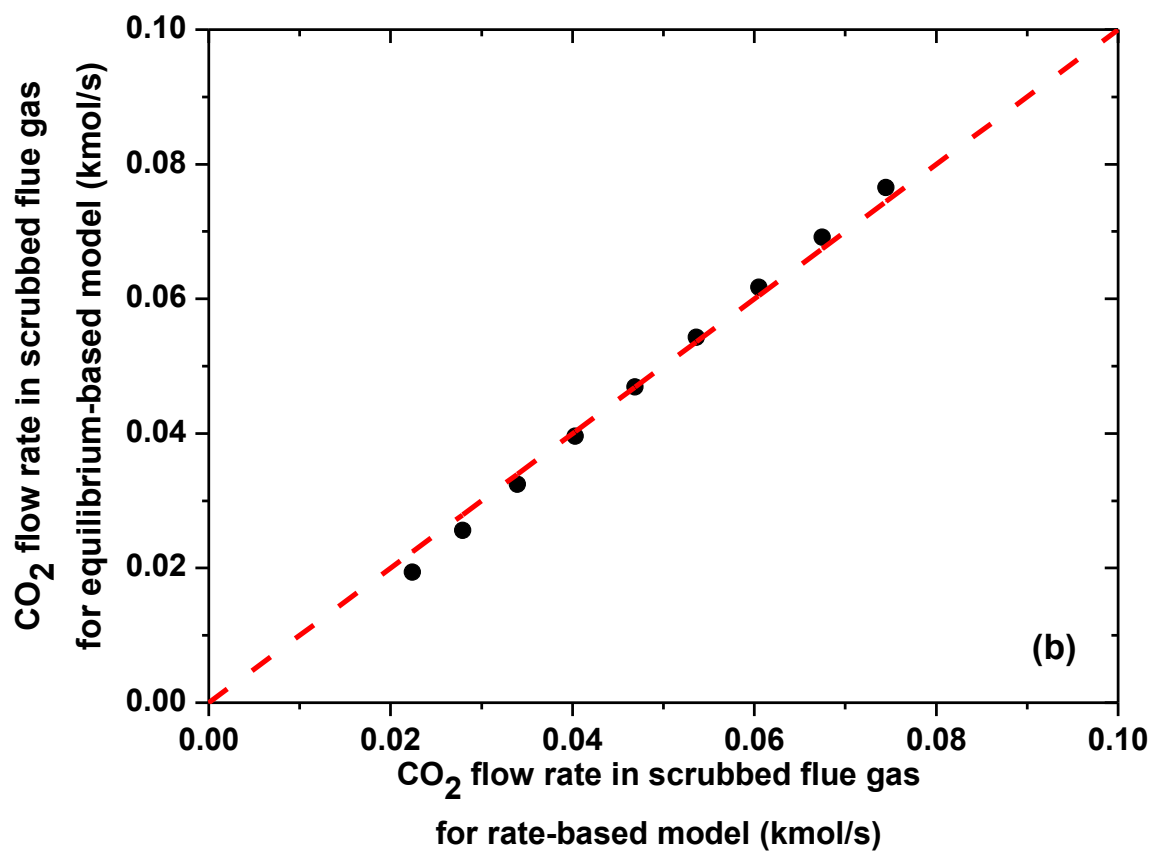

Figure 4.6 Comparisons of $\mathrm{CO}_{2}$ flow rate in scrubbed flue gas between correlated equilibrium and rate-based models under varying MEA concentrations solvent (28-32 wt. \%)

\subsection{Absorber Pressure Drop Model}

This $\mathrm{CO}_{2}$ capture process requires multiple parallel trains of absorbers and stripping columns. The flue gas distribution to each train has an important impact on the overall $\mathrm{CO}_{2}$ capture performance. In order to keep operating costs reasonable, the flue gas feed blower is not designed for a high pressure increase that would allow a precise regulation of flue gas flow rate to the individual trains of the $\mathrm{CO}_{2}$ capture process. With a low pressure increase across the blower, the pressure drop across the absorber becomes the dominant factor affecting flue gas distribution. In Aspen Plus ${ }^{\circledR}$, the pressure drop across a certain packed bed is predicted based on the packing characteristics and correlations provided by vendors. However in Aspen Plus Dynamics ${ }^{\circledR}$, this information is not available and the pressure drop across wet packing is calculated using a default equation, shown as Equation (4.7).

$$
\Delta P=K_{o} \rho_{G} V^{2}
$$

Where: 
$\Delta P=$ pressure drop across wet packing;

$K_{o}=$ constant coefficient;

$\rho_{G}=$ gas phase density;

$V=$ gas phase superficial velocity.

$K_{o}$, the constant coefficient, is automatically calculated based on the specific condition when exporting from Aspen Plus ${ }^{\circledR}$ to Aspen Plus Dynamics ${ }^{\circledR}$. Therefore, the consistency in absorber pressure drop between steady-state and dynamic models can only be met at the design point. When the process is operated at off-design conditions, it is found that the prediction of Equation (4.7) can be $23 \%$ lower than the results of Aspen Plus ${ }^{\circledR}$ model for $1 \mathrm{~m}$ of packing (Figure 4.7). Therefore, it is necessary that an accurate pressure drop model be applied to the Aspen Plus Dynamics ${ }^{\circledR}$ simulation.

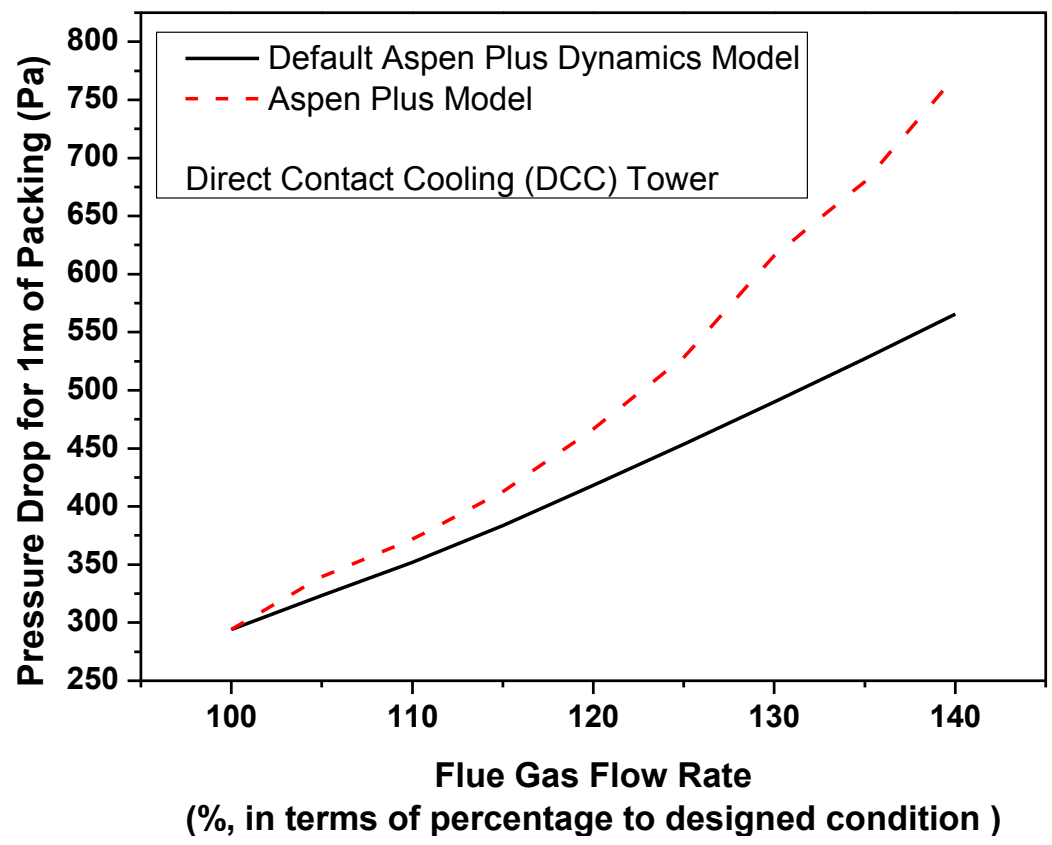

Figure 4.7 Packing pressure drop of Aspen Plus ${ }^{\circledR}$ and Aspen Plus Dynamics ${ }^{\circledR}$ default models when flue gas flow increases

By considering both the packing characteristics and vapor-liquid hydraulic properties in the column, an accurate IMTP packing pressure drop model was summarized by Nakov et al. (2012) 
based on an air-water system and is shown as Equations (4.8-4.11).

Dry packing bed pressure drop: $\Delta P_{o}=\frac{2 a\left(\frac{s}{d_{n}}\right)^{b} H_{\text {pack }} \rho_{G}\left(\frac{V}{\varepsilon}\right)^{2}}{d_{h}}$

Wet packing bed pressure drop: $\quad \Delta P=\frac{\Delta P_{o}}{\left(1-A_{O}-\Delta A\right)^{3}}$

$$
A_{o}=c R e_{L}^{d} F r_{L}^{e} E o^{f}
$$

$$
\Delta A=g F r_{L}^{h}\left(\frac{L \rho_{L}}{V \rho_{G}}\right)^{i} E o^{j}
$$

Where:

$\Delta P_{o}=$ pressure drop across dry packing;

$s=$ minimum width of the packing at the edge where it is bent to $90^{\circ}$;

$d_{n}=$ packing nominal diameter;

$d_{h}=$ packing hydraulic diameter;

$\varepsilon=$ packing void fraction;

$H_{\text {pack }}=$ packing height;

$A_{o}=$ dimensionless number that accounts for the effect of liquid holdup under the loading point;

$\Delta A=$ dimensionless number that accounts for the effect of increasing liquid holdup over the loading point;

$R e_{L}=$ liquid Reynolds number;

$F r_{L}=$ liquid Froude number;

$E o=$ Eotvos number;

$L=$ liquid phase superficial velocity;

$\rho_{L}=$ liquid phase density.

Value of coefficients $a, b, c, d, e, f, g, h, i, j$ need to be determined by fitting simulation results. The geometry of IMTP packing is listed in Table 4.1 and the resulting fitting constants are given in Table 4.2. By applying the coefficients given in Table 4.2 to the IMTP packing pressure drop model, the predicted column stage pressure drop for the direct contact cooler, absorber, and 
MEA washing section are compared with the Aspen Plus ${ }^{\circledR}$ steady-state results when flue gas flow increases from $70 \%$ to $140 \%$ of the design specification. A good match between these two models can be seen in Figures 4.8-4.9 for the absorber. The comparisons between these two models for the direct contact cooler and the MEA washing section are shown in Figures 4.10 and 4.11. Therefore, this IMTP packing pressure drop model is used to replace the simple default pressure drop equation in the Aspen Plus Dynamics ${ }^{\circledR}$ simulation. The coefficient $K_{O}$ in Equation (4.7) is determined using Equation (4.12).

$$
K_{o}=\frac{2 a\left(\frac{s}{d_{n}}\right)^{b} H}{d_{h} \varepsilon^{2}\left(1-c R e_{L}^{d} F r_{L}^{e} E o^{f}-g F r_{L}^{h}\left(\frac{L \rho_{L}}{V \rho_{G}}\right)^{i} E o^{j}\right)^{3}}
$$

Table 4.1 Geometry of IMTP Packing Used in Absorber Side

\begin{tabular}{ll}
\hline & IMTP 40 \\
Surface area $\mathrm{m}^{2} / \mathrm{m}^{3}$ & 151.0 \\
Minimum width of lamellas bending at $90^{\circ}, \mathrm{m}$ & 0.0031 \\
Void fraction & 0.98 \\
Nominal diameter, $\mathrm{m}$ & 0.038 \\
Hydraulic diameter, $\mathrm{m}$ & 0.02596 \\
\hline
\end{tabular}

Table 4.2 Fitted Coefficients Value for IMTP Packing Pressure Drop Model

\begin{tabular}{lclc}
\hline & direct contact cooler & absorber & MEA washing \\
$a$ & 0.96 & 0.918 & 0.90 \\
$b$ & 0.27 & 0.322 & 0.27 \\
$c$ & 2.50 & 2.50 & 2.60 \\
$d$ & -0.10 & -0.005 & -0.05 \\
$e$ & 0.43 & 0.43 & 0.43 \\
$f$ & 0.21 & 0.21 & 0.21 \\
$g$ & $5.325 \times 10^{-8}$ & $1.0 \times 10^{-4}$ & 365.4 \\
$h$ & -0.16 & -0.16 & 1.209 \\
$i$ & -6.788 & 1.02 & -5.607 \\
$j$ & 7.308 & 0.14 & 0.14 \\
\hline
\end{tabular}




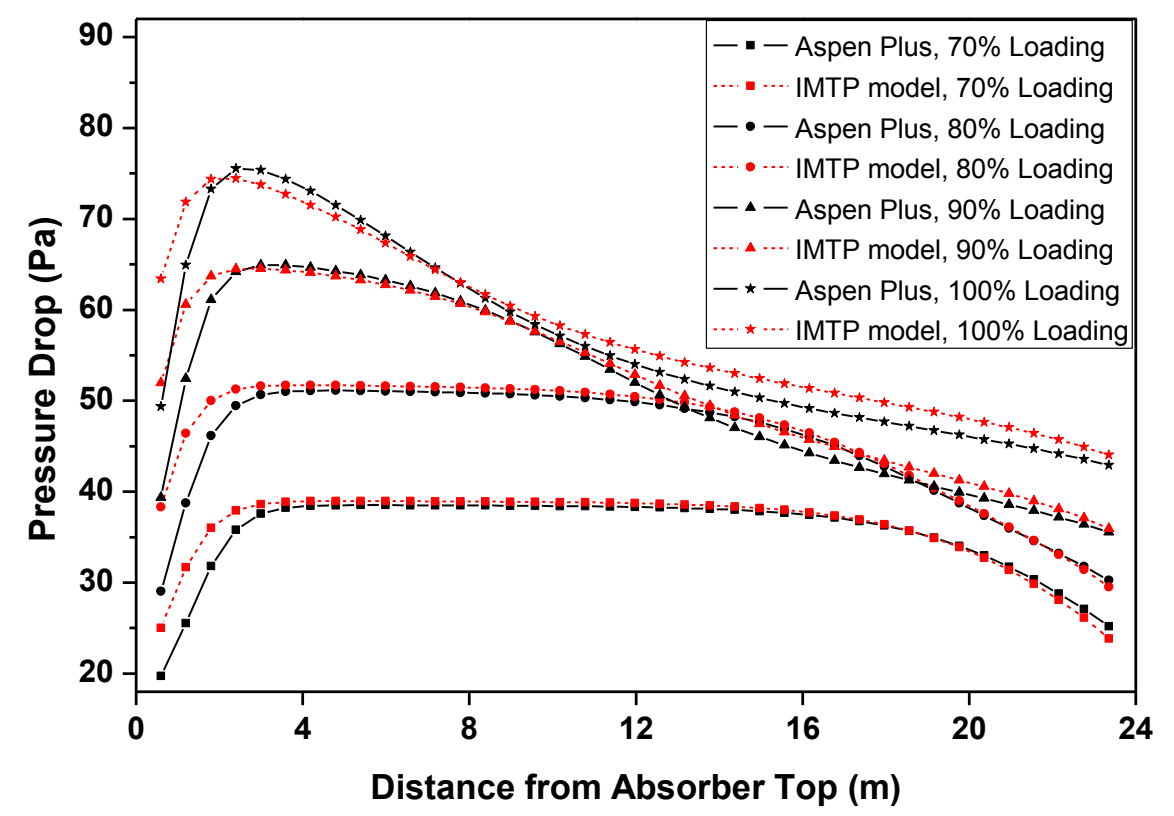

Figure 4.8 Pressure drop of Aspen Plus ${ }^{\circledR}$ and IMTP models when absorber operates below design point

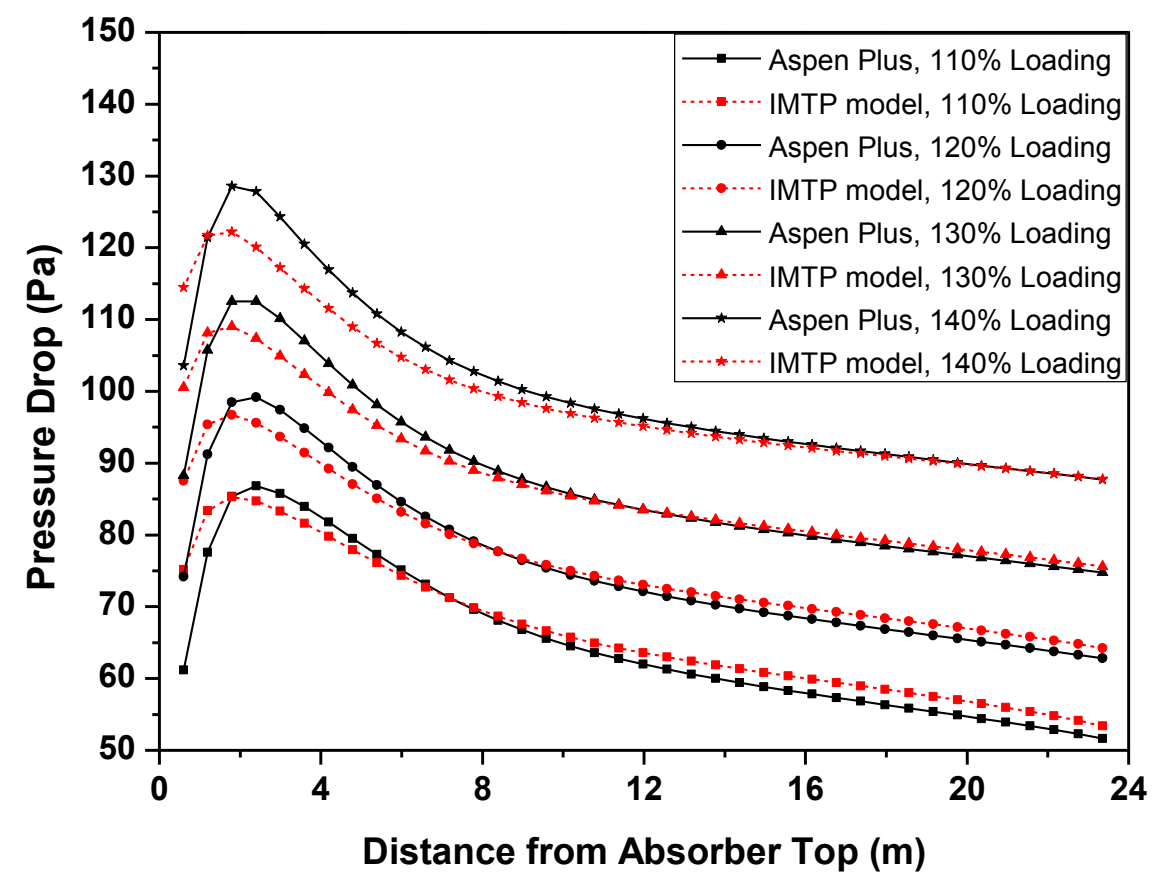

Figure 4.9 Pressure drop of Aspen Plus ${ }^{\circledR}$ and IMTP models when absorber operates above design point 


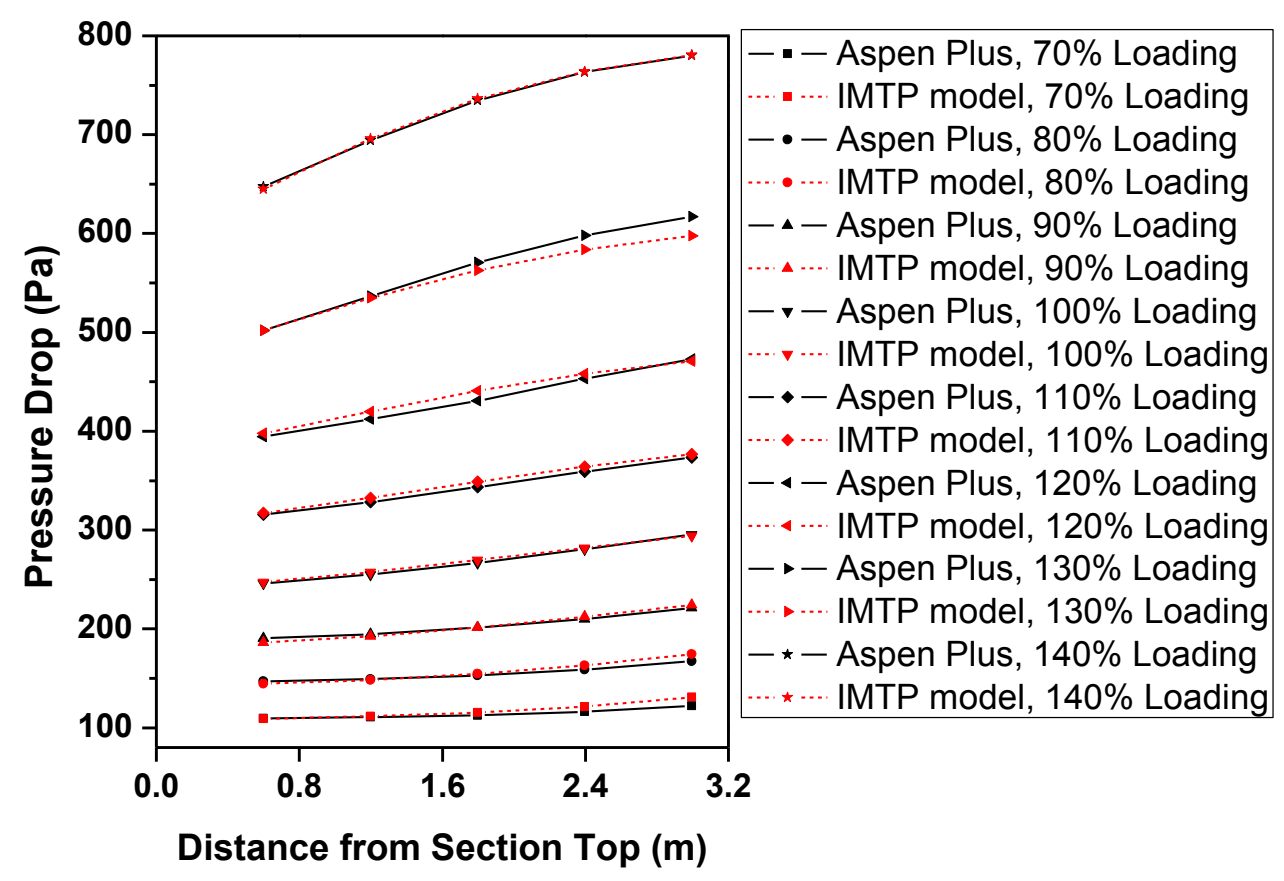

Figure 4.10 Pressure drop of Aspen Plus ${ }^{\circledR}$ and IMTP models for direct contact cooler

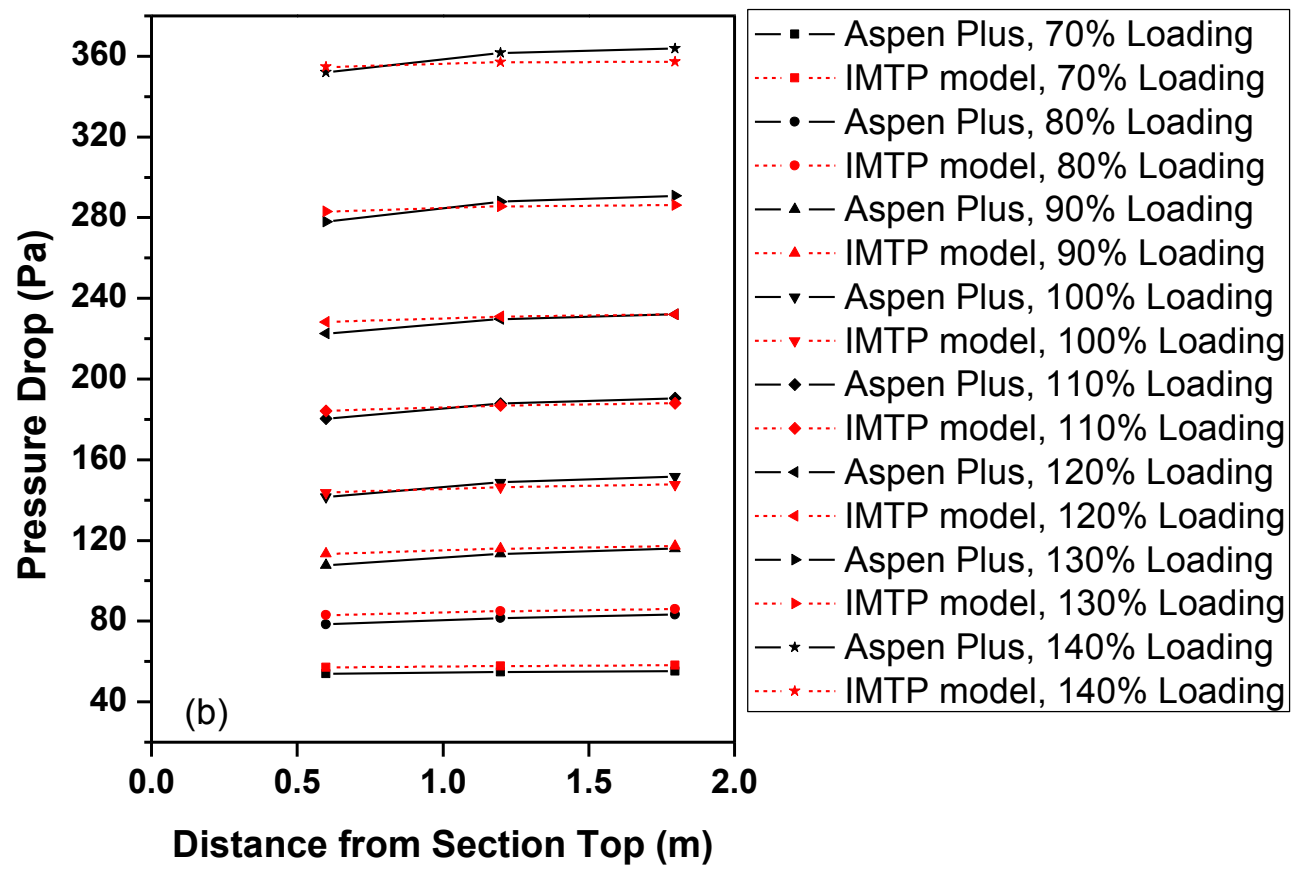

Figure 4.11 Pressure drop of Aspen Plus ${ }^{\circledR}$ and IMTP models for MEA washing section 


\section{LINEAR MODEL PREDICTIVE CONTROL}

Depending on the presence of controller, a dynamic simulation can be run as an open-loop or closed-loop model. A process is open-loop stable if the state variables return to steady-state when the input variables are perturbed. However, most process, including the $\mathrm{CO}_{2}$ capture processes, are open-loop unstable. Therefore, a control system is necessary to ensure the process variables meet the desired specification as well as guaranteeing the stability of the system in the presence of disturbances and uncertainties without violating the constraints. In this chapter, traditional PID-based and advanced LMPC-based control methods are applied to the postcombustion $\mathrm{CO}_{2}$ capture processes. The control performance is evaluated in the face of typical disturbances. The process control studies are on the basis of the dynamic model developed in Chapter 4. Design and implementation of LMPC are accomplished using available toolboxes in Matlab and Matlab Simulink.

\subsection{Plant-Wide Control Structure}

Different electricity demands during on-peak and off-peak hours lead to a variation in the load on the power plant during daily operations. Therefore, the flue gas flow rate and composition will vary and may give rise to significant deviations in the $\mathrm{CO}_{2}$ capture efficiency if this is not being controlled. Another process variable that needs to be controlled is the $\mathrm{CO}_{2}$ stripper reboiler temperature. This temperature reflects the $\mathrm{CO}_{2}$ loading of the lean solvent. Therefore, a stable temperature in the stripper reboiler can help to stabilize the $\mathrm{CO}_{2}$ capture efficiency. In addition, as the low pressure steam used in the reboiler is extracted from the steam turbine, an aggressive move of the stripper temperature control can lead to undesired oscillations in power production. Based on the literature review of the control of $\mathrm{CO}_{2}$ capture processes, the conventional control structure uses pairings of $\mathrm{CO}_{2}$ capture efficiency with lean solvent flow rate and reboiler temperature with steam rate (Nittaya et al., 2014). A similar approach is used in the current work. The flue gas temperature and MEA loss are reduced by circulating a certain amount of water 
back to the DCC and MEA washing units, respectively. Other controllers are set up based on the operation of specified units. The proposed plant-wide control structure for the MEA-based $\mathrm{CO}_{2}$ capture process is shown in Figure 5.1.

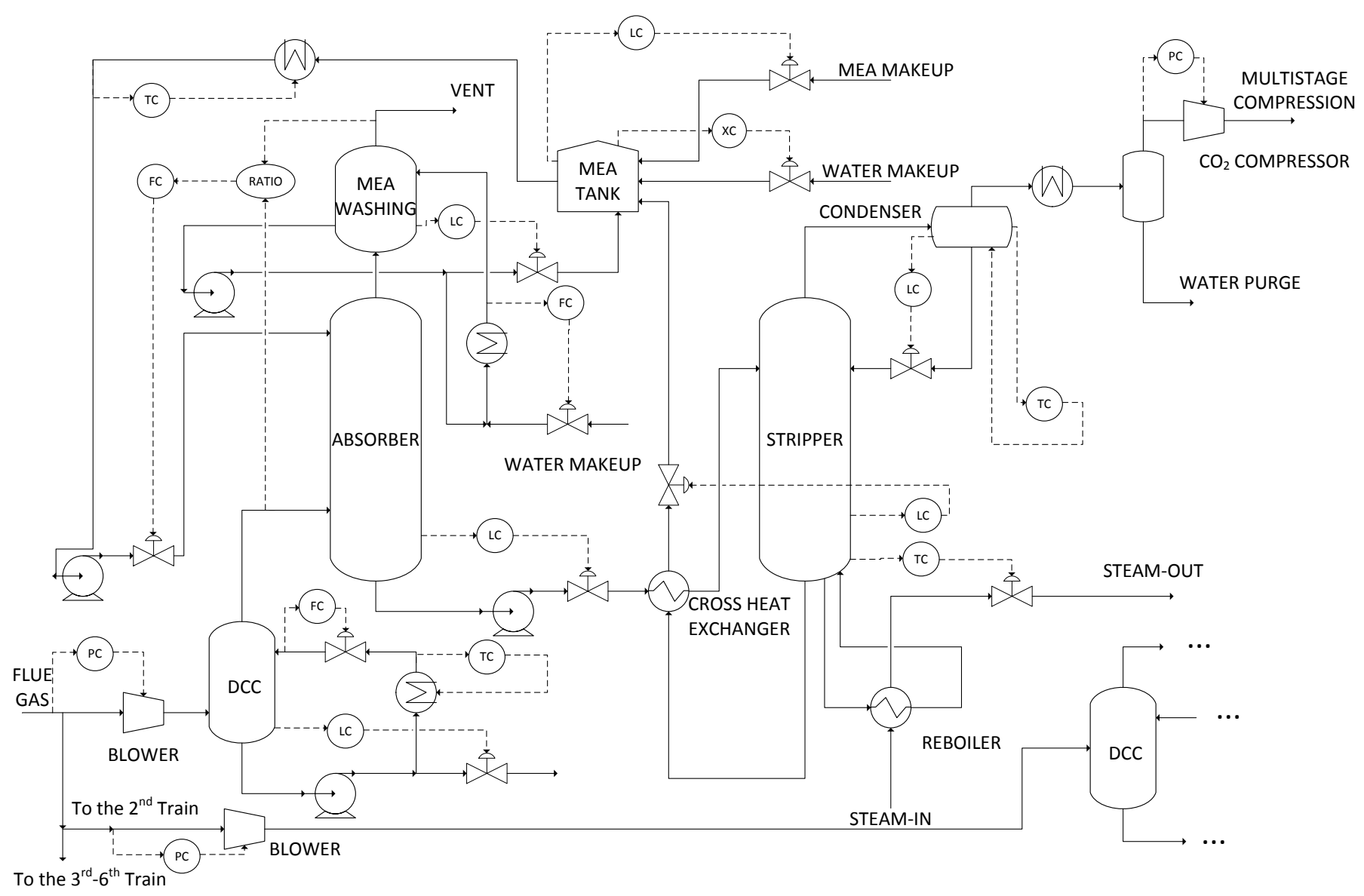

Figure 5.1 Proposed plant-wide control structure for MEA-based $\mathrm{CO}_{2}$ capture process (Zhang et al., 2016)

Traditional PID controllers have been used for all the flow rate, temperature, pressure, level (inventory), and concentration controls. For the $\mathrm{CO}_{2}$ capture efficiency and $\mathrm{CO}_{2}$ stripper reboiler temperature control, different controllers are designed and their performances are evaluated. 


\subsubsection{Flooding Control Strategy}

Flooding is the severe condition caused (in most cases) by excessive vapor flow entering a column leading to excessive liquid hold-up in the column with a subsequent increase in pressure drop across the column and significant loss in separation efficiency. The column performance deteriorates as the column approaches the flooding point and can be detected by a sharp increase in column pressure drop. The effect of flooding in Aspen Plus Dynamics ${ }^{\circledR}$ is that the dynamic simulation becomes increasingly difficult to converge, and may even fail, as the degree of column flooding increases. For the post-combustion $\mathrm{CO}_{2}$ capture process, a gas bypass (or shunt) valve is added to the parallel system to prevent either $\mathrm{CO}_{2}$ absorber from becoming flooded. Two control strategies are applied to the system to mitigate the onset of flooding and each system is investigated. These two control systems are illustrated in Figure 5.2; they are the pressure control approach (left hand diagram) and the flooding control approach (right hand diagram). In both strategies, the response to an increase in flue gas feed is to activate the bypass valve to shunt excessive flue gas around the absorber. Consequently, this control action will lead to a loss in the overall $\mathrm{CO}_{2}$ capture efficiency.
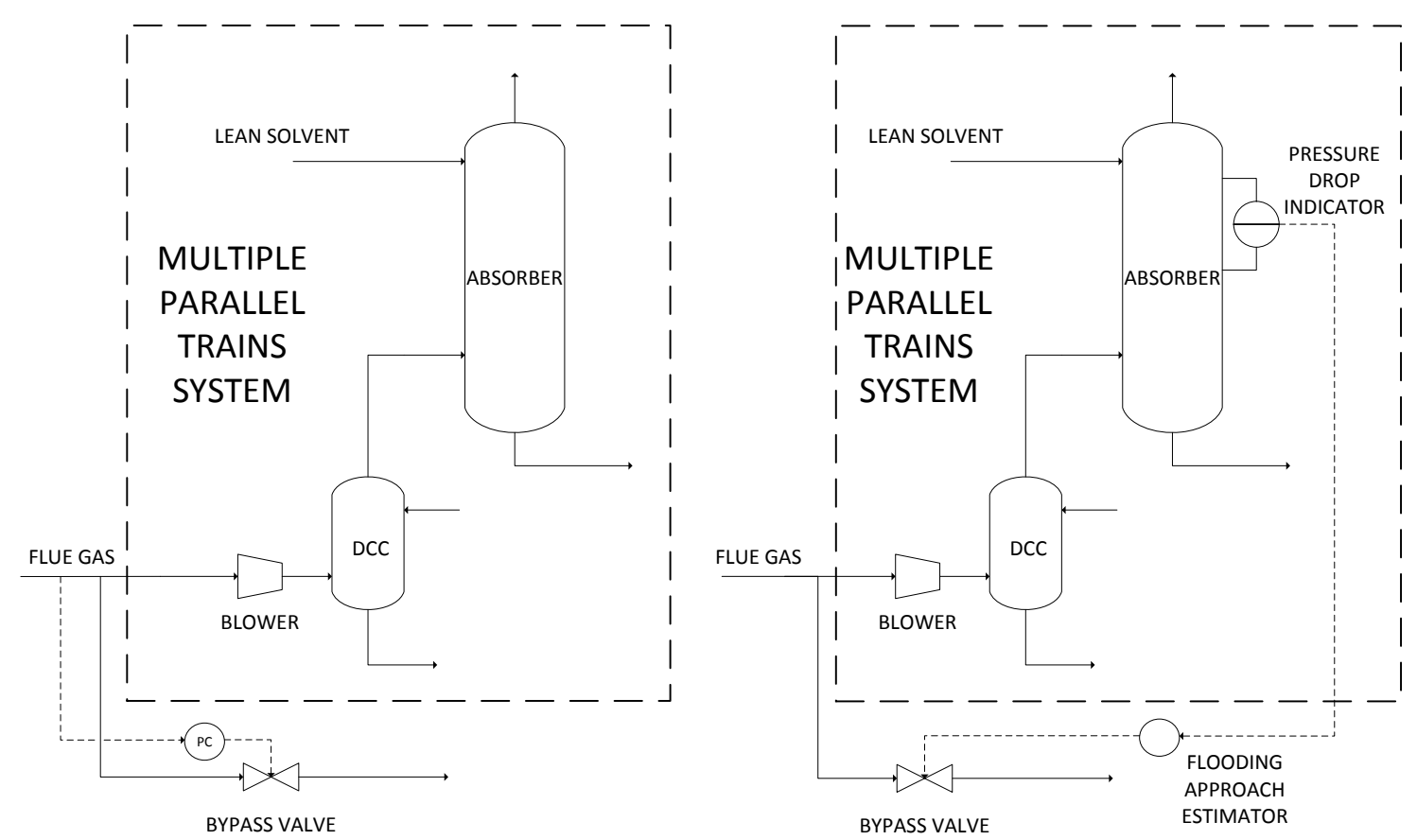

Figure 5.2 Proposed pressure control (left) and flooding approach control (right) (Zhang et al., 2016) 


\subsubsection{Correlation of $\mathrm{CO}_{2}$ Absorber Flooding Approach}

Before implementing the flooding control design, the approach to flooding in the column needed to be correlated with the packed bed pressure drop. It was found that the top section of $\mathrm{CO}_{2}$ absorber was closer to flooding point than the remaining section. Therefore, the average flooding approach for top $7.8 \mathrm{~m}$ of packing bed was correlated to the pressure drop and constrained by the flooding approach control. The correlation is shown in Equation (5.1).

$$
F A=-2.068 \times 10^{-7}(\Delta P)^{2}+7.305 \times 10^{-4} \Delta P+0.4527
$$

Where:

$F A=$ average flooding approach;

$\Delta P=$ average pressure drop per $0.6 \mathrm{~m}$ of wet packing bed $(\mathrm{Pa})$.

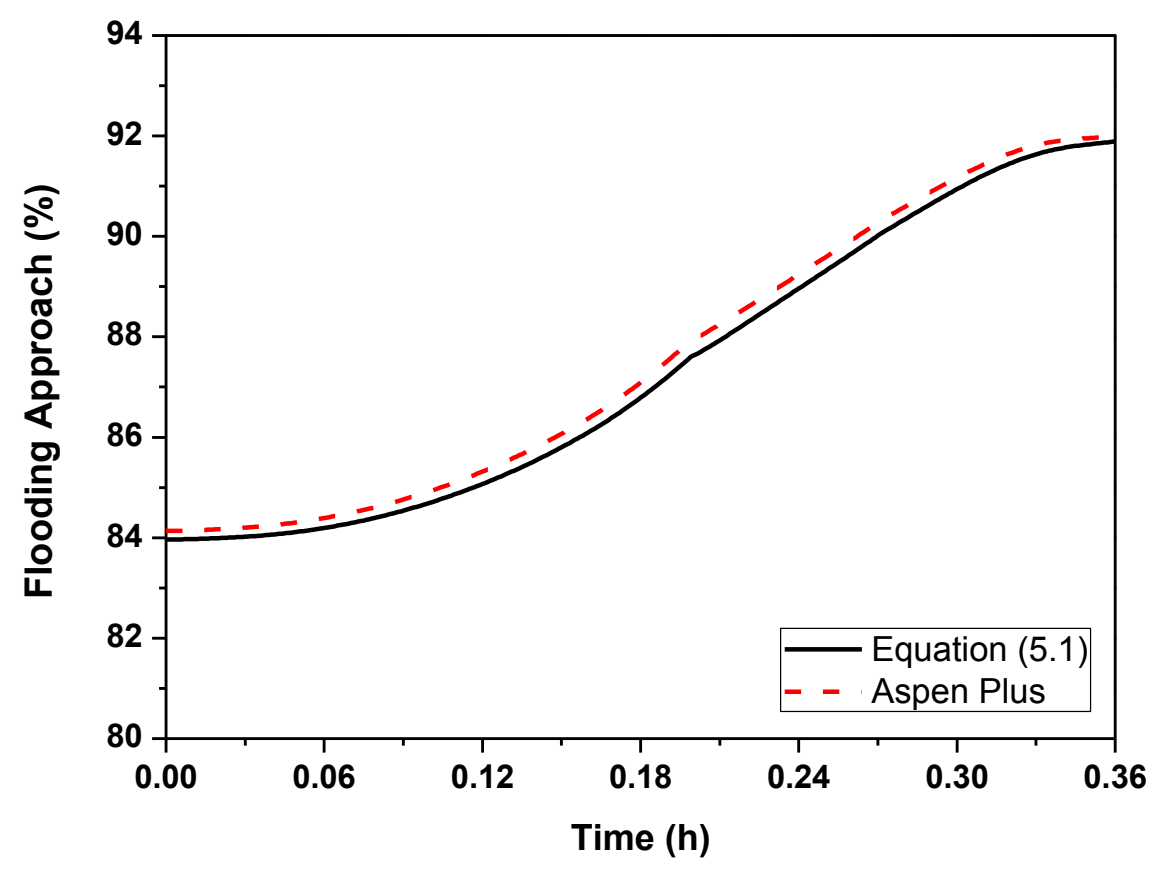

Figure 5.3 Comparison of average flooding approach for top $7.8 \mathrm{~m}$ of packing bed in $\mathrm{CO}_{2}$ absorber between Equation (5.1) and Aspen Plus ${ }^{\circledR}$ in response to an increase in flue gas feed flow 
In the Aspen Plus ${ }^{\circledR}$ model, the flooding approach is determined by relating flow variables and physical properties such as surface tension, liquid viscosity, vapor and liquid density, vapor and liquid flow rate, and by using the empirical capacity correlation chart provided by the packing vendor. Figure 5.3 shows that there is a good match between Equation (5.1) and Aspen Plus ${ }^{\circledR}$ built-in method in response to an increase in flue gas feed flow.

\subsubsection{2 $\quad \mathrm{CO}_{2}$ Absorber Flooding Control Design}

The $\mathrm{CO}_{2}$ capture units are expected to be placed at the extreme back end of the power plant. The detailed control of the ancillary upstream pressure control devices and their interactions are not considered in this work. Therefore in this study, it is assumed that the pressure set-point of the $\mathrm{CO}_{2}$ capture system can be independently set. Two control strategies for flooding control are applied to the $\mathrm{CO}_{2}$ capture process. The pressure control uses a PID controller to maintain the pressure before the flue gas blower by bypassing excessive flue gas and completely switching the bypass valve off when the pressure is below the set-point. The flooding approach control is developed by using an adaptive $\lambda$-tracker control law. The bypass valve position will be maintained at 0 if the flooding approach is below the threshold $(\lambda=0.9)$. As the operating condition moves beyond the threshold, the bypass valve is activated and the percent open position $(\mathrm{OP})$ is set to be proportional to the degree of deviation from the threshold (Equations 5.2 and 5.3).

$$
\begin{aligned}
\sigma_{\lambda}(F A) & =\left\{\begin{array}{cc}
0 & \text { if } 0 \leqq F A<\lambda \\
100(F A-\lambda) & \text { if } \lambda \leqq F A
\end{array}\right. \\
O P & =\alpha \sigma_{\lambda}(F A)
\end{aligned}
$$

Where:

$\alpha=$ adaption speed.

The comparison between the two control strategies for the response to a $20 \%$ increase in flue gas feed flow at time $=0$ followed by a decrease to the design value at time $=1 \mathrm{~h}$ is shown in Figures 5.4 and 5.5. Both control strategies prevent the absorber from becoming flooded when the flue gas feed increases. However, the flooding approach control is preferred because it is difficult to 
determine the set point for pressure control. Normal variations in the pressure due to operational change such as $L / G$ ratio and flue gas flow rate must be taken into account when a decision about the set point of the pressure controller is made. When the set point of the pressure control is set to be the designed steady-state pressure at the inlet of flue gas blower, flooding approach control shows better performance, namely loss in $\mathrm{CO}_{2}$ capture due to the control action is less than for the pressure control strategy.

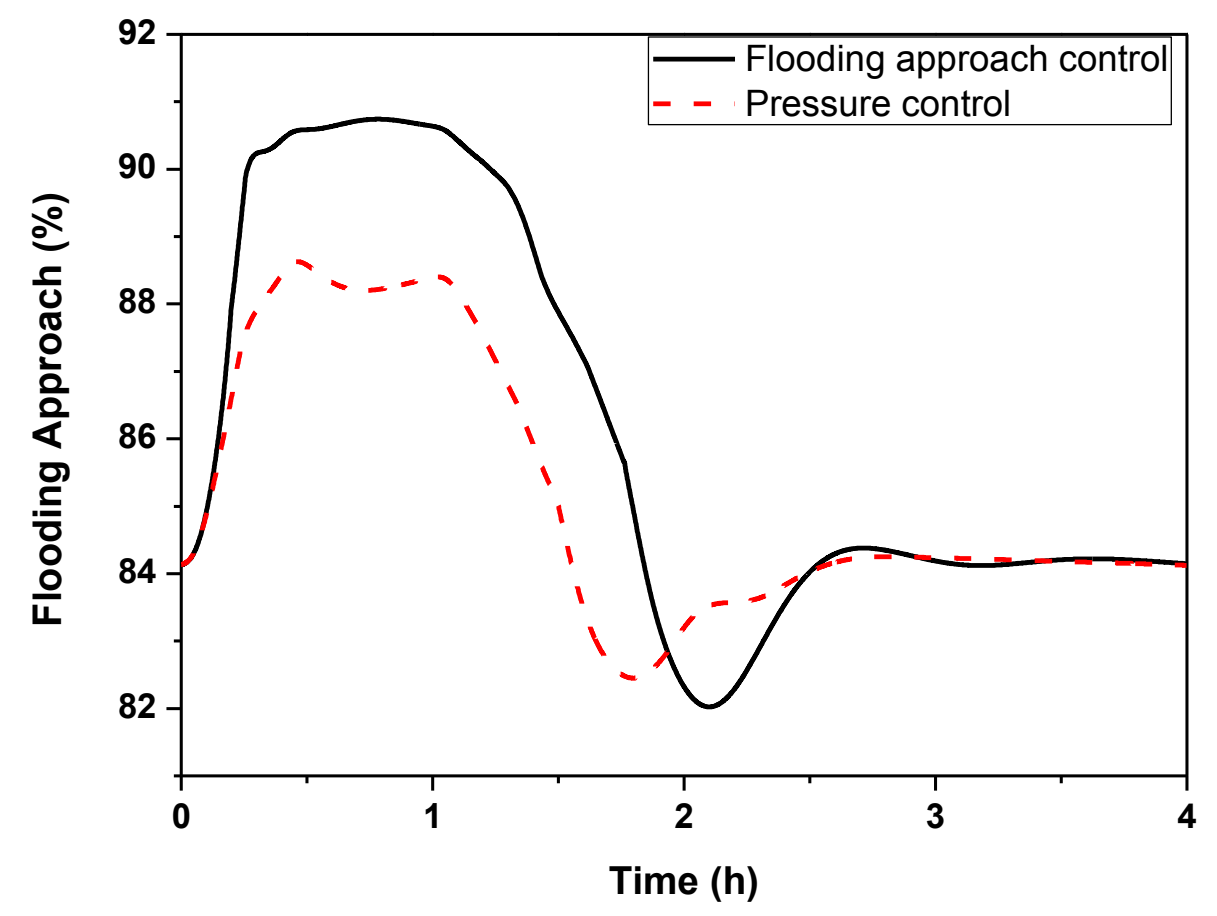

Figure 5.4 Flooding approach at $1.8 \mathrm{~m}$ of absorber (from top) in response to $20 \%$ increase in flue gas feed flow for two flooding control strategies 


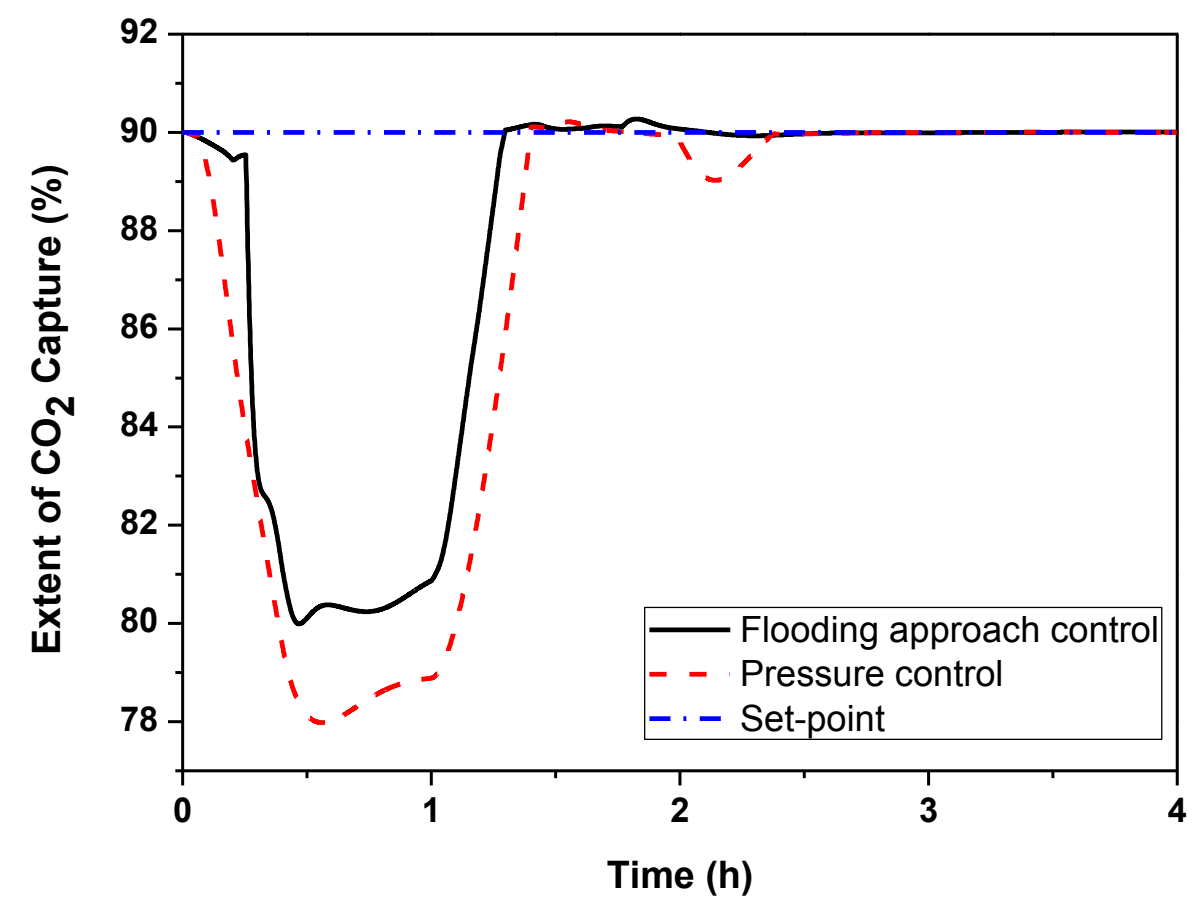

Figure 5.5 Overall $\mathrm{CO}_{2}$ capture efficiency in response to $20 \%$ increase in flue gas feed flow for two flooding control strategies

\subsection{Open-Loop System}

The open-loop responses of the capture system, without control of the $\mathrm{CO}_{2}$ capture efficiency and stripper reboiler temperature, due to a $5 \%$ ramp decrease over $0.05 \mathrm{~h}$ for the considered variables are shown for a single train of $\mathrm{CO}_{2}$ capture process in Figures 5.6 and 5.7. The $\mathrm{CO}_{2}$ capture efficiency increases in response to decreases in flue gas flow rate and $\mathrm{CO}_{2}$ composition because the residence time of flue gas in the absorber increases and $\mathrm{CO}_{2}$ loading of the lean solvent decreases. As less $\mathrm{CO}_{2}$ enters the system but with the reboiler duty fixed, the stripper reboiler temperature increases resulting in a decrease in the $\mathrm{CO}_{2}$ loading in the lean solvent. A significant interaction between $\mathrm{CO}_{2}$ capture efficiency and stripper reboiler temperature can be seen from the transient responses to changes in lean solvent flow rate. The $\mathrm{CO}_{2}$ capture efficiency decreases as less solvent enters the absorber. The steam rate is fixed and the stripper reboiler temperature increases as the sensible heat required for heating circulated solvent is 
reduced. The $\mathrm{CO}_{2}$ loading of lean solvent decreases, which accounts for the consequent increase in $\mathrm{CO}_{2}$ capture efficiency. A large time constant can be seen from the transients in response to a change in steam flow rate. During load-following by power plants, both the flue gas flowrate and $\mathrm{CO}_{2}$ composition of the flue gas can vary. To study the effect of simultaneous occurrences of these disturbances, a 5\% ramp decrease in both flue gas flow rate and $\mathrm{CO}_{2}$ composition of the flue gas in $0.05 \mathrm{~h}$ are introduced as disturbances. The lean solvent and steam flow rate are maintained at their initial values, respectively. The transient responses of the overall $\mathrm{CO}_{2}$ capture efficiency and stripper reboiler temperature are shown in Figures 5.8 and 5.9.

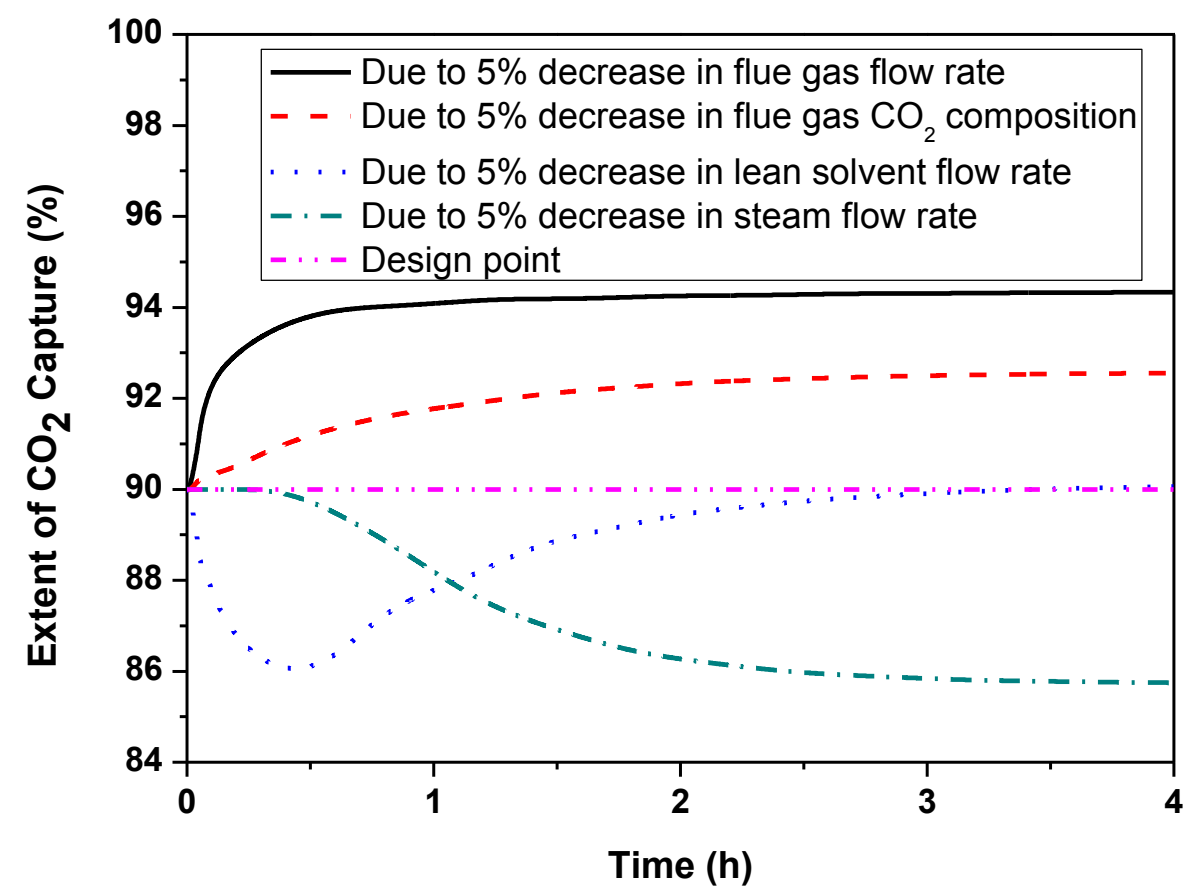

Figure 5.6 Open-loop transients of $\mathrm{CO}_{2}$ capture efficiency 


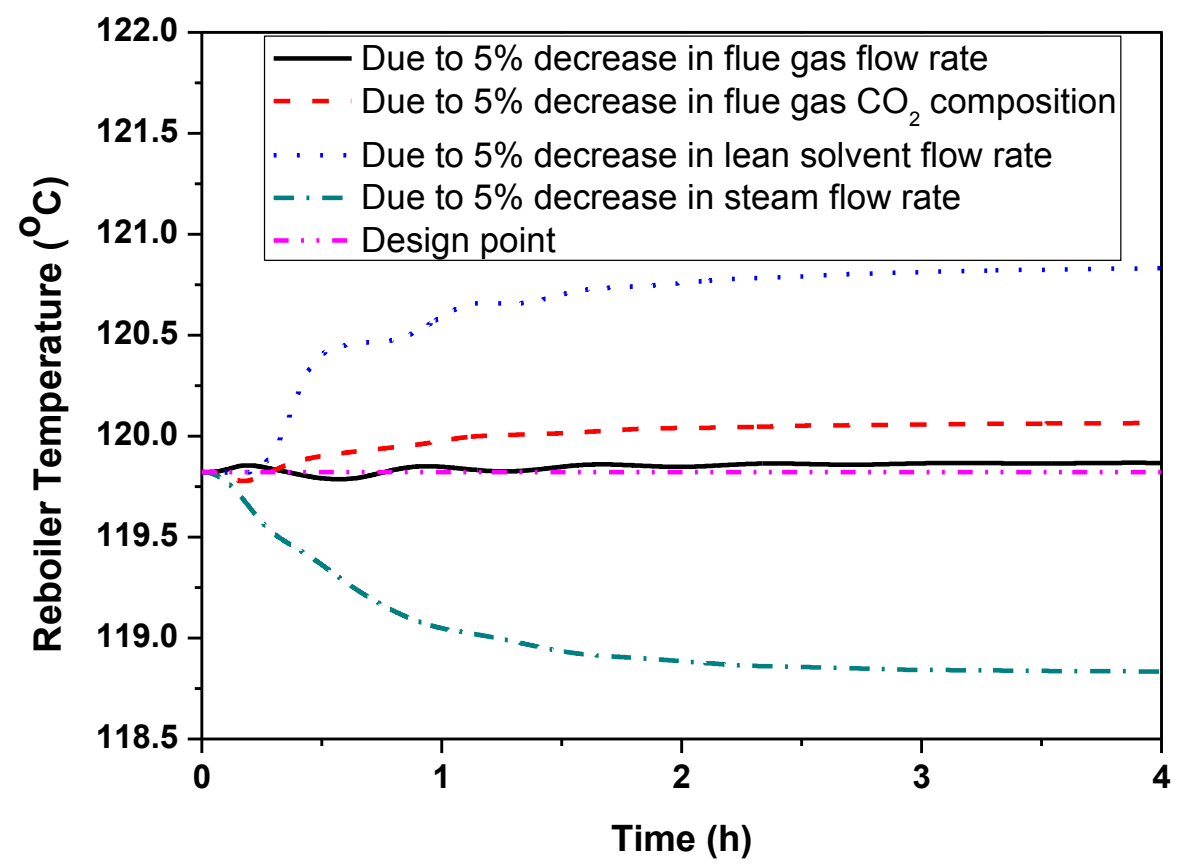

Figure 5.7 Open-loop transients of $\mathrm{CO}_{2}$ stripper reboiler temperature

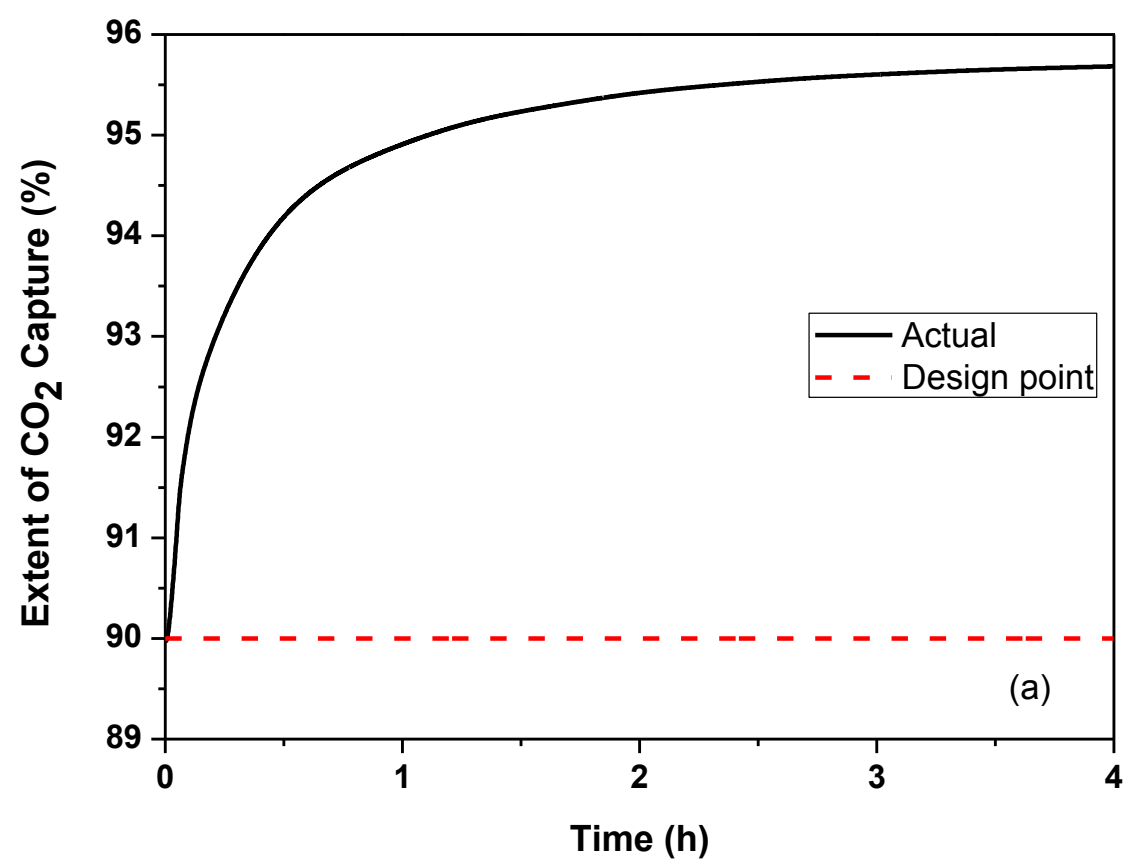

Figure 5.8 Transient of $\mathrm{CO}_{2}$ capture efficiency due to 5\% ramp decrease in flue gas flow rate and $\mathrm{CO}_{2}$ composition of flue gas 


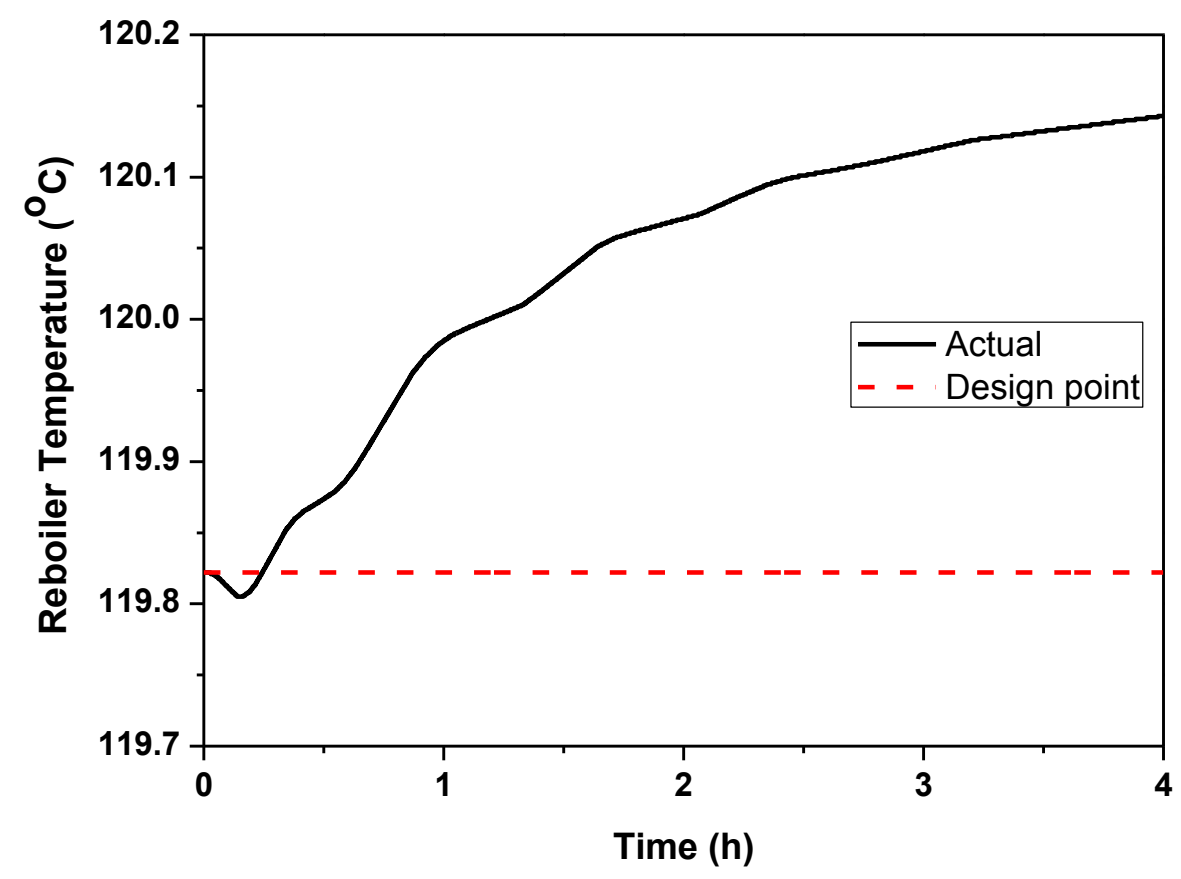

Figure 5.9 Transient of $\mathrm{CO}_{2}$ stripper reboiler temperature due to $5 \%$ ramp decrease in flue gas flow rate and $\mathrm{CO}_{2}$ composition of flue gas

\subsection{Proportional-Integral-Derivative (PID) Control and Linear Model Predictive Control (LMPC) for $\mathrm{CO}_{2}$ Capture Processes}

\subsubsection{Proportional-Integral-Derivative Control}

PID controllers are the most commonly used controllers in industrial control systems. A timedomain representation of a PID controller is given as follows:

$$
u(t)=K_{P} e(t)+K_{I} \int_{0}^{t} e(t) d t+K_{D} \frac{d e(t)}{d t}
$$

Where:

$u=$ control variable;

$e=$ error value;

$K_{P}=$ coefficient of the proportional term; 
$K_{I}=$ coefficient of the integral term;

$K_{D}=$ coefficient of the derivative term.

The proportional term $\left(K_{P} e(t)\right)$ will produce an output value that is proportional to the current

error value. The integral term $\left(K_{I} \int_{0}^{t} e(t) d t\right)$ gives an output that is proportional to both the magnitude of the error and the accumulated errors from the past. The derivative term $\left(K_{D} \frac{d e(t)}{d t}\right)$ is used to predict the future error based on the current rate of change. It can be seen that PID controllers use a generic control loop feedback mechanism and, therefore, can provide satisfactory performance without the need for a process model. Inner and outer loop PID controllers can also be cascaded to provide better dynamic performance.

In this study, all parameters for the PID controllers are tuned in Aspen Plus Dynamics ${ }^{\circledR}$ by applying different, built-in, tuning rules (open-loop and closed-loop) such as Ziegler-Nichols, Tyreus-Luyben, Cohen-Coon, Internal Model Control (IMC), Integral absolute error (IAE), integral squared error (ISE) and integral time-weighted absolute error (ITAE). The final tuning parameters for individual PID controllers are determined by comparing the performances of the tuning parameters obtained by those open-loop and close-loop tuning rules. For a single train of post-combustion $\mathrm{CO}_{2}$ capture process, PID controllers will give satisfactory performance in maintaining the $\mathrm{CO}_{2}$ capture efficiency at the desired level in the face of disturbances. However, for a multiple-train system, the overall $\mathrm{CO}_{2}$ capture can only be maintained by holding each train to the desired capture efficiency. In order to provide optimal control for a system comprising multiple trains, as well as satisfying the constraints and stability under nominal and uncertain conditions, it is necessary to implement other advanced controller strategies.

\subsubsection{Linear Model Predictive Control}

Model predictive control is a widely applied advanced control technique in the chemical process industry. The optimization objective $(J)$ of the MPC considered in this work is the typical quadratic form given by Equation (5.5), 


$$
J=\sum_{i=1}^{P H}\left(\boldsymbol{r}_{k+i}-\boldsymbol{y}_{k+i}\right)^{T} \boldsymbol{w}_{y}\left(\boldsymbol{r}_{k+i}-\boldsymbol{y}_{k+i}\right)+\sum_{j=0}^{C H-1} \Delta \boldsymbol{u}_{k+j}^{T} \boldsymbol{w}_{u} \Delta \boldsymbol{u}_{k+j}
$$

s.t.

$$
\begin{aligned}
& \mathrm{u}_{\min } \leq \mathrm{u}_{k} \leq \mathrm{u}_{\max } \\
& \Delta \mathrm{u}_{\min } \leq \Delta \mathrm{u}_{k} \leq \Delta \mathrm{u}_{\max }
\end{aligned}
$$

Where:

$J=$ optimization objective;

$\boldsymbol{r}=$ desired set-point trajectory;

$\boldsymbol{y}=$ model predictions;

$\boldsymbol{u}=$ manipulated inputs;

$\boldsymbol{w}_{y}=$ weighting matrices for outputs;

$\boldsymbol{w}_{u}=$ weighting matrices for inputs;

$P H=$ prediction horizon;

$C H=$ control horizon;

$k=$ the current time step.

In order to improve the control performance, linear model predictive control is applied to the $\mathrm{CO}_{2}$ capture efficiency and stripper reboiler temperature control. The regulation of other process variables is achieved by PID control. Based on the relative gain array (RGA, Appendix A) analysis, it is found that both lean solvent flow rate and reboiler duty have very high gains on capture efficiency and reboiler temperature (Nittaya et al., 2014). As most other variables do not have a significant effect on either $\mathrm{CO}_{2}$ capture efficiency or on the reboiler, it is decided not to include all the variables in a single MPC. Our Aspen Plus Dynamics ${ }^{\circledR}$ model also shows that relative gains among these input-output pairs can also change considerably as the operating conditions change. Therefore, a $2 \times 2$ MPC scheme is implemented in this study. 


\subsubsection{System Identification for LMPC}

Before the implementation of MPC, the Aspen Plus Dynamics ${ }^{\circledR}$ model needs to be identified as an appropriate model. The model used in MPC should represent the dynamic behavior of the Aspen Plus Dynamics ${ }^{\circledR}$ model. It is desired to use pseudo random binary sequence (PRBS) signals for obtaining the outputs for system identification. However, it is found that the Aspen Plus Dynamics ${ }^{\circledR}$ model may fail to converge when the PRBS signals are introduced for system excitation. To take care of this issue, the signals are generated by the PRBS Signal Generator in Aspen Plus Dynamics ${ }^{\circledR}$, but the signal amplitude is set to be variable (random value between 0 and 1) instead of either 0 or 1 , at each step to ensure the convergence of Aspen Plus Dynamics ${ }^{\circledR}$ model over the tested sequence. The random input signals used for flue gas flow rate, $\mathrm{CO}_{2}$ composition in flue gas, steam flow rate and lean solvent flow rate are shown in Figures 5.10 and 5.11. The magnitudes of these random signals are selected to represent small variations around the design point in the operation of $\mathrm{CO}_{2}$ capture process. The identification process is accomplished using the System Identification toolbox in Matlab. The $\mathrm{CO}_{2}$ capture efficiency and stripper reboiler temperature models are identified as first-order with process zero (Equations 5.6 and 5.7). Figure 5.12 shows comparisons between the outputs of the dynamic simulation and the identified models.

$$
\begin{aligned}
& y_{1}(s)=\frac{-21.653}{1+0.062988 s} u_{1}(s)+\frac{-302.49}{1+0.37979 s} u_{2}(s)+\frac{6.0431}{1+0.055696 s} u_{3}(s) \\
& +\frac{23.694+4.2616 s}{1+1.173 s} u_{4}(s)+\frac{3.5348-0.95687 s}{1+0.47089 s} e^{-0.001 s} y_{2}(s) \\
& y_{2}(s)=\frac{0.353+307.76 s}{1+817.04 s} u_{1}(s)+\frac{-26.945+8.11 s}{1+0.71962 s} u_{2}(s)+\frac{-286.2-494.22 s}{1+4125.9 s} u_{3}(s) \\
& +\frac{10.461}{1+0.3176 s} u_{4}(s)+\frac{-1.5493+0.0622 s}{1+0.38404 s} u_{5}(s)+\frac{0.0189+0.00218 s}{1+0.04751 s} e^{-0.001 s} y_{1}(s)
\end{aligned}
$$

Where:

$y_{1}=\mathrm{CO}_{2}$ capture efficiency $(\%)$;

$y_{2}=\mathrm{CO}_{2}$ stripper reboiler temperature $\left({ }^{\circ} \mathrm{C}\right)$;

$u_{1}=$ flue gas flow rate $(\mathrm{kmol} / \mathrm{s})$;

$u_{2}=\mathrm{CO}_{2}$ composition in flue gas (\%); 
$u_{3}=$ lean solvent flow rate $(\mathrm{kmol} / \mathrm{s})$;

$u_{4}=$ extracted low pressure steam flow rate $(\mathrm{kmol} / \mathrm{s})$;

$u_{5}=$ rich solvent flow rate $(\mathrm{kmol} / \mathrm{s})$.

$y_{1}$ and $y_{2}$ are controlled variables. $u_{3}$ and $u_{4}$ are manipulated variables. $u_{1}, u_{2}$ and $u_{5}$ are measured disturbances variables. All variables are given in terms of deviations from the initial values at the design point.

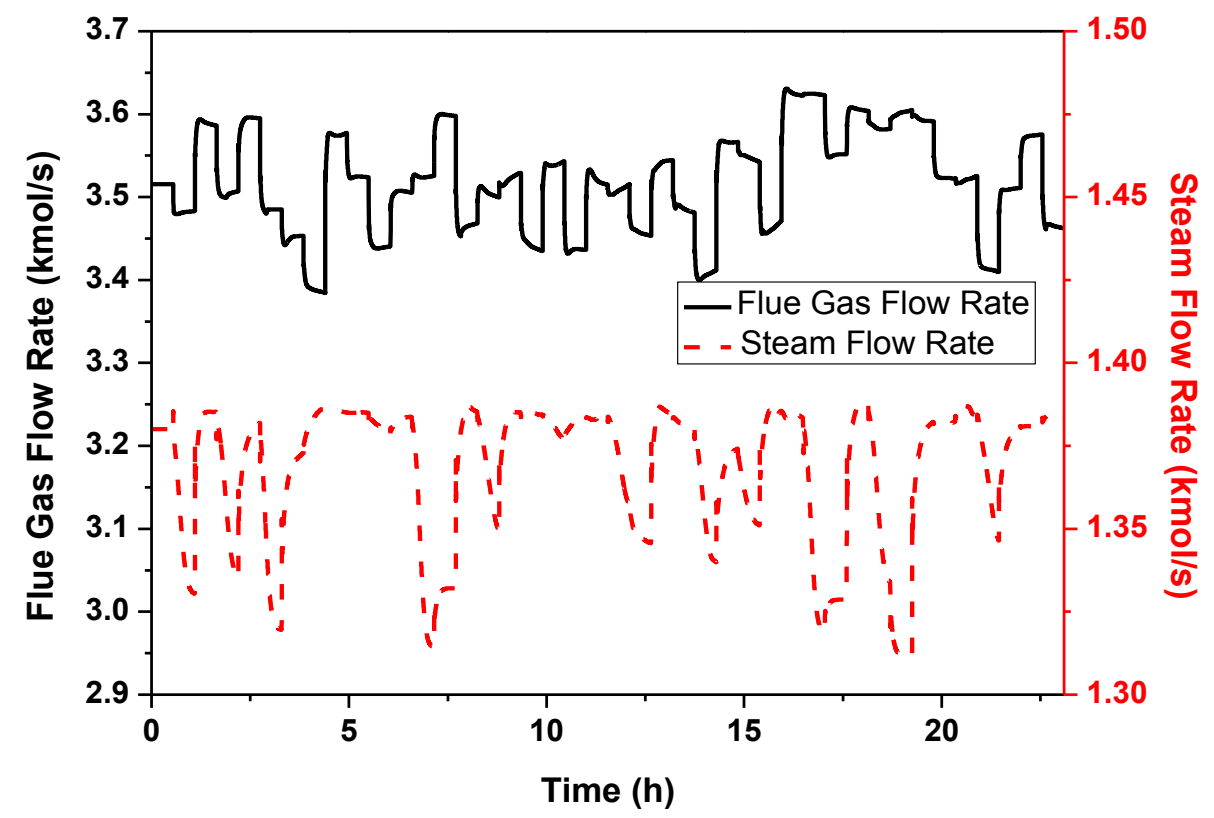

Figure 5.10 Implemented random signals of flue gas flow rate and steam flow rate for system identification 


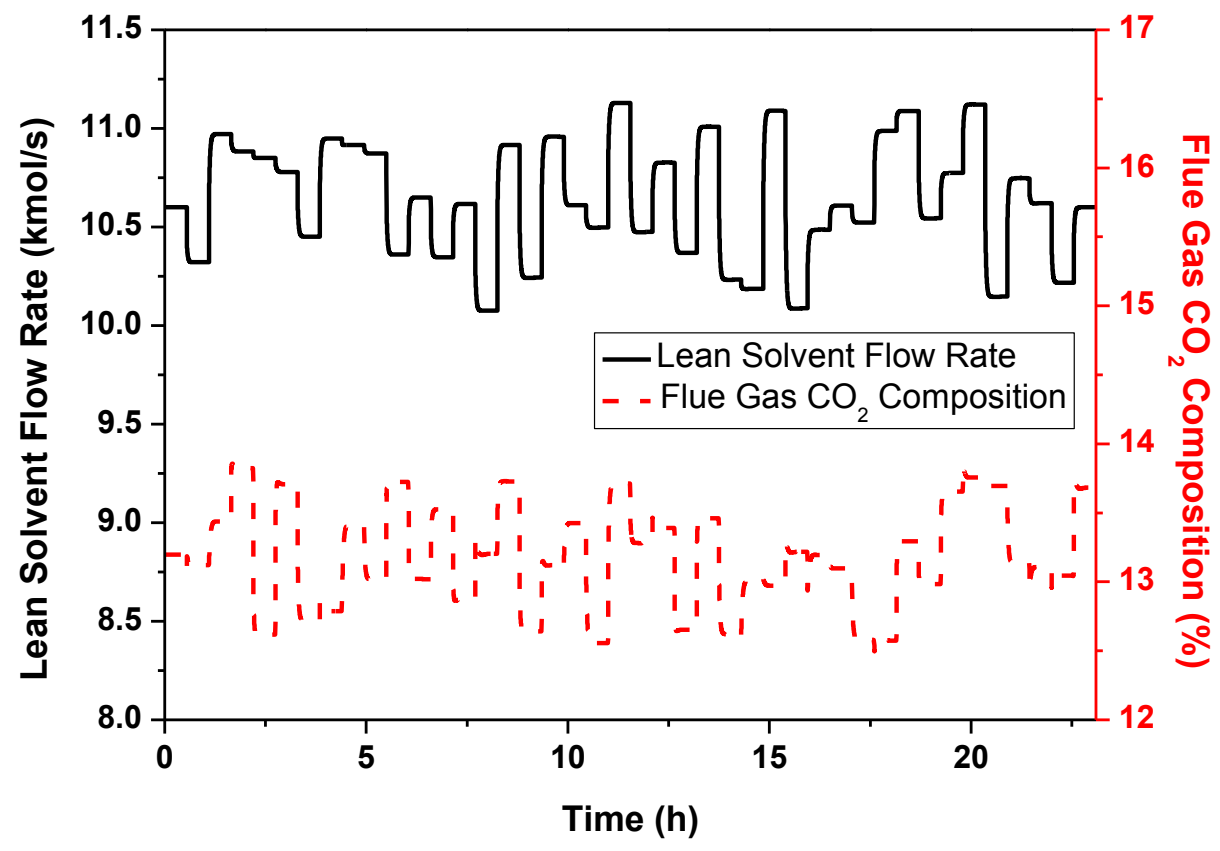

Figure 5.11 Implemented random signals of lean solvent flow rate and $\mathrm{CO}_{2}$ composition of flue gas for system identification 

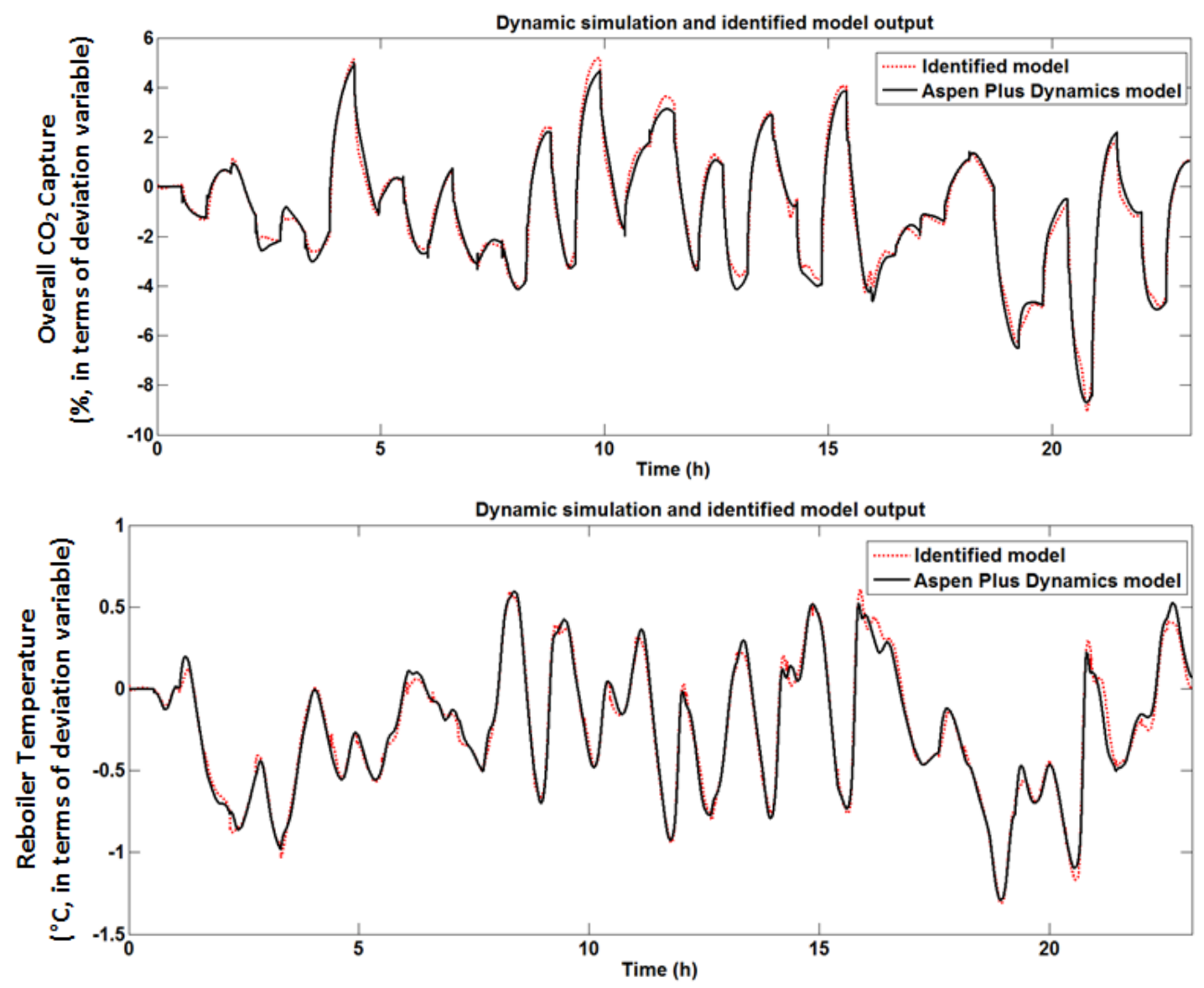

Figure 5.12 Comparison between Aspen Plus Dynamics ${ }^{\circledR}$ and identified process models (upper): $\mathrm{CO}_{2}$ capture efficiency, deviates form $90 \%$

(lower): stripper reboiler temperature, deviates from $120^{\circ} \mathrm{C}$

\subsubsection{Configuration of LMPC}

The LMPC is implemented in Matlab Simulink. Figure 5.13 shows the Simulink flowsheet. The Aspen Plus Dynamics ${ }^{\circledR}$ model is embedded in Simulink using an available custom block. The elements in the weighing matrices as well as the prediction and control horizons shown in Equation (5.5) are tuned to obtain satisfactory control performance. In this work, the weights for $y_{1}, y_{2}, \Delta u_{3}$ and $\Delta u_{4}$ are 1, 1, 0.9 and 1, respectively. The sampling interval in Aspen Dynamic model $^{\circledR}$ is set to be $0.001 \mathrm{~h}$ to ensure the convergence for this complex ionic, reactive absorption and desorption system. The prediction and control horizons of LMPC are set at $0.015 \mathrm{~h}$ and 0.01 h, respectively. The manipulated input constraints are shown in Table 5.1. In order to reduce the effect on PC plant power output due to steam extraction for $\mathrm{CO}_{2}$ recovery, the change rate of 
manipulated steam flow is set to be small. The model mismatch for LMPC is accounted for by considering unmeasured disturbance, which is estimated using the advanced estimation feature available in the Matlab MPC toolbox where the prediction error is assumed to be due to random, zero-mean white noise.

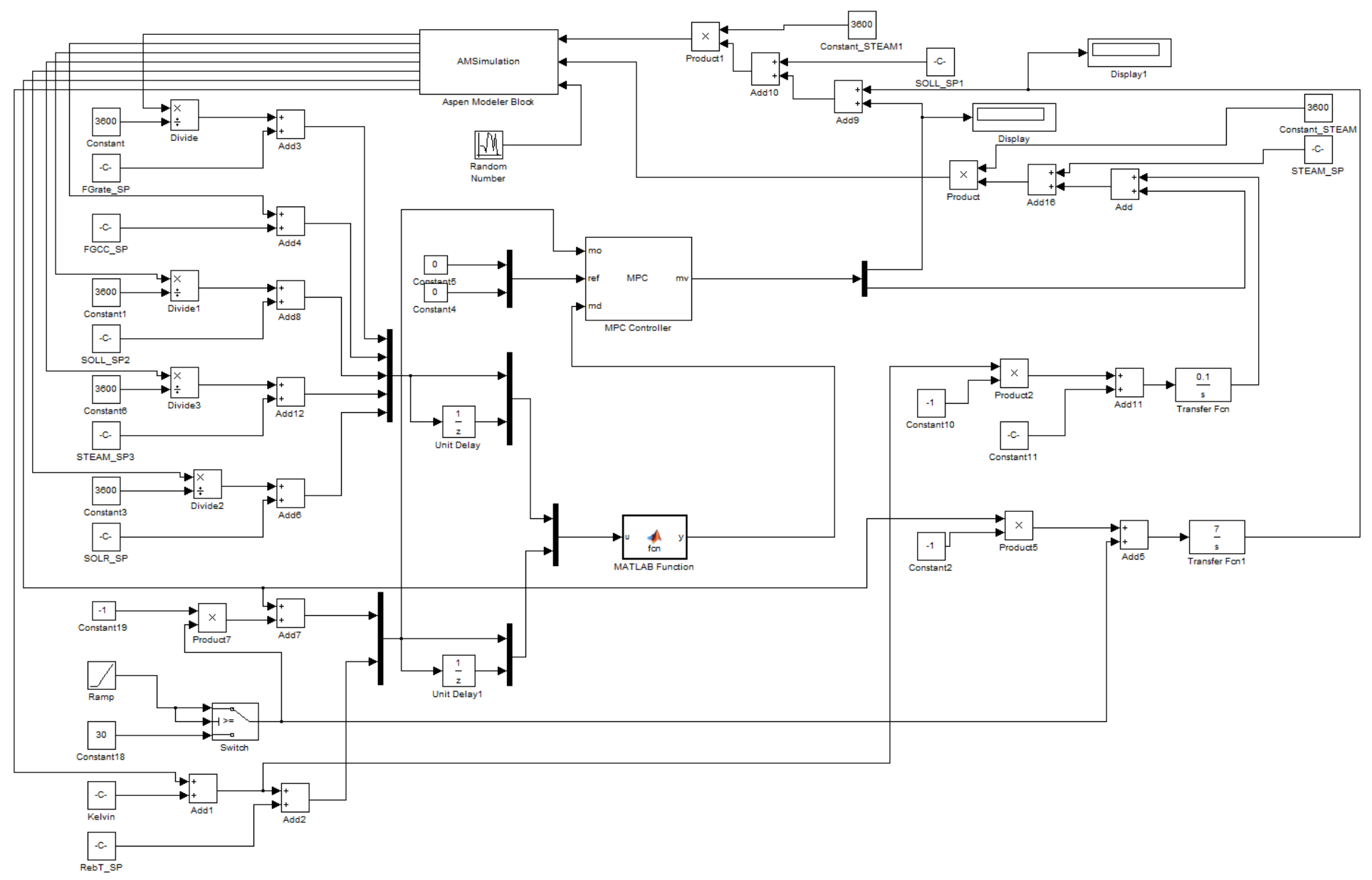

Figure 5.13 Simulink schematic of the LMPC control strategy for $\mathrm{CO}_{2}$ capture process

Table 5.1 Manipulated Input Constraints in the MPC Optimization Objective

\begin{tabular}{lcc}
\hline Input variables & \multicolumn{2}{c}{ Specification } \\
\cline { 2 - 3 } & Min & Max \\
\hline$F_{\text {solvent }}, \mathrm{kmol} / \mathrm{s}$ & 2 & 15 \\
$F_{\text {steam }}, \mathrm{kmol} / \mathrm{s}$ & 0.2 & 2 \\
$\Delta F_{\text {solvent, } \mathrm{kmol} / \mathrm{s} \cdot 0.001 \mathrm{~h}}$ & -0.4 & 0.4 \\
$\Delta F_{\text {steam }}, \mathrm{kmol} / \mathrm{s} \cdot 0.001 \mathrm{~h}$ & -0.002 & 0.002 \\
\hline
\end{tabular}


Two types of LMPC, with or without a disturbance model, are considered here. The performances of LMPCs on $\mathrm{CO}_{2}$ capture efficiency and stripper reboiler temperature are compared with traditional PID control when a $5 \%$ ramp decrease over $0.05 \mathrm{~h}$ is introduced in both flue gas flow rate and $\mathrm{CO}_{2}$ composition (Figures 5.14 and 5.15). Large overshoots and long settling times are observed for the traditional PID controller to reach the desired set-points for both $\mathrm{CO}_{2}$ capture efficiency and stripper reboiler temperature. The performances of LMPC with measured disturbance are superior to the PID control as the significant overshoots are avoided. Both LMPCs require less settling time to stabilize controlled variables. But as expected, an overshoot in $\mathrm{CO}_{2}$ capture efficiency can be seen for LMPC with unmeasured disturbance. Different rates of change in the manipulated variables for these controllers can be seen in Figures 5.16 and 5.17. Both LMPCs enable the lean solvent flow rate to reach the new operating points much quicker than the PID controller does without significant fluctuations. Since the reboiler temperature reflects the $\mathrm{CO}_{2}$ loading of lean solvent, a stable reboiler temperature can help minimize the fluctuation in $\mathrm{CO}_{2}$ capture efficiency that is introduced by the different solvent absorption capacity.

In the following studies, only LMPC with measured disturbance is considered and compared to a PID controller. It should be noted that maximum deviations of $0.6 \%$ in $\mathrm{CO}_{2}$ capture efficiency and $1.2^{\circ} \mathrm{C}$ in reboiler temperature for PID control might be acceptable in terms of magnitude. However, the disturbances considered here is for a $5 \%$ change in flue gas flow rate and $\mathrm{CO}_{2}$ composition, the performance of PID control is expected to get significantly worse results when more aggressive disturbances are introduced. 


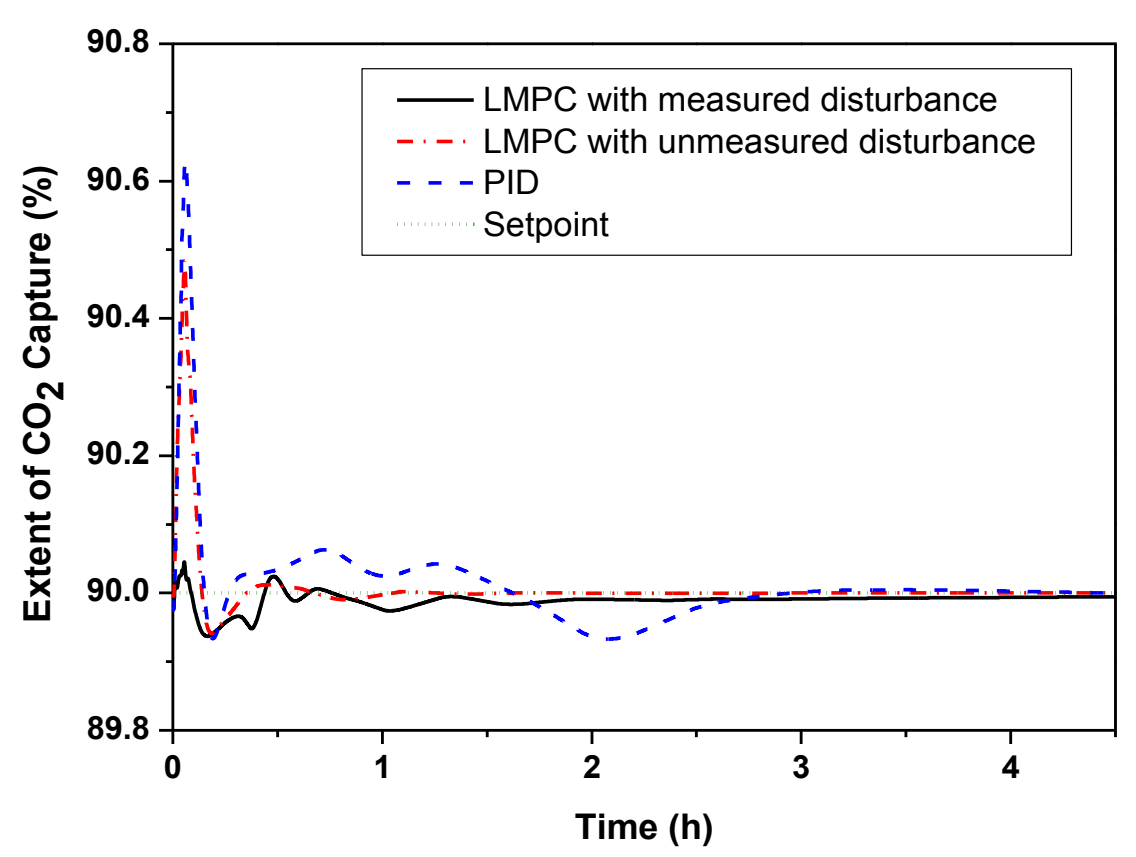

Figure 5.14 $\mathrm{CO}_{2}$ capture efficiency control performances of LMPCs and PID due to 5\% ramp decrease in flue gas flow rate and $\mathrm{CO}_{2}$ composition of flue gas

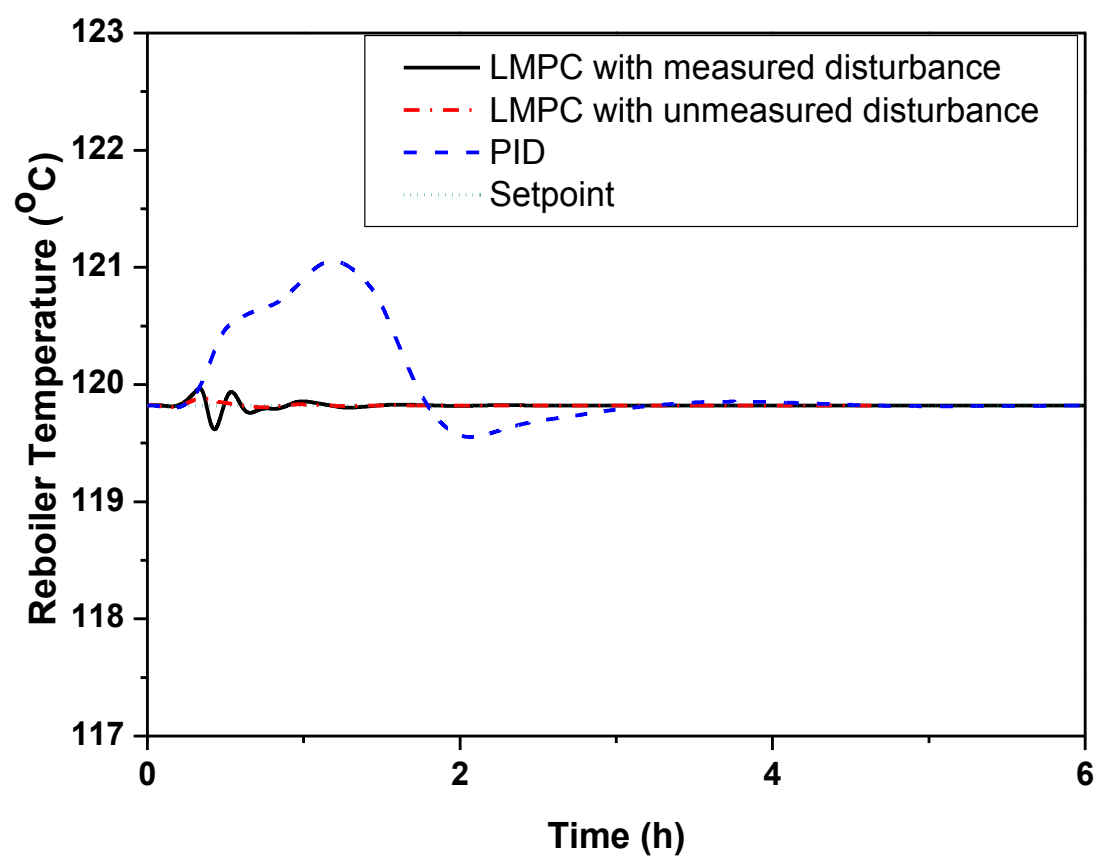

Figure 5.15 $\quad \mathrm{CO}_{2}$ stripper reboiler temperature control performances of LMPCs and PID due to $5 \%$ ramp decrease in flue gas flow rate and $\mathrm{CO}_{2}$ composition of flue gas 

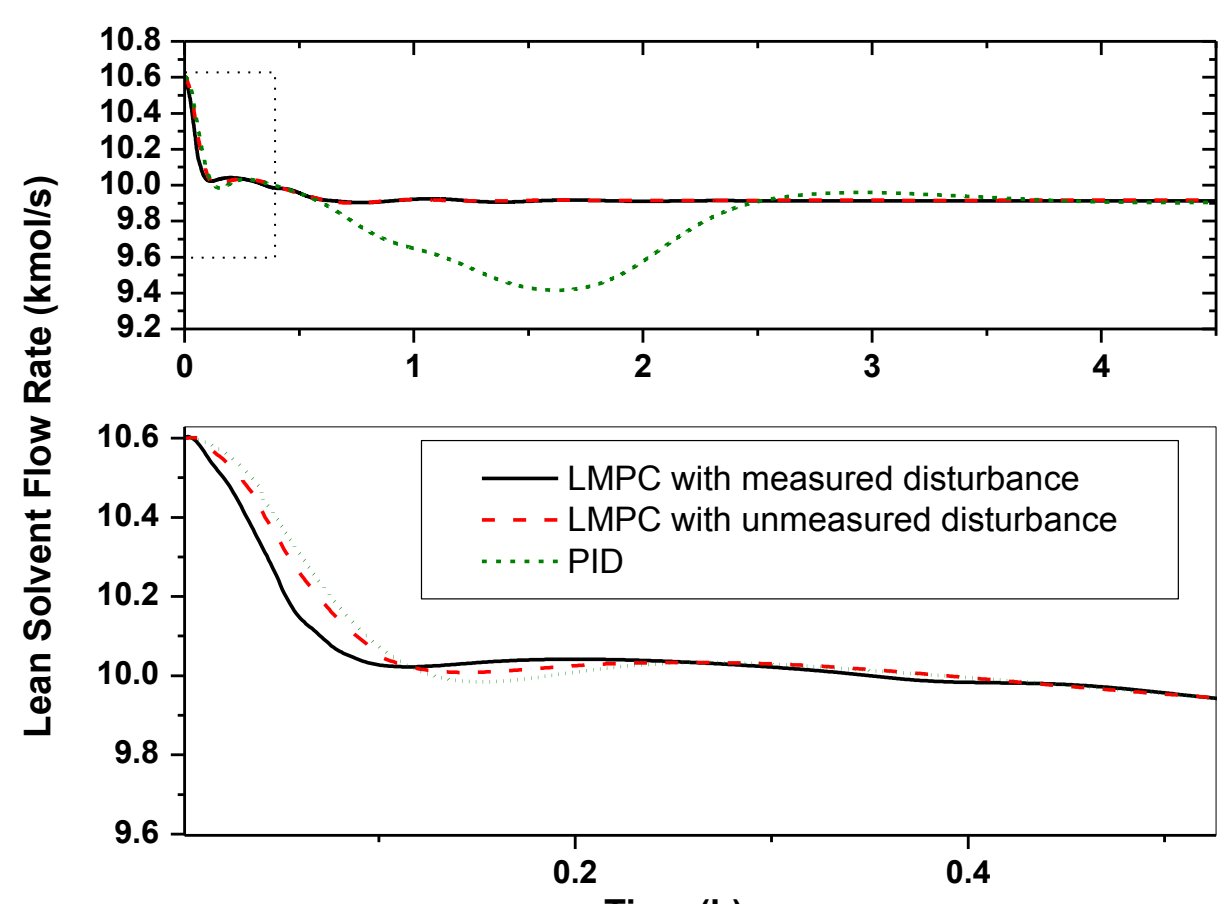

Figure 5.16 Transients of lean solvent in response to 5\% ramp decrease in flue gas flow rate and $\mathrm{CO}_{2}$ composition of flue gas

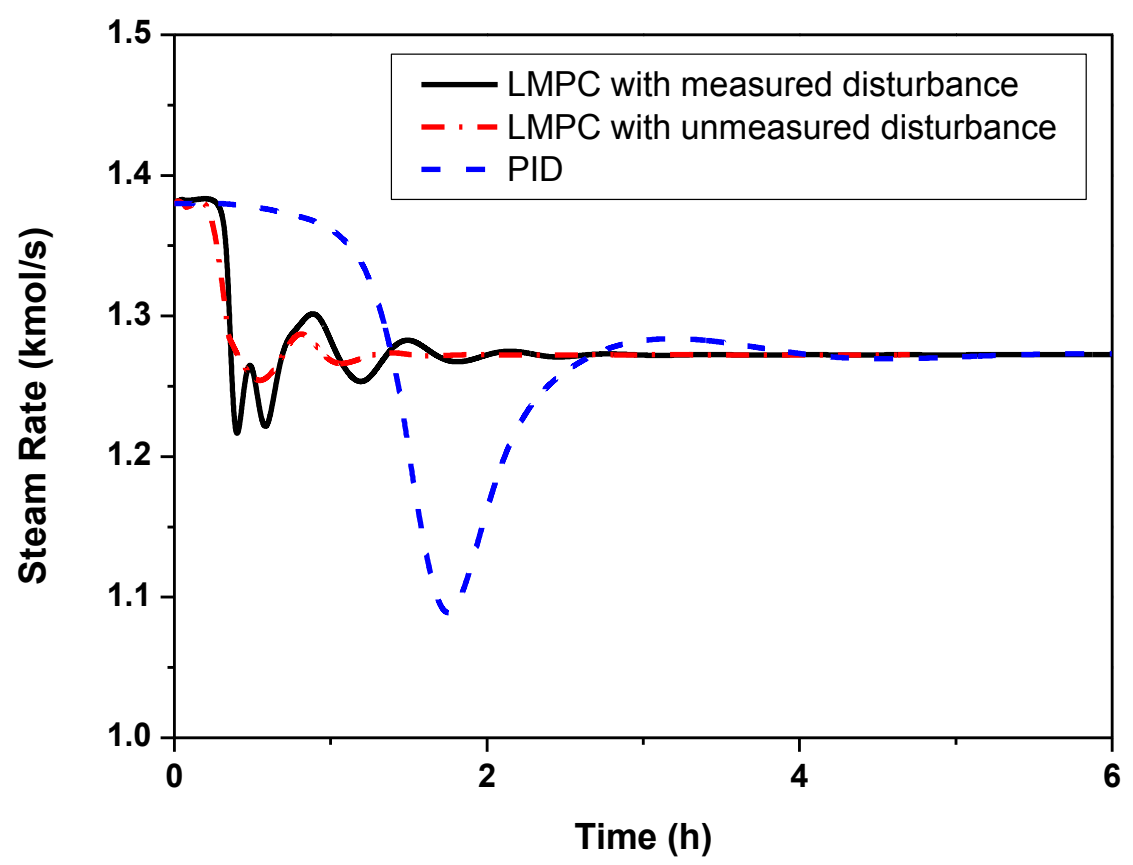

Figure 5.17 Transients of low pressure steam in response to 5\% ramp decrease in flue gas flow rate and $\mathrm{CO}_{2}$ composition of flue gas 


\subsection{LMPC Transient Studies for Other Cases}

In the control studies presented above, the $\mathrm{CO}_{2}$ capture process was identified by applying random signals to the considered process variables. The maximum amplitude of deviation was $5 \%$ of the design specs. A $5 \%$ ramp decrease in both flue gas flow rate and $\mathrm{CO}_{2}$ composition of flue gas were introduced as the disturbances. However, the operating conditions may fall out of the identified regions. The changes within the absorber, such as lower efficiency, were not identified and the need for multiple parallel trains of $\mathrm{CO}_{2}$ capture process necessary for commercial-sized PC plant was also not considered. Considering these possible scenarios, the performances of LMPC was evaluated and the results are reported in this section.

\subsubsection{Transient Responses to Ramp Changes in the Flue Gas Flow Rate}

Using the same 5\% decrease in $\mathrm{CO}_{2}$ composition of the flue gas, the effect of $15 \%$ ramp decreases in the flue gas flow rate in $0.15 \mathrm{~h}$ was investigated for the $\mathrm{CO}_{2}$ capture process. It is found that the performance of LMPC is still satisfactory when the disturbance is beyond the identified region with similar transients in $\mathrm{CO}_{2}$ capture efficiency as shown in Figures 5.14 and 5.15. The maximum deviations in $\mathrm{CO}_{2}$ capture efficiency for PID and LMPC are $0.9 \%$ and $0.1 \%$, respectively (Figure 5.18). For $\mathrm{CO}_{2}$ stripper reboiler temperature, the maximum deviation is $1.8^{\circ} \mathrm{C}$ for PID and $0.4^{\circ} \mathrm{C}$ for LMPC (Figure 5.19). PID will stabilize both controlled variables over $3 \mathrm{~h}$ while it takes LMPC $1.5 \mathrm{~h}$ to reach the steady-state. 


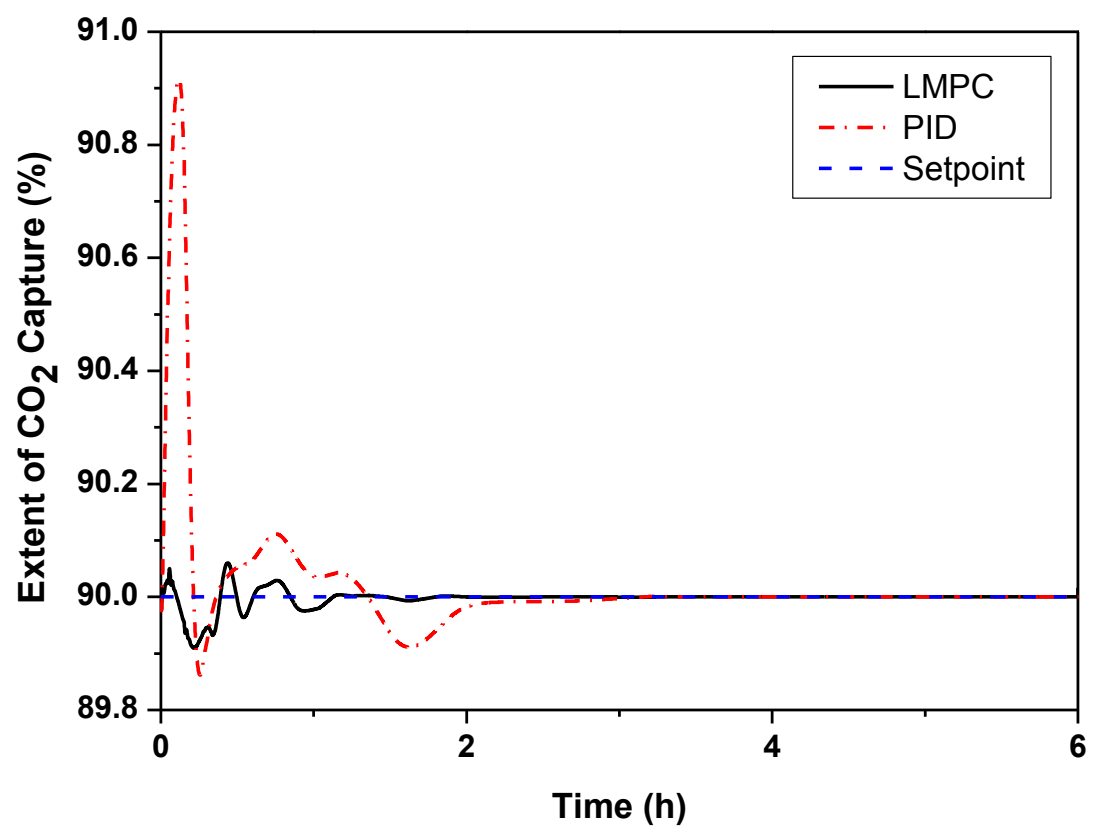

Figure 5.18 $\quad \mathrm{CO}_{2}$ capture efficiency control performances of LMPC and PID due to $15 \%$ ramp decrease in flue gas flow rate and 5\% ramp decrease in $\mathrm{CO}_{2}$ composition of flue gas

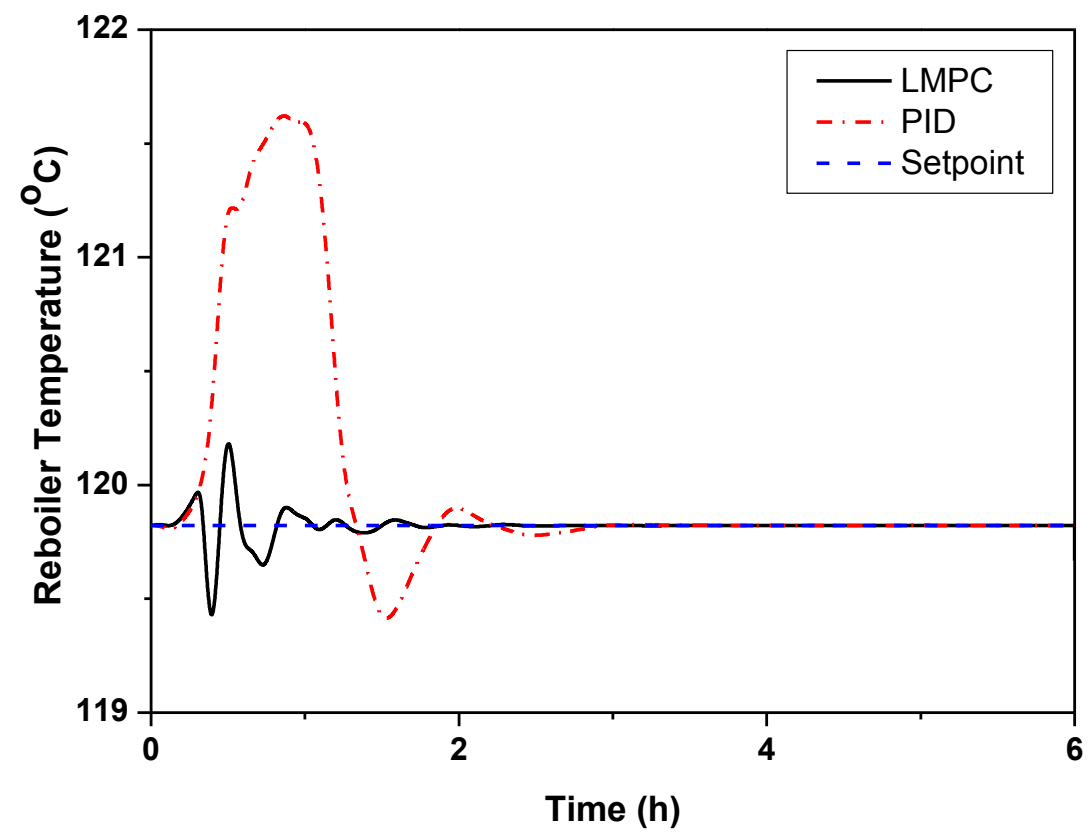

Figure 5.19 $\quad \mathrm{CO}_{2}$ stripper reboiler temperature control performances of LMPC and PID due to 15\% ramp decrease in flue gas flow rate and 5\% ramp decrease in $\mathrm{CO}_{2}$ composition of flue gas 


\subsubsection{Transient Studies for Low $\mathrm{CO}_{2}$ Absorber Efficiency}

The LMPC's performance was also evaluated under certain conditions when the efficiency of an absorber decreases due to packing damage, solids deposition, if any, or liquid channeling. Figure 5.20 shows the overall $\mathrm{CO}_{2}$ capture efficiency result using the LMPC for different absorber efficiencies in response to a $5 \%$ decrease in flue gas feed flow and $\mathrm{CO}_{2}$ composition of flue gas. It can be seen that LMPC can still provide similar control performance of $\mathrm{CO}_{2}$ capture in reference tracking and settling time when the absorber is operated at lower efficiency. For all three cases, the stripper reboiler temperatures are well maintained at design conditions with a maximum deviation of $0.2^{\circ} \mathrm{C}$ and reach steady-state in $2 \mathrm{~h}$.

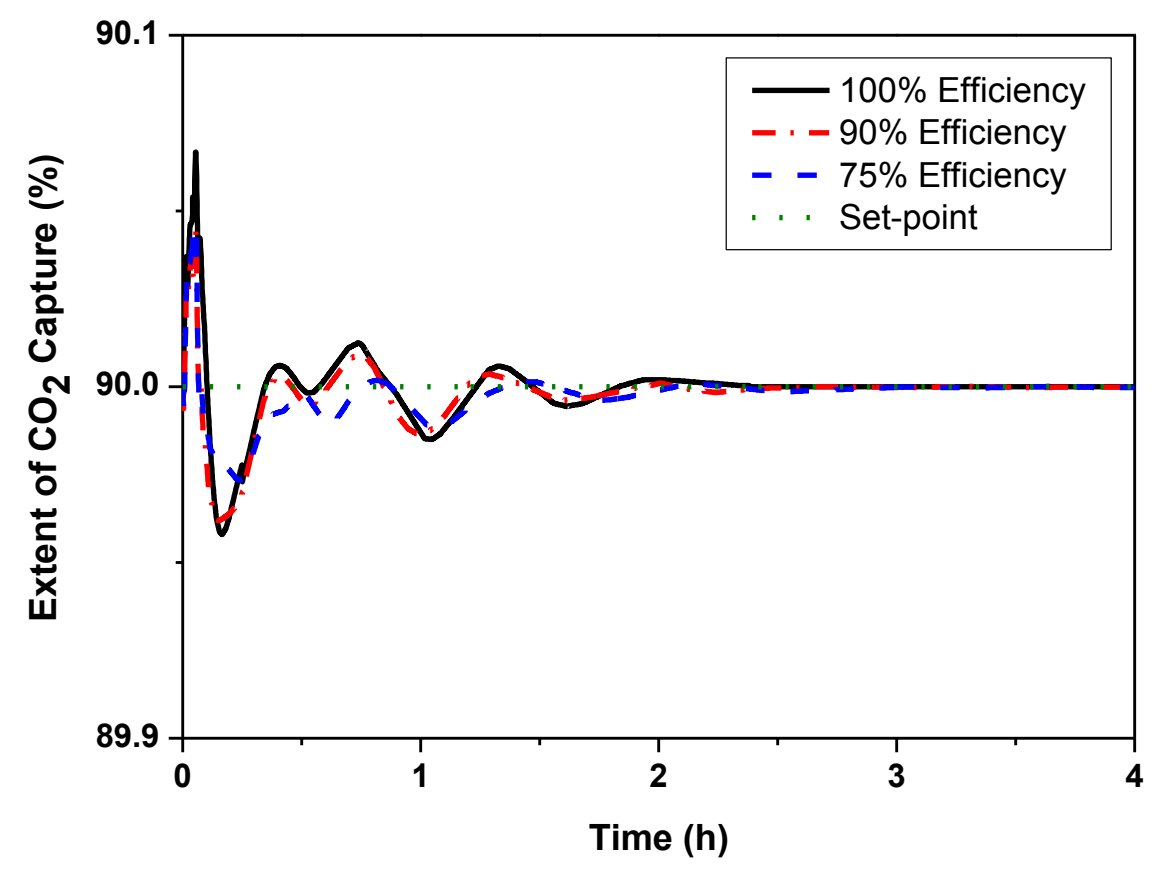

Figure 5.20 Performances of LMPC for $\mathrm{CO}_{2}$ capture control due to 5\% ramp decrease in flue gas flow rate and $\mathrm{CO}_{2}$ composition of flue gas at different $\mathrm{CO}_{2}$ absorber efficiencies 


\subsubsection{Transient Studies for Parallel Trains of $\mathrm{CO}_{2}$ Capture Processes}

Due to the limitations of maximum column size and large flue gas flow rates, multiple parallel trains of $\mathrm{CO}_{2}$ capture processes are required for a 550MWe supercritical coal-fired power plant based on the steady-state process design results. For real industrial processes, the absorbers are usually operated under different conditions and have different performances. In order to mimic the performance variability in a system of parallel trains, different absorber efficiencies were applied to different trains. However, the dynamic simulation and MPC computational speed were found to be significantly lower when more than two parallel trains were simulated. For the simulation of one train of $\mathrm{CO}_{2}$ capture process that is integrated with the power plant, the simulation time is about 3 times slower than real time. The simulation time is about 8 times slower than real time if another train is added. Therefore, only two parallel trains of $\mathrm{CO}_{2}$ capture process were selected for evaluating control performance. It should be noted that each train has its own individual flue gas blower. The fully functional train was assumed to always have an absorber efficiency of $100 \%$. The other train was assumed to have an efficiency of $100 \%$ at the initial condition and the efficiency begins to ramp down to $75 \%$ in a period of $0.25 \mathrm{~h}$. As the $\mathrm{CO}_{2}$ capture process was identified under an absorber efficiency of $100 \%$, the effect of variations in absorber efficiency on $\mathrm{CO}_{2}$ capture efficiency was considered as an unmeasured disturbance and estimated as mentioned earlier. Performances for $\mathrm{CO}_{2}$ capture efficiency using the PID controller and LMPC are shown in Figure 5.21 and 5.22, respectively. Instead of maintaining the $\mathrm{CO}_{2}$ capture efficiency at the desired level for both trains, MPC allows different trains to achieve different individual $\mathrm{CO}_{2}$ capture efficiency to control the overall $\mathrm{CO}_{2}$ capture efficiency. This is mainly due to the correction effect accomplished using the unmeasured disturbance estimator. As the deteriorated train continues to lose its efficiency, the mismatch between the identified model and actual process becomes larger. For the healthy train, the mismatch between the identified model and actual process will basically remain the same. Based on the detected mismatches, the MPC thus can adjust the $\mathrm{CO}_{2}$ capture efficiency for different trains based on different column efficiencies. For variable $\mathrm{CO}_{2}$ capture efficiency in each train for the PID controllers similar to the MPC, an optimization layer above the PID would be needed. In fact, the MPC accomplishes two tasks in this control problem. First, it implicitly sets the desired $\mathrm{CO}_{2}$ capture efficiency for individual trains even though the overall $\mathrm{CO}_{2}$ capture efficiency is considered explicitly as the 
desired output in the control objective. Second, similar to the traditional MPCs, it computes the optimal move of the manipulated variables. It should be noted that in real life the rate of decrease in column efficiency is usually much slower (except of course under some severe circumstances such as sudden carryover of solids from elsewhere or sudden, unexpected mechanical damage in the tower hardware; note even though flooding can lead to such quick change in efficiency, it has been studied separately above) than the rate simulated in this work and the $\mathrm{CO}_{2}$ capture efficiency for each train at steady-state may be different from the results shown in this work. This study is shown for illustration purposes to study the efficacy of the MPC in cases of loss in efficiency.

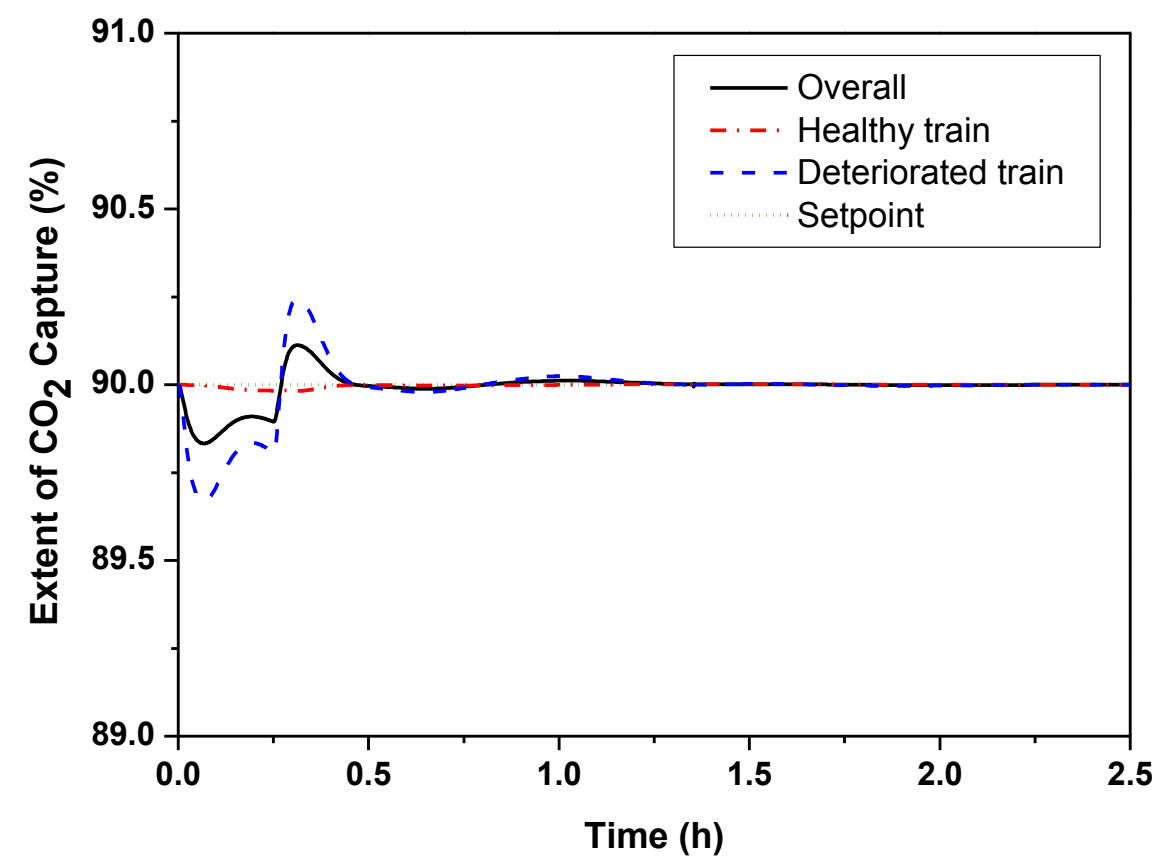

Figure 5.21 PID control performances for $\mathrm{CO}_{2}$ capture control when one absorber's efficiency deteriorates 


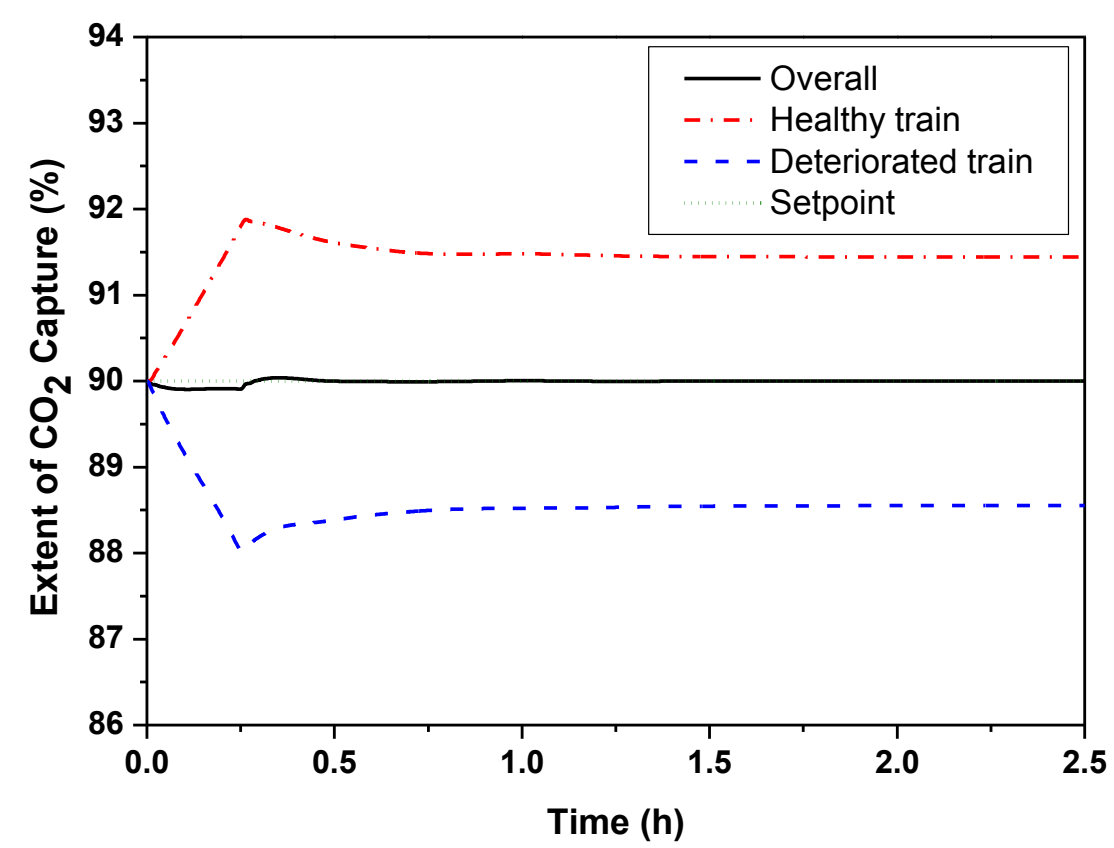

Figure 5.22 LMPC control performances for $\mathrm{CO}_{2}$ capture control when one absorber's efficiency deteriorates

\subsection{LMPC Transient Studies for Integrated System}

The two parallel trains of $\mathrm{CO}_{2}$ capture were then integrated with the simulation of the commercial sized 550MWe supercritical PC plant in Aspen Plus Dynamics ${ }^{\circledR}$. The energy for solvent regeneration is provided by extracted steam from the low-pressure steam turbines. In the operation of a supercritical steam cycle, the pressure and temperature of low-pressure steam will vary subject to different power loadings. This will introduce uncertainties into the identified $\mathrm{CO}_{2}$ capture model as the pressure and temperature of extracted steam were fixed for the system identification process. Therefore, the performance of LMPC may vary under these conditions.

\subsubsection{Transient Studies in Response to Ramp Change in Power Loadings}

A 50\% decrease in power plant load in $0.25 \mathrm{~h}$ was introduced and the performance of both PID and LMPC were evaluated with the $\mathrm{CO}_{2}$ capture efficiency fixed at $90 \%$. The dynamics of overall $\mathrm{CO}_{2}$ capture efficiency are shown in Figure 5.23. The advantage of MPC in reducing 
significant overshoot for $\mathrm{CO}_{2}$ capture control is shown by an improvement of $94 \%$ in control performance from the integral square error (ISE) analysis. However, almost the same time is required to achieve steady-state for both controllers. As the operating point moves further from the design condition, the inaccuracy of the identified linear model becomes significant and it takes the LMPC more time to eliminate the offset. Since the steam cycle has a shorter response time (on the time scale of seconds) than the $\mathrm{CO}_{2}$ capture process (on the time scale of minutes for $\mathrm{CO}_{2}$ capture efficiency and hours for reboiler temperature), stripper reboiler temperature will drop quickly as the temperature and pressure of low pressure steam decrease when the plant load is ramping down. It should be noted that the reboiler temperature takes much longer to settle for variations in the $\mathrm{CO}_{2}$ capture process. Based on the transient responses of the $\mathrm{CO}_{2}$ stripper reboiler temperature (Figure 5.24) for the integrated system, it is hard to say that the performance of LMPC is significantly superior to PID control.

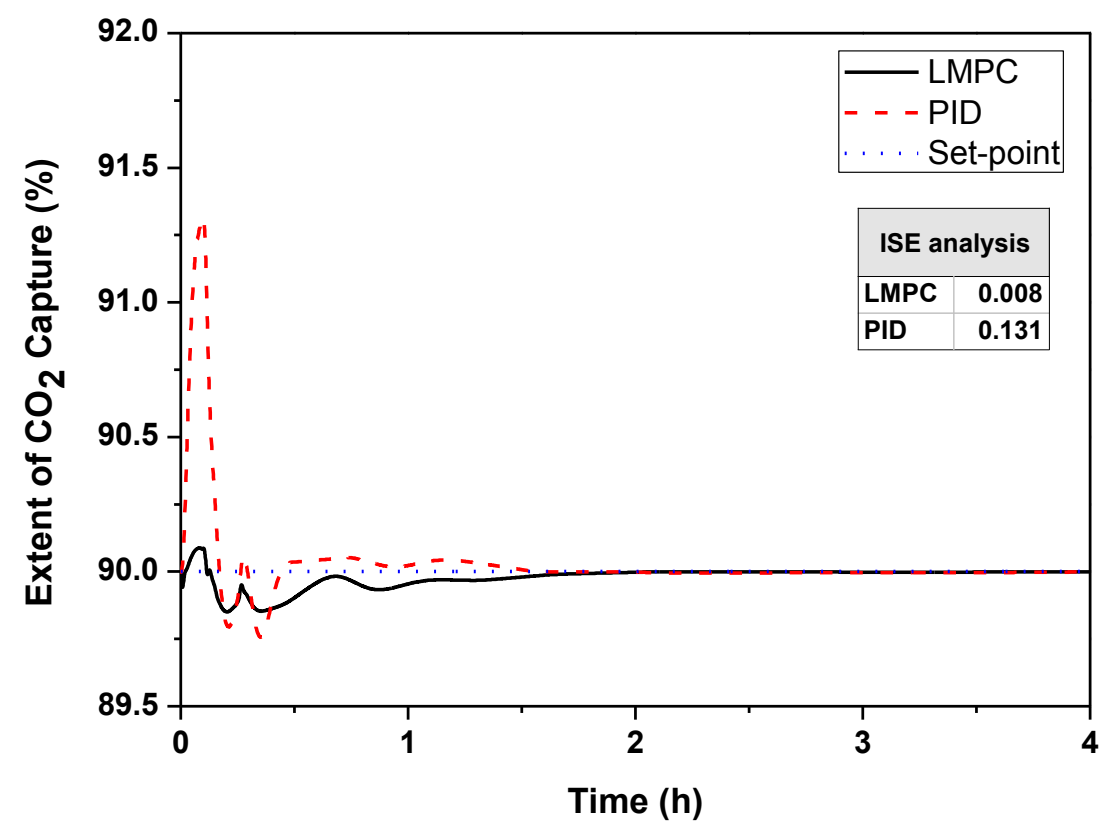

Figure 5.23 Performances of LMPC and PID for overall $\mathrm{CO}_{2}$ capture control due to 50\% ramp decrease in power plant load for integrated system 


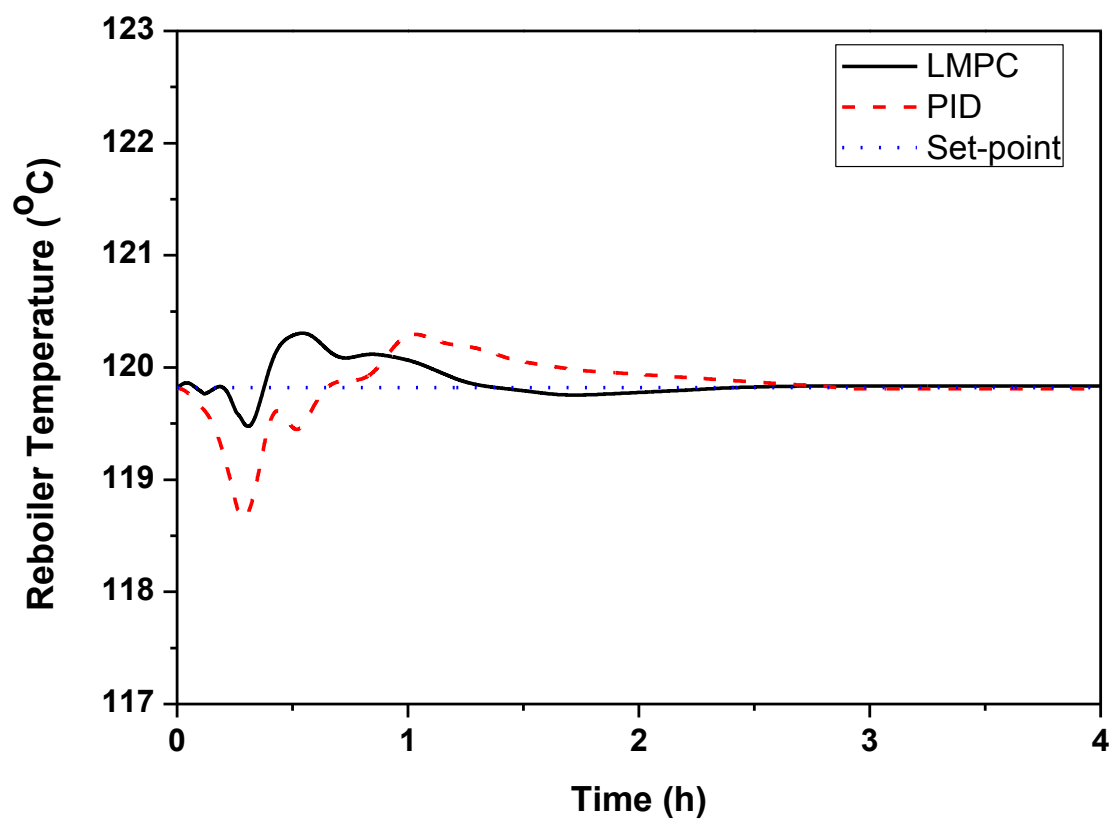

Figure 5.24 Performances of LMPC and PID for stripper reboiler temperature control due to $50 \%$ ramp decrease in power plant load for integrated system

The dynamic performance of $\mathrm{CO}_{2}$ capture efficiency was then evaluated for PID and LMPC by simultaneously ramping down the power plant load to $50 \%$ over $0.2 \mathrm{~h}$ and $\mathrm{CO}_{2}$ capture efficiency target to $70 \%$ over $0.05 \mathrm{~h}$. Figure 5.25 shows the dynamic performance of the $\mathrm{CO}_{2}$ capture efficiency. Performance of the LMPC is still superior to PID with an improvement of 79.4\% from the ISE analysis. For the $\mathrm{CO}_{2}$ reboiler temperature control, similar control performances were found for similar reasons as discussed above. 


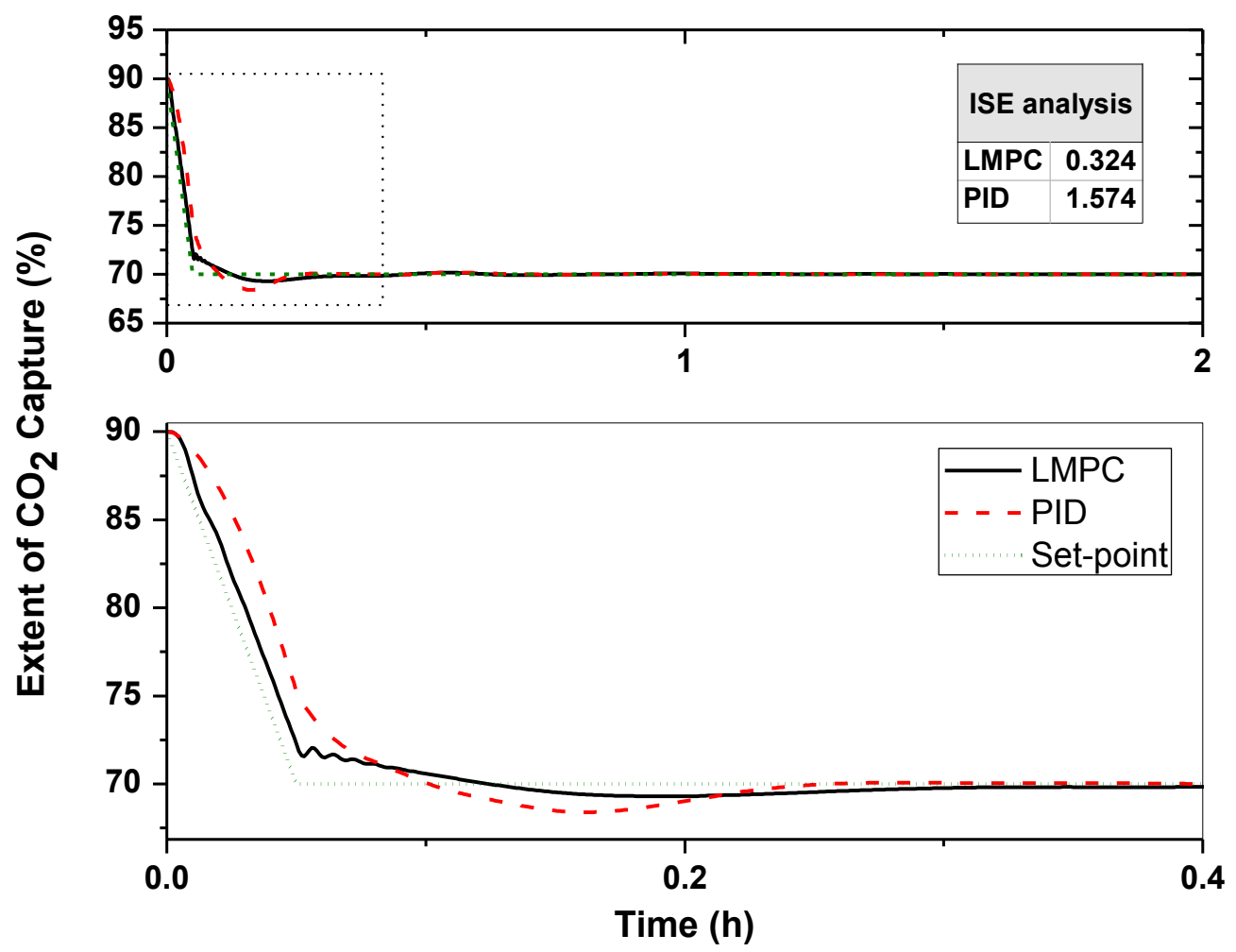

Figure 5.25 Dynamic performances of LMPC and PID for overall $\mathrm{CO}_{2}$ capture control due to $50 \%$ ramp decrease in power plant load while ramping down $\mathrm{CO}_{2}$ capture target to $70 \%$ for integrated system 


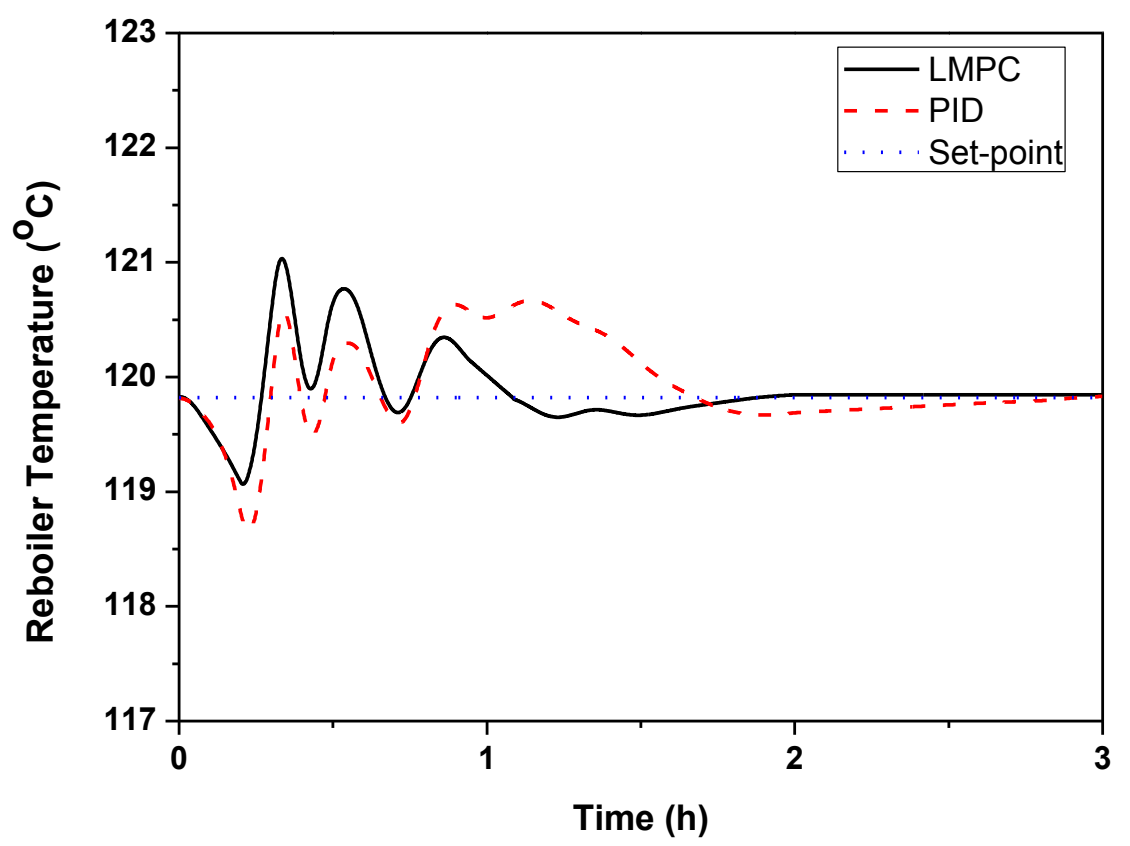

Figure 5.26 Dynamic performances of LMPC and PID for $\mathrm{CO}_{2}$ stripper reboiler temperature control due to 50\% ramp decrease in power plant load while ramping down $\mathrm{CO}_{2}$ capture target to $70 \%$ for integrated system

For both cases, the maximum deviation in $\mathrm{CO}_{2}$ capture efficiency can be found to be $1.3 \%$ for fixed capture target and 5\% for varying target for PID control. A supercritical pulverized coal plant producing 550MWe net power emits about $3 \mathrm{MM}$ tonne of $\mathrm{CO}_{2}$ per year. $1 \%$ deviation in the percentage capture target will lead to emission of about 30,000 tonne of $\mathrm{CO}_{2}$ per year. Even with a low penalty per tonne of $\mathrm{CO}_{2}$ emission, a $1 \%$ deviation from the target can quickly add up to a large dollar amount. The effects may be more pronounced depending on the magnitude and frequency of variations in the load. On the other hand, capturing more than the target will lead to loss in efficiency and therefore will directly affect the profitability of the power plant. While an economic study would be needed to fully evaluate these tradeoffs and such a study is beyond the scope of this work, it is imperative that the setpoint from such economic optimizer should be followed reasonably accurately. 


\subsubsection{Transient Studies in Response to Random Changes in Power Loadings}

In order to study the controller performance in response to continuously differing disturbances over time, a random input signal (Figure 5.27) of power plant load was introduced. The random input signal was selected to be smooth without significant change in plant load to ensure the dynamic simulation results converged when each step change is introduced. In this way, the performance of the control system is evaluated under strong variation in power production that would be required in a smart grid scenario. The variations that would be acceptable by a power plant operator would definitely depend on the economics that needs to take into account, among other things, the impact of such changes on the equipment and the additional revenue due to high real-time price of electricity. Because such economic studies are outside the scope of this work, the performance of control system under variability of input to the $\mathrm{CO}_{2}$ capture process was mainly investigated. The dynamics of the overall $\mathrm{CO}_{2}$ capture efficiency and stripper reboiler temperature are shown in Figures 5.28 and 5.29. The LMPC still provides good performance by avoiding the significant overshoot or undershoot of $\mathrm{CO}_{2}$ capture efficiency exhibited by the PID controller.

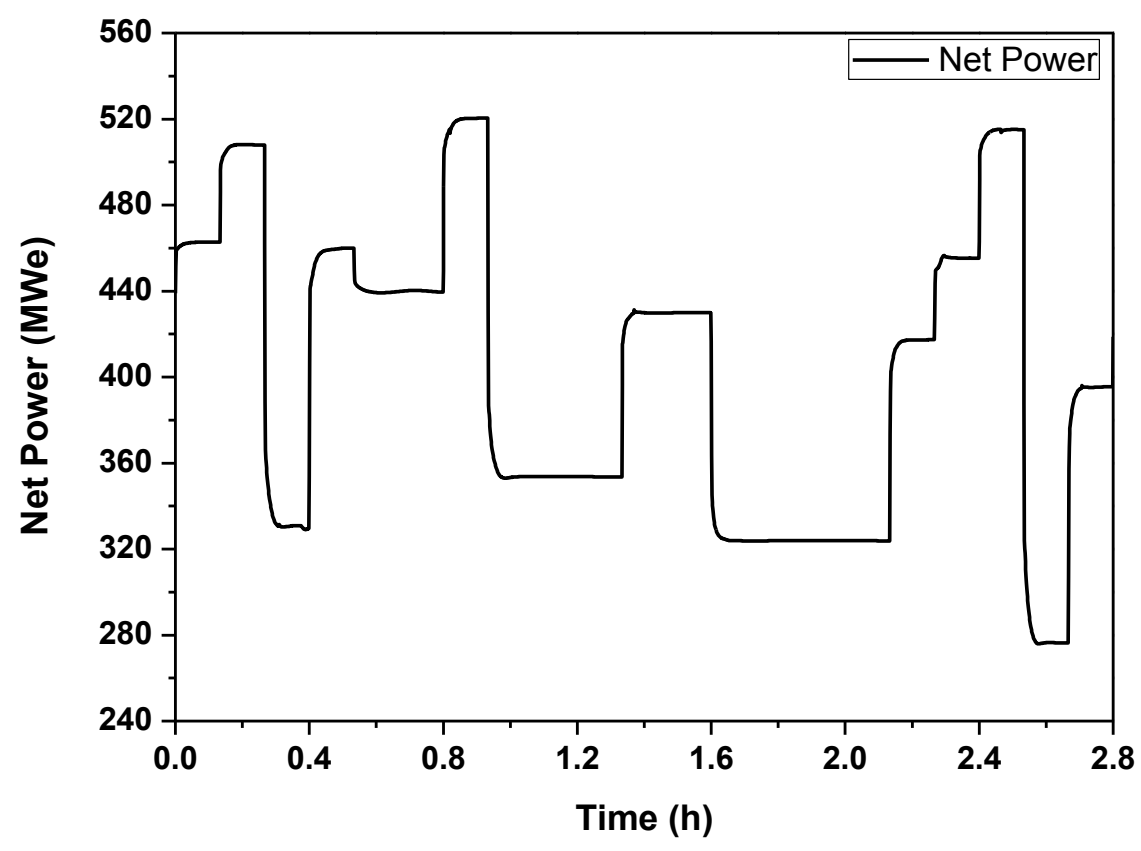

Figure 5.27 Implemented random input signal of power plant load for integrated system 


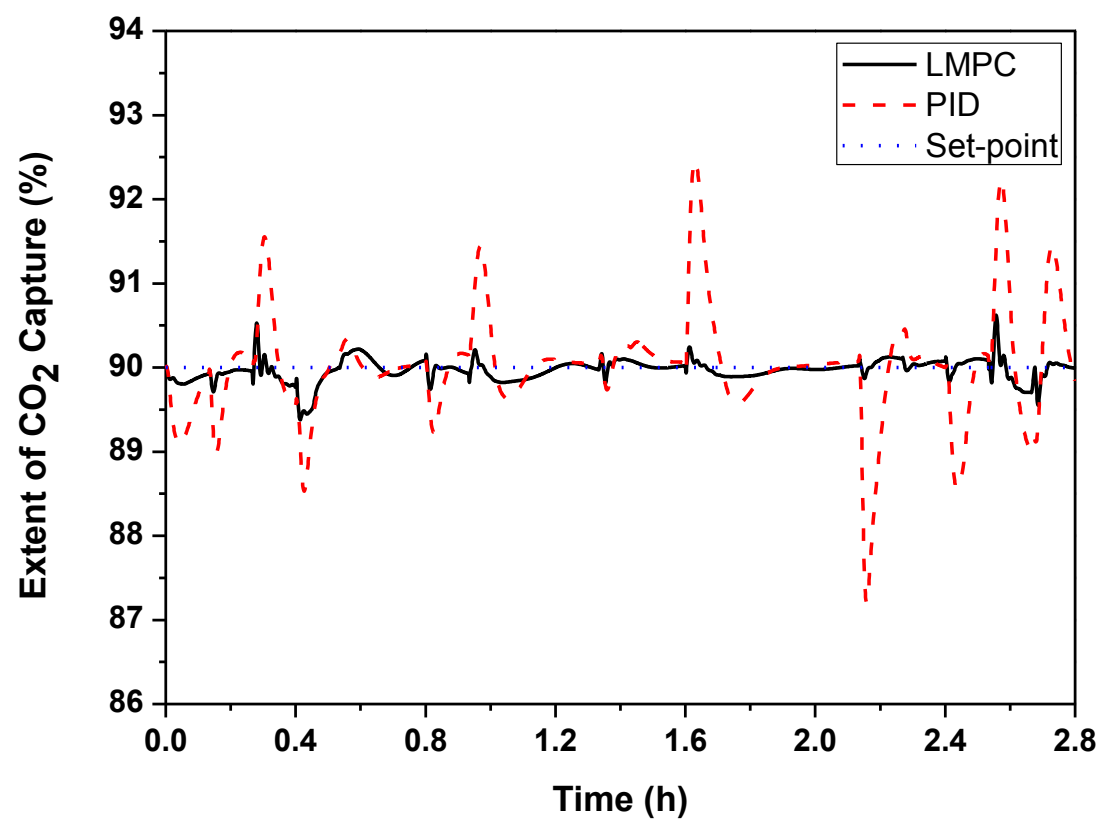

Figure 5.28 $\quad \mathrm{CO}_{2}$ capture control performances of LMPC and PID due to a random input signal of power plant load for integrated system

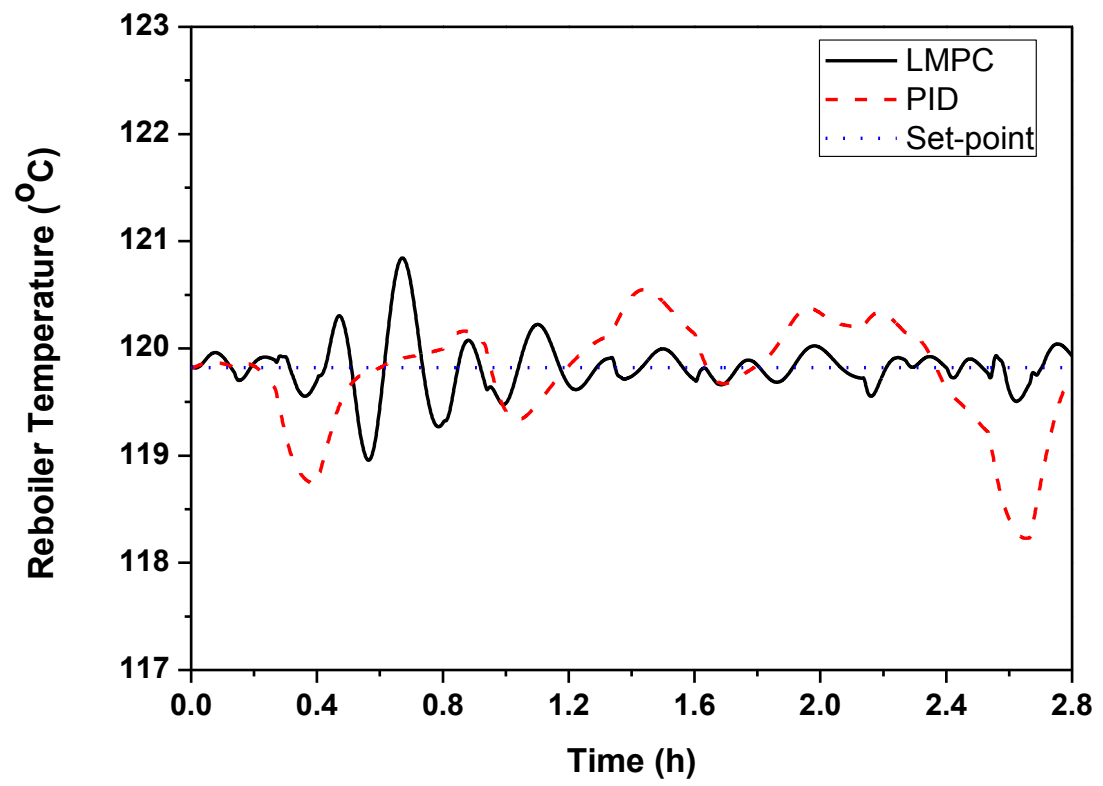

Figure 5.29 $\mathrm{CO}_{2}$ stripper reboiler temperature control performances of LMPC and PID due to a random input signal of power plant load for integrated system 


\section{NONLINEAR MODEL PREDICTIVE CONTROL}

$\mathrm{CO}_{2}$ capture using chemical absorption is inherently nonlinear. When the integration of the power plant and the $\mathrm{CO}_{2}$ capture process is considered, the situation also becomes more complicated. For example, for a load-following power plant with sliding pressure operation, as the flue gas flow rate changes in response to the load changes, there is a corresponding change in the pressure and temperature of the low-pressure steam available for the $\mathrm{CO}_{2}$ stripper reboiler. Since the time constants for the $\mathrm{CO}_{2}$ capture process are much longer than for the power plant and the loading of the MEA is strongly influenced by the stripper reboiler temperature, the response of the overall system becomes highly non-linear. The considerable time delay in the process and strong interactions between multiple variables also increase the nonlinearity of the $\mathrm{CO}_{2}$ capture process. The performance of LMPC may be limited when the nonlinearity becomes significant and Nonlinear Model Predictive Control (NMPC) is preferred. In this chapter, an NMPC-based control method is applied to the post-combustion $\mathrm{CO}_{2}$ capture processes. The nonlinear $\mathrm{CO}_{2}$ capture process model is identified as a nonlinear additive autoregressive model with exogenous variables (NAARX model). The control performance is evaluated and compared with the LMPC-based approach in the face of disturbances in power plant load and the $\mathrm{CO}_{2}$ capture target.

\subsection{System Identification for NMPC}

NMPC is conceptually similar to LMPC except that nonlinear dynamic models, such as neural networks, reduced deterministic, Hammerstein-Wiener and NAARX models are used for system prediction and online optimization. NAARX model is preferred because the model parameters can be easily checked. The NAARX model also provides good representation of time series, learning capability, and generalization performance (Lin et al., 1996; Lin et al., 1997). In this chapter, the $\mathrm{CO}_{2}$ capture efficiency and $\mathrm{CO}_{2}$ stripper reboiler temperature models were identified as nonlinear models in the form of NAARX model, which is given by Equation (6.1). 


$$
y(k)=\sum_{i=0}^{n} f_{i}(u(k-i))+\sum_{j=1}^{m} s_{j}(y(k-j))
$$

Where:

$y=$ model outputs;

$u=$ model inputs;

$f=$ input polynomials of order $P$;

$s=$ output polynomials of order $Q$;

$n=$ input memory;

$m=$ output memory;

$k=$ the current time step.

Equation (6.1) can be rewritten as Equation (6.2) when cross-terms are considered.

$$
\begin{aligned}
& y(k)=\sum_{i=0}^{n} H_{1}(i, p) u(k-i)^{p}+\sum_{j=1}^{m} H_{2}(j, q) y(k-j)^{q} \\
& \quad+\sum_{i=0}^{n} \sum_{j=0}^{n} H_{3}(i, j) u(k-i) u(k-j)+\cdots \sum_{i=0}^{n} \ldots \sum_{l=0}^{n} H_{P+1}(i, \ldots, l) u(k-i) \ldots u(k-l), \\
& p=1: P, q=1: Q
\end{aligned}
$$

Where:

$H=$ parameter vector.

In this work, $P$ and $Q$ are set to be $2, n$ and $m$ are set to be 1 . In order to comprehensively capture the dynamic characteristics of the $\mathrm{CO}_{2}$ capture process, maximum length sequence (MLS) signals, which are a type of PRBS signals were used to excite the process. The system outputs, $\mathrm{CO}_{2}$ capture efficiency, and $\mathrm{CO}_{2}$ stripper reboiler temperature were then recorded for system identification. The register length of MLS is defined as $N=2^{k}-1$, where $k$ is the order of the dynamic $\mathrm{CO}_{2}$ capture process model. For the Aspen Plus Dynamics ${ }^{\circledR}$ model used in this work, $k$ is 6 based on the state dimensional analysis. The register length of MLS is then determined as 63 . Therefore, the MLS is expected to have 32 ones and 31 zeros. In order to ensure the convergence 
of the Aspen Plus Dynamics ${ }^{\circledR}$ model over the tested sequence, the signal amplitude again was set to be variable (random value between 0 and 1) instead of either 1 or 0 at each step. The variableamplitude MLS signals used for flue gas flow rate, $\mathrm{CO}_{2}$ composition in flue gas, low pressure steam flow rate, and lean solvent flow rate are shown in Figures 6.1 and 6.2.

The NAARX models with cross-terms were then compared with the linear first-order process models from the previous chapter. Figure 6.3 shows comparisons between the outputs of the dynamic simulation, the identified linear, and the nonlinear models. It can be seen that both linear and nonlinear models cannot predict the outputs of the dynamic simulation accurately when the operating range is wide $\left(\mathrm{CO}_{2}\right.$ capture efficiency varies from $18.6 \%$ to $99.5 \%, \mathrm{CO}_{2}$ stripper reboiler temperature varies from $112.4^{\circ} \mathrm{C}$ to $126.2^{\circ} \mathrm{C}$ ). However, the nonlinear models are slight better than the linear models based on the Akaike information criterion (AIC; Akaike, 1974) values (Table 6.1), where smaller AIC values are preferred.

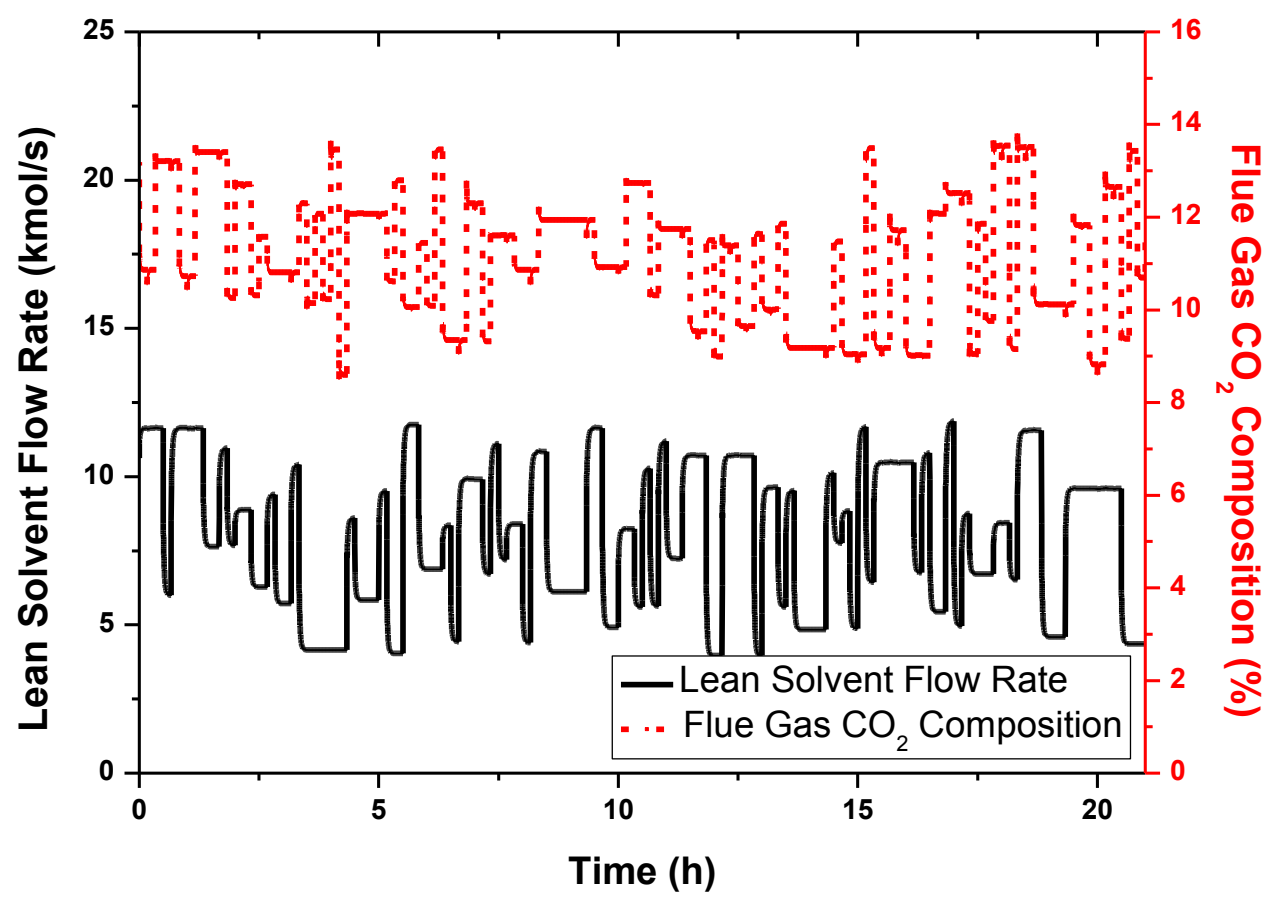

Figure 6.1 Implemented variable MLS signals of lean solvent flow rate and $\mathrm{CO}_{2}$ composition of flue gas for system identification 


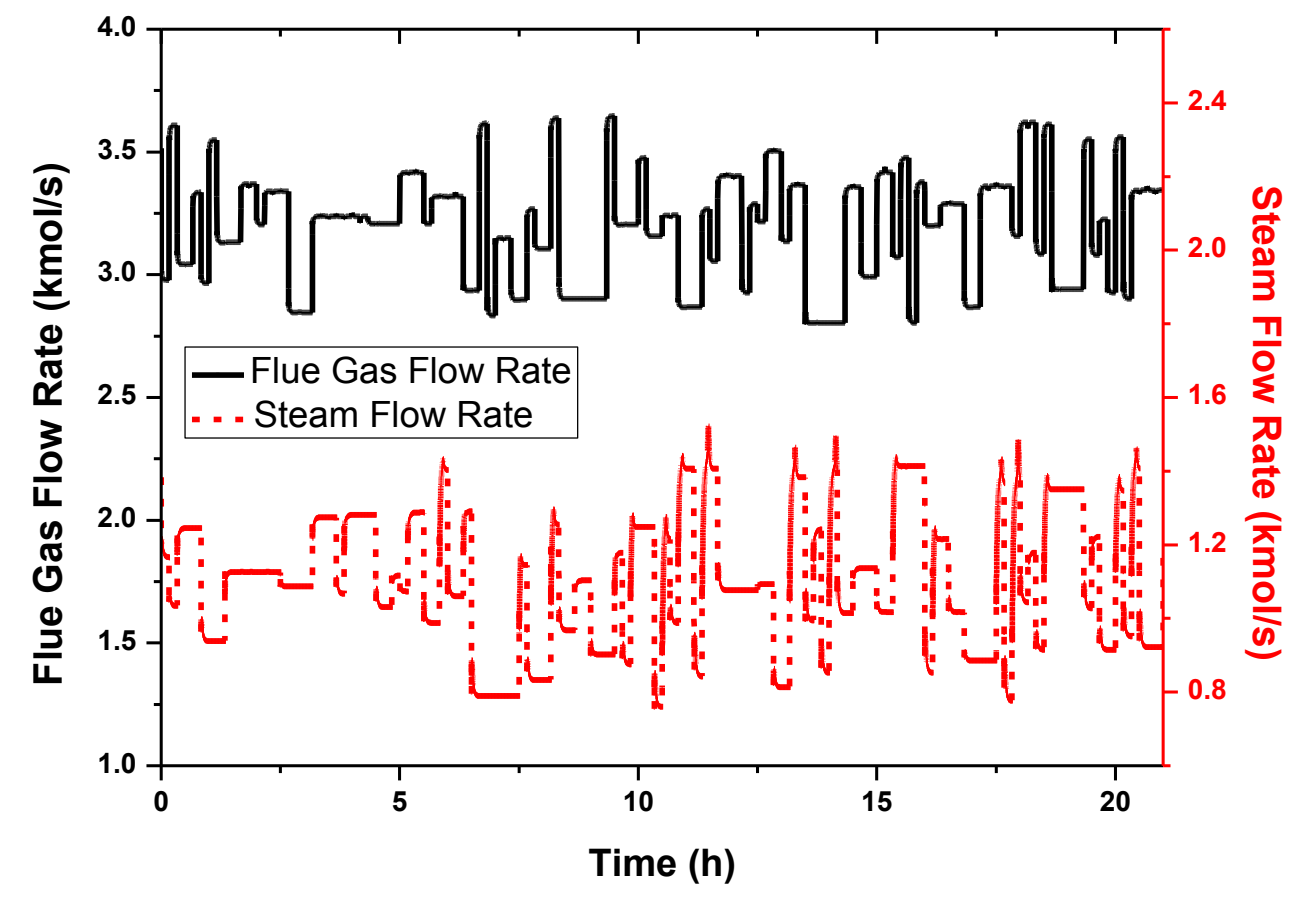

Figure 6.2 Implemented variable MLS signals of flue gas flow rate and steam flow rate for system identification

Table 6.1 AIC Values for Linear and Nonlinear Models

\begin{tabular}{lcc}
\hline & $\mathrm{CO}_{2}$ capture model & reboiler temperature model \\
\hline First-order linear process model & 3.6571 & -0.1055 \\
NAARX with cross-terms & -3.7617 & -8.7520 \\
\hline
\end{tabular}



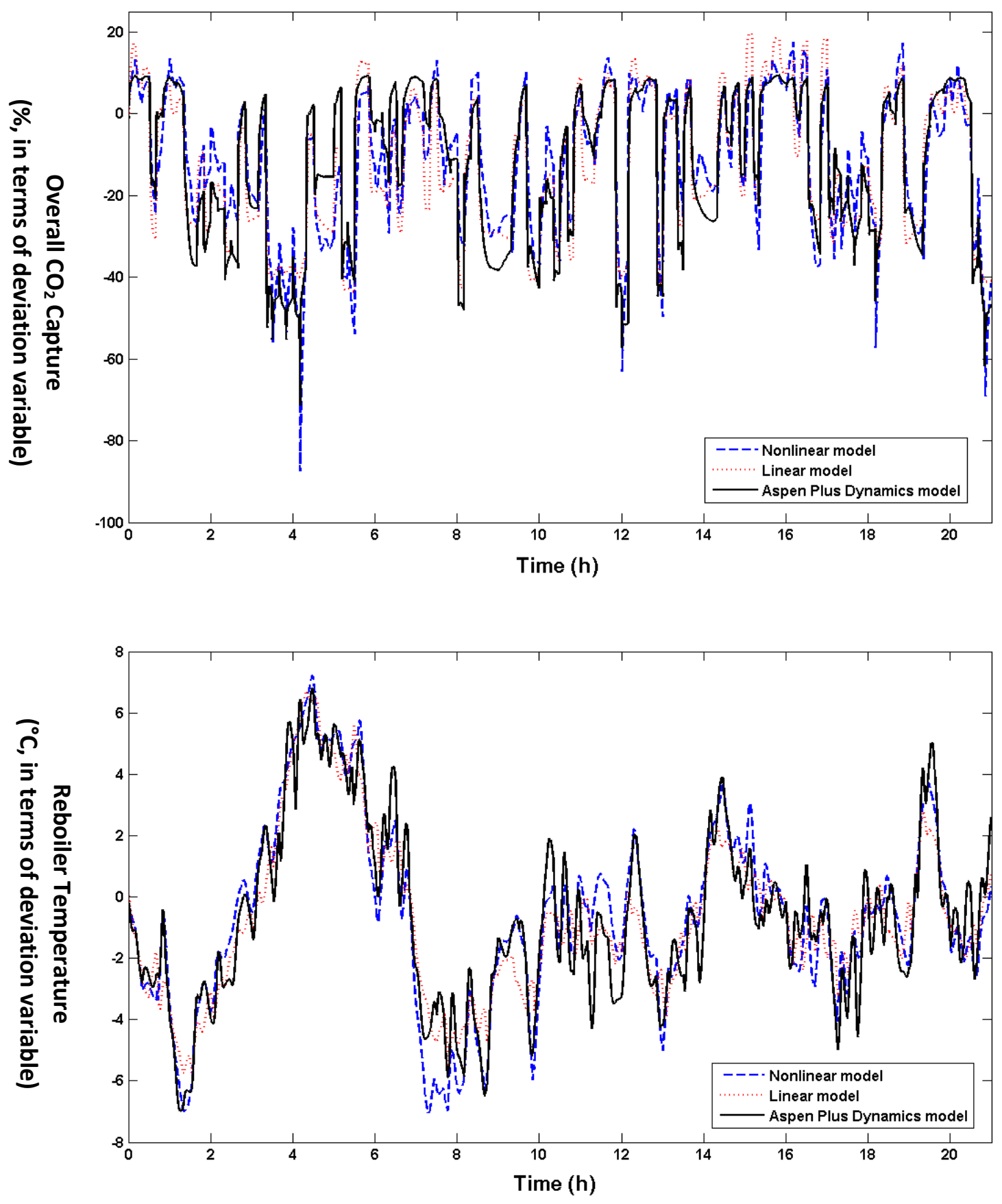

Figure 6.3 Comparisons between Aspen Plus Dynamics ${ }^{\circledR}$ and identified process models, (upper): $\mathrm{CO}_{2}$ capture efficiency, deviates from $90 \%$ (lower): $\mathrm{CO}_{2}$ stripper reboiler temperature, deviates from $120^{\circ} \mathrm{C}$ 


\subsection{Configuration of NMPC}

The NMPC is implemented in Matlab Simulink with the same flowsheet as shown in Figure 5.13. The linear first-order process model used for system prediction and optimization is replaced by the NAARX model with cross-terms. Weights for $\mathrm{CO}_{2}$ capture efficiency, $\mathrm{CO}_{2}$ stripper reboiler temperature, $\Delta F_{\text {solvent, }}$ and $\Delta F_{\text {steam }}$ are 1, 1, 10, and 10, respectively. Prediction and control horizons are $0.01 \mathrm{~h}$ and $0.002 \mathrm{~h}$, respectively. The manipulated input constraints are the same as shown in Table 5.1. The mismatch between process model and actual plant is assumed to be due to random, zero-mean white noise, which is estimated using the advanced estimation feature available in the MATLAB MPC toolbox.

\subsection{NMPC Transient Studies}

In this section, the control performance of the LMPC and NMPC are evaluated under two scenarios: ramp changes in the supercritical PC plant power output, and ramp changes in both supercritical PC plant power output and desired $\mathrm{CO}_{2}$ capture targets.

\subsubsection{Transient Studies in Response to Ramp Changes in Power Plant Load}

In the transient studies from the previous chapter, the input disturbances considered for the integrated system are the ramp and random step changes in power plant load. In the operation of a PC plant, the load is usually ramped up or down following the requirement of grid. Therefore, the step changes in plant load cannot be justified during the normal operation of a power plant. However, closed-loop response to step changes in power plant load can be used to evaluate the control performance in the face of strong variations in the flue gas flow, which is the subsequent result of load changes. Motivated by the justification for the evaluation of $\mathrm{CO}_{2}$ capture process in the normal operation of a power plant, in the following case studies, the disturbances to the $\mathrm{CO}_{2}$ capture process from the supercritical PC plant are assumed to be ramp changes in the power plant load. The average and maximum plant load ramp rates for a 540MWe supercritical PC power plants have been reported to be $1.1 \% / \mathrm{min}$ and $3.6 \% / \mathrm{min}$, respectively, based on a survey where data were collected from a large number of units (Fenton, 1982). Although the survey is somewhat old, it can be seen that the average ramp rate is approximately $1 / 3$ of the maximum ramp rate. It should be noted that an increase in the plant load ramp rate would increase the wear 
and maintenance cost of the power plant. Therefore, the ramp rate is usually limited during normal operation. Modern supercritical power plants usually have much faster design load ramp rates, for example $5 \% / \mathrm{min}$ to $8 \% / \mathrm{min}$, than the older power plants when the power load varies from $50 \%$ to $100 \%$ (Lindsay and Dragoon, 2010). In this case, the power plant load ramp rate is assumed to be $1.7 \% / \mathrm{min}$, which is $1 / 3$ of $5 \% / \mathrm{min}$. The plant load is assumed to decrease form $100 \%$ to $50 \%$. The $\mathrm{CO}_{2}$ capture target is fixed at $90 \%$. System dynamics are shown in Figures 6.4 and 6.5. Both MPCs provided superior performance in comparison to the PID controller in disturbance rejection for $\mathrm{CO}_{2}$ capture control and $\mathrm{CO}_{2}$ stripper reboiler temperature control. Although no significant deviation in reboiler temperature is seen for NMPC, the magnitude of deviation in reboiler temperature is also small $\left(\leq 0.2^{\circ} \mathrm{C}\right)$ for LMPC. Based on these findings, control performances of LMPC and NMPC are similar in response to a 50\% ramp decrease in power plant load.

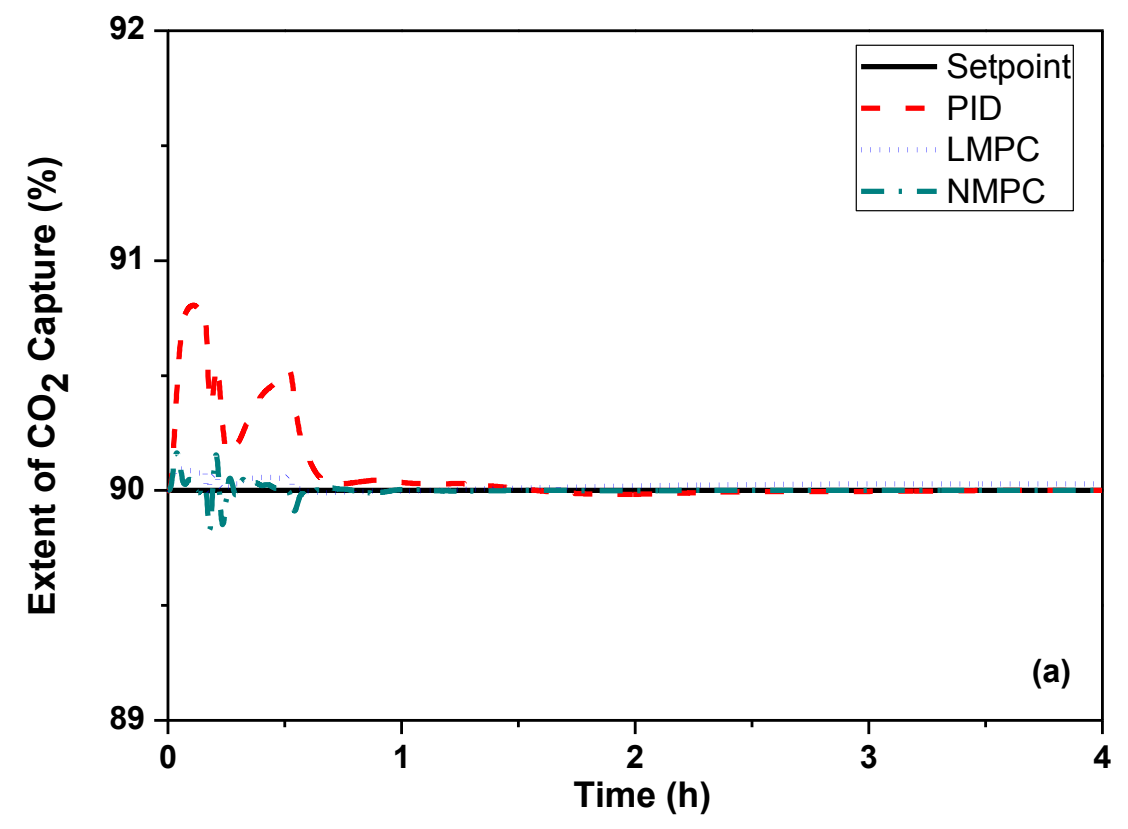

Figure 6.4 Dynamics of $\mathrm{CO}_{2}$ capture efficiency for MPCs and PID in response to 50\% ramp decrease in power plant load 


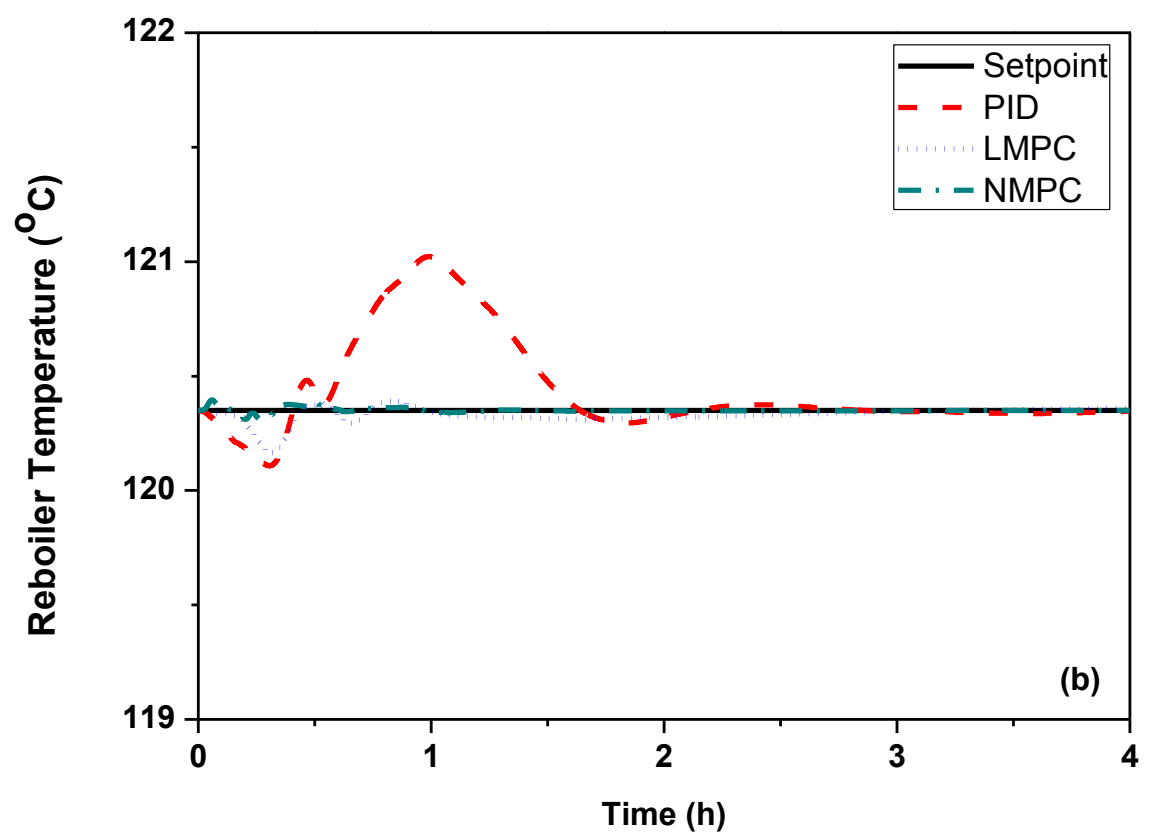

Figure 6.5 Dynamics of $\mathrm{CO}_{2}$ stripper reboiler temperature for MPCs and PID in response to $50 \%$ ramp decrease in power plant load

\subsubsection{Transient Studies in Response to Simultaneous Ramp Changes in the Power Plant Load and $\mathrm{CO}_{2}$ Capture Target}

In this case, output disturbance is also considered as the $\mathrm{CO}_{2}$ capture set point is reduced from $90 \%$ to $30 \%$ in $0.15 \mathrm{~h}$, along with the same input disturbance of ramping down the power plant load to $50 \%$ load in $0.5 \mathrm{~h}$. A strong variation in the lean solvent flow rate is expected as much less $\mathrm{CO}_{2}$ needs to be captured. As shown in Figure 6.6, both MPCs performed better than PID controller in reference tracking. According to Figure 6.7, the performances of MPCs in $\mathrm{CO}_{2}$ stripper reboiler temperature control are similar to PID control. Large deviations are seen for all three controllers and the settling times are more than $1 \mathrm{~h}$. This behavior is in part due to the different time constants for $\mathrm{CO}_{2}$ absorber and stripper. The lean solvent flow rate decreases quickly in response to a significant reduction in the amount of captured $\mathrm{CO}_{2}$. Subsequently, the amount of rich solvent entering the $\mathrm{CO}_{2}$ stripper decreases quickly resulting in a steep decrease in the energy demand in the $\mathrm{CO}_{2}$ stripper. However, the regulation of low pressure steam is slow as the flow change rate is limited, in order to reduce the disturbance introduced into the steam cycle 
due to steam extraction. Due to the power plant operation, there is a lower bound on the steam flow rate (Figure 6.8). The $\mathrm{CO}_{2}$ stripper also has a high thermal capacity. With all these factors, the accumulation of thermal energy in the $\mathrm{CO}_{2}$ stripper is significant and leads to poor performance in the $\mathrm{CO}_{2}$ stripper reboiler temperature control for PID and both MPCs.

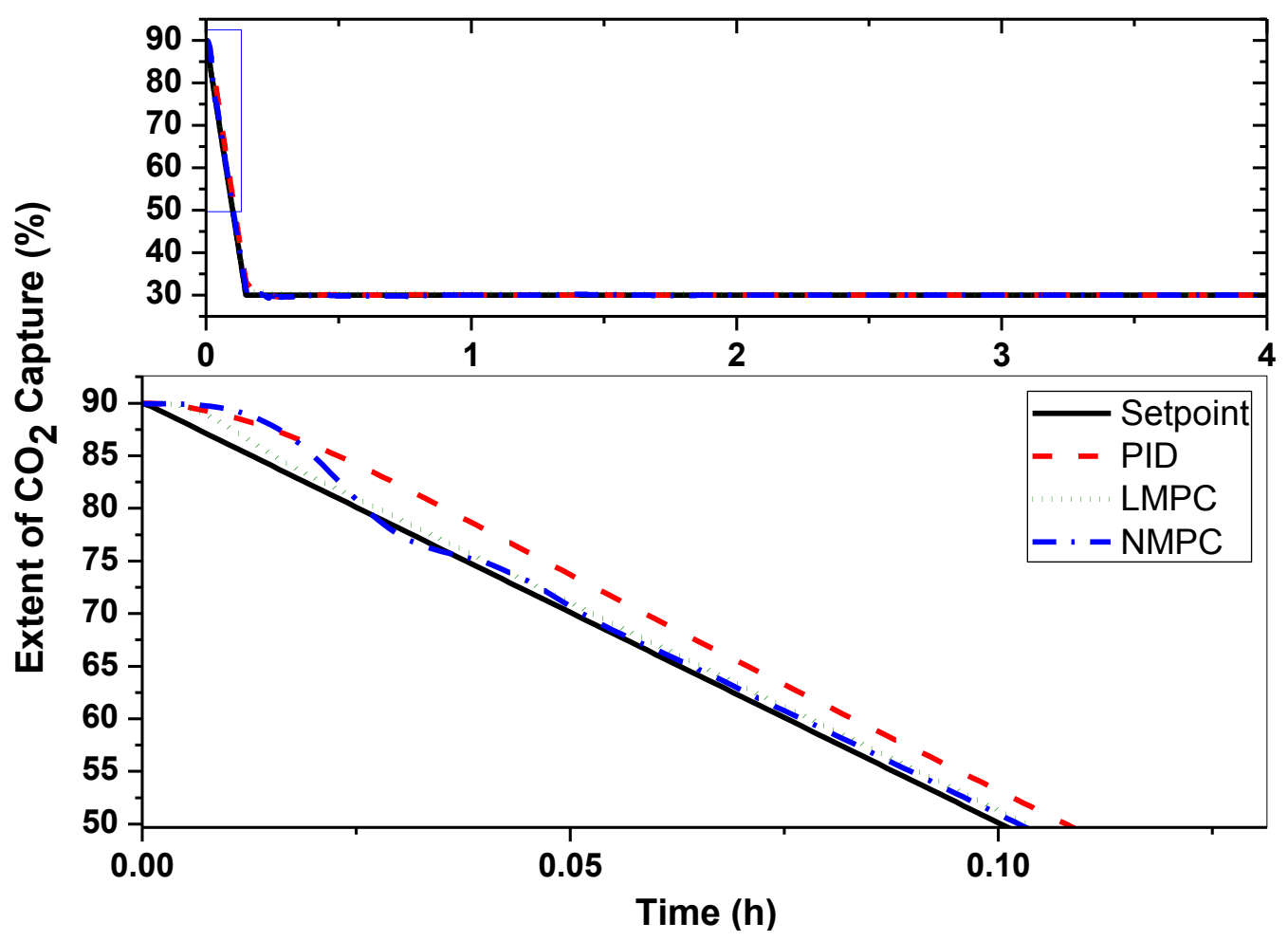

Figure 6.6 Dynamics of $\mathrm{CO}_{2}$ capture efficiency for MPCs and PID in response to 50\% ramp decrease in power plant load and reduction in $\mathrm{CO}_{2}$ capture target 


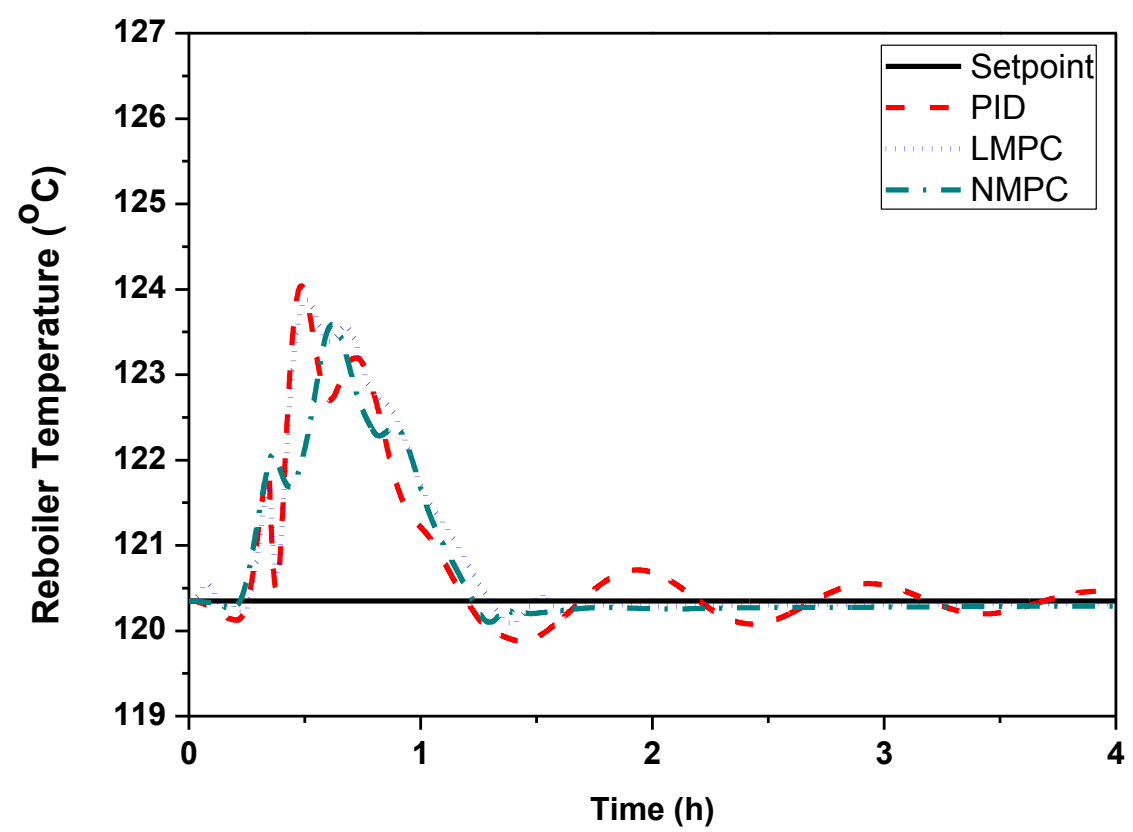

Figure 6.7 Dynamics of $\mathrm{CO}_{2}$ stripper reboiler temperature for MPCs and PID in response to $50 \%$ ramp decrease in power plant load and reduction in $\mathrm{CO}_{2}$ capture target

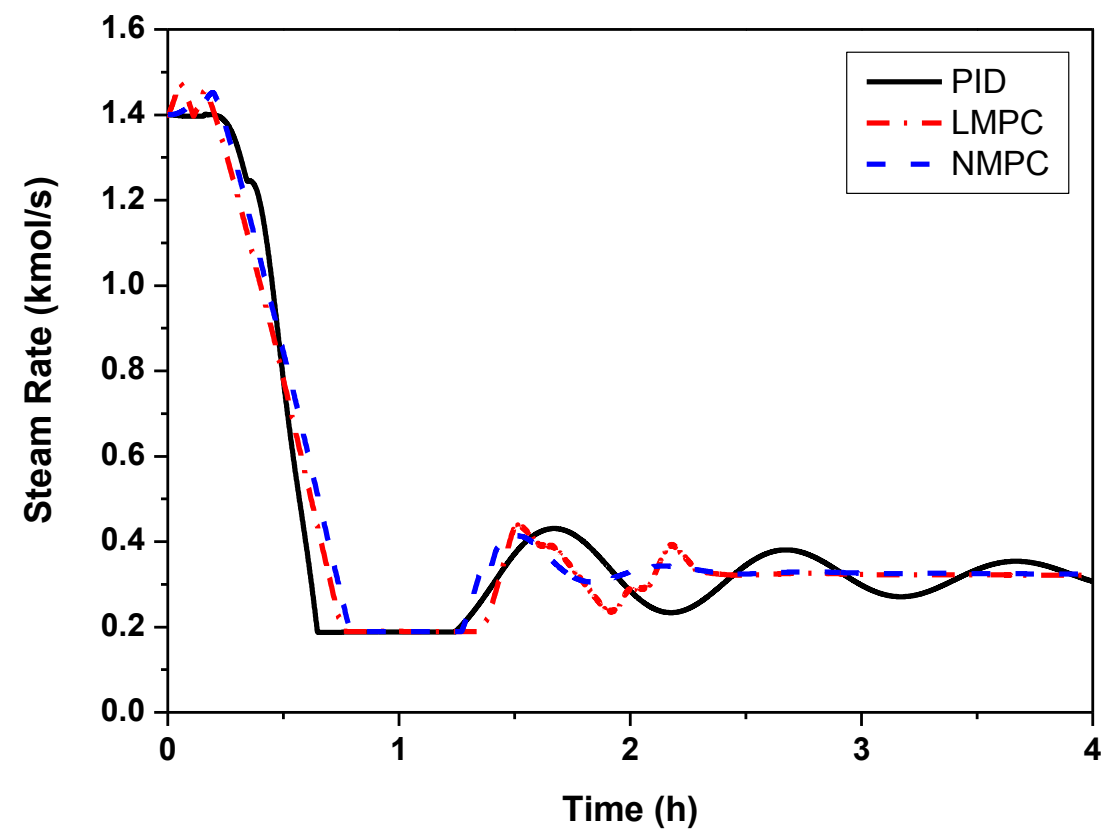

Figure 6.8 Transients of low pressure steam flow in response to $50 \%$ ramp decrease in power plant load and reduction in $\mathrm{CO}_{2}$ capture target 
The integral squared error (ISE) analysis for Cases in Sections 6.3.1 and 6.3.2 are shown in Table 6.2, the NMPC performs better than the other controllers in $\mathrm{CO}_{2}$ capture control with the smallest ISE values. For stripper reboiler temperature control, both MPCs provide better control performance than PID controller during a load-following operation with the fixed $\mathrm{CO}_{2}$ capture target. When there is a significant change in the $\mathrm{CO}_{2}$ capture target, the strong disturbance from the absorber makes the control performance similar for three controllers.

Table 6.2 Integral Square Error Analysis for PID, LMPC and NMPC

\begin{tabular}{lcc}
\hline & $\mathrm{CO}_{2}$ capture control & reboiler temperature control \\
\hline Case in Section 6.3.1 & 0.137 & 0.2157 \\
PID & 0.004 & 0.0060 \\
LMPC & 0.002 & 0.0003 \\
NMPC & & \\
Case in Section 6.3.2 & 1.749 & 3.921 \\
PID & 0.512 & 4.685 \\
LMPC & 0.321 & 3.404 \\
NMPC & & \\
\hline
\end{tabular}




\section{H-INFINITY $\left(H_{\infty}\right)$ ROBUST CONTROL}

An industrial control system should perform satisfactorily to meet certain performance criteria in the face of plausible disturbances, measurement noise, and model mismatch due to the difference between the actual process and the mathematical model in the simulation environment used for controller design. Motivated by the goal to guarantee closed-loop stability in the presence of model errors and uncertainties in real process industries, $H_{\infty}$ robust control theory was proposed in the early 1980 s to address the robustness issue and is still used today. In this chapter, an $H_{\infty}$ robust control system is designed for the post-combustion $\mathrm{CO}_{2}$ capture process. The model uncertainties are quantified and considered in the form of multiplicative input uncertainty. The original nonlinear model used as the plant in the closed-loop configuration is taken from the Aspen Plus Dynamics ${ }^{\circledR}$ model developed in Chapter 4. A linear process model is used in the design of a 2-degree-of-freedom (2DOF) $H_{\infty}$ controller. A reduced order controller is then found that preserves the robust performance of the closed-loop system. The control performance of the reduced order $H_{\infty}$ controller is finally evaluated and compared with NMPC in the face of disturbances and uncertainties.

\subsection{Robust Control of the Post-Combustion $\mathrm{CO}_{2}$ Capture Process}

Consider a standard control configuration as shown in Figure 7.1 in which $P$ denotes the generalized plant and $K$ denotes the controller. External input $w$, which consists of reference signals and disturbances, and manipulated inputs $u$ are the inputs to the plant. Error signal $z$ and measured variable $v$ are the outputs. Based on the information in $v$, controller $K$ produces the control signal $u$ so that $K$ and $P$ compose a closed-loop system. A partition of $P$ is written as follows:

$$
P=\left[\begin{array}{ll}
P_{11} & P_{12} \\
P_{21} & P_{22}
\end{array}\right]
$$


The controller $K$ can be incorporated with the plant $P$ using the lower linear fractional transformation (LLFT), which is shown as Equation (7.1). The overall objective of robust control design is to find a controller $K$ so that the peak value of the transfer function from $w$ to $z$, $\left\|T_{w z}\right\|_{\infty}$ is minimized. The peak value is defined as $\|G\|_{\infty}=\max _{\omega \in R} G(j \omega)$, where $G$ denotes the transfer function. If the peak value $\|G\|_{\infty}$ of the signal transfer function is small, the magnitude of $G$ would be small for any frequency $(\omega)$. Therefore, the influence of $w$ on $z$ is attenuated.

$$
\begin{gathered}
F_{l}(P, K)=P_{11}+P_{12} K\left(I-P_{22} K\right)^{-1} P_{21} ; \\
Z=F_{l}(P, K) w
\end{gathered}
$$

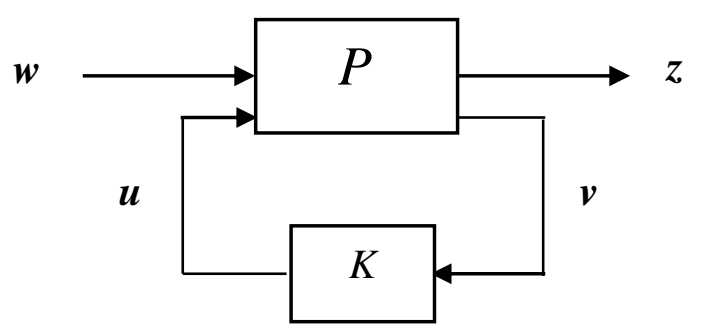

Figure 7.1 Standard control configuration

\subsection{1 $H_{\infty}$ Control Design}

Figure 7.2 shows a typical closed-loop system configuration, where $G$ is the plant and $K$ is the controller to be designed. $r, e, u, y$ are the reference input, tracking error, manipulated input, and system output, respectively. For the design of an industrial controller, it is desired to have good reference tracking as well as to limit the control signal energy. Therefore, tracking error $e_{y}$ weighted by $W_{P}$ and manipulated input $e_{u}$ weighted by $W_{u}$ are desired to be minimized. By defining $w=r, z=\left[\begin{array}{l}e \\ u\end{array}\right], v=e, u=u, P_{11}=\left[\begin{array}{c}W_{p} \\ 0\end{array}\right], P_{12}=\left[\begin{array}{c}-W_{p} G \\ W_{u}\end{array}\right], P_{21}=I$, and $P_{22}=-G$, the design objective is as follows:

$$
\min _{K \text { stabilizing }}\left\|\begin{array}{c}
W_{p} S \\
W_{u} K S
\end{array}\right\|_{\infty}
$$


The system sensitivity function, $S=(I+G K)^{-1}$, is the transfer function from reference input $r$ to tracking error $e$. For good reference tracking and disturbance rejection, the value of $\left\|W_{p} S\right\|_{\infty}$ is preferred to be small. A small value of $\left\|W_{u} K S\right\|_{\infty}$ means less control energy.

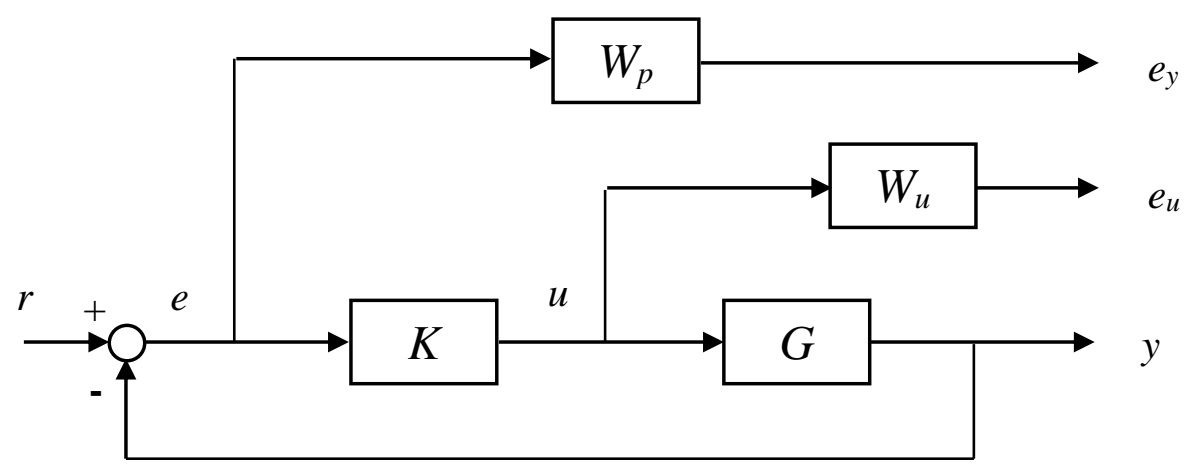

Figure 7.2 Closed-loop system configuration with weighted tracking error and manipulated input

The reference tracking performance of the 1-degree-of-freedom (1DOF) controller $K$ as shown in Figure 7.2 can be improved by a 2-degree-of-freedom (2DOF) controller. In the scheme of a 2DOF controller, a prefilter is used to minimize the difference between the output of the closedloop system and that of the reference model, and a feedback controller is used to achieve robust stability and disturbance rejection (Hoyle et al., 1991). Figure 7.3 shows the structure of a 2DOF control scheme. In this work and many other applications, all possible perturbations to the dynamic system can be represented in the form of multiplicative input uncertainty. The uncertainty block $\Delta$ is a diagonal matrix that is usually normalized so that $\|\Delta\|_{\infty} \leq 1$. $W_{\Delta}$ is the weight function for the uncertainty. Desired closed-loop dynamic behavior from the reference input to output is achieved by implementing an appropriate model $M$. $G$ denotes the nominal plant. The perturbed plant $G_{p}$, enclosed by the dashed rectangle, is given by Equation (7.3). Where $n$ is the measurement noise and $W_{n}$ is the noise shaping filter.

$$
G_{p}(s)=G(s)\left(I+W_{\Delta}(s) \Delta(s)\right) ; \quad|\Delta(j \omega)| \leq 1, \forall \omega
$$


Let the 2DOF controller be partitioned as

$$
K(s)=\left[K_{y}(s) \quad K_{r}(s)\right]
$$

Where:

$K_{y}=$ feedback controller;

$K_{r}=$ prefilter.

The transfer function matrix from $\left[\begin{array}{l}r \\ n\end{array}\right]$ to $\left[\begin{array}{l}e_{y} \\ e_{u}\end{array}\right]$ can be derived as follows:

$$
\left\|\begin{array}{cc}
W_{p}\left(S G_{p} K_{r}-M\right) & -W_{p} T W_{n} \\
W_{u}\left(I+K_{y} G_{p}\right)^{-1} K_{r} & -W_{u} S K_{y} W_{n}
\end{array}\right\|
$$

$S=\left(I+G K_{y}\right)^{-1}$ is the sensitivity function, and $T=G K_{y}\left(I+G K_{y}\right)^{-1}$ is the complementary sensitivity function.

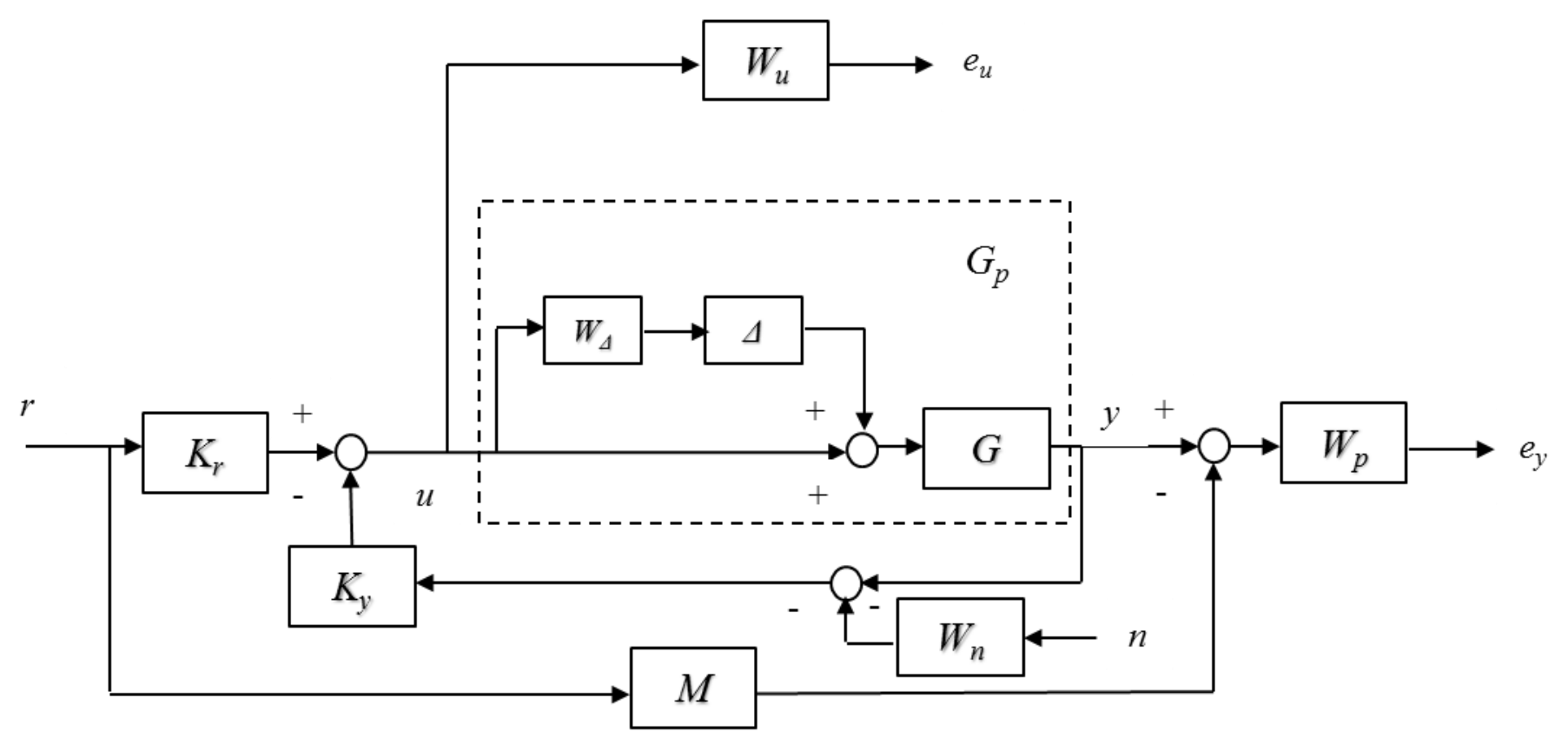

Figure 7.3 Closed-loop system configuration with 2DOF controller in the presence of model uncertainty 
In this work, the design objective is to find an optimal 2DOF robust controller so that the $H_{\infty}$ norm of Equation (7.4) is minimized in the face of all considered uncertainty by using $W_{p}, W_{u}$, $W_{\Delta}, W_{n}$, and $M$ as the tuning parameters. In this way, the robust performance of the closed-loop is guaranteed.

\subsubsection{Plant and Uncertainty Modeling for Robust Control Design}

For the nominal plant, the controlled outputs are $\mathrm{CO}_{2}$ capture efficiency and stripper reboiler temperature. They are maintained at the desired conditions by manipulating lean solvent flow rate and extracted low pressure steam flow rate, respectively. A first-order process model (Equation 7.5) was found to fit the input-output data fairly well when the $\mathrm{CO}_{2}$ capture process is operated near the design point $\left(90 \% \mathrm{CO}_{2}\right.$ capture efficiency; $\mathrm{CO}_{2}$ stripper reboiler operated at $\left.120^{\circ} \mathrm{C}\right)$.

$$
G_{1}(s)=\frac{y_{1}(s)}{u_{1}(s)}=\frac{7.8132}{1+0.088602 s} \quad G_{2}(s)=\frac{y_{2}(s)}{u_{2}(s)}=\frac{13.557}{1+0.45953 s}
$$

Where:

$y_{1}=\mathrm{CO}_{2}$ capture efficiency $(\%)$;

$y_{2}=\mathrm{CO}_{2}$ stripper reboiler temperature $\left({ }^{\circ} \mathrm{C}\right)$;

$u_{1}=$ lean solvent flow rate $(\mathrm{kmol} / \mathrm{s})$;

$u_{2}=$ extracted low pressure steam flow rate $(\mathrm{kmol} / \mathrm{s})$.

Under the constraint that $\|\Delta\|_{\infty} \leq 1$, the uncertainty weight function $W_{\Delta}$ can be determined as follows:

$$
W_{\Delta}(j \omega) \geq\left|\frac{G_{p}(j \omega)}{G(j \omega)}-1\right|, \forall \omega
$$

Therefore, the uncertainty in the perturbed plant $G_{p}$ needs to be appropriately quantified before designing the optimal robust controller. In this work, the model uncertainty is quantified by simulating the Aspen Plus ${ }^{\circledR}$ rate-based model under suitably chosen operating conditions. Then the gain and time constant of the first-order process model is modified to reflect the uncertainty 
in the process model. The sources of model uncertainties considered in this study are listed in Table 7.1. The ranges considered for these sources are obtained under reasonable assumptions to cover the majority of possible operating conditions (supercritical PC plant load cycling from 50\% to $100 \%$ with $\mathrm{CO}_{2}$ capture efficiency varying from $30 \%$ to $95 \%$ ). Based on the Aspen Plus simulation results, $\pm 30 \%$ uncertainty in the process gain of $G_{l}, \pm 20 \%$ uncertainty in the time constant of $G_{1}, \pm 20 \%$ uncertainty in the process gain of $G_{2}$, and $\pm 20 \%$ uncertainty in the time constant of $G_{2}$ are observed to cover all considered uncertainties in Table 7.1.

\section{Table 7.1 Model Uncertainties in $\mathrm{CO}_{2}$ Capture Process}

\begin{tabular}{lcc}
\hline Model uncertainty sources & Min & Max \\
\hline Flue gas temperature, ${ }^{\circ} \mathrm{C}$ & 34 & 44 \\
Flue gas $\mathrm{CO}_{2}$ composition, mol\% & 9 & 14 \\
Flue gas flow rate, $\mathrm{kmol} / \mathrm{s}$ & 2.7 & 3.1 \\
Lean solvent Temperature, ${ }^{\circ} \mathrm{C}$ & 35 & 42 \\
$\mathrm{MEA} \mathrm{concentration} \mathrm{in} \mathrm{lean} \mathrm{solvent,} \mathrm{wt} \%^{\mathrm{C}}$ & 28 & 32 \\
$\mathrm{CO}_{2}$ loading in lean solvent, $\mathrm{kmol} \mathrm{CO} / \mathrm{kmol} \mathrm{MEA}$ & 0.116 & 0.276 \\
${\mathrm{Variable} \mathrm{CO}_{2} \text { capture target, } \%}^{\circ}$ & 30 & 95 \\
Extracted steam temperature, ${ }^{\circ} \mathrm{C}$ & 243 & 291 \\
Extracted steam pressure, $\mathrm{kPa}$ & 336 & 517 \\
\hline
\end{tabular}

The frequency responses of the relative errors $\left|\frac{G_{p}(j \omega)}{G(j \omega)}-1\right|$ are computed for all the considered perturbed plants and shown in Figure 7.4. The uncertainty weight function is chosen as the upper bound of the frequency responses of the relative errors as follows:

$$
W_{\Delta 1}(s)=\frac{0.523 s+2.975}{s+14.18} \quad W_{\Delta 2}(s)=\frac{0.5339 s+0.6336}{s+2.926}
$$

Where:

$W_{\Delta 1}=$ uncertainty weight function for $\mathrm{CO}_{2}$ capture efficiency model;

$W_{\Delta 2}=$ uncertainty weight function for $\mathrm{CO}_{2}$ stripper reboiler temperature model. 

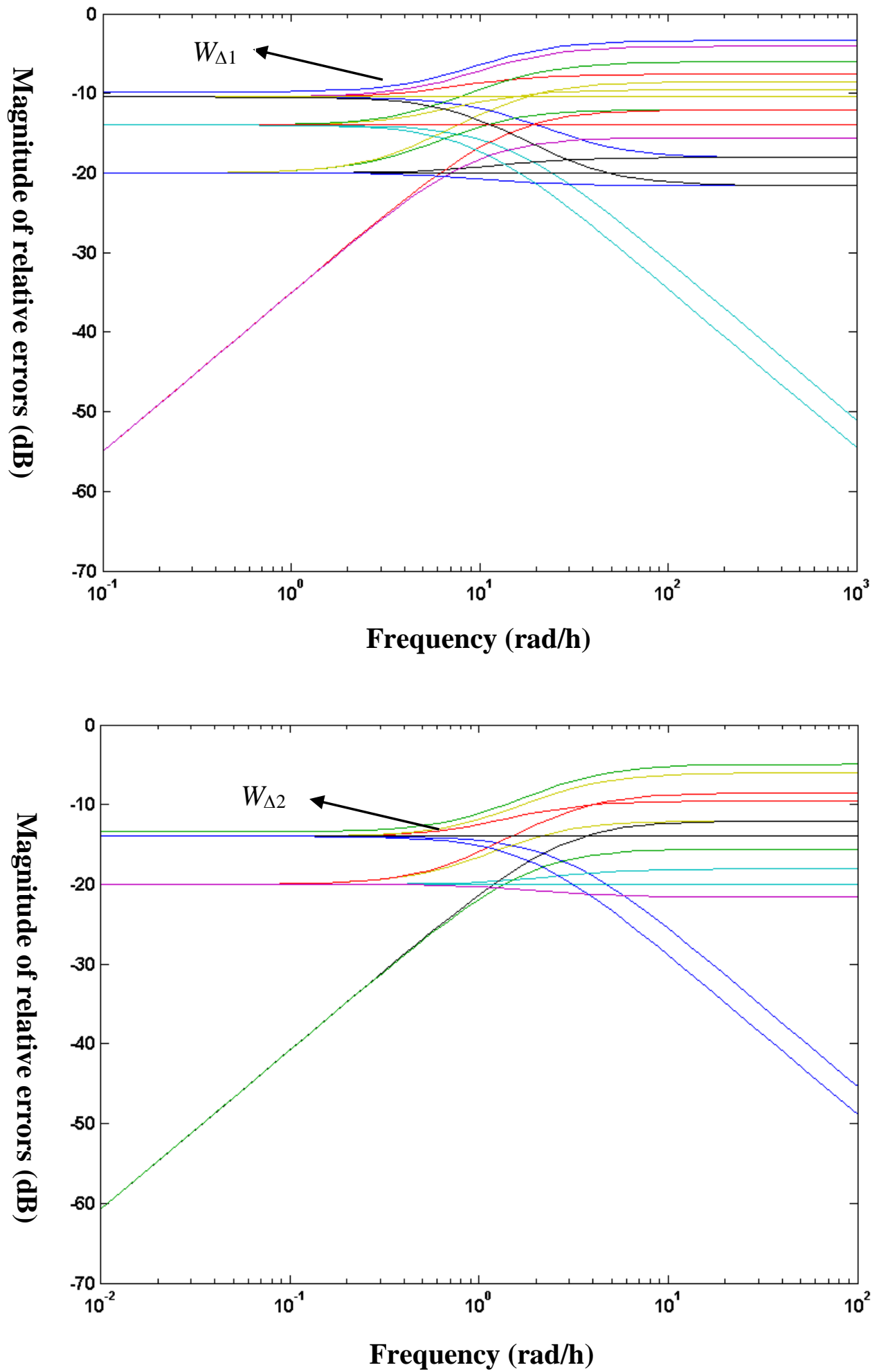

Figure 7.4 Relative errors for the perturbed plants, (upper): $\mathrm{CO}_{2}$ capture efficiency; (lower): $\mathrm{CO}_{2}$ stripper reboiler temperature 


\subsubsection{Robust Control Design and Performance Analysis}

Besides the uncertainty weight function $W_{\Delta}$, other tuning parameters used in the design of the optimal robust controller are given as follows:

$$
\begin{array}{ll}
W_{p 1}(s)=\frac{0.5 s+30}{s+0.003} & W_{p 2}(s)=\frac{0.5 s+4}{s+0.0004} \\
W_{u 1}(s)=\frac{0.54 s+0.9}{0.0001 s+1} & W_{u 2}(s)=\frac{0.08 s+0.8}{0.0001 s+1} \\
W_{n 1}(s)=\frac{0.01 s}{s+10} & W_{n 2}(s)=\frac{0.01 s}{s+10} \\
M_{1}(s)=\frac{1}{0.035 s+1} & M_{2}(s)=\frac{1}{0.0025 s^{2}+0.08 s+1}
\end{array}
$$

Where:

$W_{p 1}=$ performance weight function for $\mathrm{CO}_{2}$ capture efficiency model;

$W_{p 2}=$ performance weight function for $\mathrm{CO}_{2}$ stripper reboiler temperature model;

$W_{u 1}=$ control action weight function for $\mathrm{CO}_{2}$ capture efficiency model;

$W_{u 2}=$ control action weight function for $\mathrm{CO}_{2}$ stripper reboiler temperature model;

$W_{n 1}=$ noise shaping filter for $\mathrm{CO}_{2}$ capture efficiency model;

$W_{n 2}=$ noise shaping filter for $\mathrm{CO}_{2}$ stripper reboiler temperature model;

$M_{1}=$ reference model for $\mathrm{CO}_{2}$ capture efficiency;

$M_{2}=$ reference model for $\mathrm{CO}_{2}$ stripper reboiler temperature.

The frequency response of model $M$ is shown in Figure 7.5. The value of $M$ is chosen to achieve a small settling time and overshoot in the time response to the reference signal. The magnitude plots of the inverse of the performance weight function $W_{p}$ and the control action weight function $W_{u}$ are shown in Figures 7.6 and 7.7. Since $1 /\left|W_{p}\right|$ is the upper bound on the sensitivity function $|S|, W_{p}$ should be large enough to achieve a small difference between the system and model outputs, and a small effect on the disturbance on the system outputs over the lowfrequency range. $W_{u}$ is chosen to limit the magnitude of control actions over the high-frequency range and achieve robustness. The speed of response of the dynamic system depends on $W_{p}$ and $M$. A faster time response is usually preferred; however, robust performance becomes more difficult to satisfy. Design of the optimal robust controller is accomplished by using the Matlab 
Robust Control Toolbox. $W_{p}, W_{u}, W_{\Delta}, W_{n}$, and $M$ are used for $\mu$-synthesis and the DK-iteration algorithm (Appendix B) is applied to find the optimal robust controller. After several trials of DK-iterations, an appropriate controller is obtained with satisfactory robust performance. In general, the structured singular value (SSE, Appendix C) is used to analyze the robust performance. As shown in Figure 7.8, the structured singular value $\mu$ of the closed-loop perturbed plant is always less than 1 at any frequency. The DK-iteration algorithm usually results in a controller of high order. In this study, the optimal robust controller $K$ obtained has an order of 19. In order to make the optimal robust controller easy to implement in a practical situation, a reduced-order controller $K_{\text {red }}$ of order 6 is used to approximate $K$. Figure 7.9 shows a comparison of the frequency responses of the maximum singular values between the full-order and reducedorder controllers. A difference between the responses of the two controllers can only be observed at very high frequency, which is much more than the bandwidth of the closed-loop system. Therefore, the full-order controller can be replaced by the reduced-order controller for control performance evaluation. 

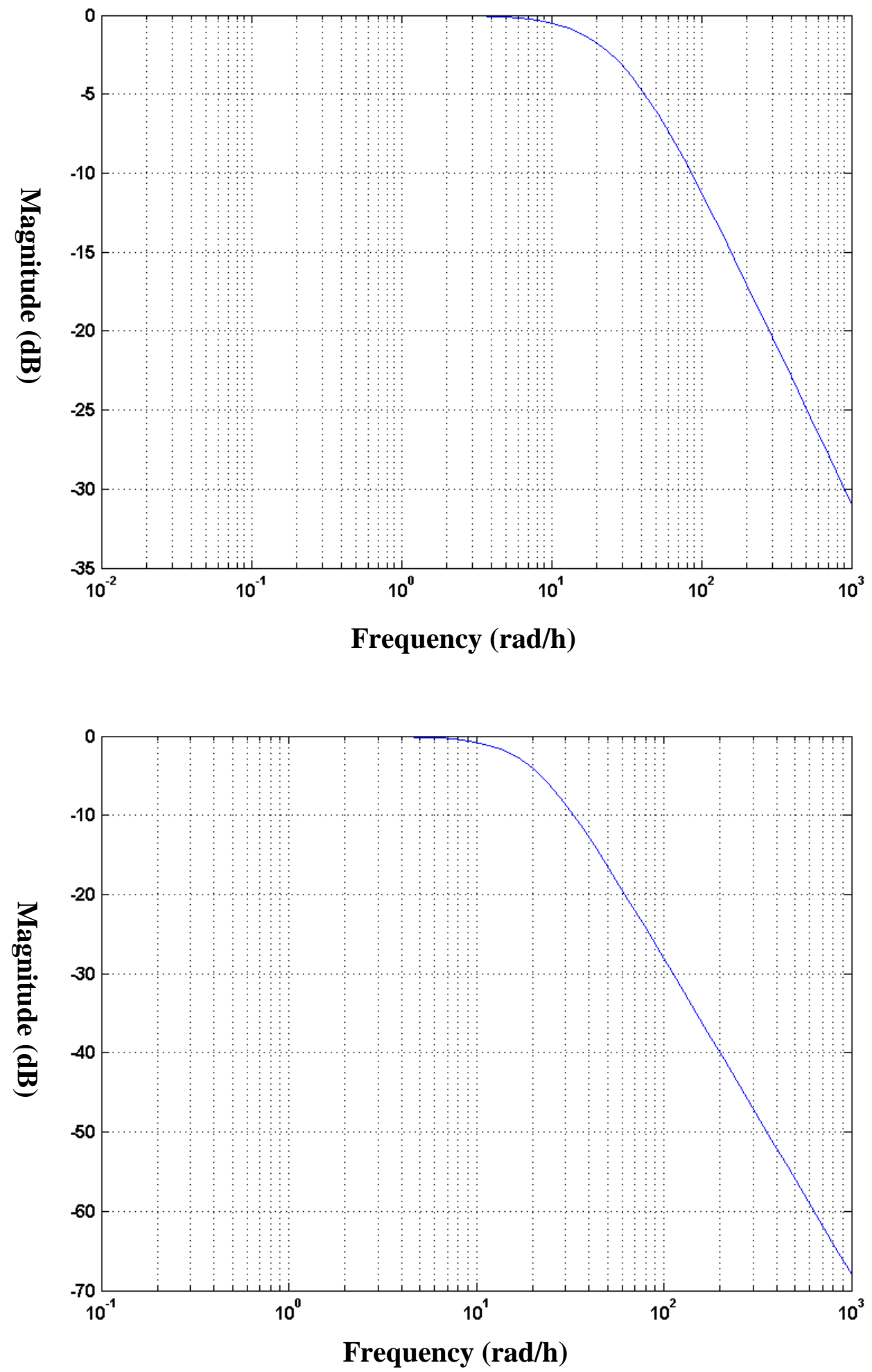

Figure 7.5 Desired model frequency response, (upper): $\mathrm{CO}_{2}$ capture efficiency; (lower): $\mathrm{CO}_{2}$ stripper reboiler temperature 

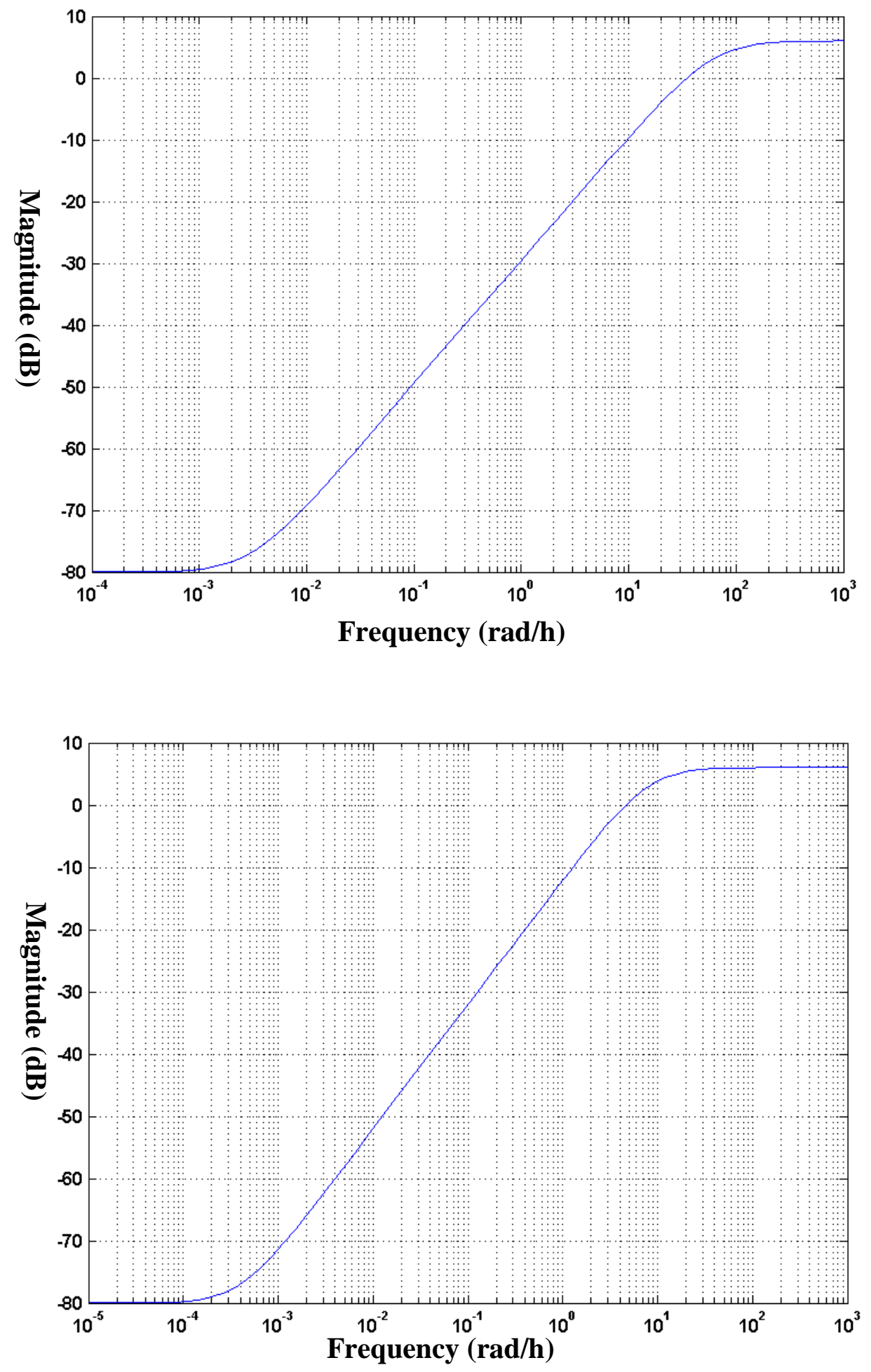

Figure 7.6 Inverse of performance weight function, (upper): $\mathrm{CO}_{2}$ capture efficiency; (lower): $\mathrm{CO}_{2}$ stripper reboiler temperature 

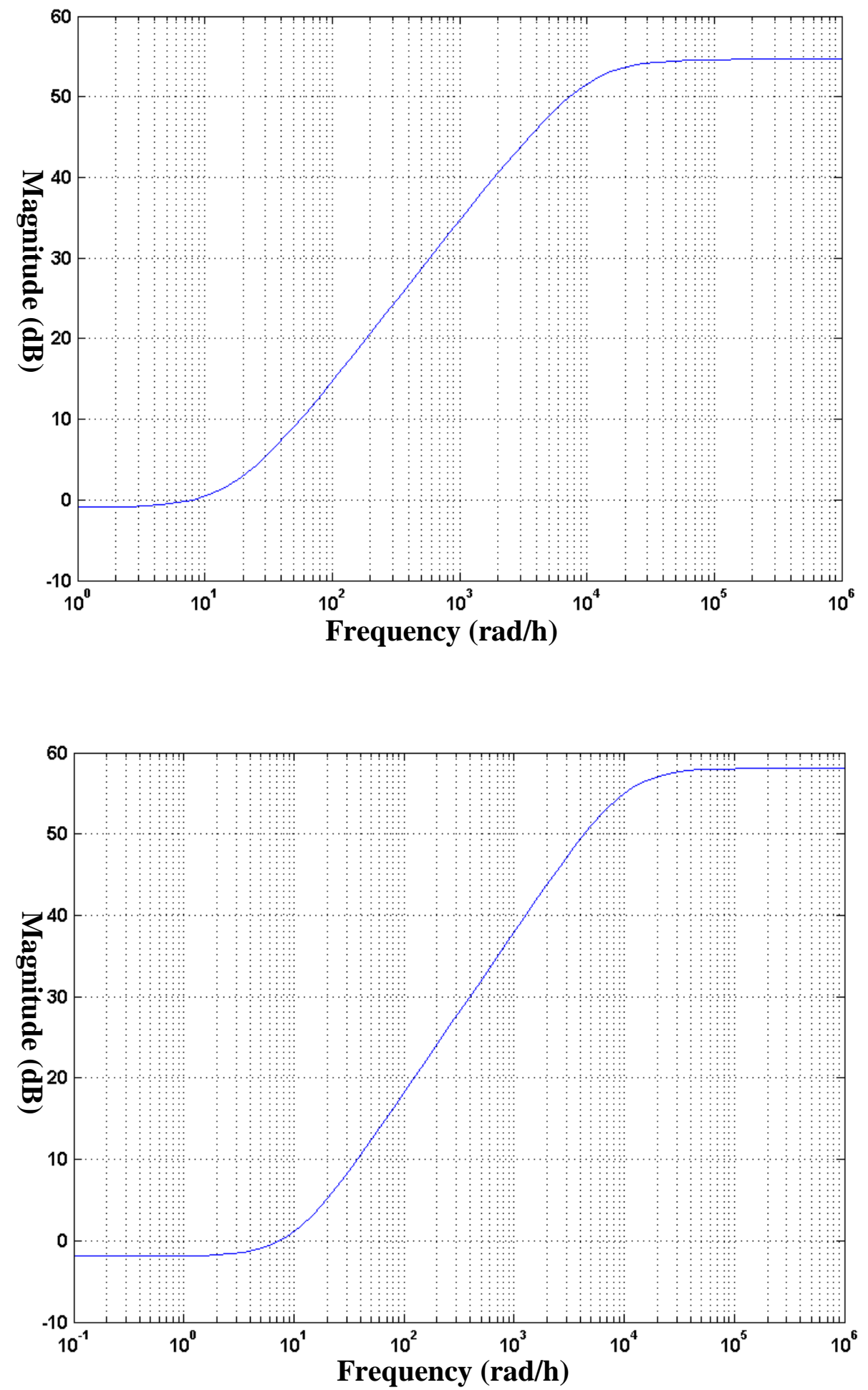

Figure 7.7 Control action weight function, (upper): $\mathrm{CO}_{2}$ capture efficiency; (lower): $\mathrm{CO}_{2}$ stripper reboiler temperature 


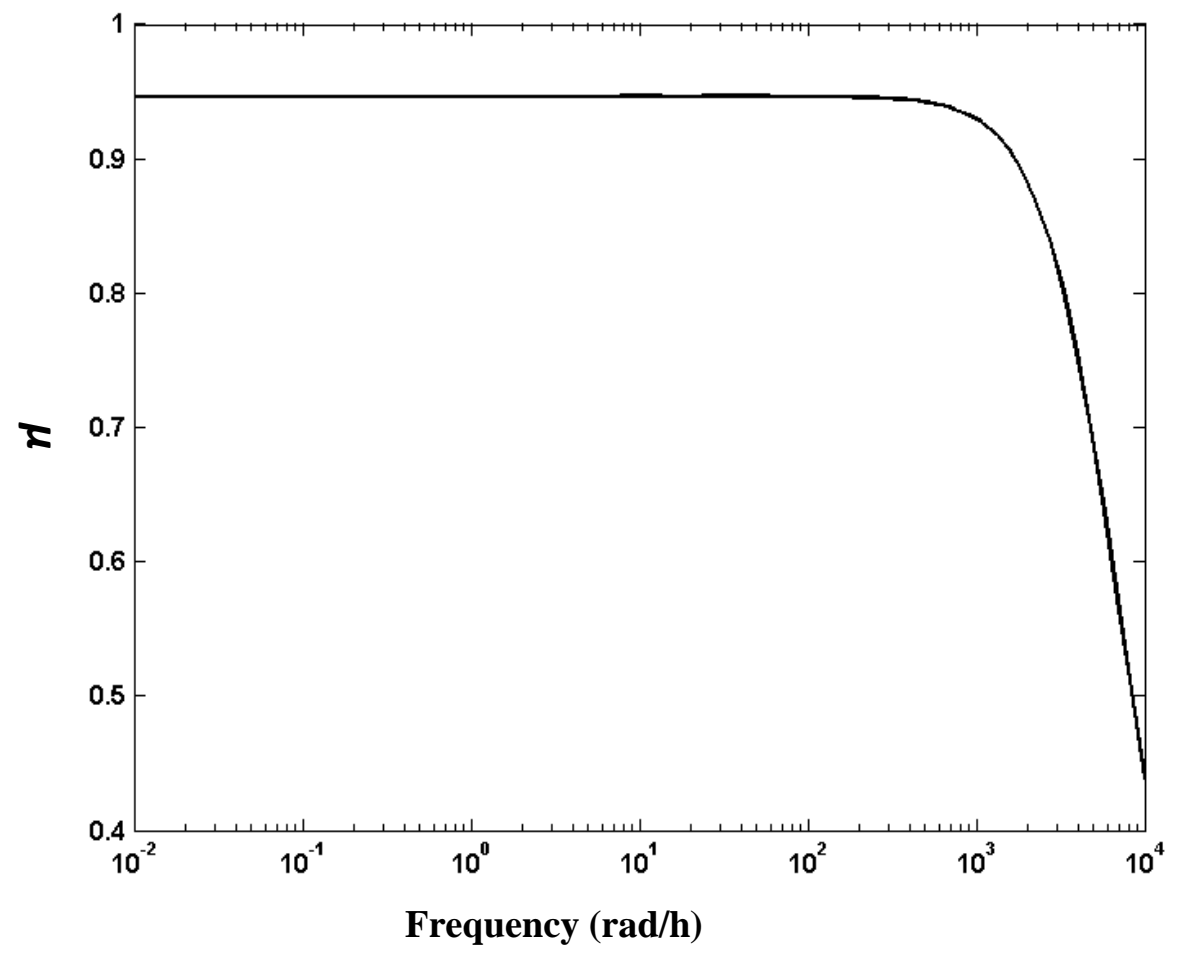

Figure 7.8 Robust performance of the designed 2DOF $H_{\infty}$ robust controller

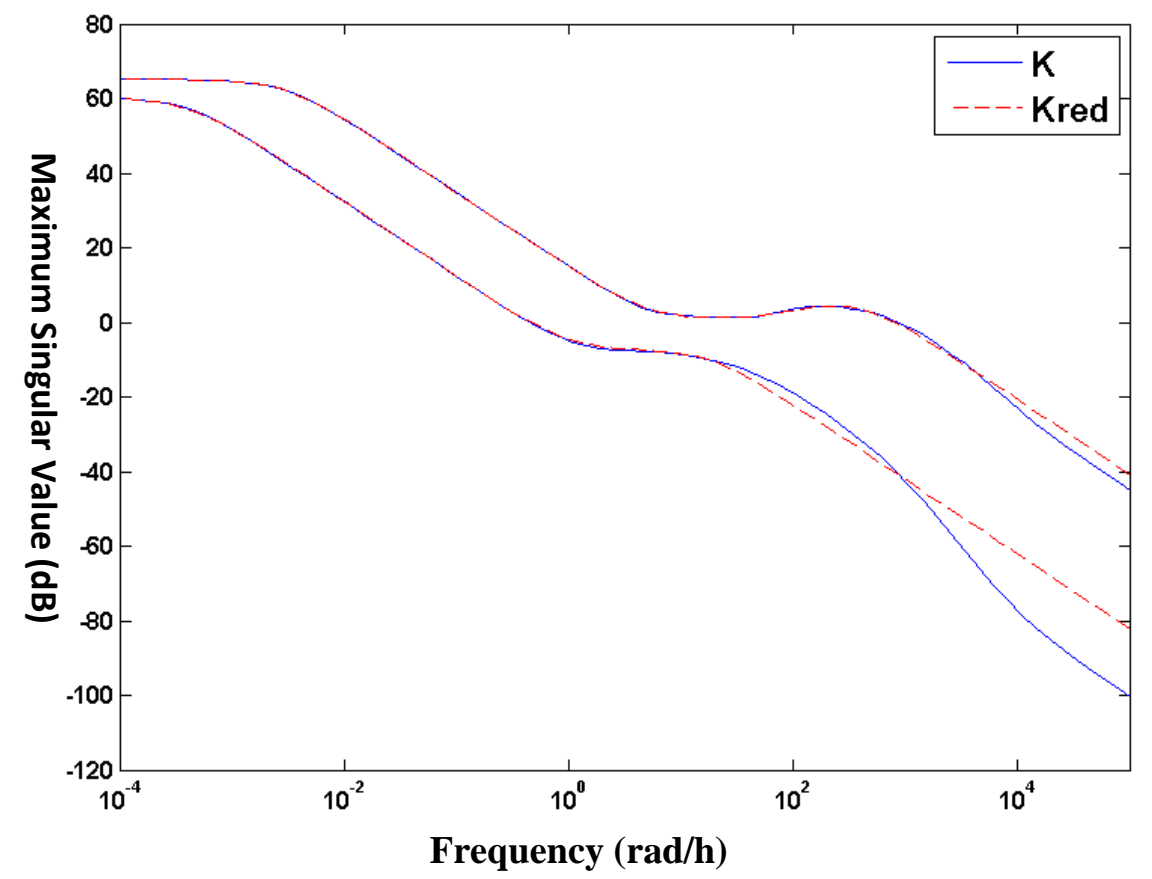

Figure 7.9 Frequency responses of the full-order controller and reduced-order controller, upper: $\mathrm{CO}_{2}$ capture controller; lower: reboiler temperature controller 


\subsection{Robust Control Transient Studies}

In this section, the control performances of the proposed NMPC and 2DOF $H_{\infty}$ robust controller were evaluated in the face of model uncertainty under 2 scenarios: the supercritical PC plant is operated at, either design load or varying loads, with random $\mathrm{CO}_{2}$ capture targets. In the NMPC configuration, since flue gas flow rate and flue gas $\mathrm{CO}_{2}$ composition are used as measured disturbances to predict the system outputs, input uncertainty was considered in the measurement of these two variables. In order to provide control of the real-time overall $\mathrm{CO}_{2}$ capture efficiency, the flow rates and $\mathrm{CO}_{2}$ compositions of both the flue gas and scrubbed gas need to be measured. Output uncertainty was considered in the measurement of the $\mathrm{CO}_{2}$ capture efficiency for both NMPC and robust control. Moreover, the $\mathrm{CO}_{2}$ absorber is usually operated under different conditions and has different performances in a real process. The uncertainty in the column performance was also considered.

A thermal mass flow meter is commonly used for monitoring the flow rate of nonabrasive gases, such as flue gas and scrubbed flue gas. In a typical thermal mass flow meter, a measured amount of heat is applied to the heater of the sensor. The loss of the heat depends on the flow rate of measured fluid. As flow rate increases, more heat is lost. Therefore, the thermal properties, such as heat capacity, of the flowing fluid need to be known. The heat capacities of flue gas under different power plant loads are found to be slightly different as the composition of the gas mixture changes. By simulating the supercritical PC plant from 50\% load to $100 \%$ load, the heat capacity of flue gas changes by $2 \%$. Therefore it is assumed that there might be $\pm 2 \%$ uncertainty in measuring the flue gas flow rate. The $\mathrm{CO}_{2}$ composition in a gas mixture can be continuously measured by using non-dispersive infrared technology. The repeatability for a non-dispersive infrared multi-gas analyzer is usually less than $2 \%$. It should be noted that there may be additional sources of uncertainties in the measurement of flowrate and composition of the flue gas. In addition, measurement uncertainties can greatly differ depending on the measurement technology and manufacturer and can be different than the values considered here. The $\mathrm{CO}_{2}$ absorber used in this work is a packed column and the column performance depends on the packing characteristics, as well as the liquid and vapor distribution. With durable packing and a 
well-designed distributor and considering absence of particulates in the incoming flue gas and assuming absence of solids in the circulating solvent, the performance of a packed column is usually stable. So the uncertainty in column performance is assumed to be small, and has a larger time-scale in comparison to the measurement uncertainties in process variables. Based on these assumptions, band-limited white noises are applied to the inlet and outlet flue gas flowrate sensors and to the inlet and outlet flue gas $\mathrm{CO}_{2}$ composition sensors to represent the input and output uncertainties. The magnitude of the measurement noises are limited to $\pm 2 \%$ of the full scale for each of the inlet and outlet flow rate sensors, inlet and outlet flue gas $\mathrm{CO}_{2}$ composition sensors, and $\mathrm{CO}_{2}$ capture efficiency sensor, respectively. A random additive factor was applied to the $\mathrm{CO}_{2}$ Murphree efficiency model (Equation 4.6) for each stage to represent the uncertainty in the $\mathrm{CO}_{2}$ absorber performance. The magnitude of the additive factor in the $\mathrm{CO}_{2}$ Murphree efficiency model was limited to $\pm 1.5 \%$ of the $\mathrm{CO}_{2}$ stage efficiency. The input and output measurement uncertainties are introduced at every sampling interval, which is $0.001 \mathrm{~h}$ to ensure the convergence for this complex ionic, reactive absorption and desorption system under the Aspen Plus Dynamics ${ }^{\circledR}$ environment. Uncertainty in $\mathrm{CO}_{2}$ absorber performance is introduced every 20 sampling intervals $(0.02 \mathrm{~h})$. Different sized uncertainty samples are applied to the $\mathrm{CO}_{2}$ absorber to determine the adequate size for simulating the uncertainty. It is found that the power density functions of simulated $\mathrm{CO}_{2}$ capture efficiency remain identical when the sample size is greater than 400 .

\subsubsection{Transients in Response to Random $\mathrm{CO}_{2}$ Capture Targets under Design Power Plant Load}

In order to evaluate the performance of the control system under strong variations in the operation of a $\mathrm{CO}_{2}$ capture process, random step changes in desired $\mathrm{CO}_{2}$ capture targets are introduced to the dynamic system for simulating the output disturbance while the supercritical PC plant operates at the design load. The variation in magnitude of the random $\mathrm{CO}_{2}$ capture targets is set to be from $30 \%$ to $95 \%$. As the simulation speed is approximately $3 \sim 4$ times slower than the real-time and a simulation for very long times can lead to memory limitations, the simulation time is set to be $13 \mathrm{~h}$. The dynamics of $\mathrm{CO}_{2}$ capture efficiency and $\mathrm{CO}_{2}$ stripper reboiler temperature are shown in Figures 7.10 and 7.11. For $\mathrm{CO}_{2}$ capture efficiency control, 
NMPC provides much quicker control action than the $H_{\infty}$ robust controller. NMPC can track the reference immediately in response to each introduced step change, while it takes the $H_{\infty}$ robust controller approximately $0.2 \mathrm{~h}$ to reach the desired target. It should be noted that the $H_{\infty}$ robust controller is optimal with respect to the robust performance and does not necessarily provide the optimal control performance in terms of the normal criteria, such as settling time. The reference tracking speed of PID control is between NMPC and $H_{\infty}$ robust controller. Instabilities are not seen for either controller. Significant overshoot or undershoot, and oscillations are seen for NMPC. For NMPC implementation, as mentioned earlier in the previous chapter, the model uncertainty is accounted for by estimating a random, zero-mean white noise. NMPC is observed to be very sensitive to the uncertainty. Oscillations are also seen for PID control. In contrast, the $H_{\infty}$ robust controller shows good resistance to the uncertainty with smooth dynamic behavior. For $\mathrm{CO}_{2}$ stripper reboiler temperature control, NMPC and PID controllers are significantly worse than the $H_{\infty}$ robust controller as larger variations in reboiler temperature are seen for NMPC and PID control.

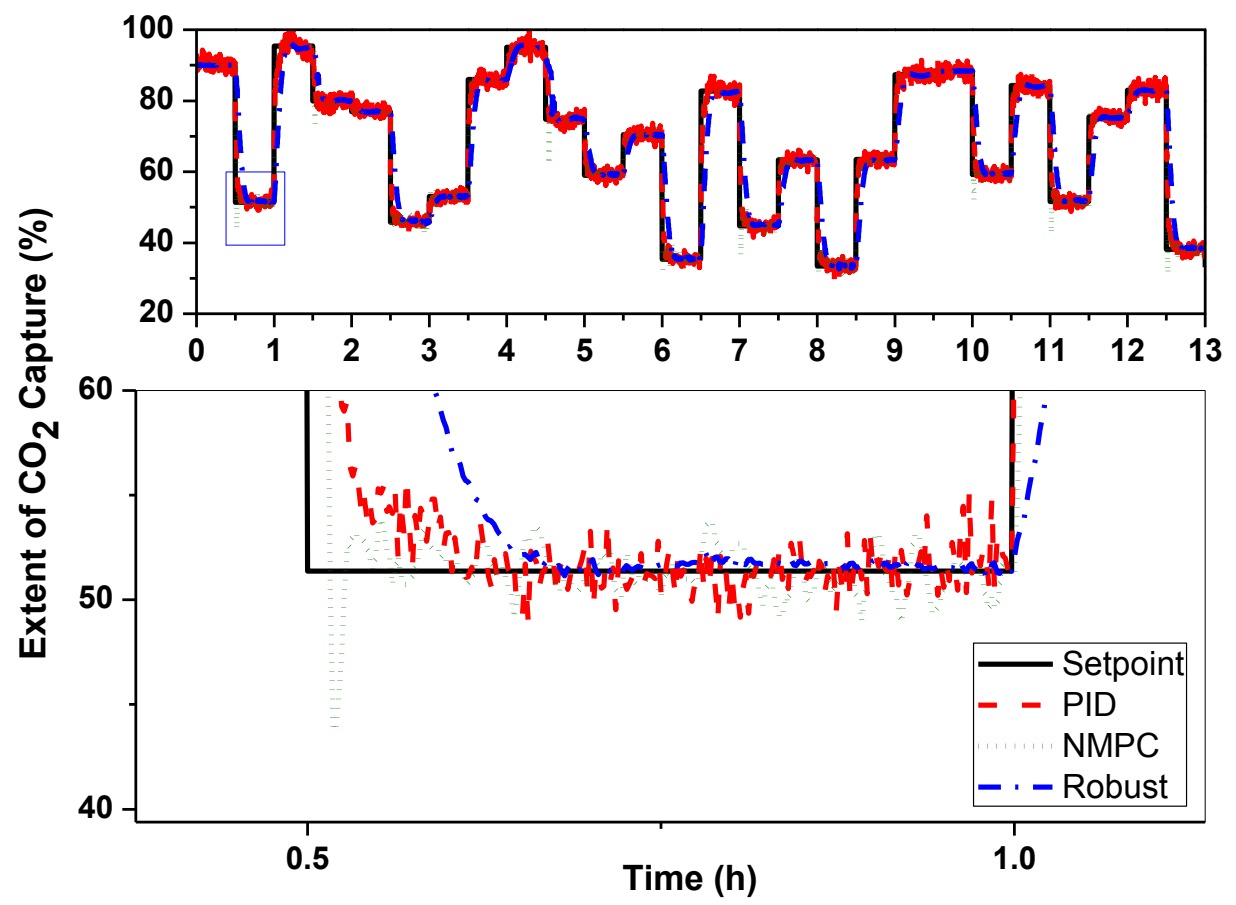

Figure 7.10 Dynamics of $\mathrm{CO}_{2}$ capture efficiency for PID, NMPC and $H_{\infty}$ robust controller in response to random $\mathrm{CO}_{2}$ capture target under design power plant load in the face of uncertainty 


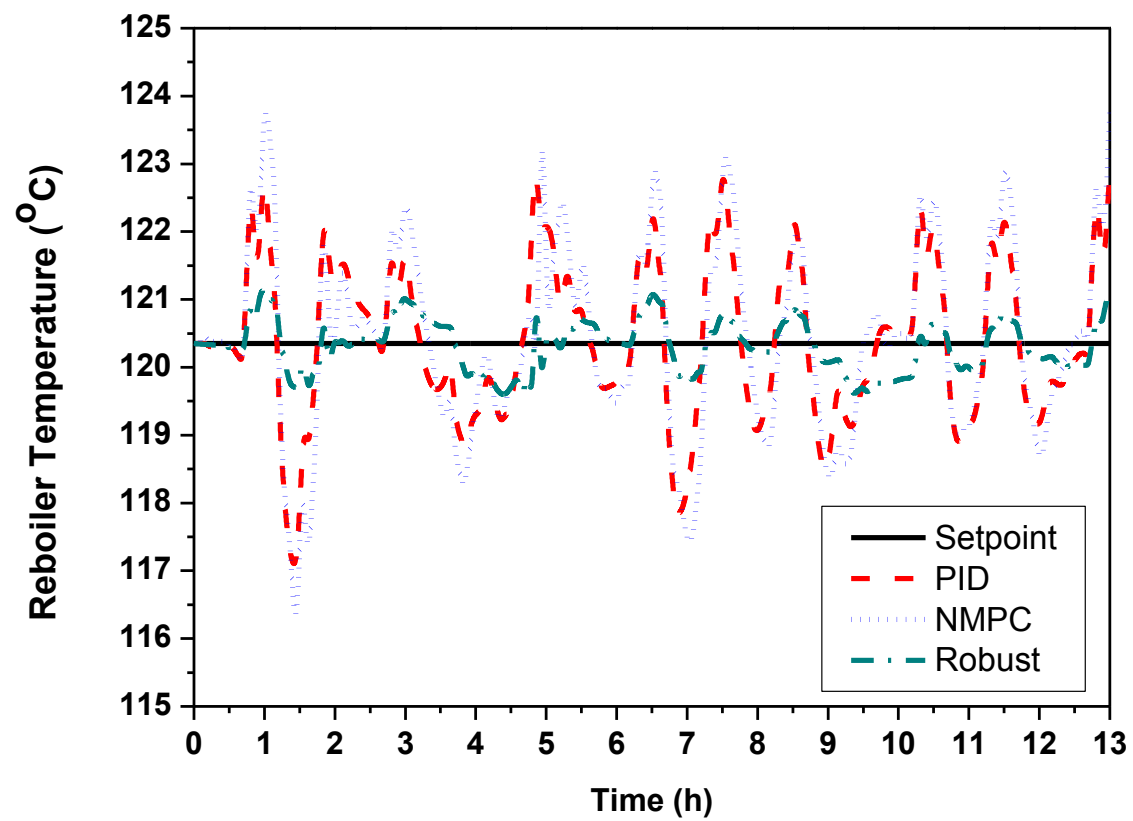

Figure 7.11 Dynamics of stripper reboiler temperature for PID, NMPC and $H_{\infty}$ robust controller in response to random $\mathrm{CO}_{2}$ capture target under design power plant load in the face of uncertainty

These results are mainly due to the different time constants for the $\mathrm{CO}_{2}$ absorber and stripper. Compared with the NMPC and PID controllers, $H_{\infty}$ robust controller has a slower control action resulting in a slower change in the lean solvent flow. Subsequently, the rich solvent entering the $\mathrm{CO}_{2}$ stripper would change more moderately and introduce less disturbance to the $\mathrm{CO}_{2}$ stripper, resulting in a smaller variation in the $\mathrm{CO}_{2}$ stripper reboiler temperature (Figure 7.12). The control moves in the low pressure steam for $H_{\infty}$ robust controller is also not as aggressive as the other controllers (Figure 7.13). This means that the disturbance introduced to the steam cycle by the $H_{\infty}$ robust controller is smaller than the NMPC and PID controllers. Strong variation in temperature would result in a strong variation in the solvent composition, and subsequently in the capture capacity. Based on the dynamics of $\mathrm{CO}_{2}$ capture efficiency, no significant effect due to the changes in the solvent capture capacity is found as NMPC has a good disturbance rejection 
ability. However, for an industrial $\mathrm{CO}_{2}$ capture plant, the MEA thermal degradation in the $\mathrm{CO}_{2}$ stripper can become significant as temperature increases beyond certain limits. Heat-stable salts are formed that are corrosive and introduce severe damage to the equipment and result in considerable performance degradation. Therefore, the MEA make-up cost and plant equipment maintenance cost might be increased due to the large fluctuations in the $\mathrm{CO}_{2}$ stripper reboiler temperature. Although the economic analysis as well as the MEA thermal degradation are outside the scope of this study, it is preferred that the variations in the $\mathrm{CO}_{2}$ stripper reboiler temperature remain small.

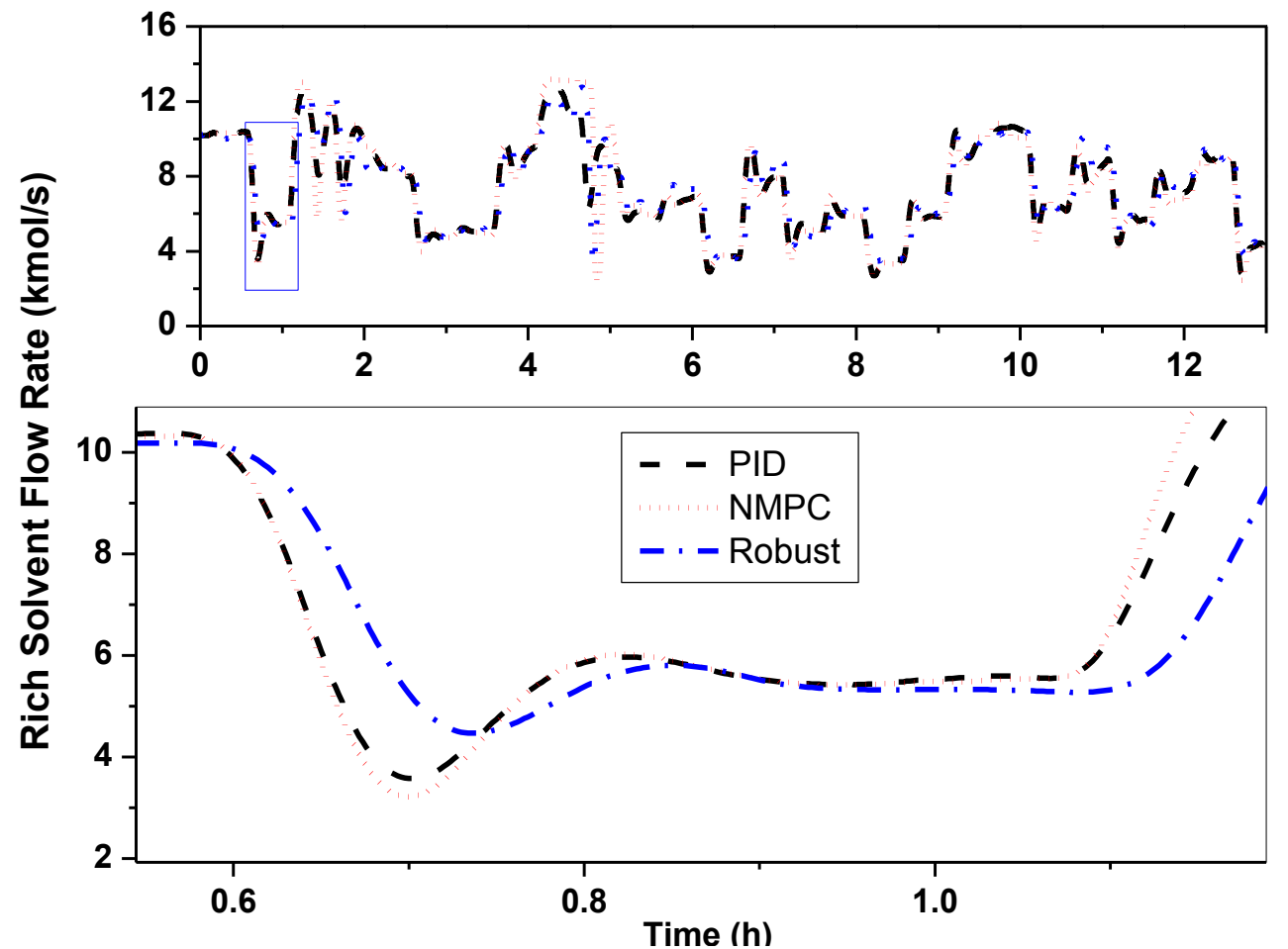

Figure 7.12 Transients of rich solvent flow in response to random $\mathrm{CO}_{2}$ capture target under design power plant load in the face of uncertainty 


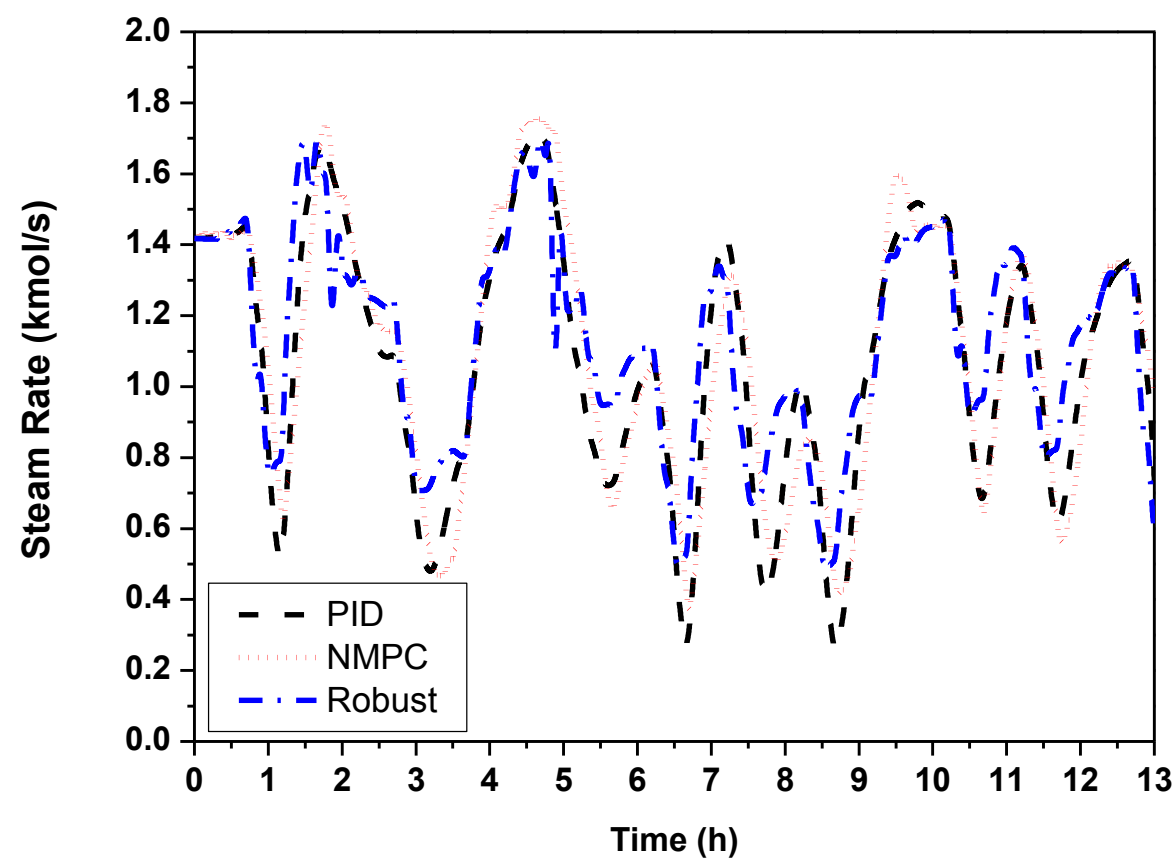

Figure 7.13 Transients of low pressure steam flow in response to random $\mathrm{CO}_{2}$ capture target under design power plant load in the face of uncertainty

\subsubsection{Transients in Response to Random $\mathrm{CO}_{2}$ Capture Targets under a Cyclic Power Plant Load}

With higher penetration of renewable energy sources into the grid, conventional PC plants are required to have flexible operating capability. For example, the PC plant might be operated under part-load at midday when photovoltaic generators feed the grid (International Energy Agency, 2013). Therefore, the performance of NMPC and $H_{\infty}$ robust controller are evaluated when the PC plant is operated under cyclic operation with random step changes in the desired $\mathrm{CO}_{2}$ capture target as in Section 7.2.1. The applied PC plant load profile is taken from the International Energy Agency's report (2013) and shown as Figure 7.14. It should be noted that the magnitude of cyclic power plant loads can vary and depends on the other energy sources and energy consumption demands. The simulation is assumed to start at 8:00 am and end at 21:30 pm. 


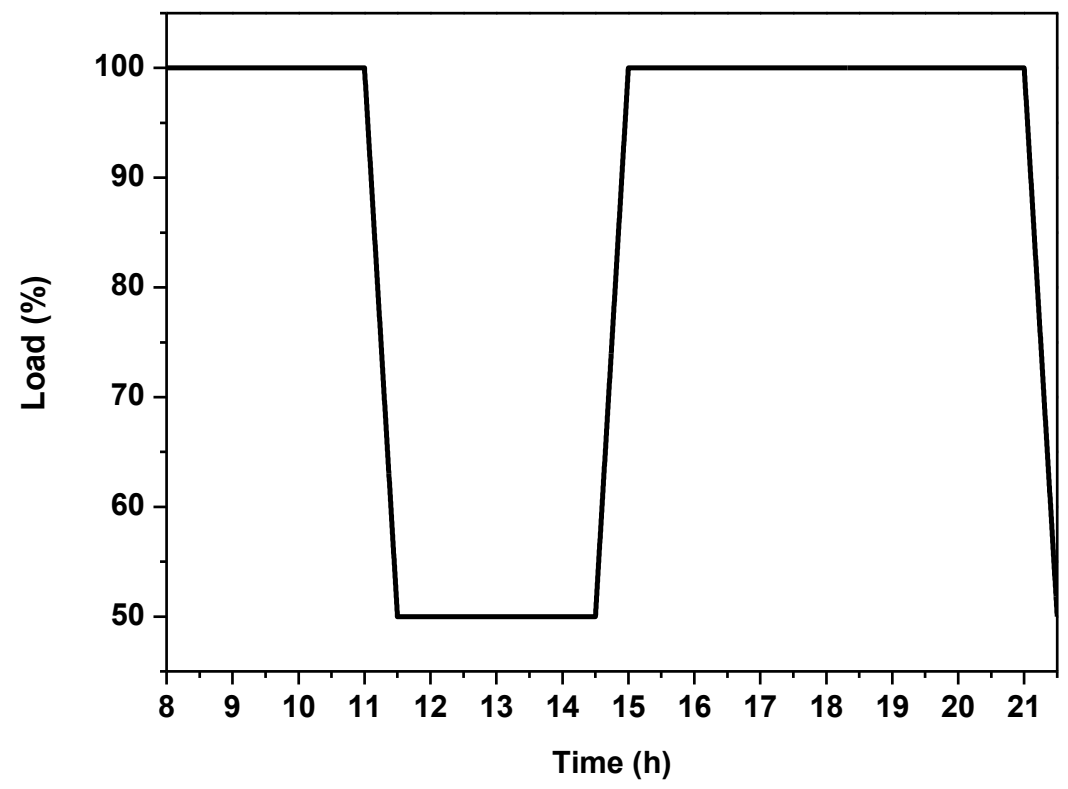

Figure 7.14 Implemented power plant load profile for the integrated system based on International Energy Agency's report (2013)

As shown in Figures 7.15 and 7.16, the dynamics of $\mathrm{CO}_{2}$ capture efficiency and $\mathrm{CO}_{2}$ stripper reboiler temperature are found to be similar to Section 7.2.1. The dynamic systems remain stable when the supercritical PC plant is operated at off-design loads (11:00 15:00, and 21:00 21:30). Similar to Section 7.2.1, it is observed that even though the NMPC is faster in comparison to the robust controller, it leads to high overshoots and undershoots and oscillations in $\mathrm{CO}_{2}$ capture efficiency control. Performance of the robust controller is far superior to the NMPC for the reboiler temperature control. 


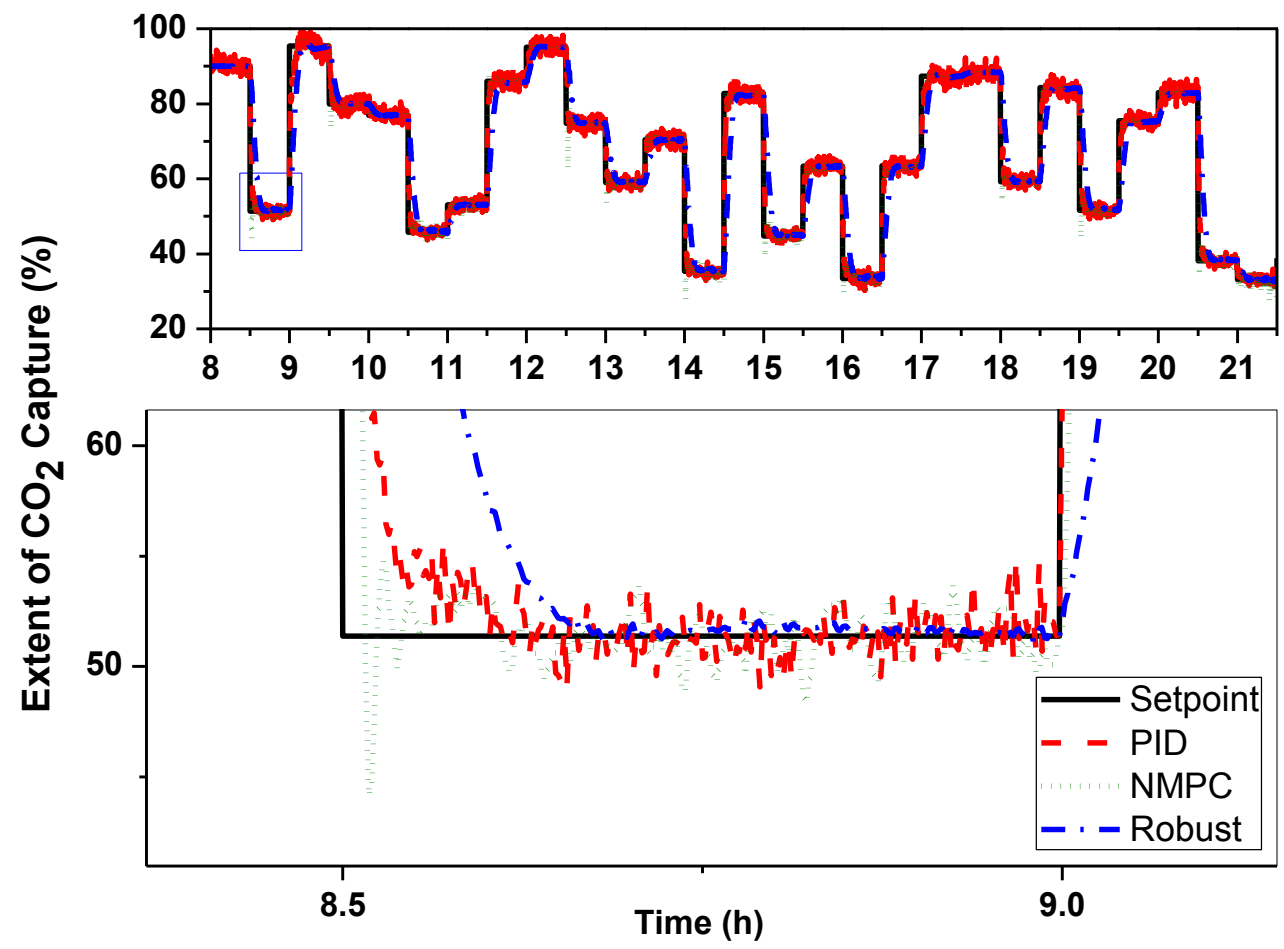

Figure 7.15 Dynamics of $\mathrm{CO}_{2}$ capture efficiency for PID, NMPC and $H_{\infty}$ robust controller in response to random $\mathrm{CO}_{2}$ capture target under cyclic power plant load in the face of uncertainty 


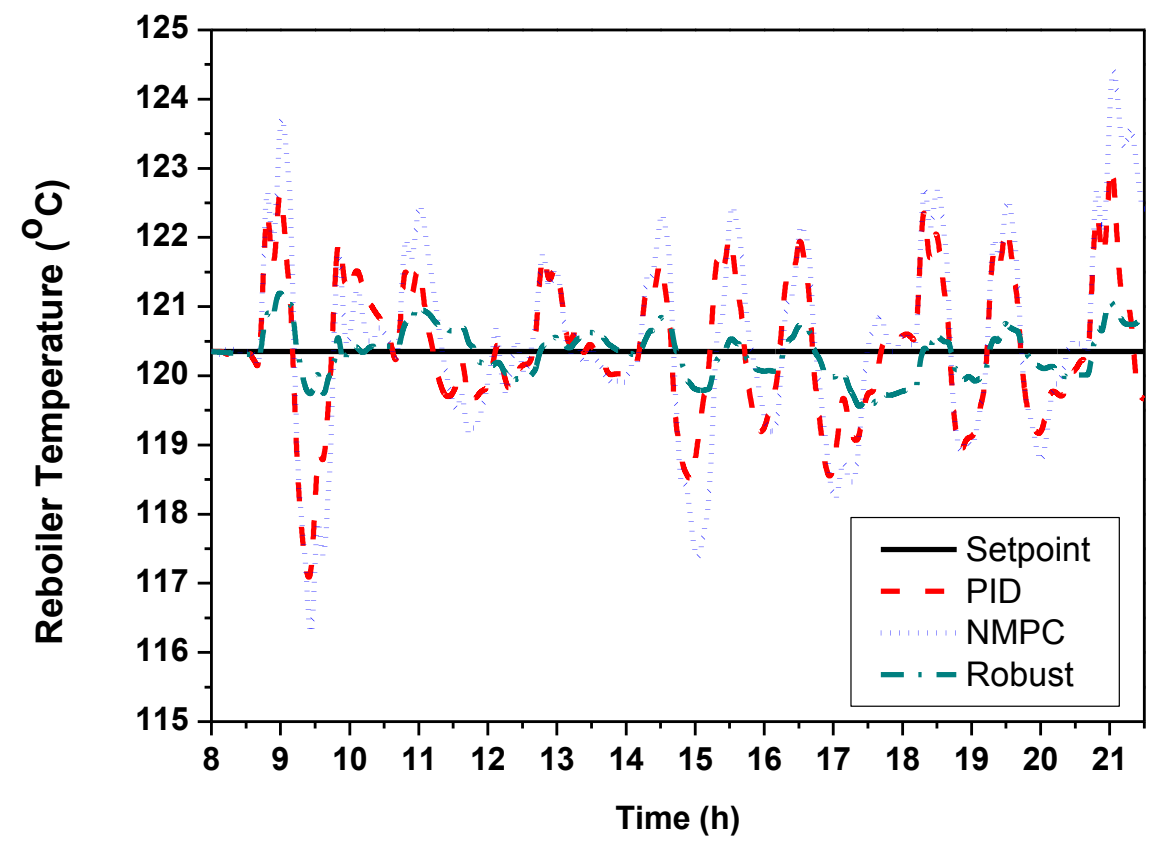

Figure 7.16 Dynamics of stripper reboiler temperature for PID, NMPC and $H_{\infty}$ robust controller in response to random $\mathrm{CO}_{2}$ capture target under cyclic power plant load in the face of uncertainty

\subsubsection{Transients in Response to Random $\mathrm{CO}_{2}$ Capture Target under a Daily Cyclic Power Plant Load with Tight Constraints on the Rate of Change in Manipulated Variables for NMPC}

In order to reduce the oscillations in the dynamics of extent of $\mathrm{CO}_{2}$ capture for NMPC, the constraint on $\Delta F_{\text {solvent }}$ was adjusted from $\pm 0.4 \mathrm{kmol} / \mathrm{s}$ per $0.001 \mathrm{~h}$ to $\pm 0.025 \mathrm{kmol} / \mathrm{s}$ per $0.001 \mathrm{~h}$ so that the undershoot/overshoot and oscillations in its response can be minimized with a reasonable tracking performance. Then the performance of NMPC was reevaluated under the same conditions as in Section 7.2.2. Figures 7.17 and 7.18 show the dynamics of the extent of $\mathrm{CO}_{2}$ capture. No significant overshoot or undershoot or oscillations can be observed for the NMPC, but at the cost of a slower response of the NMPC. The $H_{\infty}$ robust controller is still superior to the NMPC as the robust controller has faster response than the NMPC but has absolutely no oscillation. For the $\mathrm{CO}_{2}$ stripper reboiler temperature control, as NMPC is forced to have a similar control action as the $H_{\infty}$ robust controller, the change in rich solvent flow becomes 
moderate and introduces smooth disturbance into the $\mathrm{CO}_{2}$ stripper. The stripper reboiler temperature control performance of NMPC is thus significantly improved compared with the previous cases.

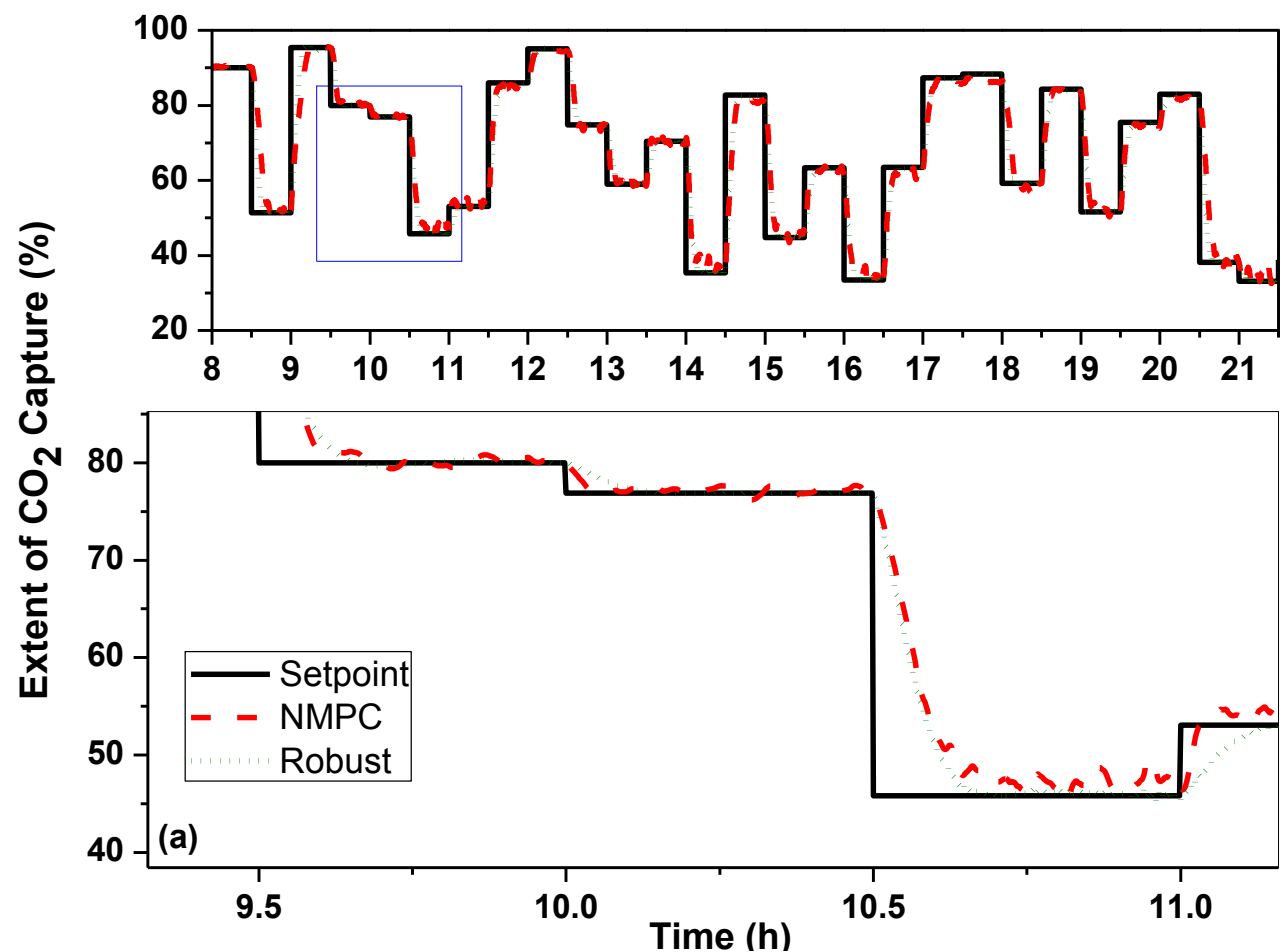

Figure 7.17 Dynamics of $\mathrm{CO}_{2}$ capture efficiency for constrained NMPC and $H_{\infty}$ robust controller in response to random $\mathrm{CO}_{2}$ capture target under cycled power plant load in the face of uncertainty 


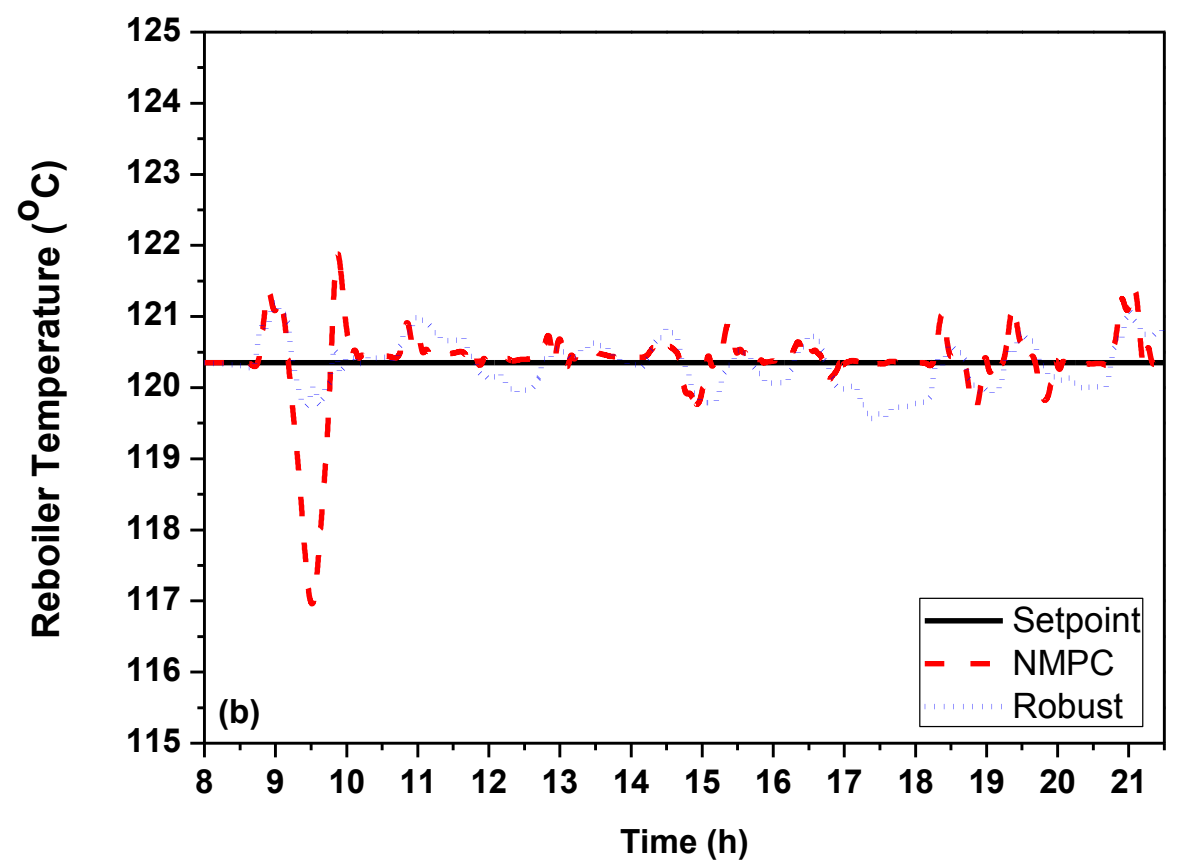

Figure 7.18 Dynamics of stripper reboiler temperature for constrained NMPC and $H_{\infty}$ robust controller in response to random $\mathrm{CO}_{2}$ capture target under cycled power plant load in the face of uncertainty

The ISE analyses of cases in Sections 7.2.1, 7.2.2 and 7.2.3 are given in Table 7.2. NMPC without a tight constraint on lean solvent flow rate and PID controller have smaller values than $H_{\infty}$ robust controller in $\mathrm{CO}_{2}$ capture control. Although NMPC provides quicker reference tracking than PID controller, the significant overshoots/undershoots make the ISE values of NMPC even larger than PID controller. The $H_{\infty}$ robust controller has the largest ISE values due to the slow response. For the $\mathrm{CO}_{2}$ stripper reboiler temperature control, $H_{\infty}$ robust controller has the smallest ISE value as only small variations are found in the dynamics for $H_{\infty}$ robust controller. When a tight constraint is applied to the NMPC to reduce the significant overshoots/undershoots and oscillations, the ISE value of $\mathrm{CO}_{2}$ capture control for NMPC increases significantly while the ISE value of reboiler temperature control decreases. 
Table 7.2 Integral Square Error Analysis for Cases in Sections 7.2.1, 7.2.2, and 7.2.3

\begin{tabular}{lcc}
\hline & $\mathrm{CO}_{2}$ capture control & reboiler temperature control \\
\hline Case in Section 7.2.1 & 143 & 16.59 \\
PID & 182 & 24.67 \\
NMPC & 767 & 1.81 \\
Robust & & \\
\hline Case in Section 7.2.2 & 135 & 13.88 \\
PID & 176 & 26.38 \\
NMPC & 761 & 1.65 \\
Robust & & \\
\hline Case in Section 7.2.3 & 948 & 4.10 \\
NMPC & 761 & 1.65 \\
Robust & & \\
\hline
\end{tabular}




\section{CONCLUSIONS}

In this work, a model of an MEA-based $\mathrm{CO}_{2}$ capture processes integrated with a $550 \mathrm{MWe}$ supercritical PC plant was developed in the Aspen Plus ${ }^{\circledR}$ simulation environment. The reactive absorption and regeneration processes were accurately modeled using RateSep ${ }^{\mathrm{TM}}$, a rigorous rate-based separation approach available in Aspen Plus ${ }^{\circledR}$. Based on the simulation results for the 550 MWe supercritical PC plant, multiple parallel trains of $\mathrm{CO}_{2}$ capture processes (six trains in this study) were required to achieve $90 \% \mathrm{CO}_{2}$ capture from the flue gas leaving the power plant. An intensive sensitivity analysis on different process variables, such as flue gas and solvent temperatures, lean solvent loading, $\mathrm{CO}_{2}$ absorber and stripper operating pressures was conducted with the goal to minimize the energy penalty due to implementation of the $\mathrm{CO}_{2}$ capture process. The energy performance of the optimized case was found to be consistent with the reported literature and industrial data.

An equilibrium-based, pressure-driven dynamic model of an MEA-based $\mathrm{CO}_{2}$ capture process integrated with a 550 MWe supercritical PC power plant was then developed in Aspen Plus Dynamics $^{\circledR}$ based on an Aspen Plus ${ }^{\circledR}$ steady-state model. The major equipment were sized appropriately to provide information on the volumes, hold-up for different phases, and metal mass. Since the rate-based calculation method is not supported in Aspen Plus Dynamics ${ }^{\circledR}$, an additional absorber Murphree efficiency model and a rigorous packing pressure drop model were integrated into the dynamic simulation to ensure consistency between design and off-design results from rate-based and equilibrium-based models. Good matches were found in the predictions between the rate-based models and equilibrium-based models with custom efficiency and pressure drop models. Therefore, the dynamics of the rigorous rate-based $\mathrm{CO}_{2}$ capture process can be accurately represented using the modified equilibrium-based, pressure-driven dynamic model developed in this work. 
The Aspen Plus Dynamics ${ }^{\circledR}$ model was identified as a first-order linear process model for the implementation of LMPC. PID and LMPC controllers for $\mathrm{CO}_{2}$ capture efficiency and stripper reboiler temperature were then designed and evaluated in the face of disturbances in flue gas flow rate and $\mathrm{CO}_{2}$ composition of flue gas under different scenarios. A $2 \times 2$ scheme was used in MPC by pairing $\mathrm{CO}_{2}$ capture efficiency and reboiler temperature with lean solvent and low pressure steam flow rates. The performance of the LMPC is superior to the PID controller in reducing the large overshoot and long settling time. For parallel trains of $\mathrm{CO}_{2}$ capture processes, the advantage of MPC is observed as the overall extent of $\mathrm{CO}_{2}$ capture for the process is maintained by adjusting the extent of capture for each train based on the absorber efficiencies. Instead of capturing the same amount of $\mathrm{CO}_{2}$ in different absorbers, as done by the PID controller, MPC enables the high-efficiency absorber to capture more and keeps the overall $\mathrm{CO}_{2}$ capture efficiency at the desired level. When LMPC is applied to the integrated $\mathrm{CO}_{2}$ capture and power plant system, even though there is uncertainty in the conditions of the low-pressure steam and there is a large time-delay in the closed-loop system, the performance in $\mathrm{CO}_{2}$ capture control of the LMPC controller is superior to the PID controller for simulated load changes and ramp changes in the $\mathrm{CO}_{2}$ capture target. However, the performance in the stripper reboiler temperature control of the LMPC becomes similar to the PID control mainly because of model discrepancy and time-delay.

In the face of absorber flooding, two control strategies, namely a flooding approach control and pressure control, were studied by increasing flue gas flow rate above the design capacity. Both control strategies can prevent the absorbers from becoming flooded. Since, in general, it is difficult to determine the set point of the pressure controller, the flooding control approach is preferred. The flooding approach leads to less bypassing of flue gas and hence gives higher overall $\mathrm{CO}_{2}$ capture if the set point of pressure control is set at the designed steady-state value.

The Aspen Plus Dynamics ${ }^{\circledR}$ model was then identified as a NAARX model for the implementation of NMPC. The NAARX model was found to be superior to the first-order linear process model in representing the nonlinear post-combustion $\mathrm{CO}_{2}$ capture process. The NAARX model was then implemented in the same $2 \times 2$ MPC scheme for system output prediction. The performance of the NMPC controller in $\mathrm{CO}_{2}$ capture and stripper reboiler temperature control 
was compared with the LMPC and PID controllers by considering disturbances in PC power plant load and desired $\mathrm{CO}_{2}$ capture target. The performance of both LMPC and NMPC controllers are superior to the PID controller for disturbance rejection in response to load changes in the supercritical PC plant with fixed $\mathrm{CO}_{2}$ capture efficiency (90\%), while the NMPC performs the best with the smallest ISE values. For $\mathrm{CO}_{2}$ stripper reboiler temperature control, as the rate of manipulated steam is constrained to reduce the effect on power output of the steam cycle, performances of NMPC and LMPC controllers become poor in response to large variation in the desired $\mathrm{CO}_{2}$ capture target and the subsequent large disturbance in the rich solvent flow entering the $\mathrm{CO}_{2}$ stripper.

Uncertainty is unavoidable for the $\mathrm{CO}_{2}$ capture system. After quantifying the plausible model uncertainties and modeling these uncertainties in the form of multiplicative input uncertainty, a 2DOF $H_{\infty}$ robust controller was finally designed using $\mu$-synthesis with DK-iteration algorithm. Performances of NMPC and $H_{\infty}$ robust controllers for the $\mathrm{CO}_{2}$ capture and stripper reboiler temperature control were then evaluated in the face of input/output and model uncertainty for a load-following supercritical PC plant with variable $\mathrm{CO}_{2}$ capture targets under design and cyclic load operation. Stable dynamics of the closed-loop system were found for both NMPC and $H_{\infty}$ robust controllers. Compared with the $H_{\infty}$ robust controller, NMPC tracks the desired $\mathrm{CO}_{2}$ capture target quicker but leads to higher undershoot/overshoots and oscillations in the extent of $\mathrm{CO}_{2}$ capture. The $H_{\infty}$ robust controller has considerably superior control performance for the stripper reboiler temperature. The NMPC results in quick changes in the lean solvent flowrate in response to a step change in the $\mathrm{CO}_{2}$ capture target resulting in a large variation in the rich solvent flowrate that leads to high oscillation in the stripper reboiler temperature. The rate of change in the lean solvent flowrate was constrained for the NMPC in order to reduce overshoot/undershoot and oscillation with a satisfactory tracking performance in the extent of $\mathrm{CO}_{2}$ capture. However, this action results in a slower response than the robust controller but the stripper reboiler temperature control performance is improved. Overall, it is observed that in the face of uncertainty, the robust controller is superior to the NMPC while the NMPC results in faster tracking performance. Therefore the tradeoff between the fast tracking performance and the superior robust performance must be carefully evaluated for designing the control system of the $\mathrm{CO}_{2}$ capture units. 


\section{SUGGESTIONS FOR FUTURE WORK}

In this chapter, suggestions are offered for the improvement and enhancement of the modeling and control of $\mathrm{CO}_{2}$ capture process integrated with supercritical PC plant.

\subsection{Supercritical PC Plant Model}

As the penetration of intermittent renewable energy sources into the electrical grid keeps increasing, traditional PC plants are expected to cycle their loads more frequently than in the past. For a load-following PC plant with triple-pressure steam turbine, the temperature and pressure of the steam would be different during cyclic operation. The changes in the steam condition have a direct effect on the isentropic efficiency, and subsequently the power output of the steam turbine. In this study, the high-, intermediate- and low-pressure steam turbines use the reported isentropic efficiencies from the DOE report (Black, 2010), which is the optimal value at the design-point for the steady-state modeling. When the dynamic model is exported into Aspen Plus Dynamics ${ }^{\circledR}$, a default performance curve on the basis of steady-state results is applied to the steam turbine to calculate the power output under different steam conditions. However, the default performance curve can only be used as an approximation for the dynamics of the steam turbine. The actual performance curves for steam turbines depend on the type of turbine and could be different from the default curve given by Aspen Plus Dynamics ${ }^{\circledR}$. In order to capture the accurate dynamics of steam turbine for a load-following PC plant, it is suggested that a rigorous stage-by-stage steam turbine model be developed.

\subsection{MEA-Based Post-Combustion $\mathrm{CO}_{2}$ Capture Process Model}

High $\mathrm{CO}_{2}$ stripper temperature is preferred by the endothermic $\mathrm{CO}_{2}$ desorption reactions. However, the degradation of MEA becomes significant as temperature increases beyond certain limits, which causes heat-stable salts to be formed. Since fluctuations are found in the dynamic profiles of the $\mathrm{CO}_{2}$ stripper reboiler temperature when there are strong variations in the process 
operating conditions, the thermal degradation of MEA may be significant under some conditions. Subsequently, the MEA loss increases. In this study, only the MEA loss from the absorber top is considered and a MEA washing section is used to minimize this loss. Therefore, the MEA makeup is found to be very small. In order to accurately estimate the operation cost of $\mathrm{CO}_{2}$ capture process due to MEA make-up, it is suggested that an MEA degradation model be applied to the $\mathrm{CO}_{2}$ capture process model. The MEA make-up cost can be further incorporated into the objective of the advanced control system design to maximize the economic performance of $\mathrm{CO}_{2}$ capture process integrated with PC plant.

\subsection{Advanced Control of $\mathrm{CO}_{2}$ Capture Processes}

Profitability is the most important criteria for the performance evaluation of an industrial process. Although steady-state operation is typically used in industrial processes, it may not guarantee the most economic performance. Therefore, an economic objective function should be considered in the design of an advanced control system. Such a control strategy is known as economic MPC (EMPC). By employing an economic-related cost function for real-time control, EMPC can optimize the economic operating cost of the process rather than maintain the process variables at the desired steady-state values. For the fossil fuel power plant, the plant profitability would decrease when the $\mathrm{CO}_{2}$ capture process is integrated due to the new environmental regulations on $\mathrm{CO}_{2}$ emission. Energy penalties for $\mathrm{CO}_{2}$ regeneration and compression make the $\mathrm{CO}_{2}$ capture processes have high operating costs. When multiple parallel trains of $\mathrm{CO}_{2}$ capture processes are required, each train may have different efficiency and the operating cost for each train is thus different. Therefore, it is suggested to implement the EMPC strategy to the $\mathrm{CO}_{2}$ capture processes.

In addition, with growing penetration of renewable energy into the grid, the fossil fuel power plant with $\mathrm{CO}_{2}$ capture is expected to follow the fluctuating load. Therefore, optimal scheduling of power plant dispatch and the $\mathrm{CO}_{2}$ capture targets are needed in order to maximize the plant profitability over a period of time by considering the carbon tax, electricity price, operating costs, etc., and to design economically efficient operating policies for fossil fuel power plants with $\mathrm{CO}_{2}$ capture. 


\section{References}

Aaron, D.; Tsouris, C. Separation of $\mathrm{CO}_{2}$ from flue gas: a review. Sep. Sci. and Technol. 2005, 40, 321-348.

Abu-Zahra, M. R.; Schneiders, L. H.; Niederer, J. P.; Feron, P. H.; Versteeg, G. F. $\mathrm{CO}_{2}$ capture from power plants: Part I. A parametric study of the technical performance based on monoethanolamine. Int. J. Greenh. Gas Control. 2007, 1, 37-46.

Akaike, H. A new look at the statistical model identification. IEEE Trans. Auto. Control. 1974, 19, 716-723.

Åkesson, J.; Laird, C. D.; Lavedan, G.; Prölss, K.; Tummescheit, H.; Velut, S.; Zhu, Y. Nonlinear Model Predictive Control of a $\mathrm{CO}_{2}$ Post-Combustion Absorption Unit. Chem. Eng. Technol. 2012, 35, 445-454.

Arce, A.; Dowell, N. M.; Shah, N.; Vega, L. F. Flexible operation of solvent regeneration systems for $\mathrm{CO} 2$ capture processes using advanced control techniques: Towards operational cost minimisation. Int. J. Greenhouse Gas Control. 2012, 11, 236-250.

Aspen Plus. Rate Based model of the $\mathrm{CO}_{2}$ capture process by MEA using Aspen Plus. Aspen Technology Inc, Cambridge, MA, USA, 2008.

Austgen, D. M.; Rochelle, G. T.; Peng, X.; Chen, C. C. Model of vapor-liquid equilibria for aqueous acid gas-alkanolamine systems using the electrolyte-NRTL equation. Ind. Eng. Chem. Res. 1989, 28, 1060-1073.

Bahakim, S. S.; Ricardez-Sandoval, L. A. Optimal Design of a Postcombustion $\mathrm{CO}_{2} \mathrm{Capture}$ Pilot-Scale Plant under Process Uncertainty: A Ranking-Based Approach. Ind. Eng. Chem. Res. 2015, 54, 3879-3892. 
Bedelbayev, A.; Greer, T.; Lie, B. Model Based Control of Absorption Tower for $\mathrm{CO}_{2}$ Capturing. $49^{\text {th }}$ Scandinavian Conference. 2008.

Black, J. Cost and performance baseline for fossil energy plants: Volume 1: Bituminous coal and natural gas to electricity. Final report (2nd ed.) DOE/NETL-2010/1397, Nov 2010, Available online: http://www.netl.doe.gov.

Bravo, J. L.; Patwardhan, A. A.; Edgar, T. F. Influence of effective interfacial areas in the operation and control of packed distillation columns. Ind. Eng. Chem. Res. 1992, 31, 604608.

Bravo, J. L.; Rocha, J. A.; Fair, J. R. Mass transfer in gauze packings. Hydrocarbon Process. $1985,64,91-95$.

Bristol, E. On a new measure of interaction for multivariable process control. IEEE Trans. Autom. Control. 1966, 11, 133-134.

Chalmers, H.; Lucquiaud, M.; Gibbins, J.; Leach, M. Flexible Operation of Coal Fired Power Plants with Postcombustion Capture of Carbon Dioxide. J. Environ. Eng. 2009, 135, 449458.

Chang, H.; Shih, C. M. Simulation and Optimization for Power Plant Flue Gas $\mathrm{CO}_{2}$ Absorption-Stripping Systems. Sep. Sci. Techno. 2005, 40, 877-909.

Chapel, D. G.; Mariz, C. L.; Ernest, J. Recovery of $\mathrm{CO} 2$ from flue gases: commercial trends. Canadian Society of Chemical Engineers Annual Meeting. 1999.

Chilton, T. H.; Colburn, A. P. Mass transfer (absorption) coefficients prediction from data on heat transfer and fluid friction. Ind. Eng. Chem. Res. 1934, 26, 1183-1187.

Cousins, A.; Wardhaugh, L. T.; Feron, P. H. Analysis of combined process flow sheet modifications for energy efficient $\mathrm{CO}_{2}$ capture from flue gases using chemical absorption. Energy Procedia. 2011, 4, 1331-1338.

Dai, L.; Mahmoud, M. S.; Fu, M.; Xia, Y. Discrete-time model predictive control. INTECH Open Access Publisher, 2012. 
Davis, J.; Rochelle, G. Thermal degradation of monoethanolamine at stripper conditions. Energy Procedia. 2009, 1, 327-333.

Dowell, N. M.; Samsatli, N. J.; Shah, N. Dynamic modelling and analysis of an amine-based post-combustion $\mathrm{CO}_{2}$ capture absorption column. Int. J. Greenhouse Gas Control. 2013, 12, 247-258.

Doyle, J. Analysis of feedback systems with structured uncertainties. In IEE proceedings. 1982 Nov (Vol. 129, No. 6, pp. 242-250).

Dugas, R.; Alix, P.; Lemaire, E.; Broutin, P.; Rochelle, G. Absorber model for $\mathrm{CO}_{2}$ capture by monoethanolamine - application to CASTOR pilot results. Energy Procedia. 2009, 1, 103107.

Edwards, T. J.; Maurer, G.; Newman, J.; Prausnitz, J. M. Vapor-liquid equilibria in multicomponent aqueous solutions of volatile weak electrolytes. AIChE J. 1978, 24, 966976.

Fenton, F. Survey of cyclic load capabilities of fossil-steam generating units. IEEE Trans. Power App. Syst. 1982, 6, 1410-1419.

Flø, N. E.; Kvamsdal, H. M.; Hillestad, M. Dynamic simulation of post-combustion $\mathrm{CO}_{2}$ capture for flexible operation of the Brindisi pilot plant. Int. J. Greenhouse Gas Control. 2016, 48, 204-215.

Freguia, S.; Rochelle, G. T. Modeling of $\mathrm{CO}_{2}$ capture by aqueous monoethanolamine. AIChE J. 2003, 49, 1676-1686.

Gaspar, J.; Gladis, A.; Jørgensen, J. B.; Thomsen, K.; von Solms, N.; Fosbøl, P. L. Dynamic Operation and Simulation of Post-Combustion $\mathrm{CO}_{2}$ Capture. Energy Procedia. 2016, 86, 205-214.

Harun, N.; Nittaya, T.; Douglas, P. L.; Croiset, E.; Ricardez-Sandoval, L. A. Dynamic simulation of MEA absorption process for $\mathrm{CO}_{2}$ capture from power plants. Int. J. Greenhouse Gas Control. 2012, 10, 295-309. 
Hikita, H.; Asai, S.; Ishikawa, H.; Honda, M. The kinetics of reactions of carbon dioxide with monoethanolamine, diethanolamine and triethanolamine by a rapid mixing method. Chem. Eng. J. 1977, 13, 7-12.

Hoyle, D. J.; Hyde, R. A.; Limebeer, D. J. N. An $\mathrm{H}_{\infty}$ approach to two degree of freedom design. Proceedings of the $30^{\text {th }}$ IEEE Conference on Decision and Control. 1991, 2, 1581-1585.

International Energy Agency. $21^{\text {st }}$ Century Coal Advanced Technology and Global Energy Solution. 2013, Available online: https://www.iea.org/ publications/insights/insightpublications/21stCenturyCoal_FINAL_WEB.pdf.

Jayarathna, S. A.; Lie, B.; Melaaen, M. C. Amine based $\mathrm{CO}_{2}$ capture plant: dynamic modeling and simulations. Int. J. Greenh. Gas Control. 2013, 14, 282-290.

Jones, G.; Dole, M. The viscosity of aqueous solutions of strong electrolytes with special reference to barium chloride. J. Am. Chem. Soc. 1929, 51, 2950-2964.

Kent, R. L.; Eisenberg, B. Better data for amine treating. Hydrocarbon Process. 1976, 55, 87-90.

Kucka, L.; Müller, I.; Kenig, E. Y.; Górak, A. On the modelling and simulation of sour gas absorption by aqueous amine solutions. Chem. Eng. Sci. 2003, 58, 3571-3578.

Kvamsdal, H. M.; Hetland, J; Haugen, G; Svendsen, H. F.; Major, F; Karstad, V.; Tjellander, G. Maintaining a neutral water balance in a 450MWe NGCC-CCS power system with postcombustion carbon dioxide capture aimed at offshore operation. Int. J. Greenhouse Gas Control. 2010, 4, 613-622.

Lawal, A.; Wang, M.; Stephenson, P.; Koumpouras, G.; Yeung, H. Dynamic modelling and analysis of post-combustion $\mathrm{CO}_{2}$ chemical absorption process for coal-fired power plants. Fuel. 2010, 89, 2791-2801.

Lawal, A.; Wang, M.; Stephenson, P.; Obi, O. Demonstrating full-scale post-combustion $\mathrm{CO}_{2}$ capture for coal-fired power plants through dynamic modelling and simulation. Fuel. 2012, $101,115-128$. 
Leonard, G.; Mogador, B.C.; Belletante, S.; Heyen, G. Dynamic modelling and control of a pilot plant for post-combustion $\mathrm{CO}_{2}$ capture. Computer-Aided Chem. Eng. 2013, 32, 451-456.

Leung, D. Y.; Caramanna, G.; Maroto-Valer, M. M. An overview of current status of carbon dioxide capture and storage technologies. Renew. Sustainable Energy Rev. 2014, 39, 426443.

Lin, T. N.; Giles, C. L.; Horne, B. G.; Kung, S. Y. A delay damage model selection algorithm for NARX neural networks. IEEE Trans. Signal Process. 1997, 45, 2719-2730.

Lin, T.; Horne, B. G.; Tino, P.; Giles, C. L. Learning long-term dependencies in NARX recurrent neural networks. IEEE Trans. Neural Netw. 1996, 7, 1329-1338.

Lin, Y. J.; Pan, T. H.; Wong, D. S. H.; Jang, S. S.; Chi, Y. W.; Yeh, C. H. Plantwide control of $\mathrm{CO}_{2}$ capture by absorption and stripping using monoethanolamine solution. Ind. Eng. Chem. Res. 2011, 50, 1338-1345.

Lin, Y. J.; Wong, D. S. H.; Jang, S. S.; Ou, J. J. Control strategies for flexible operation of power plant with $\mathrm{CO}_{2}$ capture plant. AIChE J. 2012, 58, 2697-2704.

Lindsay, J.; Dragoon, K. Summary report on coal plant dynamic performance capability. Aug 2010, Available online: http://www.rnp.org/node/1002.

Ma'mun, S.; Svendsen, H. F.; Hoff, K. a.; Juliussen, O. Selection of new absorbents for carbon dioxide capture. Energy Convers. Manage. 2007, 48, 251-258.

Mariz, C. L. Carbon dioxide recovery: Large scale design trends. J. Can. Pet. Technol. 1998, 37, $42-47$.

Metz, B., Davidson, O.; De Coninck, H. C.; Loos, M.; Meyer, L. A. IPCC special report on carbon dioxide capture and storage. Prepared by Working Group III of the Intergovernmental Panel on Climate Change. IPCC, Cambridge University Press: Cambridge, United Kingdom and New York, USA, 2005. 
Modekurti, S.; Bhattacharyya, D.; Zitney, S. E. Dynamic Modeling and Control Studies of a Two-Stage Bubbling Fluidized Bed Adsorber-Reactor for Solid-Sorbent $\mathrm{CO}_{2}$ Capture. Ind. Eng. Chem. Res. 2013, 52, 10250-10260.

Mores, P.; Scenna, N.; Mussati, S. Post-combustion $\mathrm{CO}_{2}$ capture process: equilibrium stage mathematical model of the chemical absorption of $\mathrm{CO}_{2}$ into monoethanolamine (MEA) aqueous solution. Chem. Eng. Res. Des. 2011, 89, 1587-1599.

Morgan, J. C.; Bhattacharyya, D.; Tong, C.; Miller, D. C. Uncertainty quantification of property models: Methodology and its application to $\mathrm{CO}_{2}$-loaded aqueous MEA solutions. AIChE J. $2015,61,1822-1839$.

Nakov, S. T.; Dzhonova-Atanasova, D. B.; Kolev, N. N. Pressure drop of high performance random Intalox Metal Tower Packing. Bulg. Chem. Commun. 2012, 44, 283-288.

Nittaya, T.; Douglas, P. L.; Croiset, E.; Ricardez-Sandoval, L. A. Dynamic modelling and control of MEA absorption processes for $\mathrm{CO}_{2}$ capture from power plants. Fuel. 2014, 116, 672-691.

Nittaya, T.; Douglas, P. L.; Croiset, E.; Ricardez-Sandoval, L. A. Dynamic Modeling and Evaluation of an Industrial-Scale $\mathrm{CO}_{2}$ Capture Plant Using Monoethanolamine Absorption Processes. Ind. Eng. Chem. Res. 2014, 53, 11411-11426.

Onda, K.; Takeuchi, H.; Okumoto, Y. Mass transfer coefficients between gas and liquid phases in packed columns. J. Chem. Eng. Jpn. 1968, 1, 56-62.

Onsager, L.; Samaras, N. N. The Surface Tension of Debye-Hückel Electrolytes. J. Chem. Phys. $1934,2,528-536$.

Panahi, M.; Skogestad, S. Economically efficient operation of $\mathrm{CO}_{2}$ capturing process part I: Selfoptimizing procedure for selecting the best controlled variables. Chem. Eng. Process. 2011, $50,247-253$.

Panahi, M.; Skogestad, S. Economically efficient operation of $\mathrm{CO}_{2}$ capturing process. Part II. Design of control layer. Chem. Eng. Process. 2012, 52, 112-124. 
Pellegrini, G.; Strube, R.; Manfrida, G. Comparative study of chemical absorbents in postcombustion $\mathrm{CO}_{2}$ capture. Energy. 2010, 35, 851-857.

Pinsent, B. R. W.; Pearson, L.; Roughton, F. The kinetics of combination of carbon dioxide with hydroxide ions. Trans. Faraday Soc. 1956, 52, 1512-1520.

Plaza, J. M.; Van Wagener, D.; Rochelle, G. T. Modeling $\mathrm{CO}_{2}$ capture with aqueous monoethanolamine. Int. J. Greenh. Gas Control. 2010, 4, 161-166.

Rao, A. B.; Rubin, E. S. A Technical, Economic, and Environmental Assessment of AmineBased $\mathrm{CO}_{2}$ Capture Technology for Power Plant Greenhouse Gas Control. Environ. Sci. Technol. 2002, 36, 4467-4475.

Razi, N.; Svendsen, H. F.; Bolland, O. Assessment of mass transfer correlations in rate-based modeling of a large-scale $\mathrm{CO}_{2}$ capture with MEA. Int. J. Greenhouse Gas Control. 2014, 26, 93-108.

Riedel, L. The heat conductivity of aqueous solutions of strong electrolytes. Chem. Ing. Tech. 1951, 23.

Robinson, R. A.; Stokes, R. H. Electrolytic solutions; Butterworths: London, 1959.

Rodriguez, J.; Andrade, A.; Lawal, A.; Samsatli, N.; Calado, M.; Ramos, A.; Lafitte, T.; Fuentes, J.; Pantelides, C.C. An Integrated Framework for the Dynamic Modelling of Solvent-based $\mathrm{CO}_{2}$ Capture Processes. Energy Procedia. 2014, 63, 1206-1217.

Sahraei, S. H.; Ricardez-Sandoval, L. A. Controllability and Optimal Scheduling of a $\mathrm{CO}_{2}$ Capture Plant Using Model Predictive Control. Int. J. Greenhouse Gas Control. 2014, 30, $58-71$.

Samanta, A.; Zhao, A.; Shimizu, G. K.; Sarkar, P.; Gupta, R. Post-combustion $\mathrm{CO}_{2}$ capture using solid sorbents: a review. Ind. Eng. Chem. Res. 2011, 51, 1438-1463.

Stichlmair, J.; Bravo, J. L.; Fair, J. R. General model for prediction of pressure drop and capacity of countercurrent gas/liquid packed columns. Gas Sep. Purif. 1989, 3, 19-28. 
Tait, P.; Buschle, B.; Ausner, I.; Valluri, P.; Wehrli, M.; Lucquiaud, M. A pilot-scale study of dynamic response scenarios for the flexible operation of post-combustion $\mathrm{CO}_{2}$ capture. Int. J. Greenhouse Gas Control. 2016, 48, 216-233.

Taylor, R.; Krishna, R.; Kooijman, H. Real-world modeling of distillation. Transfer. 2003, 1000, 1.

Tobiesen, F. A.; Juliussen, O.; Svendsen, H. F. Experimental validation of a rigorous desorber model for $\mathrm{CO}_{2}$ post-combustion capture. Chem. Eng. Sci. 2008, 63, 2641-2656.

Tönnies, I.; Mangalapally, H. P.; Hasse, H. Sensitivity study for the rate-based simulation of the reactive absorption of $\mathrm{CO}_{2}$. Energy Procedia. 2011, 4, 533-540.

Turton, R.; Bailie, R. C.; Whiting, W. B.; Shaeiwitz, J. A.; Bhattacharyya, D. Analysis, synthesis and design of chemical processes; Pearson Education, 2012.

U.S. Energy Information Administration. Energy in Brief: what are greenhouse gases and how much are emitted by the United States? Jan 2016, Available online: http://www.eia.gov/energy_in_brief/article/greenhouse_gas.cfm.

U.S. Environmental Protection Agency. Carbon pollution emission guidelines for existing stationary sources: electric utility generating units. 2015-22842, Dec 2015, Available online: https://www.gpo.gov/fdsys/pkg/FR-2015-10-23/pdf/2015-22842.pdf.

Zames, G. Feedback and optimal sensitivity: Model reference transformations, multiplicative seminorms, and approximate inverses. IEEE Trans. Autom. Control. 1981, 26, 301-320.

Zames, G.; Francis, B. Feedback, minimax sensitivity, and optimal robustness. IEEE Trans. Autom. Control. 1983, 28, 585-601.

Zhang, Q.; Turton, R.; Bhattacharyya, D. Development of Model and Model-Predictive Control of an MEA-Based Postcombustion $\mathrm{CO}_{2}$ Capture Process. Ind. Eng. Chem. Res. 2016, 55, $1292-1308$. 
Zhang, R.; Bonnin-Nartker, E. P.; Farthing, G. A.; Ji, L.; Klidas, M. G.; Nelson, M. E.; Rimpf, L. M. RSAT ${ }^{\mathrm{TM}}$ process development for post-combustion $\mathrm{CO}_{2}$ capture: Scale-up from laboratory and pilot test data to commercial process design. Energy Procedia. 2011, 4, $1660-1667$.

Zhang, Y.; Chen, H.; Chen, C. C.; Plaza, J. M.; Dugas, R.; Rochelle, G. T. Rate-based process modeling study of $\mathrm{CO}_{2}$ capture with aqueous monoethanolamine solution. Ind. Eng. Chem. Res. 2009, 48, 9233-9246.

Ziaii, S.; Rochelle, G. T.; Edgar, T. F. Dynamic modeling to minimize energy use for $\mathrm{CO}_{2}$ capture in power plants by aqueous monoethanolamine. Ind. Eng. Chem. Res. 2009, 48, 6105-6111. 


\section{Appendix A: Relative Gain Array (RGA)}

The following analysis was developed by Bristol (1966), RGA can be used to determine the appropriate input-output pairings for multi-input-multi-output (MIMO) systems. The relative gain $\left(\lambda_{i j}\right)$ between input $j$ and output $i$ and RGA are defined as follows:

$$
\begin{gathered}
\lambda_{i j}=\frac{\text { gain between input } j \text { and output } i \text { when all other loops open }}{\text { gain between input } j \text { and output } i \text { when all other loops closed }} \\
R G A=\Lambda=\left[\begin{array}{ccc}
\lambda_{11} & \cdots & \lambda_{1 n} \\
\vdots & \ddots & \vdots \\
\lambda_{n 1} & \cdots & \lambda_{n n}
\end{array}\right]
\end{gathered}
$$

If $\lambda_{i j}>1$, the gain of input $j$ on output $i$ will decrease when all other loops are closed. Similarly, $\lambda_{i j}<1$ indicates that the gain of input $j$ on output $i$ will increase when all other loops are closed. When $\lambda_{i j}<0$, the changes in input $j$ has an opposite effect on output $i$ when all other loops are closed. If it is desired to pair $i$ with $j$, the value of the relative gain is preferred to be close to 1 , which means that the gain of input $j$ on output $i$ remains the same no matter whether the other loops in the system are closed or not. The numerical sum of any row or column in the RGA is equal to 1 . A $2 \times 2$ system is used to show how to determine the variable pairing using RGA analysis. The RGA is given as follows:

$$
\Lambda=\left|\begin{array}{cc}
\lambda & 1-\lambda \\
1-\lambda & \lambda
\end{array}\right|
$$

When $0 \leq \lambda<0.5$, pairing $y_{1}$ with $u_{2}$ and $y_{2}$ with $u_{1}$ are preferred. When $0.5<\lambda \leq 1$, pairing $\mathrm{y}_{1}$ with $\mathrm{u}_{1}$ and $\mathrm{y}_{2}$ with $\mathrm{u}_{2}$ are preferred. If $\lambda<0$, it is not desirable to pair $y_{1}$ with $u_{1}$ and $y_{2}$ with $u_{2}$ since the sign of the gain changes when the loops are closed. Likewise, it is not desirable to pair $y_{1}$ with $u_{2}$ and $y_{2}$ with $u_{1}$ when $\lambda>1$. 


\section{Appendix B: D-K Iteration Algorithm}

Proposed by Doyle (1982), D-K iteration is a controller design method that combines $H_{\infty}$ synthesis with $\mu$-analysis to find a controller that can minimize the structured singular value $\mu$ (Appendix C) of the corresponding perturbed plant. Let the closed-loop interconnection structure be defined as $N$. For the 2DOF $H_{\infty}$ control scheme, $N$ can be written as follows,

$$
N=\left\|\begin{array}{cc}
W_{p}\left(S G_{p} K_{r}-M\right) & -W_{p} T W_{n} \\
W_{u}\left(I+K_{y} G_{p}\right)^{-1} K_{r} & -W_{u} S K_{y} W_{n}
\end{array}\right\|
$$

then a scaling matrix $D$ is chosen such that $D$ commutes with the uncertainty $\Delta$, i.e. $D \Delta D^{-1}=\Delta$. The upper bound for $\mu(N)$ can be defined as:

$$
\mu(N)=\mu\left(D N D^{-1}\right) \leq \min _{D \in D} \bar{\sigma}\left(D N D^{-1}\right)
$$

The synthesis objective is then to find a controller $K$ so that the upper bound of $\mu(N)$ is minimized:

$$
\min _{K}\left(\min _{D \in D}\left\|D N(K) D^{-1}\right\|_{\infty}\right)
$$

The D-K iteration thus proceeds as follows:

(1) Start with an initial guess for $\mathrm{D}$, usually set $\mathrm{D}=\mathrm{I}$;

(2) Solve the $H_{\infty}$-optimization for the scaled problem $\min _{K}\left\|D N(K) D^{-1}\right\|_{\infty}$ with fixed $D(s)$;

(3) Fix $K$ and find $D(\mathrm{j} \omega)$ to minimize $\bar{\sigma}\left(D N(K) D^{-1}(j \omega)\right)$ at each frequency;

(4) Curve fit $D(\mathrm{j} \omega)$ to get a stable minimum-phase transfer function $D(s)$ and go to step (2) and repeat until $\bar{\sigma}\left(D N(K) D^{-1}(j \omega)\right)<1, \forall \omega$ or reach the specified maximum iteration number. 


\section{Appendix C: Structured Singular Value}

Given a complex matrix $M$ and structures uncertainty $\Delta=\operatorname{diag}\left\{\delta_{1} I_{r l}, \ldots, \delta_{K} I_{r_{K}}, \Delta_{1}, \ldots, \Delta_{L}\right\}$ with $\bar{\sigma}(\Delta) \leq 1$, where $\delta_{i}$ is the scalar uncertainty and $\Delta_{i}$ is the matrix uncertainty, the structured singular value $\mu_{\Delta}(M)$ of $M$ with respect to $\Delta$ is the number defined such that $\mu_{\Delta}^{-1}(M)$ is equal to the smallest $\bar{\sigma}(\Delta)$ needed to make $(I-M \Delta)$ singular.

$$
\mu_{\Delta}(M)=\frac{1}{\min \{\bar{\sigma}(\Delta): \quad \operatorname{det}(I-M \Delta)=0 ; \bar{\sigma}(\Delta) \leq 1\}}
$$

If no $\Delta$ exists such that $\operatorname{det}(I-M \Delta)=0$, then $\mu_{\Delta}(M)=0$. If $\mu=1$ this means that there exists a perturbation with $\bar{\sigma}(\Delta)=1$ making $(I-M \Delta)$ singular. A small value of $\mu$ is preferred as it means that a large perturbation makes $(I-M \Delta)$ singular. 